\title{
Sibylle Schneider
}

\section{Studien zur Romantechnik Miroslav Krležas}

Verlag Otto Sagner München · Berlin - Washington D.C.

Digitalisiert im Rahmen der Kooperation mit dem DFG-Projekt „Digi20“

der Bayerischen Staatsbibliothek, München. OCR-Bearbeitung und Erstellung des eBooks durch den Verlag Otto Sagner:

http://verlag.kubon-sagner.de

() bei Verlag Otto Sagner. Eine Verwertung oder Weitergabe der Texte und Abbildungen, insbesondere durch Vervielfältigung, ist ohne vorherige schriftliche Genehmigung des Verlages unzulässig. 


\section{SLAVISTISCHE BEITRÄGE}

Unter Mitwirkung von M. Braun, Göttingen - † P. Diels, München - J. Holthusen, München - E, Koschmieder, München - W. Lettenbauer, Freiburg/Br. J. Matl, Graz

F. W. Neumann, Mainz - K.-H. Pollok, Regensburg · L. Sadnik-Aitzetmüller, Saarbrücken $\cdot J$. Schütz, Erlangen

HERAUSGEGEBEN VON A. SCHMAUS, MÜNCHEN

Technische Redaktion: P. Rehder, München

Band 37 
SIBYLLE SCHNEIDER

\section{STUDIEN ZUR ROMANTECHNIK MIROSLAV KRLEŽAS}

VERLAG OTTO SAGNER - MÜNCHEN 1969

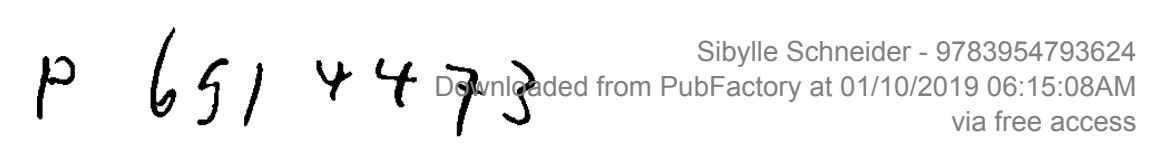




\section{Bayerischn}

Eratablbliv: ..

Monctien :)

Copyright by Verlag otto Sagner, vünchen 1969

Abteilung der $\mathrm{Pa}$. Kubon \& Sagner, Nünchen

Druck: Pa. W.u.I.M. Salzer

8 München 2, SchleiBheimerstr. 20 


\section{INHAIT}

EINLEITUNG

KAPITEL I: TECHIIK DER PERSONENDARSTELLUNG

1. Einführung ..................... 20

2. Beschreibung ...................... 24

3. Charakterisierung $\ldots \ldots \ldots \ldots \ldots \ldots \ldots \ldots . \ldots . \ldots$

KAPITEL II: DARSTELLUNGSFORREN DER REDE UND DER GEDANKEN

1. Die Redeformen und ihr Verhältnis zu-

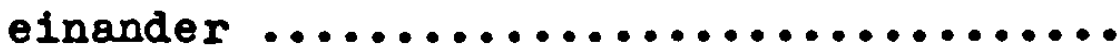

2. Direkte Rede und indirekte Rede ........ 58

3. Erlebte Rede ...................... 69

4. Gedankenbericht .................... 84

5. Monolog und Dialog als wesentliche Darstellungsformen der Romane Krlezas ......

KAPITEL III: KOMPOSITION

1. Einsträngigkeit des Erzäblten ("Die Rückkehr des Filip Latinovicz", "Am Rande des Verstandes") ........................

104

2. Zweisträngigkeit des Erzählten ("Bankett in Blitwien", "Banner") ............... 110

3. Zeitliche Strukturierung ............. 118 a. Zeitgerüst der Romane ............. 118

b. Die gebrochene Chronologie .......... 130

4. Prinzip der Kapiteleinteilung .......... 139

5. Punktion und Integration der selbstän-

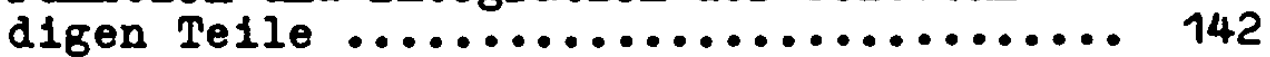

6. tberlagerung der Handlung durch

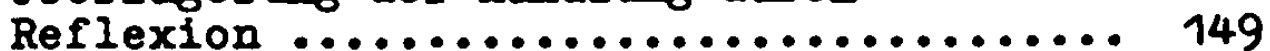

RAPITEL IV: DER ICH-ROMAN ("Am Rande des Verstandes").. 152 
KAPITEL V: DIE ER-ROMANE ("Die Rückkehr des Filip

Latinovicz", "Bankett in Blitwien",

"Banner")

1. Erzähler - Erzähltes - Leser ......... 177

2. Die Kommentare des Erzählers ......... 204

3. Der auktoriale Erzähler als typische Erzählergestalt der Romane Krležs .... 207

4. Romanfiguren, Erzähler und Autor in ihrem Verhältnis zur Wirklichkeit ..... 211

5. Der Satiriker Krleza ................ 215

KAPITEL VI: DIE SUBJEKTIVE KOMPONENTE IM STIL

\section{KRIEZZAS}

1. Erzählhaltung und Stil ............. 221

2. Krlezas Stil im Urteil der Interpreten ........................ 222

3. Der expressive Rhythmus ............ 224

4. Funktion gewisser Partikeln ......... 232

5. Bildlichkeit der Sprache Krlezas ...... 234

a. Akustische und visuelle Elemente .... 234

b. Vergleiche und Metaphern ..........236

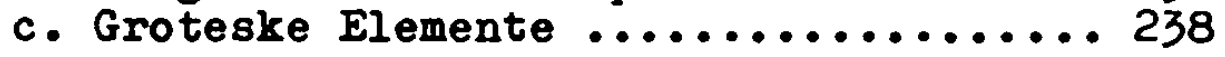

6. Hyperbolik .................... 247

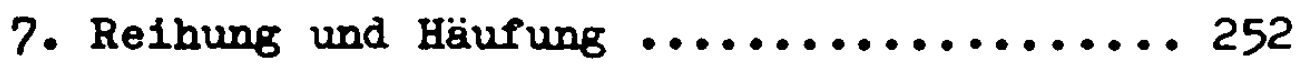

8. Das Demonstrativpronomen .......... 258

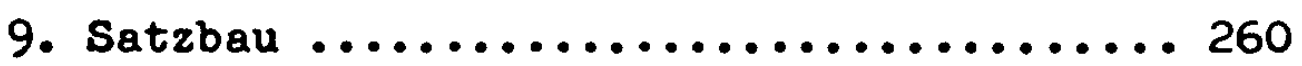

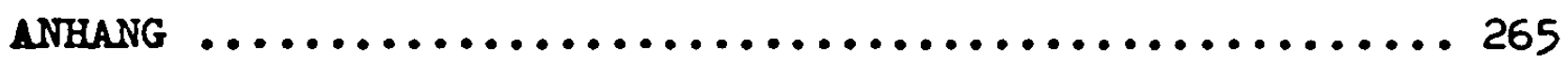

IITERATURVERZEICHIVIS $\ldots \ldots \ldots \ldots \ldots \ldots \ldots \ldots \ldots \ldots \ldots \ldots$

NACHWORT 


\section{EINLEITUNG}

Der heute vierundsiebzigjährige Miroslav Krleza, dessen literarische und publizistische Tätigkeit bereits ein halbes Jahrhundert umfaßt - im Jahre 1914 murde sein erstes Werk, das lyrische Drama "Legende", veröffentlicht - ist nicht nur das stärkste literarische Talent der Kroaten, sondern zweifellos auch einer der bedeutendsten Vertreter der Jugoslavischen Literatur des zwanzigsten Jahrhunderts. Er ist der Typ des unbequemen, weil leidenschaftlich engagierten, kompromiBlosen, revolutionären Schriftstellers, der sich sein ganzes Leben unbeugsam für seine tberzeugung einsetzte und daher immer wieder auf erhebliche Schwierigkeiten stieB und heftigen Angriffen ausgesetzt war. Krležas vier marxistisch orientierte literarische Zeltschriften, in denen er seine eigenen Arbeiten veröffentlichte, gegen seine Widersacher heftig polemisierte, sich mit aktuellen politischen und gesellschaftlichen Ereignissen kritisch auseinandersetzte und für seine progressiven gesellschaftlichen Ideen eintrat, wurden alle verboten. Seine Dramen wurden längere Zeit nicht angenommen, und das schlieblich akzeptierte Drama "Galicija" wurde eine Stunde vor der Premiere wieder abgesetzt. Eines seiner besten Werke, die "Balade Petrice Kerempuha", konnte 1936 nur in Slowenien erscheinen, und die Herausgabe der gesammelten Werke Krležas muBte mehrmals wieder abgebrochen werden, da nach dem Erscheinen der ersten Bände eine weitere Herausgabe verboten wurde. Im Jahre 1941 murden Krleza und sein Verleger S. KopCok sogar verhaftet, und die Bücher wurden verbrannt.

Krležs außerordentlich umfangreiches Werk, das ungerähr 40 Bände umfaBt, erscheint seit 1953 in der Zagreber Verlagsanstalt "Zora". In Deutschland bis vor kurzem noch kaun bekannt, wurden in den letzten Jahren eine ganze Reihe seiner Werke übersetzt, so die drei Romane, einige Erzählungen und die Dramentrilogie "Die Glembays", und vor zwel Jahren fand In Graz die deutschsprachige Oraufführung der "Glembays", eines der besten Dramen Krležas, statt. 
Krleza ist ein ungewöhnlich vielseltiger Mensch von universaler Bildung; sein Interesse gilt nicht nur der Literatur, sondern auch der Kunst, der Kulturphilosophie und Kulturgeschichte, sowie politischen und gesellschaftlichen Fragen. Trotz der Vielseitigkeit, die sich in seiner Betätigung als Iyriker, Dramatiker, Essayist, Romancier, Novellist, Publizist, Literaturkritiker und Kulturhistoriker manifestiert, bleibt Krleža doch einem verhältnlsmäBig engen Kreis von Themen verhaftet. Für den engagierten Moralisten, Humanisten und Kriegsgegner Krleza gilt es in erster Linie, Kritik zu üben an den gesellschaftlichen MiBständen seiner Zeit, die er, Karl Kraus geistig verwand, analysiert und heftig anprangert. Seine Haltung drückt sich - ebenso wie die seiner Helden - in Protest und Rebellion gegen die bestehende gesellschaftliche Ordnung aus, gegen Krieg, gegen diktatorische Systeme, gegen Lüge und Dummeit und überhaupt gegen alles, was den Menschen entmürdigt und entstellt.

Der erste der vier Romane Krležas, "Die Rückkehr des Filip Latinovicz", der 1932 erschien, gehört thematisch noch zum Glembay-Komplex, den er abschlieBt. In diesem psychologischen und gesellschaftskritischen Roman rechnet Krleza mit der provinziellen Variante des Glembay-Zneiges ab, mit dem gehobenen degenerierten kroatischen Bürgertum, das die politische und soziale Wirklichkeit des zwanzigsten Jahrhunderts ignoriert und noch in der Zeit der $k$. und $k$. Monarchie lebt.

Sechs Jahre später folgt der zweite Roman, die bittere Satire auf die Zagreber bürgerliche Gesellschaft der dre1- . Biger Jahre mit dem bezeichnenden Titel "Am Rande des Verstandes". 1938 und 1939 erscheinen die ersten beiden Bücher von "Bankett in Blitwien", des letzten der drei Romane, die Krleza in den dreiBiger Jahren schretbt. Das dritte Buch wird vierundzwanzig Jahre später (1962) in der Zeitschrift Forum der Jugoslavischen Akademie veröffentlicht. "Bankett in Blitwien" ist ein groBer politischer Zeitroman, eine 
scharfsichtige Satire, die sich auf die unmittelbare politische Artualität bezieht, auf die faschistische Diktatur nicht nur Jugoslaviens, sondern auch anderer europäischer Staaten. Der fiktive Raum, in dem die Handlung angesiedelt ist, erlaubt es Krleža, den Rahmen des Geschehens wesentlich zu erweltern und sämtliche Varianten zu erfassen. Die Aktualität des Themas und die erstaunliche Weitsichtigkeit Krlezas erwiesen die Erelgnisse des zweiten Weltkrieges, die er in den ersten beiden, noch vor dem Kriege erschienenen Büchern vorweggenommen hatte.

Der bisher letzte und noch unvollständige Roman Krlezas, "Banner", erscheint seit 1962 in unregelmäBigen Abständen in der Zeitschrift Forum. 1 Dieser groBangelegte politische und historische Roman - Irleza selbst bezeichnet ihn als Chronik - ist eine "retrospektive Vision des jugoslavischen Problems der Jahre 1912 bis 1922". 2 Die Tatsache, das KrleZa mit diesem Roman nach einer literarischen Tätigkeit von über fünfzig Jahren wieder zu seinen Anfängen und damit zu den Erscheinungen zurückkehrt, die inm an meisten verhaBt sind, der k. und k. Monarchle und deren gesellschaftlichem System, zeigt, wie sehr Krleza mit dieser Zeit verbunden 1st. "Im Grunde, und bel aller ideologischen Präzisierung seines heutigen Standorts, ist er ein Rebell altösterreichischer Prägung geblieben, ein Einzelgänger aus 1ronischem Bedürfnis, ein Satiriker nicht aus Menschenverachtung, sondern aus Menschenliebe." 3

1

Das erste Buch des Romans erschien in fortlaufender Folge von März 1962 bis Dezember 1962. Das zweite Buch erscheint mit Unterbrechungen seit 1964.

2

Vaupotie, Miroslav: Siva boja smrti. Interpretacija Krležine novele "Crrל̌ak pod rodopadom". In: Kolo, RS, 1, 1963, 6,70 .

3 Torberg, Friedrich: Jugoslawische Premiere in Graz. "Die Glembajs" - Schauspiel von Miroslav Krleza erstmals in deutscher Sprache. In: Süddt. Ztg. 3./4.7.1965, 8. 11. 
Angesichts des großen Einflusses, den Krleža Jahrzehnte hindurch ausübte und auch noch ausübt, sowie in Anbetracht der Bedeutung und des Umfangs seines literarischen Werkes ist es nicht verwunderlich, $d a B$ die jugoslavische Literaturkritik sich in besonderem Maße dieser ausgeprägten und widerspruchsvollen Persönlichkeit annahm. Vom zweiten bis zum siebten Jahrzehnt unseres Jahrhunderts ist sehr viel über Krleža geschrieben worden. Er wurde sowohl heftig angegriffen und abgelehnt als auch gelobt und nachgeahmt. Im Rahmen dieser Einführung muB ein kurzer Uberblick über die Krležaforschung genügen. Dies vor allem im Hinblick auf die Tatsache, daß anläBlich des fünfzigjährigen Jubiläums seines literarischen Schaffens kurz nacheinander zwei Sammelbände erschienen, die die wichtigsten, bis dahin in verschiedenen Zeitschriften verstreuten Aufsätze über Krleža zusammenfassen. Der erste, 1963 von der Jugoslavischen Akademie in Zagreb herausgegebene umfangreiche Sammelband enthält zweiundsiebzig Arbeiten von fünfundvierzig Autoren und stellt eine "Anthologie von Kritiken, Essays, Studien und Artikeln über das Werk Miroslav Krležas aus einem Zeitraum von einigen Dezennien (1917-1963)" dar. ${ }^{4}$ Der zweite Sammelband, 1964 rom Institut für Iiteraturwissenschaft der Philosophischen Fakultät der Universität Zagrev uerausgegeben, enthält vierundzwanzig meist in letzter Zeit erschienene Aufsätze von zwölf Autoren, die der Zagreber Fakultät angehören. 5 Beide Sammelbände wurden in der in Sarajevo erscheinenden Zeitschrift Izraz ausführlich besprochen, mit-

4 Zbornik o Miroslavu Krleži. Hrsg. V. Marijan Matkovic. Zagreb: JAZU, Odjel za suvremenu književnost $i$ Institut za književnost, 1963.

5 Brležin Zbornik. Hrsg. v. Ivo Frangeš u. Aleksandar Flaker. Zagreb 1964. (= Institut za nauku o knjizevnosti Filozofskog fakulteta Sveutilišta u Zagrebu. Knj. 1.) 
einander verglichen und beurteilt. 6

Die beiden sehr unterschiedlichen Sammelbände zeigen die Entwicklung, die sich in der Krlezaforschung vollzogen hat. Es lassen sich zwei verschiedene Richtungen unterscheiden. Erstens jene, die fast ausschlieblich im ersten Sammelband vertreten ist. Es sind dies Arbeiten von heute meist älteren Autoren, die vorwiegend inhaltlichgehaltliche Fragen behandeln, sich mit der Person KrleZas, seinen Ideen und seiner Haltung befassen, Krleza ablehnen oder loben und sich im wesentlichen mit Feststellungen begnügen. Die künstlerische Struktur der Werke Krležas wird dabei außer acht gelassen. Vertreter dieser Richtung sind unter anderem:

- M. Bogdanović ("Pripovetke Miroslava Krleže", 1922; "O znąaju drame u delu Miroslava Krleže,"1954; "O Krleži", 1956). 7

- V. Gligorié ("U logoru' od Miroslava Krleže", 1938; "Pripovedačka proza Miroslava Krleže" I, II, 1960; "U olujnim vremenima. Prva knjiga romana 'Zastave' Miroslava Krleže", 1963).

- M. Matković ("Marginalija uz Krlezino dramsko stvaranjen , 1949; "O knjizi Miroslava Krleže 'Davni dani'", 1957).

- M. Ristić ("Krležini Glembajevi", 1929; "Fuga Krležiana", 1953;

"Za šezdeseti rodjendan Miroslava Krleže", 1953; "Krleža", 1954;

"Alfabetske varijacije na (ugu Krležianu", - 1959).

- E. Sinko ("Istina Miroslava Krleže", 1952; "Lirika u komediji jedne karnevalske not1", 1953; "Krvavi mit" I-VI, 1956/7;

"Palanga antikrista 1 drugi komentari", 1957;

"Poet koji pripada svima nama. U povodu sedamdesete godisnjice rodjenja Miroslava Brieže", 1963).

6 Der erste Sammelband wurde von Mate Lontar kritisch besprochen ("Pred književnim djelom Miroslava Krleze". In: Izraz, 9, 1965, 190-199), der zweite von Nikola Ivaniłin ("Rasprava o Krležinu Zborniku", ebd., 1194-1213).

7 Es wird hier jeweils nur das Jahr angeführt, in dem die Arbeit erschienen ist. Nähere Angaben sind im Literaturverzeichnis zu finden. 
Die zweite Richtung, die ibren Anfang etwa in der zweiten Bälfte der füfziger Jahre nahm, wird von der jüngeren Generation serbokroatischer Iiteraturwissenschaftler vertreten, die ibre Arbeiten hauptsächlich in der formalen Pragen der Iiteraturwissenschaft gewidmeten Zeltschrift der Kroatischen philologischen Gesellschaft Zagreb Umjetnost rijel, sowie in den Zeitschriften Kolo (Matica Hrvatska, Zagreb), Republika (Zora, Zagreb), Delo (Nollt, Beograd) und Izraz (Svjetlost, Sarajevo) veröffentlichten. Die meisten Beiträge stammen aus dem Jubiläumsjahr 1963. Diese Richtung stellt das künstlerische Werk Krležas in den vittelpunkt der Betrachtung und versucht, den Zugang von der formalen Seite her zu gewinnen. Arbelten dieser Art bestimmen den Charakter des zweiten Sammelbandes. Die wichtigsten Vertreter dieser Richtung sind:

- D. Brigljerie ("O Krlezinu 1zrazu. Na marginama romana 'Porratak Pilipa Latinovicza'", 1955).

- M. Engelsfeld ("yiroslar Krleža: 'Baraka Pet Be'. Primjedbe uz stil", 1958; "Joð o stilu Mirosiava Krleže", 1962).

- M. Feller ("Rritið̌ki fragmenti' o Miroslavu Krleži", 1953).

- A. Plaker ("Motivacija 1 stil", 1962; "In extremis. Krleza u svjetlu kojiževnih poredjenja", 1963;

"'Nepoznat Netko'. O jednoj analognoj pojari u ruskoj 1 hrvatskoj književnost1 20. stoljęa, 1964"; 8 "Covjek 1 porijest u Krlezinim novelama", 1964) 8.

- I. Pranger ("stvarnost 1 umjetnost u Krlezinoj prozi. Novela: "Veliki mestar sviju hulja"n, 1958; "U potrazi $2 a$ izgubljenim djetinjstrom. Nekoliko paralela uz 'Povratak Filipa Latinovicza'", 1963;

"Slobodni neupravni govor kao stilska osobina. Krležini 'Davn1 dani'", 1963).

- P. Guberina ("Teorija o ritmu 1 primjena na jedno Krlezino djelo", 1953).

- Z. Malit ("Lutke. Pokusaj rekons trukcije autorskog komentara u 'Banketu u Blitvi'", 1963;

8 Da bel den Arbeiten des zweiten Sammelbandes weder Erscheinungsort noch Jahr angegeben ist, $11 \mathrm{eB}$ ich bei den Aufsätzen, die mir nicht aus Zeltschriften zugänglich waren, das Erschelnungsjahr des Sammelbandes gelten. 
"Vlastita imena kao stilska kategorija 'Banketa u Blitvi"", 1964) 8.

- A. Petror ("Pozorifte lutaka u Erlezinim romanima", 1962).

- K. Pranjit ("Tehnika pauze kao st1lakl postupak. Uz tekst Miroslava Krleze 'Slom Prana Supila'", 1928; "O Krlezinu proznom ritmu", 1963).

- M. Vaupotie "Siva boja smrt1. Interpretacija Brlezine novele 'CrrCak pod rodopadom'", 1963; "Socijalni smisao Krlezina djeín", 1964) 8.

- I. Vidan ("Dvije raznine 'Banketa u blitvi'", 1963).

- R. VuČkovit ("Legenda o fatumu mržnje. Uz Kriežln roman 'Banket u Blitvi'", 1963).

- B. Vuletir ("O nekim elementima Krlezine Iirike", 1963).

- D. Zečevie ("Krlezina rexenica. Drije prinjedbe o Krležluoj pro 1 u comanima 'ila iuou pameti' 1 'Fovratak Pilipa Latinovicza"n, 1965).

Obwohl die Iiteratur über Krleza sehr umfangreich ist, gibt es bis heute nur eine einzige Gesamtdarsteliung se1nes Werkes, die zudem die Essays Krležas nicht berücksichtigt und mit dem zweiten Buch von "Bankett in Blitwien" abschliebt - also Krležas literarisches Werk nur bis zum Ende der dreiBiger Jahre umfaBt. S. Vucetil interpretiert in diesem Buch ("Krležno knjizevno djelo", Sarajevo 1958) in chronologischer Abfolge die einzelnen Werke Krlezas, die er abschliebend zu klassifizieren versucht, Indem er sie in fünf verschledene stilistische Entwicklungsphasen einordnet. Die Interpretationen befassen $81 \mathrm{ch}$ im wesentlichen mit der inhaltlich-gehaltilchen Selte der Werke Krležas.

AuBer dem Buch Vučeties erschienen noch elnige andere Bücher über Krleža - allerdings kelne Gesantdarstellungen. Die Essays und Kritiken M. Bogdanovits murden in einem schmalen Bändchen zusammengeraBt und unter dem Titel "O Krlezi" (Beograd 1956) herausgegeben. Marko Risties Buch über Krleža erschien 1954 in Zagreb ("Krleža"). Essajs stammen von $\boldsymbol{M}$. Matkovie ("Marginalija uz Krležino dramsko stvaranje". In: Dva eseja. Zagreb 1950, s. 5-89), B. Kreft ("Fragmenti o Miroslavu Krleži". In: Portret1. Lubljana 
1956, S. 27-86) und E. Šinko ("Palanga antikrista 1 drugi komentari". Zagreb 1957). SchlieBlich ist noch V. Gligorit mit seinen in dem Buch "U vihoru" (Beograd 1962) gesammelten Studien über Lyrik, Erzählprosa, Dramen und Romane Krležas zu nennen. Was die Romane Krlezas betrifft, so wurden sie im Vergleich zu seinem übrigen Werk - vor allem Im Verhältnis zu den Erzählungen, zur Lyrik und zum Drama zweifellos vernachlässigt. 9 Von den zweiundsiebzig Aufsätzen des ersten Sammelbandes beschäftigen sich nur sechs mit jeweils einem der Romane. Vier davon sind jedoch lediglich Buchbesprechungen (M. Bogdanović bespricht den Roman FI, I. Kozartanin und I.G. Kovačit den Roman NRP und V. Gigorić das erste Buch von Z), und einer ist ein 2 war ausführlicher, aber formale Pragen kaum berücksichtigender Kommentar zu den ersten beiden Büchern von BB (E. Šinko: "Krvavi mit"). 10 P. Džadžit stellt in den Mittelpunkt seiner Betrachtung den Typ des revoltierenden Helden, der in allen Romanen Krležas in verschiedenen Varianten vertreten ist ("Pobunjenl čovjek u Krležinom romanu. Uz ponovno objavljivanje 'Banketa u Blitvi' 1 'Pilipa Latinovicza'", 1954). Selbst im zweiten Sammelband beschäftigen sich nur vier der vierundzwanzig Arbeiten mit einem der Romane Krležas. Drel davon sind dem Roman BB gewidmet. Z. Malit untersucht die Punktion des Autor-Kommentars und der Namen, und $I$. Vidan geht in seiner ausführlichen und fundierten Studie im wesentlichen auf die Struktur dieses Romans ein - vor allem im Hinblick auf die strukturelle bedeutung des dritten Buches von BB. Der Aufsatz von I. Frangeš über FI befaBt sich ebenfalls in erster Iinie mit der struktur

9 Vgl. M. Lončar ("Pred književnim djelom Miroslava Krleže", S. 196).

$10 \mathrm{Vgl}$. Verzeichnis der in dieser Arbeit verwendeten $\mathrm{Ab}-$ kürzungen (S. 17). 
dieses Romans. Von den nicht in den beiden Sammelbänden vertretenen Arbeiten über das Romanwerk Krležas sind die meisten - vor allem die aus früherer Zeit - Buchbesprechungen oder Inhaltskommentare. So die Aufsätze von $M$. Selakovic und S. Dragojevit (1939) über NRP; Dragojevit geht auch kurz auf Krležas Stil sowie auf das dialektische Prinzip des Romans ein. Weiterhin sind die Arbeiten von B. Novakovit, I. Kršić und V. Pakic (1933) über FI zu nennen, sowie die von M. Lončar (1963) und R. Trifkovit (1963) über das erste Buch von $Z$.

Außer den im zweiten Sammelband vertretenen vier Aufoätzer, die de: Untersichune jewcils einez bostimntin formalen Problems in einem der Romane Krležas dienen, erschienen in letzter Zeit lediglich noch fünf Arbeiten dieser Art. D. Brigljevic befaßt sich mit dem Stil des Romans FL und schenkt vor allem der bis dahin nicht beachteten Syntax Krležas besondere Aufmerksamkeit. R. Vučkovit untersucht die Struktur von BB, C. Dalibor ("Mitska interpretacija romana 'Povratak Filipa Latinovicza'", 1963) wendet die vier Archetypen der Literatur von N. Frye auf den Roman FL an, A. Petrov geht auf das Puppenmotiv, auf den Erzähler und die dialogische Struktur der ersten drei Romane ein, und $D$. Zečevic beschäftigt sich mit einigen formalen Aspekten der beiden Romane FL und NRP. Von B. Klaic stammt schlieblich noch ein Kommentar zur Lexik von $Z$, in dem er Fremdwörter und heute ungebräuchliche und vergessene Begriffe eines Kapitels dieses Romans erklärt ("LeksiČke bilješke uz jedan Krležin tekst", 1953).

Da die bisherigen Arbeiten über die Romane Krležas sich entweder auf eine inhaltich-gehaltliche Analyse meist eines Romans beschränkten und auch die in letzter zeit erschienenen Arbeiten, die sich der formalen Seite des Werkes Krležas zuwenden, fast durchweg nur e 1 n e n formalen Aspekt e $i \mathrm{n}$ e $s$ e $i \mathrm{n} z$ e $l$ n e $n$ Romans untersu- 
chen, erscheint es angebracht, s ä m $t$ i c h e Romane Krležas zum Gegenstand einer systematischen Untersuchung zu machen. ${ }^{11}$ Ich beschränke mich dabel bewuBt auf die e r 2 ähltechn 1 s c he $D$ arbietung der $R \circ$ m a $e$, da gerade sie noch nicht genügend beachtet murde. Elne alle Romane Krležas einbezlehende Untersuchung erzähltechnischer Pragen ist gerade bel einem so bemuBt arbeltenden Autor wie Krleža wichtig, der sich vor allem in seinem Tagebuch, aber auch in verschiedenen Essays immer wieder mit formalen Problemen der Darstellung befaßte.

Die Zitate aus dem Werk Krležas murden möglichst wörtlich übersetzt. Unübersetzt mußten alle jene zitate bleiben, bei denen es um die sprachliche und stilistische Form der Aussage geht.

11 Da der letzte Roman (z) noch nicht vollständig erschienen ist, wird im wesentlichen nur das bis jetzt abgeschlossene erste Buch des Romans herangezogen. 
Folgende Abkürzungen murden verwendet:

$\begin{array}{ll}\text { FI } & =\text { Povratak Filipa Latinovicza } 12 \\ \text { NRP } & =\text { Na rubu pameti } \\ \text { BB } & =\text { Banket u Blitvi (Buch I und II) } \\ \text { F } & =\begin{array}{l}\text { Banket u Blitvi (Buch III, 1962 in den } \\ \text { ersten beiden Nummern der Zeitschrift } \\ \text { Forum erschienen) }\end{array} \\ \text { Z } & =\text { Zastave } \\ \text { Z, 1 } & =\text { Zastave (Buch I, erschienen in: Forum, } \\ \text { Z, } 2 & =\text { Zastave (Duch I, erschienen in: Forum, } \\ \text { G } & =\text { Glembajevi (Proza) } \\ \text { DD } & =\text { Davni dani } \\ \text { ZMK } & =\text { Zbornik o Miroslavu Krlezi } \\ \text { KZ } & =\text { Krleżin Zbornik } \\ \text { UR } & =\text { Umjetnost rijeci }\end{array}$

12 Für Zitate aus Krležas Werk gelten die Siglen nebst Seitenangabe. 


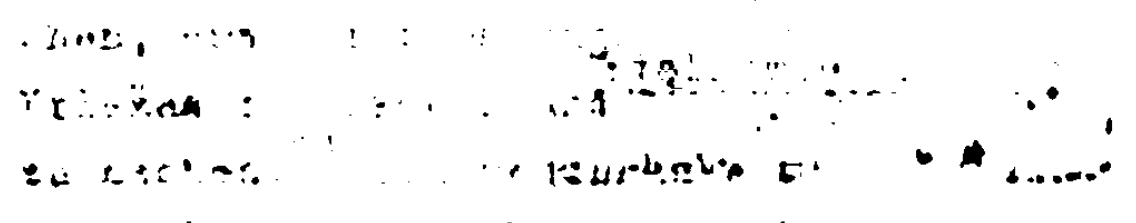

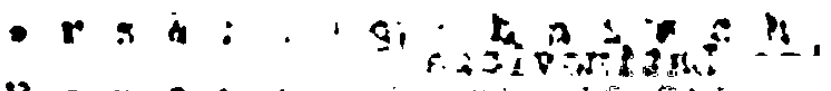

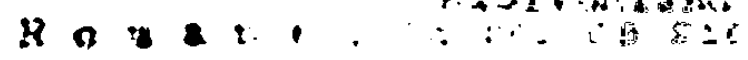

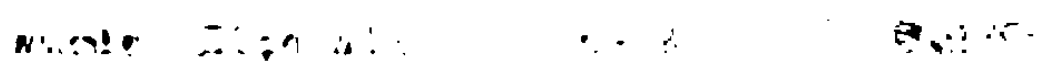

b. : . - :

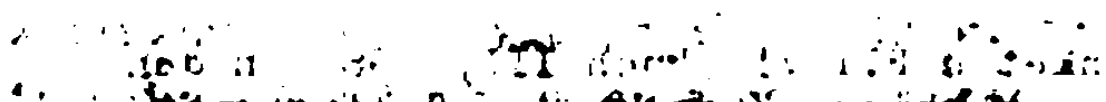

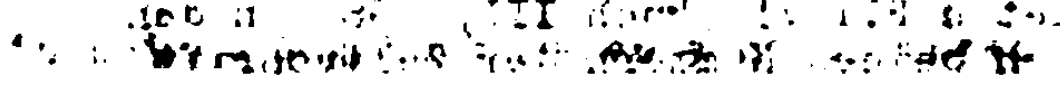

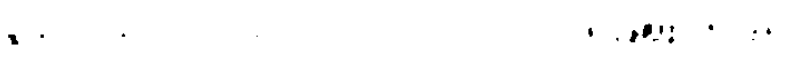

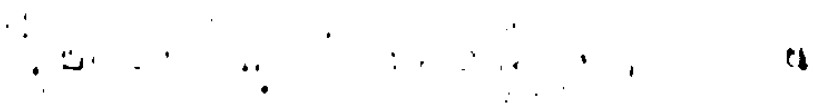

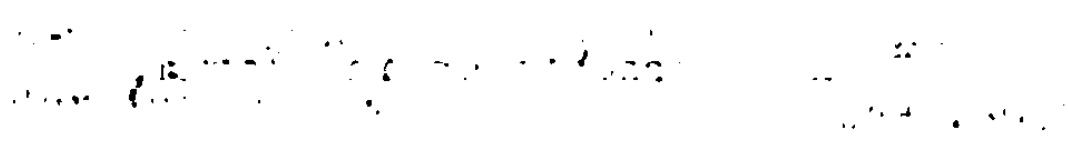

$; \quad \because 1, \ldots, \cdots$

$1 \div \operatorname{se} 1$

$\mathbf{I}$

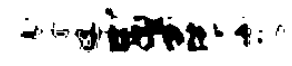




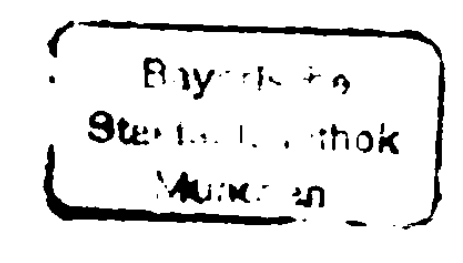

K A P I T E I I

\begin{abstract}
TE C H N I K D E R
PERSONEN DARSTELI UNG
\end{abstract}

Die Einführung der Personen richtet sich in erster Linie nach der Bedeutung, die ihnen in der Handlung zukommt. Die Beschreıbung des Äußeren und die Charakterisierung ist jedoch primär von der Gruppenzugehörigkeit und damit von ihrer Einteilung in positive (Helden, Außenseiter, Frauen und Vertreter des Volkes) und negative Figuren (Vertreter des Bürgertums und des hohen Beamtentums, der Wirtschaft und Industrie, Vertreter des Adels und Träger der politischen Macht) abhängig. Die Haltung des Autors Krleža gegenüber den Personen seiner Romane erweist sich als ausschlaggebend für die verschiedenartige Darstellungsweise. 


\section{Einführung}

Die Methode der Einführung - unter Einführung sei die erste Nennung verstanden - differiert bei den Helden, den Haupt- und den Nebenpersonen. 1

Das Auftreten der Helden vollzieht sich auf Grund des für sämtliche Romane charakteristischen medias-in-resBeginns, ohne vorbereitende Einführung. Eine Ausnahme von diesem Schema bilden lediglich die beiden letzten Romane. BB beginnt mit einem Prolog, in dem der Erzähler die beiden Helden des Romans und einige weitere Hauptfiguren einführt. Der Roman selbst beginnt jedoch in der üblichen Weise. Allerdings tritt hier nicht der eigentliche Held gleichsam wie auf einer Bühne vor uns auf und beginnt seinen Monolog, sondern sein "negativer" Gegenspieler. Auch in $\mathrm{Z}$ tritt der Held Kamilo nicht ohne vorbereitende Einfühmung auf. Er wird nach dem für die Hauptpersonen bezeichnenden Prinzip eingeführt: stets in einigem Abstand vor ihrem Auftreten. So wird der geheimnisvolle Kyriales einige kurze Kapitel vor seinem Erscheinen durch einen einzigen Satz in Frageform in einem Monolog Balocanskis eingeführt. Unmittelbar vor Kyriales' Auftreten beschäftigt sich Filip in einem seiner Monologe ebenfalls in Form einiger Pragen mit dem Georgier, der ihn beunruhigt. In beiden Fällen bleiben die Fragen, die jeweils gegen Ende des Monologs auftauchen, unbeantwortet. Die undurchdringliche Atmosphäre, die Kyriales umgibt, wird auch anläBlich seiner Vorstellung durch den Erzähler selbst nicht aufgehoben, sondern betont aufrechterhalten. An Hand dieses Beispieles wird ersichtlich, wie sorgfältig Krleža das

1 Die Unterscheidung von Helden und Hauptpersonen ist insofern angebracht, als die Helden, was Einführung, Beschreibung und Charakterisierung betrifft, eine gesonderte Behandlung durch den Erzähler erfahren. 
Auftreten seiner Hauptpersonen vorbereitet. Das Prinzip der allmählichen Einführung ist allgemein üblich, so daß der Leser stets ein mehr oder veniger bestimmtes Bild von der betreffenden Person besitzt, sobald sie aktiv am Geschehen des Romans teilnimmt. Im Gegensatz zu den Helden werden die Hauptpersonen in der Regel nicht vom Erzähler eingefübrt, sondern vom Helden oder von bereits anwesenden anderen Personen. Die Einfihrung der Hauptpersonen wird auf diese Meise ohne Unterbrechung der Handlung und obne Hervortreten des Erzählers vollzogen.

Die Neben- und Randfiguren der Romane werden im Gegensatz zu dar Hauptfiguren unritte]bar vor sder wäbrend ibres Auftretens eingeführt. Da sie meist nur einmal auftreten, erfolgt die Einfürung in der Regel zusammen mit ibrer Charakteristik und eventuell mit einer Beschreibung ihres äußeren. Als wesentliches lierkmal ist hierbei das Eingreifen des Erzählers hervorzubeben, der die Einfïhrung entweder in Form des Berichts vor dem Auftreten oder in Form des Autor-r̈ommentars während des Auftretens gibt. Da die Nebenfiguren in erster Linie der kritisierten Schicht angehören, tritt der Erzähler gerade bei diesen Personen mit seinem direkten Urteil hervor und ist nicht gewillt, diese Aufgabe einer Romanperson zu überlassen.

Am deutlichsten kommt die subjektive Anwesenheit des Erzählers bei der Einführung der Nebenpersonen in NRP zum Ausdruck. Es erweist sich gerade hier als besonderer Vorteil, daß dieser Roman in der Ich-Form abgefaßt ist und das Hervortreten des irzäblers nicht als Einmischung empfunden wird, da er selbst ein Bestandteil der Fiktion ist. Für IRP gilt folgendes Schema, das in nicht ganz so konsequenter Veise auch für die übrigen Romane bestimmend ist: 1. Einführung und Charakterisierung durch den Erzähler; 2. kurze Szene zur Illustrierung und Bestätigung der Torte des Erzählers; eventuell folgt nach der Szene eine Fortsetzung der eingangs abgegebenen Charakteristik. Als Vari- 
ante zu diesem Schema wird von einer zweiten Art der Einführung Gebrauch gemacht, die jedoch weniger häufig ist: 1. unvorbereitetes Auftreten der betreffenden Person, die, ohne eingefüht $z u$ werden, $z u$ sprechen beginnt; 2. namentliche Vorstellung und meist kurze Charakterisierung durch den Erzähler, der die Rede der Person unterbricht (fast immer nach den ersten Worten); 3. Fortsetzung der Rede.

Ein typisches Beispiel aus NRP. Der Icn-Erzähler trifft in der Sixtina mit einem seiner litbürger zusammen:

- Oh, Sie sind es, Doktor? Was machen denn Sie da? /Der Ich-Erzähler antwortet; daraufhin wieder sein litbürger:/ - Ach sol Großartig ... sie schwelgen sozusagen in der Kunst? Und wie lange sind Sie schon in Rom? Bleiben Sie in Rom? ier hätte das gedacht? Was für ein merkwïrdiger Zufall ... / Hier schaltet sich der Erzähler ein, um den Gesorächspartner vorzustellen./ Es war Herr Golombek mit seiner Frau. Der Generaldirektor einer Käsefabrik, die den extrafetten Schweizer Spezial-Emmentaler "Elvira" erzeugt, der extrafette Herr Karl Golombek mit seiner extrafetten Gattin Elvira, einer geborenen von Goumbek. /Anschließend wird Golombeks Rede fortgesetzt./ (NRP, 272)

Ein gutes Beispiel für eine besonders geschickte Art der Einführung findet sich in Krležas letztem Roman. Eine neue Person wird, ohne die direkte Rede Emeričkis zu unterbrechen, von diesem eingeführt. Emerički sitzt mit seinem Sohn Kamilo in einem Budapester Restaurant und ist in ein Gespräch mit ihm verwichelt, als sein alter Freund Arpad eintritt, den er schon lange Zeit nicht mehr gesehen hat. Erst nachdem Arpad durch Emericki eingefihrt und in seiner äußeren Erscheinung beschrieben worden ist, unterbricht der Erzähler die szene, um den Neuankömmling kurz zu charakterisieren. Der tbergang von der direkten Rede Dmeričxis zum Lommentar des Erzählers und vieder zurück zur abgebrochenen Rede der Personen geht mitten im Satz vor sich lind ist lediglich durch ein Komma gekennzeichnet. 
(...) das Meer ist unser gröBter Reichtum, aber auch unsere offene Wunde, Gott verzeih, oh, träume ich, Arpad, Servus amice, bist du es wirklich, und das ausgerechnet hier bel Macas, was für ein Zufall, BrüB dich Alter, nach so vielen Jahren, lab mich nachdenken (...) ich sehe, ein Elegant tritt ein, ich sehe, prima vista ein Fechter von Rasse, den Bewegungen, dem blick und der weiBen Krawatte nach zu schlieBen - noch immer die weiBe Krawatte - immer noch in beneidenswerter Form, freilich, es ist Arpad, mein alter Arpad, grüB dich Kollege, ach du hast ja keine Ahnung wie glücklich ich bin, und so küBten sie sich ritterlich auf beide Wangen, "Wenger, Horváth, dva bratanki, co do szably, co do czaszi", 2wei Erlauchte, 2wei gute alte Freunde, zwei Sekundanten aus der Zeit, in der man die Angelegenheiten noch auf ritteriche Weise löste, mit Säbeln und mit Gläsern, Dr. Arpad Lukács-Knobel, Obergespan des Komitats Bač-Bodroß̌ka, ein madjarisierter Schwabe aus Bačka Palanka (...). $(2,1,476)$

Die geschickte Verschmelzung von Handlung und Einführung einer Person verlangt trotz allem eine Einschaltung des Erzählers, um eine kurze direkte Charakteristik Arpads einzufügen, bevor dieser eine bezeichnende Episode aus seinem Leben erzählt, der ausschlieblich charakterisierende Bedeutung zukommt.

In Krležas letztem Roman wird die Technik der dramatischen Einfübrung mehrmals in ihrer konsequentesten Form gebraucht: die Personen führen sich selbst ein, der Erzähler mischt sich nicht ein. Allerdings werden auf diese Weise während einer szene stets nur Randfiguren eingeführt, die nicht der kritisierten Schicht angehören. In all diesen Fällen ist zu beachten, daB die Perspektive des Zuhörers oder Zuschauers streng gewahrt bleibt. Wir erfahren den Namen der sprechenden Person erst dann, wenn diese sich selbst vorstellt.

- Meine Herren, Sie sprechen über das Buch dieses Kretins Neuilly-Faure, nicht wahr - wandte sich ein Mann vom Nachbartisch, der augenscheinlich das Gespräch des Dichters Patrizius Baltik mit dem neuangekommenen blitwischen Fmigranten belauscht hatte, an Nielsen. Sichtbar erregt 
durch diesen Namen, erhob sich der Unbekannte ohne besondere Aufforderung von seinem Tisch, warf die Zeitung hin, die er bis zu diesem Moment in den Händen gehalten hatte, und trat an ihren Tisch. -Dr. Mazurkinis- stellte er sich vor, indem er Nielsen die Hand reichte $(. .$.$) .$ (BB, 372 f.)

Ist der Erzähler hier noch in den Szenenanweisungen spürbar, so hat er sich in folgendem Beispiel völlig zurückgezogen:

- Ich bin Professor Trailovit, meine Herren Kollegen, gestatten Sie, daB ich mich Ihnen vorstelle, ich bin Professor Simeon Trailovic, ein Serbe aus Budapest $(\ldots)$.

$(z, 2,478)$

Zusammenfassend ist festzustellen, daß die Einführung der Helden im allgemeinen durch den Erzähler selbst vorgenommen wird, da sie gewöhnlich als erste auftreten. Einführung und Auftreten fallen dementsprechend fast unmittelbar zusammen. Die Einführung der Hauptpersonen dagegen geschieht meist ohne Einmischling des Erzählers und camit in Verbindung mit der Handlung. Das Auftreten dieser Personen ist im allgemeinen auf lange sicht vorbereitet. Bei der Einfürrung der Neben- und Randfiguren treffen wir diese Art der Einführung nur selten an, und zwar nur bei Personen von episodischer Bedeutung, denen entweder keine oder nur eine sehr geringe gesellschaftskritische Funktion zukommt. Die übliche Einführung dieser Personen wird unmittelbar vor oder während ihres Auftretens durch den Erzähler vollzogen, der direkt und unmiBverständlich mit kritischem Urteil und ironisch gefärbtem Ton hervortritt.

\section{Beschreibung}

Das Erscheinungsbild sämtlicher Helden Krležas bleibt seltsam unbestimmt und verschwommen. Nie erhalten wir eine nähere Beschreibung ihres Xußeren, obwohl wir in Laufe des 
Geschehens $z u$ intimer Kenntnis ihrer verborgensten Gedanken und Gefühle gelangen. So zahlreich die typisierenden Bezeichnungen wie "Intellektueller", "Neurastheniker" oder "Romantiker" sind, so spärlich bleiben die Angaben, die ihr AuBeres betreffen. Die Helden der Romane sind völlig unplastische Erscheinungen, die fast ausschlieblich von ihrer menschlichen Haltung und ihrer Gedankenwelt bestimmt werden. Zwei Gründe scheinen mir für diesen Sachverhalt ausschlaggebend zu sein. Krleža macht seine Helden auf groBen Strecken der Romane zum Träger der Perspektive. Der Autor vermeidet es aus diesem Grunde konsequenterweise, sie von außen zu sehen und eine Beschreibung ihrer Erscheinung zu geben. Da Krleža sich in den drei Er-Romanen jedoch keineswegs nur auf die Perspektive der Helden beschränkt, wäre eine solche Beschreibung durchaus möglich. Der hauptsächliche Grund für das unanschauliche Außere der Helden liegt daher in der von Krleža angestrebten Typisierung. Die Existenz eines typischen Helden wird auf diese Weise gefestigt. Geistig und wesensmäßig gehören diese körperlosen Helden alle einer Familie an, ihr Außeres unterscheidet sie nicht voneinander, da es keine Rolle spielt. Abgesehen von Kamilo sind sie sogar ungefähr gleichen Alters. Weiterhin üben alle auBer F1lip dieselben Berufe aus oder betätigen sich auf denselben Gebieten des öffentlichen Lebens. 2 Betrachten wir die wenigen Stellen, wo das Xußere der Helden beschrieben wird, so stellen wir fest, daB wir kaum je konkrete, charakteristische Einzelheiten erfahren. Die Angaben individualisieren die Gestalt nicht, sondern beziehen sich lediglich auf den augenblicklichen seelischen Zustand, in dem sie sich befindet. Hinzu kommt, daß diese wenigen Hinweise bei sämtlichen Helden im Prinzip dieselben bleiben. Ihre Gesichter sind

2 Der Doktor aus NRP ist Advokat, Nielsen ist Publizist und Doktor der Rechte, Kamilo studierte ebenfalls Rechtswissenschaften und betätigt sich publizistisch. 
bleich und müde und die Augen von Schatten ungeben. In fast allen Fällen wird das Außere der Helden in der für den Roman der Innenweltdarstellung charakteristischen Weise beschrieben. So erblickt sich Filip in einem Spiegel des Cafes von Kaptol; der Doktor aus NRP sieht sich sowohl im Spiegel als auch im Fenster eines Zugabteils.

Dieselbe Tendenz zur Unanschaulichkeit ist bei der Darstellung der meisten positiven Personen der Romane Krležas zu bemerken. ${ }^{3}$ Die Außenseiter der Gesellschaft und die Vertreter des Volkes werden entweder gar nicht oder kaum beschrieben. Auch hier scheint mir wiederum die Typisierung dafür verantwortlich zu sein, daB ihr Äußeres keine Rolle spielt. In sämtlichen Fällen wird der Typencharakter der verschiedenen Figuren direkt ausgesprochen. Der Kutscher Joža Podravec steht stellvertretend für "zweihundert killionen" ebensolcher Kutscher und Valent erscheint als die ideale Verkörperung sämtlicher positiver Eigenschaften des einfachen Volkes. (FL, 63, 65; NRP, $200 \mathrm{ff}$. )

Beschreibt Krleža das Xußere einer Figur ausführlicher, die nicht der kritisierten Schicht von Personen angehört, so nur, wenn der äußeren Erscheinung eine bestimmte Funktion zukommt. Aber auch in diesen Fällen sind es "nur wenige, ganz bestimmte Züge, die herausgegriffen werden. So wird der geheimnisvolle Kyriales, der Filip als die Verkörperung des teuflischen Prinzips erscheint, auf solche Weise beschrieben, daB dieser Eindruck bestätigt und aufrechterhalten wird. Er ist dunkelhäutig und finster, sein Gesicht ist verschlossen und abweisend, seine Haare sind üppig gelockt und von dunkler Farbe, seine aschgrauen Augen sind trübe und blutunterlaufen und seine langen, schmalen Hände feucht und kalt.

3 Eine Ausnahme bildet der Roman $Z$, in dem die Personen ganz allgemein ausführlicher beschrieben werden als in den übrigen Romanen. 
Für die Frauengestalten Krležas - mit Ausnahme Karins gilt dasselbe wie für Kyriales. Auch von ihnen erhalten wir ein Bild der äußeren Erscheinung, obwohl sie zu der als positiv bezeichneten Personengruppe gehören. Ihr XuBeres ist deshalb von Bedeutung, weil sie in erster Linie auf Grund dieser Erscheinung einen so fatalen Einfluß auf die Männer ihrer Ungebung ausüben. Das Körperliche, die Sinnlichkeit, steht bei fast allen diesen Frauen im Vordergrund. Ihr Wesen ist von zweitrangiger Bedeutung. Auch hier wird das Bild der äußeren Erscheinung zur Typisierung herangezogen. Diese typische Frauengestalt ist weißhäutig, hat üppige, dufterde Haare, sshöne, a'sslruskstolle Augor und etns loisht rauhe Stimme. Wenige gleichbleibende Merkmale, die immer wieder herausgehoben werden, verhindern auch hier die Gestaltung einer einmaligen und unverwechselbaren Persönlichkeit.

Die Beschreibung des Außeren wird in der Regel mit der Handlung verknüpt und geschieht meist im Rahmen eines Gedankenmonologs, indem die betreffende Person, fast immer der Held, sein Gegenüber betrachtet, während dieses spricht oder sich bewegt. ${ }^{4}$ Häufig erinnert sich der Held aber auch an das Aussehen einer Figur, über die er nachdenkt. Auf diese Weise wird zum Beispiel das XuBere Annas in immer neuen Ansätzen beschrieben. Sie ist während des ganzen ersten Buches von $Z$ nie direkt anwesend, sie beherrscht jedoch Kamllos Gedankenwelt in ungewöhnlicher Weise.

Die weitgehend szenische Darstellungsweise der beiden letzten Romane, insbesondere $\nabla 0 n$ BB, legt diese mit dramatischen Mitteln gestaltete Einführung und Beschreibung der Personen nahe. Obwohl für die dramatische Technik das Zurücktreten des Erzählers charakteristisch ist, ergreift der Erzähler der Romane Krležas jedoch auch hier häufig

4 Sowohl Aladar, ein Schulkamerad Kamilos, als auch Fräulein Tommaseo werden in $Z$ auf diese Weise beschrieben. $(2,1,4811 . ; 2,2,723)$ 
die Gelegenheit, die Beschreibung einer Erscheinung wit einem - meist negativen - Urteil oder mit einem ebensolchen Vergleich zu verbinden. Entweder geht das Urteil vom Erzähler aus oder aber vom Helden, der in diesem Falle stellvertretend für den Erzähler steht. Ersteres ist in folgendem Beispiel der Fall. Burgwaldsens Außeres wird erst in dem Moment beschrieben, als er Barutanski entgegengeht und dieser Gelegenheit hat, es zu bemerken. Der Erzäbler verrät sich jedoch durch einen eindeutig negativen, wertenden Vergleich.

Barutanski ging auf Burgwaldsen zu, der aus der Tiefe des langen Korridors vom Appartement Barutanskis herkam. Schlank und ergraut, als schwarze Silhouette, das Ministerportefeuille unter dem Arm, von vollendeter Artigkeit, vorgebeugt wie ein Lakai oder ein gut erzogener Butler, der einem hohen Gast Wein einschenkt.

$(B B, 323)$

Die ganze Verachtung, die Krleža vor den Vertretern der Gesellschaft empfindet, kommt in der Schilderung ihrer Erscheinung zum Ausdruck. Bei der Darstellung all dieser Personen spielt die Beschreibung des Außeren eine wichtige Rolle. 5 Das negative Wesen dieser Figuren offenbart sich In ihrem AuBeren, das meist abstoBend und häBlich oder aber von überbetonter Soigniertheit ist.

In der detaillierten Beschreibung der Garderobe des alten Liepach geht der Erzähler ironisch auf die übertriebene Bedeutung ein, die diese Klasse von altmodischen Adeligen völlig unbedeutenden Dingen zumiBt.

Noch als junger Gentleman und Wiener Doktor der achtziger Jahre hatte er sehr viel Wert auf seine Garderobe gelegt. Sein Chesterfield, die Revers mit Biesen eingefaBt, fiel von den

5 Die Ausführlichkeit, mit der diese meist episodischen Piguren beschrieben werden, steht in keinem Verhältnis zu ihrer Bedeutung. Es geht Krleža in all diesen Fällen lediglich um die uberspitzte Darstellung bestimmter Figuren von typischer Gestalt und typischem Wesen. 
drei Linien der Taille sehr schlank herab: karierte Hosen, spitze Wildlederschuhe, Zylinder, lauter erstkiassige Wiener Arbeit aus den Händen der besten Schneider, das alles hob (in diskreter Weise) diesen jungen Aristokraten hervor als einen Yenschen, der Sinn für einen betonten, aber unauffälligen $Z_{\text {ug }}$ in seiner Kleidung hatte (...). Wenn er so fast täglich seine Freundin, Frau Latinovicz-Valenti (Filips Mutter) besuchte, im hellgrauen Sakko, mit hellen cremefarbenen Gamaschen, Ebenholzstock, weiBer Krawatte und außerordentlich glänzenden Kragen und Manschetten, dann sah er aus wie eine graue Puppe aus einem seltsamen altertümlichen Album. (FL, $101 \mathrm{f}_{\text {. }}$ )

Den Typ Liepachs finden wir sowohl in $G$ als auch in $Z$ wieder: er ist die Verkörperung des konservativen Adeligen, der in einer erstarrten Welt von überkommenen Idealen lebt, der innerlich hohle, stutzerhafte Elegant, dem die Pflege seiner äußeren Erscheinung und die Zugehörigkeit zu einer adeligen Familie über alles geht. AuBerlich gleichen sie sich alle: die obligatorische weiBe Krawatte, helle Handschuhe, die Brillantnadel in der Krawatte, weiBe Manschetten, der Elfenbeinstock und eventuell noch ein wohlgepflegtes, gepudertes und gefärbtes Bärtchen, vervollständigen das bild des pseudoeleganten Bonvivants. 6 Der Banalbeamte Ivan Križovec gleicht äußerlich (und innerlich) dem alten Emerički; beide repräsentieren sie denselben, Krleža verhaBten und immer wieder von ihm angegriffenen Typ des im Sinne der österreich-ungarischen Politik wirkenden hohen Beamten, mit dem er vor allem in $G$ abrechnet und der in seinem vorerst letzten groBen Roman wiederum auftaucht. Die äußere Erscheinung des hohen Banalpolitikers Emeričk1 ist der adäquate Ausdruck seines beschränkten, einfältigen, überheblichen Wesens. Die Typisierung und einseitige tbertreibung seiner Erscheinung lassen inn zur Karikatur werden. Der siebzehnjährige Mitschüler Kamilos, Aladar, ver-

6 Vgl. G, 35, 224 . 
gleicht Emerički mit der berühmten politischen Karikatur Daumiers, dem Ratapoil.

$$
\begin{aligned}
& \text { (...) dein Alter ist so ein gerupfter Hahn, ein } \\
& \text { Provinz-Elegant (...) dein Alter gleicht Ratapoil, } \\
& \text { er trägt dasselbe Bärtchen und denselben gezwir- } \\
& \text { belten Schnurrbart wie Ratapoil (...). } \\
& \text { (z, 1, 481) }
\end{aligned}
$$

Dieser hier zum erstenmal erwähnte Schnurrbart Emeričkis wird bei jeder neuen Beschreibung seines AuBeren durch Kamilo immer wieder erwähnt und zum stehenden Kennzeichen dieser etwas lächerlichen Gestalt.

Bezeichnenderweise bemüht sich Krleža nicht nur in der Darstellung dieser Gestalten um die Schaffung eines Zerrbildes. Aus dem Bedürfnis heraus, sein Anliegen möglichst deutlich und unmiBverständlich vorzubringen, läBt er die Helden der Romane immer wieder direkt aussprechen, daB diese oder jene Figur eine Karikatur sei. So wiederholt und bestätigt Kamilo in einem Gedankenmonolog anläBlich der Heimfahrt mit seinem Vater nach dem Begräbnis der Mutter die ausführlichen und unzweideutigen Worte Aladars.? Von dem alten Professor Erdélyi, den Kamilo als fantastische Mumie bezeichnet, sagt er, er sei eine zahnlose und kurzsichtige Karikatur. 8

Kurzsichtigkeit, Zahnlosigkeit und außerdem noch Kahlhelt scheinen für Krleža der Inbegriff des Lächerlichen und des Abstoßenden zu sein. So ist Liepachs Schwester kahlköpfig;sie trägt allerdings eine Perücke (ebenso wie Pilips Mutter). AuBerdem ist sie ungewöhnlich mager und groB. Die einzigen karikierten Gestalten aus BB sind bezeichnenderweise schwerhörig und kahlköpfig (S. 170 f.). In NRP wird Amalia Aquacurti-Sarvaš-Daljska als alte, zahnlose und schwachsinnige Vogelscheuche bezeichnet und die Mitbürger
$7 \mathrm{z}, 1,805 \mathrm{r}$.
$8 \mathrm{z}, 2,435$. 
des Ich-Erzählers insgesamt als kurzsichtige Kahlköpfe. Zahnlos ist der Typ des lyrischen Dichters aus NRP; ebenso Hugo-Hugo. Der Richter Rugvay trägt einen Zwicker und sein Blick wird mit dem eines lisches verglichen; auch er ist kurzsichtig und sein Gesicht 1st pickelig.

Zu Karikaturen werden in erster Linie harmlose und lächerliche Figuren. Aus diesem Grunde sind die Gestalten von $B B$ kaum als Karikaturen zu bezeichnen, abgesehen von elnigen Randfiguren. Groteske Elemente spielen in BB genauso wie in NRP eine wesentliche Rolle bei der Gestaltung der Personen, die ihrem Wesen und ihren Bewegungen nach zum groBen Teil Fuppen, Automaten oder tieräholiche tesen siud. 9 Die Physiognomie Masnovs aus $B B$ weist keinerlel menschliche Züge mehr auf.

Nielsen lauscht dem glorrelchen aragonischen Krieger (...) und er kann sich durchaus nicht des überaus hartnäckigen Gedankens erwehren, daB aus diesem Kadaver, dessen Nase, auf der ein Zwicker saB, so spitz war wie der Schnabel eines Aasgelers, daB aus diesem kurzsichtigen, besoffenen Kretin die kompakte Mehrheit der biltwischen Hosen und Opanken brüllte $(\ldots .$.$) .$ $(F, 217)$

\section{Charakterisierung}

Unter Charakterisierung sei im Gegensatz zur Beschreibung des XuBeren einer Person die Darstellung ihres Wesens verstanden, obwohl sich letzten Endes auch die äuBere Frscheinung für den Charakter einer Romanfigur als aufschluBreich erweist. Allgemein ist festzustellen, daB Krleža seine Personen in ihrer äuBeren Erscheinung nur wenig beschreibt - es sel denn, dieser komme eine bestimmte Punktion zu -, sie aber ausführlich charakterisiert.

9 VGl. Kap. VI, S. 238 ff. 
Wir unterscheiden zweierlei Möglichkeiten der Charakterisierung: die d $i r e k t e$, in der der Erzähler oder eine Romanperson Angaben über eine Gestalt der Dichtung macht, und die i $\mathrm{a} i \mathrm{r} e \mathrm{k} e$, in der wir auf Grund von Rede und Handlung Rückschlüsse auf den Charakter der betreffenden Gestalt ziehen.

Die obige Definition der direkten Charakteristik soll dahingehend erweitert werden, daß wir außer den direkten Angaben des Erzählers oder einer Person auch noch die Namengebung, die Beschreibung des Interieurs und vor allem die Beschreibung und Interpretation der Gesten miteinbeziehen. Wenn diese auch nur ergünzende Funktion besitzen, spielen sie doch bei der direkten Charakterisierung eine Rolle.

Wellek u. Warren bezeichnen die Namengebung als die "einfachste Form der Charakterisierung". "Each 'appelation' is a kind of vivifying, animizing, individuating". 10 GemäB dem satirischen und teilweise grotesken Charakter der Romane Krležas kommt den Namen der Romanpersonen eine wichtige Funktion zu, die in erster Linie jedoch nicht in der Aussage über das Wesen des Namensträgers besteht. Hinter einer Vielzahl von Namen stehen keine Individuen, sondern leblose Wachspuppen und Masken. ${ }^{11}$ Namen, die eine direkte Anspielung auf den Charakter der betreffenden Person enthalten oder ihren Beruf oder die soziale Stellung erkennen lassen, sind bei Krleža nicht allzu häufig; die meisten allegorischen Namen finden wir in BB. Nanchmal bleibt der Zusammenhang 2 wischen Name und Charakter ziemlich vage. Des öfteren ist der Bezug ausgesprochen ironisch. Einige Beispiele: Barutanskis Name steht in unmittelbarem Bezug zu seiner Devise "plumbum et pulvis et nihil aliud" und spielt weniger

10 Wellek, R., u. Warren, A.: Theory of Literature. New York 1949, S. 226.

$11 \mathrm{Vgl}$. 2. Malic: Vlastita imena kao stilska kategorija "Banketa u Blitvi". In: K2, 214. 
direkt auf seinen Charakter als Individuum an als vielmehr auf die Rolle des Tyrannen, die er spielt; allerdings entspricht sie ihm auch wesensmäBig bis zu einem gewissen Grade (barut = SchieBpulver). Das blatwische Pendant zu Barutanski, der kriegerische Feldmarschalleutnant, heiBt BellonisBellonen (bellum = Krieg). Aldo Bauer-Kmetynis, der einzige Sohn reicher Bauern und Chef der Agrarier während der parlamentarischen Regierung Muzikovski (mužik - Bauer), wird von Nielsen als halbgebildeter Primitivling bezeichnet. Dem deutschen Ausdruck "Bauer" entspricht das serbokroatische Wort "kmet" nicht direkt, sie liegen aber beide auf einer Bedeutuzgscbsre. Rcmar Rajevcki, repräcejtativer Gunilis usd Prophet der blitwischen Rasse, leitet seinen Namen von "raj" (- Paradies) ab. Vanini-Schiavone, gebürtiger Italiener und blitwischer Kulturhistoriker, ein verlogener, eitler und opportunistischer Vertreter der Gesellschaft auf Beauregard, trägt einen Namen, der unmittelbar auf sein Wesen anspielt (vano = eitel, leer). Der blatwische lorbeergekrönte Dichter und "Jupiter Tonans" der blatwischen Dichtung heiBt Oktavijan Deziderije Kronberg, ein klassenbemuBter Dichter Tamjan Apolonski (tamjan = Weihrauch), der kriegerische und patriotische Kanonikus Trompeta, Generäle heiBen von Säbelglanz, NiederschmeiBer und Ausrotter. Der faschistisch orientierte Verfechter einer nationalen Wiedergeburt aus NRP heiBt ironisch Dizdar-Barjaktarevic (barjak = Pahne, Banner) und der Mann, der das Genie Iran Mestrovits in pathetischen Floskeln verherrlicht, Mitar Mitrovit (mit - Mythos). Aus den angeführten Beispielen wird deutlich, daB nur ein sehr geringer Tell dieser Namen einen Hauptcharakterzug der betreffenden Person versinnblidicht, die meisten dagegen den Stand der Personen karikieren, die Rolle, die sie spielen, oder die Weltanschauung, die sie vertreten. Bezeichnend für dieses Verfahren ist, daß einige Namen als Pluraletantum erwähnt werden.

12 Vgl. F, 39, 85, 90, 182, 225, 231, 233. 
Häufiger als allegorische Namen sind solche, die auf Grund ihrer ungewöhnlichen Etymologie oder vor allem auf Grund inres Blanges eine lächerliche Wirkung hervorrufen. Blithauer, dem sein Name als Fluch erscheint, beleuchtet in einem seiner Monologe die Art der Namenbildung, wie sie für eine ganze Reihe von Namen der Romane Krležas charakteristisch ist. Ein groBer Teil der Namen in den Romanen sind entstellt und infolgedessen komisch. Nicht zufällig erwähnt Blithauer bei dieser Gelegenheit den Namen Gogol's.

- Ich wurde als Blitwitz geboren, als Kind des Samuel Abramovic, Sohn des Abraham Mojsjevic. Wenn man schon als Samika Blitwitz auf die Welt gekommen ist und in diesem Land und unter diesen Verhältnissen als solcher leben muß, so konnte die Fee, das werden Sie mir zugestehen, einen Neugeborenen an der Wiege kaum mit einem beneidenswerteren Schicksal bedenken. Mein alter Samika (...) hat mir von den wunderbaren Chancen unseres Geschlechts, wie ich zugeben muB, relativ weise erzählt: es sel noch niemand geboren worden, der aus seiner beschnittenen Haut hätte fahren können, und demnach müsse sich der Mensch damit abfinden, daB er ohne seine besondere Absicht oder Schuld als Blitwitz geboren worden ist, und wenn er schon dazu verurteilt ist, seinen beschnittenen Namen wie eine Karikatur zu tragen, so sollte er ihn wenigstens so stolz tragen, als wäre er zumindest ein kurländischer Pürst. Man muB stolz auf seinen Namen sein ohne Rücksicht darauf, ob er die Heiterkeit der blitwischen Esel erregt, die sich mit ihren volkstüljchen Namen wie "Prdjelji" (prdjeti " furzen), "Smrkulji" (šmrkati = rotzen), "Crijeviči" (crijevo = Darm), "Balege" (balega = Viehmist) oder "Svinjače" (svinjac = Schweinestall) zum Beispiel schon erhaben dünken, aber darüber hat Gogol', wenn Sie sich erinnern, schon alles gesagt. $(F, 85)$

W. Kasack macht in seiner Arbeit über die Technik der Personendarstellung bel Gogol' darauf aufmerksam, daB die Spitznamen den Ausgangspunkt für Gogol's Namentechnik bilden dürften. 13 Gogol's Vorliebe für etjmologisch ungewöhnliche und

Die Technik der Personendarstellung bel N.V. Gogol'• Wiesbaden 1957, S. 16. 
klanglich komische Namen und sein weitgehender Verzicht auf allegorische Namen ist genau so bei Krleža festzustellen. Weiterhin werden von beiden die ausgefallensten Namen gerade für solche Personen ausgesucht, die nie auftreten und deren Namen infolgedessen lediglich auf die Wirkung hin berechnet sind. Da diese Personen nicht charakterisiert werden und keinerlel Rolle im Geschehen spielen, können ihre Namen nie allegorischer Natur sein. Selbst die Vorliebe für Reduplikationen, die Kasack bei Gogol' feststellt, gllt auch für Krleža. ${ }^{14}$ Einige Beispiele für etymologisch ungewöhnliche Namenbildungen seien angeführt: Graf Wurmbrandt, Wolkenstein (Küchenchef), Doktor Mitternacht, Philippe Pot (pot = SchweiB), Gallus-Kokotor (gallus = Hahn; kokot = Hahn), Amadeo Bogoljub Trupac (trupac = Leichnam, Rumpl).

Häufig wird die komische Wirkung durch ungewöhnlich klingende Namen, durch endlose Aneinanderreihung verschiedener, möglichst fremdartiger Namen oder durch ausgefallene Vornamen erreicht, die zum Teil in krassem Gegensatz zu den banalen Nachnamen stehen. Die Träger solcher Namen gehören ausschlieblich der Gesellschaft an und sind gröBtentells adeliger Herkunft. Der Kontrast zwischen den langen Namen und der Bedeutungslosigkeit, die der so benannten Person im Geschehen zukommt, erhöht die beabsichtigte lächerliçhe Wirkung. Um die Namen möglichst lang anwachsen zu lassen, nennt Krleža nicht nur den eigentlichen Namen der betreffenden Person, sondern er fügt in den meisten Fällen auch noch den Yädchennamen mit an, wenn es sich um eine verheiratete, verwitwete oder geschiedene Frau handelt, sonst den Namen eines Verwandten. ${ }^{15}$ Fast alle diese Personen haben zumindest Doppel-

14 So z.B. die einfache Verdoppelung banaler Vornamen wie Oto-0 to oder Hugo-Hugo (NRP). Oder aber die Verdoppelung entsteht dadurch, daB der serbokroatische Name in eine Premdsprache übertragen wird: Bauer-Kmetynis, GallusKokotov (BB), Kronberg-Koronaj (Z). Mit diesen Namen karikiert Krleža das Streben nach fremden und damit vornehm klingenden Namen.

15 Vgl. FI, 981. 
namen oder Namen, die durch viele 'de' und 'et' verlängert werden. Ihr pseudomondäner Klang ist vor allem auf die Verwendung von fremdsprachlichen Namen zurückzufübren.

Neben operettenhaft klingenden Namen wie Gorbo-Dador Jekenö (Bürgermeister von Vajdahunnen), Graf Tokaj (Innenminister der hunnischen Republik), Aurel Csalloközhamvassiczk1 (Präsident der blatwischen Republik), von Floden-Poncière Italo, wirken besonders die ungewöhnlichen Vornamen komisch, die in erster Linie mit bürgerlichen, einfacheren Namen kontrastieren: Titus Andronicus Pabriczy, Panteleon Gazibar, Pankrac1je Harambaševit, Marko Anton1je Javoršek, Aldo Bauer-Kmetynis, Oktavijan Deziderije Rronberg, Romualdo Reykjavis; der brutale Kerin1s, der für Barutanski bedenkenlos mordet, heiBt mit seinem Vornamen Hyacinth (oder Hifacint).

Bezelchnend für die satirische Punktion der Namengebung ist die Tatsache, daB der einzige Romanheld, der einer adeligen Familie entstammt, Kamilo Emerički, stets nur mit der einfachen kroatischen Form seines Nachnamens und ohne Hinzufügung der Adelsprädikate, sein Vater dagegen fast 1mmer unter dem längeren und vornehmer klingenden Namen "de Emericzi" oder "plementt1 Emericzi" genannt wird. Die Namen der Helden und der übrigen positiven Personen sind in der Regel unauffällig und kurz und stimmen mit der Herkunft der Personen (PI) oder mit dem Piktiven Schauplatz des Romans überein (BB). 16

Welche Bedeutung Krleža den Namen seiner Personen im Rahmen der gesellschaftskritischen und satirischen Romane bei-

16 Pilip, dessen vutter Polin ist, heiBt eigentlich Sigismund (Zjgmusik) Kazimir Latinovicz. Die unauffälligen Namen Niels Nielsens, Olaf Knutsons und Karin Michelsons zum Beispiel sind der fiktiven Welt des Romans BB angepaBt (Blitwien 1st ein nördliches baltisches Land). Die Namen der Ieute aus dem Volk werden auf dieselbe Weise gebildet: der pannonische Kutscher aus PI helBt Joža Podravec, die Hilfskraft bel Liepachs wird nur Jaga genannt. Valent Zganec und Pero Krneta, sowie Matko aus NRP und der Kutscher Perika Bočkaj aus Z tragen ebenso wie sämtliche anderen positiven Personen unentstellte Namen. 
miBt, geht nicht nur aus der groBen Anzahl von ungewöhnlichen Namen hervor, sondern auch aus einer Reihe von Stellen in den Romanen selbst, wo er oder eine Romanperson sich mit der Namengebung auseinandersetzt. Am häufigsten treffen wir in $G$ auf solche Hinweise, die die satirische Funktion der Namen beleuchten. So übt Krleža in einem ausführlichen Kommentar über den madjarisierten Namen der kroatischen Pamilie der Križovec heftige Kritik an dieser Gesellschaft, die nur Namen und Titel gelten läBt. 17

Neben der Namengebung, die begrenzt zur Charakterisierung herangezogen wird, dient die Beschreibung des Interieurs in den meisten Fällen ausschlieblich der Charakterisierung. Wir haben es hier nicht mit einer Vielfalt von verschiedenen Interieurs zu tun, sondem mit einigen venigen, die für bestimmte Kreise der kroatischen Gesellschaft, des gehobenen Bürger- und Beamtentums und des Adels, typisch sind. Der bevorzugte und für diese Gesellschaft geradezu verbindliche Einrichtungsstil orientiert sich an dem Wien der achtziger Jahre des neunzehnten Jahrhunderts. Wiener Directoire, Amerling und vor allem immer wieder Makart, dessen prunkvoller, dekorativer Stil dem Geltungsbedürfnis und Snobismus der wohlhabenden und arrivierten Gesellschaftsschicht entgegenkommt, sind symptomatisch für den Geschmack der konservativen kroatischen Kreise. Imitation, falscher Prunk und therladenheit dieser typischen Mohnungseinrichtungen lassen jeden individuellen Stil vermissen. Die Angst, nicht standesgemäB eingerichtet zu sein und sich nicht an den Richtlinien des als "chic" Geltenden zu orientieren, ist charakteristisch für diese Piguren. Schlechter Geschmack ist für Krleža gleichbedeutend mit fehlender Moral, und seine Kritik an dem Lebensstil dieser Gesellschaft, die ihren Ausdruck in der Beschreibung des Interieurs findet, geht

17 G, 244. Vgl. weiterhin: ebd., s. $12,35,88$ I., 228 f., 239,247 1.; NRP, 53. 
tiefer, als dies auf den ersten Blick der Fall zu sein scheint. In einem Absatz der Prosafragmente (G) schildert Krleza auf höchst subjektive Teise ein solches typisches, ihm verhaßtes Interieur.
Alles kann man kaufen! Und all das, was man kau- fen kann, ist immer dasselbe: Lampen mit Seiden- schirmen, Jalousien im Halbdänmer irgendwelcher, sogenannter prunkvoller Räume. An den iiänden im- mer Irgendwelche barocke Husaren oder Ritter mit Stuartkrägen oder in der neuesten bürgerlichen Ara: Amerling-Interieurs und Portraits von Damen mit Pincenezs und Herren mit Tabatieren fir Schnupftabak. Immer Gobelins mit reicher tropischer Flora, mit Dianen, Ruinen oder mit Europa auf dem schwarzen Stier. Immer Barock-Lehnsessel oder deko- rative "Peluche-Möbel" aus dem "Seconde-Empire", Teppiche mit Lilien darauf und jene verfluchten, langweiligen und einförmigen Gipsstukkaturen. Oh, diese langweiligen Makart-Speisezimmer, mit den stummen Dienern, diese englischen Kamine mit den Chippendale-Sesseln und den venezianischen Iü- sternl (...) Und dieses Holz, diese Bronze, die- se Tapeten und diese holländischen Gobelins, all diese erstklassige Ware, all das kan man kaufen! (...) und all das ist leer und langweilig und eigentlich sinnlos!
$(G, 36 \mathrm{f.}) 18$

Wesentlich wichtiger und vor allem häufiger als die Charakterisierung durch den Namen und die Beschreibung des Interieurs ist die durch Wimik und Gestik. Krleza beschreibt die Gebärden der handelnden Personen meist mit großer Ausführlichkelt und weitaus häufiger als etwa ibr Aussehen. Past immer erfahren wir, wi e die Personen etwas tun, und nicht nur, was sie tun. Die Gestik als ifittel der direkten Charakterisierung dient inm dazu, die sich aus Handlung und Sprache ergebende indirekte Charakteristik zu ergänzen und vor allem zu verdeutlichen. Bezeichnend für Krlezas Darstellungsweise ist es daher, daß er die Gebärden in den mei-

$18 \mathrm{Vgl}$. weiterhin: $G, 40,57 \mathrm{ff}, 224,228 ; \mathrm{DD}, 39 \mathrm{f}$. In FI wird vor allem Liepach auf diese Weise charakterisiert; in $Z$ das Thepar Emericki und Amanda von Therry-Adlersberg. 
sten Fällen nicht etwa nur beschreibt und dem Leser den Schluß auf das Wesen der betreffenden Gestalt überläBt, sondern $\mathrm{da} B$ er die Gebärden selbst interpretiert oder sie von dem Perspektiventräger wahrnehmen und interpretieren läBt. Auch diese Art der Charakterisierung wird in erster Linie wieder bei der Darstellung der negativen Personen angewandt; sie dient in diesen Fällen der Entlarvung der betreffenden Person, die sich durch ihre Gebärden verrät. Eine andere wichtige Funktion erfüllt die Gestik vor allem in dem am weitestgehend szenisch gestalteten Roman, in BB. Das Verhältnis der verschiedenen Personen zueinander könnea wir grëßtenteils an itron cestar ablescn. 19

Der eltle, heuchlerische Vaninl-Schiavone, einer der widerlichsten Vertreter der Gesellschaft von Beauregard, wird zu einem wesentlichen Teil durch die Beschreibung seiner schmierigen, unangenehmen Gesten charakterisiert, die sein wahres Tesen bloblegen. Der ganze Abscheu des Erzählers vor dem Typ des opportunistischen Speichelleckers kommt in diesen Beschreibungen zum Ausdruck. Unmittelbar bevor Vanini seine schamlose Lobpreisung eines Reliefs des blitwischen Bildhauers und zukünftigen Präsidenten der Republik Roman Rajevskis beginnt, das er noch kurz zuvor kritisiert hatte, wird folgende Schilderung eingeschoben:

Vanini, der listig mit dem linken Auge blinzelte und zufrieden mit der Zunge schnalzte, weil er den richtigen Ausweg aus dieser unklaren und unangenehmen Situation gefunden hatte, in die inn dieser undurchsichtige und in jeder Beziehung rätselhafte Jules Fleury gebracht hatte, beleckte seine Zigarre, schenkte zuerst sich, dann auch Fleury ein Glas Courvoisier ein, pfiückte nit zwei Fingern ein paar Beeren von der Traube, die vor ihm auf einem Silberteller lag, steckte sie in den kund, nahm noch eine und wischte sich dann mechanisch die Finger an der Serviette ab und fuhr sich anschließend mit den gleichen beiden

19 Auf diese Weise werden z.B. Georgis und Barutanski noch vor Beginn ihrer ersten Dialogszene charakterisiert. $V_{g l}$. Kap. V, S. 185 . 
Fingern über die Iippen (und zwar mit Daumen und Zeigefinger der linken Hand, in der Art von Marktweibern), nahm zwei, drei volle saftige Züge aus seiner Havanna, lehnte sich wieder in die weichen Kissen der kalifornischen Schaukel zurück und drehte sich träge wie ein Nashorn im warmen Hasser zu Rajevskis Nußholzrelief $(\ldots)$. $(\mathrm{BB}, 175 \mathrm{f.})$

Bezeichnend für Krležas Darstellungsweise sind die beiden negativen Vergleiche, die mit aller Deutlichkeit auf die subjektive Anwesenheit des Srzählers hinweisen, der die Gesten Vaninis interpretiert.

Fenden wir uns nun den direkten Angaben über den Charakter der Personen zu. Obwohl Namengebung, Interieur und Gestik im Grunde nicht $z u$ den direkten Angaben zu rechnen sind, ist die Grenze bei Krleža schwer zu ziehen. Vie wir aus den Beispielen sahen, enthalten die Beschreibungen des Interieurs und vor allem der Gebärden häufig solche direkten Angaben. Dies ist als charakteristische Besonderheit für sëmtliche Romane Krležas festzustellen. Der Grund hierfür liegt in der für Krleža bezeichnenden Neigung, alles, was ihm wesentlich erscheint, direkt und unmiBverständlich darzustellen.

Diese Tendenz Krležas zur Direktheit und tiberdeutlichkeit in der Aussage legt eine besondere Bevorzugung der direkten Charakterisierung bei der Darstellung der Personen nehe. Auch in den Fällen, wo eine Person indirekt charakterisiert wird - und dies ist selbstverständlich bei allen Fersonen der Fall, die eine Rolle in der Handlung spielen wird die Viertunf oder die Interpretation tast immer früher ojer später direkt ausgesprochen und nicht dem Ieser überlassen. Da die Romanpersonen mit wenigen iusnahmen im Verlauf der jardlung keine liandlung durchmachen und bereits als fertige Gestalten eingeführt und charakterisiert werden, kownt der indirekten Charakteristik in fast allen Fällen eine ausschlieBlich illustrative Bedeutung zu.

iieil Erlež seine Personen vom Leser in einer ganz be- 
stimmten Weise aufgefaBt wissen will, liegt es nabe, daB er in der Regel $v$ o dem Auftreten einer Person eine direkte Charakteristik bringt. Dies ist mit wenigen Ausnahmen durchgehend festzustellen. Im allgemeinen gelten für die Charakterisierung dieselben Prinzipien, die wir bel Elnführung und Beschrelbung der Personen festgestellt haben. Die Helden und die melsten Hauptpersonen werden erst allmählich charakterisiert. Das Bild lihres Wesens ergibt sich nach und nach und unter Anwendung der belden Yethoden der Charakterisierung. Zwar gehen die direkten Angaben über ihr Wesen hauptsächlich vom Erzähler aus, aber eln gewisser Tell dieser Austünrungen blelbt den Personen selbst überlassen. Die Nebenpersonen erhalten vor allem dann, wenn sie der kritislerten Schicht von Personen angehören und in diesen Fällen für die Handlung bedeutungsios sind, stets vor ihrem Auftreten eine direkte Charakteristik durch den Erzähler selbst. Bezeichnend für diese Art der Darstellung ist die Behandlung des Iiepach-Kreises in FI. In Kapitel 11 charakterisiert der Erzähler zuerst kurz die Schwester Ilepachs, Indem or thr direktes Charakterbild auf einen einzigen Grundzug hin entwirft, der bereits mit den ersten Worten genannt wird. Sie 1st eine konservative Dame im Sinne der neunziger Jahre. Die direkte Charakteristik des Erzählers wird durch einige bezelchnende Aussprüche der Person bestätigt und veranschaulicht. Auf ganz ähnliche Weise, nur ausführlicher, schlieBt sich die Charakteristik Ilepachs an, die wichtige und vor allem kennzelchnende Ereignisse aus seinem Vorleben miteinbezieht. Die direkte Charakteristik, die auch in diesen Fall durch einige tJpische Aussprüche Liepachs ergänzt wird, erfolgt zuerst ausführlich durch den Erzähler und unmittelbar anschlieBend durch Pilip, der - in Form eines Gedankenmono$10 g 8$ - dle direkten Angaben des Erzählers bestät1gt und Ile- 
pach typisiert. 20 Diesem Kapitel (Kap. 11), das last ganz von der Handlung losgelöst ist und statischen Charakter aufweist, folgt ein wlederum sehr langes Kapitel (Kap. 14), in dem glelch zu Beginn zwel weitere Personen dieses Kreises elne direkte Charakteristik durch den Erzähler erhalten, bevor sie alle schlieblich in einer gemeinsamen Dialogszene auftreten. 21 Die nun abrollende Gesprächsszene dient lediglich der Illustrlerung der direkten Anführungen des Erzählers. Die indirekte Charakteristik stimmt mit der direkten völlig überein und enthüllt wns kelnen wirklich neuen Wesenszug. Der Erzähler 1st aber auch während dieser Szene anwesend und überläBt die von inm bereits charakterisierten Gestalten nlcht sich selbst. Durch negative Vergleiche und direkte Ortelle ergänzt er die indirekte Charakteristik, die die Sprechenden hier von sich selbst geben. Außerdem wird Fillp als Perspektiventräger vorgeschoben. Wie in allen diesen Fällen, wo der Held als beobachtendes und reflektierendes Mediun zur direkten Beurteilung der kritisierten Personen anwesend ist und die Rolle des Erzählers übernimnt - und dies 1st in den Romanen Krlezas sehr häuIif der Pall - stimmt die direkte Charakteristik des Helden mit der Diagnose des Erzählers überein. 22

20 FL, 102, 108. Bezelchnend für Krležas Darstellungsweise lst es, daB die direkte Charakteristik des Erzählers stets durch Aussprüche oder Gedankengänge der charakterisierten Person oder sogar durch kleine bezeichnende Szenen aufgelockert und veranschaulicht wird. So wechselt die direkte Charakteristik Amandas mit typischen Aussprüichen von verschiedener länge und mit Auszügen aus Dialogen zwischen Amanda und Emeričkt, zwischen Herrn und Frau Emericki und zwischen Kamilo und seiner lutter über Amanda. ( $2,1,811$ ff.)

21 Der AnlaB zum gemeinschaftlichen Auftreten ist, wie so oft bei solchen Fällen, ein gesellschaftliches Ereignis, das dem Erzähler Gelegenheit gibt, alle kritisierten Personen auf einmal in Szene zu setzen.

In PL geht die Ubereinstimmung in Urtell sogar so weit, das Pilip den Vergleich des Erzählers, mit dem dieser Tassillo Pacak charakterisiert, übernimmt und weiter ausführt (PI, 134 f.). In BB wird dieser Vergleich nochmals verwendet, um Vaninl zu charakterisieren (s. 177 f., 321). 
In PI erhalten nicht nur die Nebenpersonen eine von der Handlung isolierte direkte Charakteristik durch den Erzöhler, sondern auch einige Hauptpersonen. Um Charakter und Vorgeschichte Ksenifas und Baločanskis darsustellen, wird die laufende Handlung sogar sechs Kapitel lang unterbrochen. In keinem anderen Roman 18t die in PI angewand te Technik der Blockcharakterisierung, die, losgelöst von der Handlung, auf mehrere Kapitel ausgedehnt werden und die Vorgeschlchte der Personen umfassen kann, so ausgeprägt. Lediglich in $\mathrm{Z}$, die, was Thematik und Darstellung betreffen, in engem Zusammenhang zu Krležas erstem Roman stehen, finden wr eine ähliche fechnik der Charakterisierung wie in PL. Allerdings wrd diese Art der direkten, zusammenhängenden Blockcharakterisierung auf eine ganz neue Weise gehandhabt. Wesentlich freier und nicht so schematisch wie in PL geht der Erzähler mit spielerischer Ironte auf das Verlangen des Lesers ein, vor dem Auftreten der Personen Näheres über sie zu erfahren. Auf diese Weise werden Jedoch ausschlieblich Personen der Gesellschaft charakterisiert, so Fmericki und Amadeo. Emerick wi wird nach seinem ersten indirekt charakterisierenden Gespräch mit dem Baron, mit dem der Roman eröffnet wird, und nach einem kurzen Gedankenmonolog vom Erzähler unterbrochen. Nach sechs Seiten, während derer er vom Erzähler charakterisiert, typisiert und seine Herkunft beleuchtet wird, geht die Handlung mit einew zweiten Telephongespräch weiter ( $\mathrm{z}, 1,255 \mathrm{ff}$.$) .$

Wesentlich häufiger als diese Art der von der Handlung losgelösten Charakteristik durch den Erzähler 1st die direkte Charakteristik der Hauptpersonen, die in die fortlaufende Handlung miteinbezogen wird. In $Z$ und noch viel mehr in BB läBt der Erzähler des öfteren eine Pigur des Romans durch eine andere charakterisieren. Hierzu bedient sich Krleža einiger Kunstgriffe. So liest Nielsen das Tagebuch Karins, das ihm nach deren Tode zugestellt murde. Die erschöpfendsten Angaben über Nielsens Wesen erbalten wir aus einem psychosnalytischen Befund, den Doktor Rassmusen über 
Nielsen angefertigt hat. Sehr häufig fällt aber auch dem Helden des Romans die Aufgabe $2 u$, andere Figuren innerhalb seiner Gedankenmonologe zu charakterisieren und deren Vorgeschichte wederzugeben. In diesem Zusammenhang werden die Grenzen des Monologs häufig überschritten. ${ }^{23}$ Am deutlichsten wird dies anläBlich der Charakterisierung Masnovs und Kmetynis' gegen Ende des Romans BB (F, 207 ff.).

Wird die Vorgeschichte nicht in Porm von Gedankenmonologen wedererinnert, so läBt Krleža elnige Personen ibr eigenes Leben erzäblen - eine Technik, die jedoch nicht ausschlieblich für die Charakterisierung der Hauptpersonen verwendet wird. 24 In BB erzählt Blithauer in elnem langen Monolog über sich und berichtet unter anderem eine wesentliche Eplsode, die ihn dazu bewog, Blitwien zu verlassen. Sein ungewöhnlich langes Selbstbekenntnis erhält eine mehrmalige Motivierung: er ist angetrunken und aus diesem Grunde redselig und offen. 25

Die Hauptpersonen und vor allem die Helden werden viel seltener als die Nebenpersonen direkt durch den Erzähler oder durch eine andere Person des Romans charakterisiert. Bezeichnenderweise charakterisieren sie sich nicht nur in-

23 Vgl. Kap. II, S. 92 ff.

24 Auch einige Nebenpersonen werden auf diese Weise charakterisiert - allerdings ausschlieBlich solche, die nicht zu der kritisierten Schicht von Personen gehören. In FI erzählt der Kutscher Podravec über sich, in NRP Valent und in 2 der Serbe Mihailovic-Gruic und Fräulein Tommaseo. Diese Selbstcharakteristiken beginnen alle auf dieselbe Weise. Ein Beispiel: "Und jetzt, beim Mittagessen im großen Speisesaal in der Jurjevska ulica begann Stev$t_{e}$ von sich und seinem Leben zu erzählen $(\ldots) \cdot(z, 2$, 77).

25 Vgl. P, 86, 100. Knutson spricht seinen langen Monolog ebenfalls unter dem EinfluB von Alkohol; auch er enthüllt Nielsen sein Innerstes ( $B B, 151 \mathrm{ff}$.$) .$ 
direkt durch ihre Gespräche oder durch ihre Gedankenmonologe, sondern des öfteren auch direkt. Diese Tendenz, direkte Aussagen auch in den eigentlich der indirekten Charakteristik dienenden Bereich der Rede und der Gedanken einzufügen, ist in sämtlichen Romanen Krlezas sehr verbreitet. Einige Beispiele für diese Art der Charakteristik. 1. Direkte Selbstcharakteristik innerhalb des Gedankenmonologs:

Er, der atheistische, westlerische, erregbare Tölpel, Neurotiker und Decadent auf dem Hagen des Joza Podravec (...).

(FI, 70)

2. Direkte Selbstcharakteristik in der Rede:

In der Frage des Broterwerbs und des sogenannten gesellschaftlichen Erfolges habe ich mich nicht als besonders begabt erwiesen, in dieser Beziehung murde ich bereits als eine Art von unfähigem Dummixopf geboren (...). $(F, 95)$

Die direkte Form der Aussage über das eigene Hesen, die in Zusammenhang mit der Häufigkeit der direkten Charakteristik zu sehen ist, wirkt insofern meist nicht unglaubwirdig oder unkünstlerisch, als die Helden und auch einige andere Personen ausgesprochen zur Erforschung der eigenen Person, zum Grübeln und zur Beschäftigung mit ihren verschiedenen Komplexen neigen.

Gesondert zu betrachten ist noch die Charakterisierung der Prauen. Obwohl sie zu den Hauptpersonen zu rechnen sind, treten sie während der Handlung entweder gar nicht oder aber nur sehr wenig auf. ${ }^{26}$ Die Nöglichkeit, sie indirekt zu charakterisieren, wird daher stark eingeschränkt. AuBerdem werden sie nur wenig durch den Erzähler charakterisiert. Inr Wesensbild wird größtenteils von den lelden gezeichnet, die sie nie ganz durchschauen. Daher rührt das Rätselhafte, Undurchsichtige und Zwielichtige ibres ivesens. Lediglich Ksenija erhält gemäB der in FI ïblichen Blockcharakterisierung eine ausführliche direkte Charakteristik

26 Vgl. Kap. III, S. 114, Anm. 9. 
durch den Erzähler. Aber selbst dieser gibt vor, nicht alles über sie zu wissen. 27

Es wurde bereits festgestellt, daB die indirekte Charakteristik eine auBerordentlich untergeordnete Rolle in den Romanen Krležas spielt. Sie dient in erster Linie der Veranschaulichung und Bestätigung der direkten Charakteristik, die einen auffallend breiten Raum einnimmt. Zme1 Möglichke1ten kommen für die indirekte Charakteristik in Betracht: Wir beurteilen den Charakter elner Person auf Grund Ihrer Handlungen und ihres Verhaltens ganz allgemein oder auf Grund dessen, a sie spricht und 1 e sie spricht.

Charakterzelchnung durch Handlung wird, abgesehen von BB, bei der Darstellung der Personen nur sehr wenig herangezogen. Die Indirekte Charakteristik erfolgt in sämtlichen Romanen in erster Linie durch die Rede der Personen und nicht zuletzt durch ihre Gedankenmonologe. Die Handlungsarmut der Romane Krležas, in denen lange Diskussionen, Monologe und essajistische Telle gegenüber der Handlung überwiegen, dürfte der wesentliche Grund für diesen Sachverhalt sein. ${ }^{28} \mathrm{Fa}-$ bel und Sujet sind weniger wichtig. Krleža geht es vor allem darum, Gesellschaftskritik zu üben, bestehende MiBstände anzugreifen und Widersprüche aufzudecken. Wird die Handlung zur Charakterisierung herangezogen, so geschieht dies in erster linie, um die Hauptpersonen, und vor allem die Helden, durch die Darstellung bezeichnender Episoden zu beleuch-

27 PL, 140 f. Ahnlich 2wiespältig bleibt der Eindruck, der uns von Karin (BB) vermittelt wird. Den elnzig zuverlässigen Schlüssel zu lhrem Wesen liefert uns ihr Tagebuch, das erst in Buch III des Romans auszugsweise wiedergegeben wird (F, 155 ff.; vgl. Kap. IlI, S. 143.)

VGl. Kap. III, S. $149 \mathrm{ff}$. 
ten, die meist in der Vergangenheit liegen. Diese charakterisierenden Eplsoden werden entweder vom Erzähler oder von. einer Person berichtet. Häurig erinnert sich der Held an eine bezelchnende Episode aus seiner Vergangenhelt.

Plilp, der während der Handlung des Romans weniger durch das charakterisiert wird, was er tut, als durch das, was or n 1 c b $t$ tut, wird durch die Wiedergabe einfiger charakterisierender Episoden in seinem labilen, sinnlichen, morbiden Wesen beleuchtet. Bezelchnenderwelse werden diese oft direkt interpretiert. Ein Beispiel aus PL sel angeführt. Pllip rährt mit dem Kutscher Podravec von Kaptol nach Kostanferec. Als sie Kaptol verlassen, kommen sie an elnem Bordell vorbel, und der Kutscher spricht das Wort "Irajle" aus, das in Pillp Assoziationen an ein vergangenes Abenteuer hervorruft. Die Interpretation dieser Episode folgt nicht unmittelbar danach, wie in ähnlichen Fällen, sondern erst im zweiten Tell des Romans.

Die Augen der ganzen Stadt (...) auf der düsteren grauen Trafik, auf selner lutter, und besonders auf $1 \mathrm{hm}$, dem Kind der Lust und Sünde all das hatte in Pilip seltsame und krankhafte Nelgungen eben zu dem Wollüstigen und Sündhaften in uns gefördert, so daB seine öffentliche Plucht damals in das Bordell am Ende der Krajizka ulica der Durchbruch elnes starken Charakters war, der sich aus Trotz vor den Augen aller mit Schlamm besudeln wollte. (PI, 118 I.)

In BB spielt die Charakterisierung durch Handlung eine gröBere Rolle als in den übrigen Romanen. Das Operettenund Parcenhafte dieses Romans kommt nicht zuletzt in den Handlungen der Leute auf und um Beauregard zum Ausdruck. Barutanskis Gehilfen tauchen auf, von Telefononrufen oder klingelzeichen herbeizitiert, nehmen in soldatisch respektvoller Haltung Befehle entgegen und verschwinden genauso mechanisch und puppenhaft, wie sie aufgetaucht sind. Die Handlungen, die sich auf der gegenwärtigen Ebene des Romans abspielen, verdeutlichen ebenso wie die direkten Charakteristiken keine individuellen Personen. Abgeseben von eint- 
gen wenigen Individuen wie Nielsen oder Knutson, agieren die Figuren gemäB ihrer Rolle. Barutanski drückt eine 21garette in Georgis' Gesicht aus, und Georgis bringt den gefesselten Knutson mit einem Jagdmesser brutal um.

Da die Handlung einen nur geringen Beitrag zur indirekten Charakteristik der Romanpersonen Krležas leistet, spielt die Charakterisierung durch die Rede eine um so gröBere Rolle. Die direkte Rede 1st für die Darstellung der Personen von hervorragender Bedeutung, da sie das Wesen des Sprechenden am unittelbarsten enthüllt. In direkter Rede und im Dialog, die mit Vorliebe zur Charakterisierung der Personen herangezogen werden, emprängt der Leser die Illusion, die Außerungen der Personen unittelbar und unverstellt aufzunehmen. Charakterisierende Funktion kommt Jedoch nicht nur den Gesprächen zu, sondern auch den Gedankenmonologen oder den gesprochenen Monologen, die häufig nicht in direkter, sondern in erlebter Rede abgefaßt sind.

Als Mittel der Charakterisierung durch die Rede bieten sich dem Autor 2wei Möglichkeiten: sowohl der Inhalt des Gesprochenen offenbart das Wesen des Sprechenden als auch die Sprache oder der Sprachstil. Krleža, der Karl Kraus nahesteht, widmet der Sprache seiner Personen groBe Aurmerksamkeit, denn durch die Sprache verraten die negativen Personen ihr Wesen. ${ }^{29}$ Der Satiriker Krleža entlarvt die Vertreter der Gesellschaft nicht zuletzt mittels ibrer Sprache, die inm symptomatisch scheint für eine ganz bestimmte Weltanschauung und menschliche, beziehungsweise unenschliche Haltung. Krlě̌a zieht die Sprache als Mittel der Charakterisierung aus diesem Grunde in erster Iinie zur Darstellung der kritisierten Schicht von Personen heran.

29 Kamilos polemischer Angriff auf den Grafen A.P., aus dessen schlechtem Stil er Bückschlüsse auf das Wesen des Schreibers zieht, wirft ein bezeichnendes Licht auf die Auffassung Krležas selbst, der Kamilo hier wie so oft zu seinem Sprachrohr gemacht hat. ( $2,1,595$ ff.) 
Eine Ausnahme bilden hier lediflich die Vertreter des einfachen Volkes und einice wenige andere Personen. Hier dient die Sprache der realistischen Verlebendigung durchwegs positiver Figuren. Die Verwendung des Dialekts bewirkt in diesen Fällen eine Steigerung der Illusion. Kamilos Grobvater, der das allmähliche Verschwinden des kajkavischen Dialekts mit Bedauern konstatiert, spricht Kajkavisch. Der sympathische Serbe Stevan Gruit bedient sich seiner Herkunft gemäB des ekav1schen Dialekts. Er spricht eine bilderreiche, farbige Sprache, die wit vielen volkstümlichen Sprichwörtern angereichert ist.

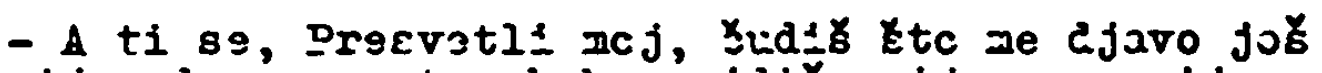
nije odneo, a eto, kako, vidiz, nije, e - nije, dobru konju griva ne opada, a kwnem ti se Bogom 1 Zivotom svoga unuka, eto, sacuvalo me sto ne Živim u Beogradu nego pod vlastitim odžakom u Koviljali, jer one beogradske lije za dvorskom trpezom, $i$ oni ministarski zečevi tamo, u radikalnim gacama, brate, ono bi me bilo oklaprnjalo, a ovako, fala Gospodu, ostao sam sroj na svome, 1 ne dam se ... $(\mathrm{z}, 2, \ddot{6} \ddot{7} \mathrm{f}$.

In Gegensatz zu den Vertretern der Gesellschaft sprechen diese Personen die Sprache ihrer Herkunft und Volkszugehörigkeit. Gruic und Kamilos Grobvater geben durch ihre Sprache zu verstehen, daB sie ihre Berkunft nicht verleugnen. Krleza, dem der kajkavische Dialekt seit frühester Kindheit durch seine Großmutter vertraut ist und der in der autobiographischen Studie "Djetinjstro u Agramu" schreibt, er besitze bis zum heutigen Tag ein überaus empindiches Ohr für alle Nuancen des Kajkavischen, läBt alle Vertreter des Volkes in seinen Romanen in dieser Mundart sprechen, die in den "Balade Petrice Kerempuha" zum durchrehenden Ausdrucksmittel wird. 30 In seinem Tagebuch und in dem Roman NRP verherrlicht er geradezu die Sprache des Volkes und den Geist, der in ihr zum Ausdruck kommt. Henschlichkeit, natürliche Schlauheit, Witz und Galgenhumor, Resignation und iberlegenheit kennzeichnen die lentalität all dieser positiven und mit viel Liebe gezeichneten Figuren. Valent 
aus NRP, die ideale Verkörperung dieses lienschenschlages, hat seinen realen Vorgänger in DD. Krlež gibt hier ein in Kajkavisch geführtes Gespräch zwischen ihm und dem Feuerwehrmann Kvakar auf dem Exerzlerplatz wieder und charakterisiert in diesem Zusammenhang die Sprache Kvakars (S. 109 f.).

Eine wesentliche Rolle spielt die Sprache bei der Charakterisierung der negativen Personen. Die Romane Krlezas, die am stärksten gesellschaftskritisch und gesellschaftssatirisch orientiert sind, wie NRP, $Z$ und in geringerem MaBe PL, bieten aus diesem Grund das meiste Material zur Untersuchung der Sprache als Mittel der Entlarvung.

In $P I$ und in $Z$ sprechen die Vertreter der Gesellschaft eine ganz bestimmte Sprache, die für das Milieu der Adeligen und höhergestellten Bürger der Stadt Agram um die Jahrhundertwende charakteristisch ist, die der Glembajs. Es ist dies ein österreichisch gefärbtes Deutsch, das mit kroatischen, kajkavischen, französischen, englischen, lateinischen, 1talienischen und ungarischen Brocken durchsetzt ist. Dieses "Agramer Deutsch" wird ausschließlich von den Vertretern der Gesellschart gesprochen. Die Sprache wird hier zum kritischen Regulativ. Krleza greift die Haltung dieser Menschen an, die sich von ihrer Herkunft distanzieren und ihre Muttersprache verleugnen, die ihnen zu gewöhnlich erscheint. Snobismus, Standesdünkel und Verachtung alles Kroatischen als zurückgeblieben, primitiv und provinziell sind für diese Menschen symptomatisch. Kamilos Tante Amanda, die typische Austro-Kroatin, ist die Verkörperung dieser von Krleža heftig angegriffenen Schicht von Menschen. Sie verachtet und verspottet das kleinstädtische Agram, orientiert sich an wien und spricht dasselbe Gemisch aus Kroatisch, Kajkavisch und Deutsch wie Vugrovecki, der Arzt der Familie Emericki.

- Pa dobro, dragi Kamilo, a kaj se vraga vi regnikolàrci špinčite s tom vašom regnikolarnom unionistickom pólitikom, em vam Zagreb zgledi kak gancgevènlih selèndra, jer da glavni grad jednog tako lojalnog carskog naroda, koji 
je bas od Madzara spasio dinastiju, 1 to baš od tih vasih regnikoldrnih Madzara, prosim, mora zgledati kak kakvo provincijalno gnezdo, pa to je sramota, nema na ovom svetu takve zaostalosti, pa kaj vas al sram da trpite onu vasu cingilingi-sramotu nasred grada, mit diesem säuerlichen Pferdeäpfel-Geruch und dieser fortwährenden so indiskreten, wie soll ich sagen, Purzerei, je, pa kak dugo bu jos taj škandal od konjskog tramvaja, oprostite - prdil po toj vašoj blatnoj Ilici, a to ni vic, to je sramota, 1 punktum. $(2,1,811)$

2 beginnt mit einem Telefongespräch 2wischen Emerički und einem Baron, die sich beide dieses typischen Sprachgomisches bedienen, das durch die ständige Benutzung von lateinischen, französischen und italienischen Ausdrücken und Zitaten zu einer Karikatur des Sprachstils der Banalbeamten wird. Sie werden nicht nur durch die Sprache charakterisiert, sondern vor allem auch durch die Art, 1 e sie sprechen. Sie bedienen sich immer wieder solcher Floskeln, wie "prosim pokorno" und "kajne", sprechen in sätzen, die durch stets neue Einschübe verlängert werden, häufig unvollendet bleiben und einen ganz spezifischen Rhythmus besitzen. Sie geben ein konventionelles, phrasenhaftes Geplapper von sich. 31

Mit Vorliebe zieht Krleža gesellschaftlicho Onterhaltungen zur Entlarvung sämtlicher Betelligter heran, die er durch direkte Kommentare verdeutlicht. Triviale, inhaltslose, oberflächlich dahinplätschernde Unterhaltungen, die nur scheinbar harmlos sind, enthüllen das negative Wesen der Gesprächspartner. Hinter der Harmlosigkelt dieser Dialoge läBt Krleza unvermittelt die Abgründe aufleuchten, die durch Phrasen und konventionelles Gehabe verdeckt werden. Zwel tjpische Gespräche seien erwähnt. In $Z$ unterhalten sich Emericki und zwe1 Tanten Kamilos, Amanda und Ursula, unittelbar nach dem Be-

31 In G charakterisiert Krleža diese typische Sprache der Banalbeamten, die in $\mathrm{Z} z$ einem wesentlichen Ausdrucksmittel wird ( S. 240). 
gräbnis von Hortensie Emericki. Zuerst streiten sie um die Hinterlassenschaft Hortensies und anschlieBend diskutieren sie darüber, ob das Begräbnis "standesgemäB" war oder ärmlich, wie Amanda behauptet, die sich über die "Tollette" der Verstorbenen erregt. Emeriłkis Rechtfertigung wirft ein bezeichnendes licht auf seinen Charakter und die Mentalität dieses Milieus.

- Sto znad1 "poveretto", pogreb Ajnc-A, "Grande Enterprise de Pompes Funebres", Ajnc-A, ne znam fto se tu jos traz1? (...) Ponavl jam, devetstopedeset forinti aufbarung, tristo vijenci, 8 topedeset pjevacki zbor, tristo biskupi, tristo fijakeri, pitam se zta se tu mož vise? $(\mathrm{z}, 1,821 \mathrm{f}$.)

In dem Gespräch im Liepach-Kreis (FL) kommt das Verhältnis dieser Menschen der Sprache gegenüber - und damit auch ihre Weltanschauung - aufs deutlichste zum Vorschein. Mit Verachtung und Verständnislosigkeit blicken sie auf Jaga, das einfache Mädchen aus dem Volk, über das sie sich lustig machen und dessen Sprache sie nicht zu varstehen vorgeben. Jaga spricht Kajkavisch, die Liepachs Deutsch mit kroatischen Brocken vermischt, und Tassillo fungiert als "Dolmetscher" zwischen den beiden Lagern. In einem der Kommentare, die diese Szene deutend begleiten, bringt Krleža seine Kritik an diesen Menschen zum Ausdruck, die das Volk als Plebs bezeichnen und ihre Herkunft leugnen, indem sie eine fremde Sprache sprechen.

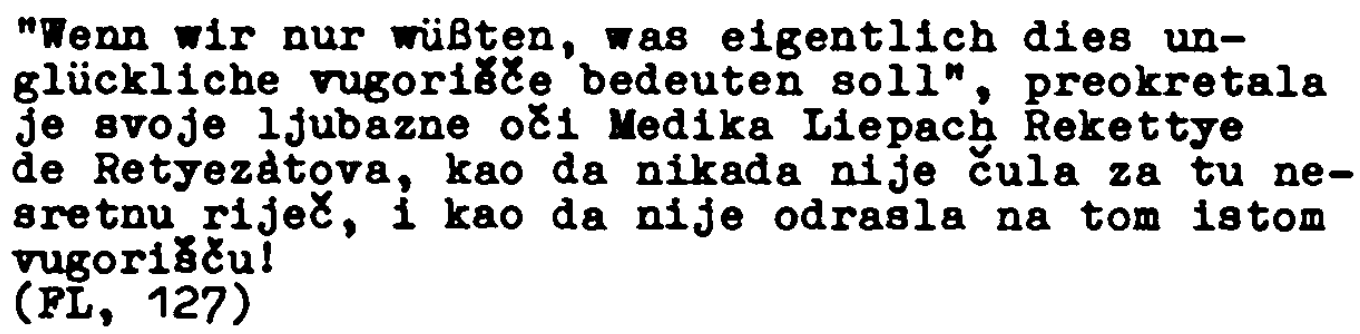

Tassillo drückt in seinen Worten das, was in dieser Szene - zum Vorschein kommt, direkt aus. Volk und Adel stehen sich wie Ausländer gegenüber. "Elgentlich zwel Welten und zwei Sprachen, die nebenelnander reden!" (PI, 129) 
Es wurde festgestellt, daB Krleza zwel verschiedene Gruppen von Personen durch die Sprache charakterisiert, die Vertreter des Volkes und die der Gesellschaft. So unterschledlich die Funktion der Sprache in beiden Fällen ist, so ähnlich ist doch die beabsichtigte Wirkung, die durch die Verwendung einer spezifischen Sprache in den Romanen erreicht wird. Krleža geht es in beiden Fällen nicht um eine individualsprachliche Darstellung, sondern um Typisierung. Die bereits durch die direkten Charakteristiken typisierten Personen sprechen eine für ihre Herkunft und ihr Milieu charakteristische Sprache. Dies geht so weit, daß sich vornehmlich Verirete: $d \in r$ Geseilschaft zuwezlen aesseiben vokabulars und sogar ähnlicher oder derselben Sätze bedienen. 32

Personen, die nicht durch die Verwendung einer charakteristischen Sprache gekennzeichnet werden können, wie in NRP und $B B$, werden vornehmlich durch ihren Sprachstil oder den Inhalt ihrer Rede charakterisiert. In NRP greift Krleža häufig zur Karikierung des Sprachstils, macht die Betroffenen auf diese Weise lächerlich und offenbart vor allem die Verlo-· genheit und Phrasenhaftigkeit ihrer Rede. Abgebrochene Sätze, ständig wiederkehrende Floskeln, sinnlose Püllwörter sind nicht Ausdruck sprachlicher Unbeholfenheit, sondern vielmehr der Falschheit und Unaufrichtigkeit dieser Menschen, die entweder keine eigene Meinung haben oder aber sie nte offen aussprechen. Der Ex-Minister Javoršek gibt in seiner Unterredung mit dem Ich-Erzähler nicht nur eine Reihe bezeichnender Phrasen von sich, sondern er kennzeichnet sich auch durch seinen gewundenen Sprechstil, der sein kriecherisches und falsches Wesen des geborenen Opportunisten offenbart. Krleža karikiert inn ebenso wie einige andere Per-

32 Der alte Ambroz Glembay äußert sich mit ganz ähnlichen Worten über das Volk wie Iiepach. (G, $168 \mathrm{ff} . ; \mathrm{FL}, 100$ f.) Vgl. Matkovie, Marijan: Marginalija uz Kriežino dramsko stvaranje, S. 83; Borozan, Braslav: Jezik 1 psihofizičko osećanje Kriežinih likova. In: Hogućnosti, $4,1957,2,924$. 
sonen dieses Romans durch die Sprache, indem er gewisse Wendungen übersteigert.

(...) aber andererselts, freundschaftlich, unter uns, unter Kollegen (mehr als das: unter Kameraden), Sie werden mir gestatten, Ihnen zu sagen, daß 1ch mich nicht des Eindrucks erwehren kann, daB Sie sich - wie soll ich es nur sagen - nervilich in einer immerhin etwas erhöhten Disposition befinden (...) es wäro besser, einen EntschluB auf der Iinfe des geringsten Widerstandes zu fassen und dementsprechend diese Affalre im Sinne der Opportunit tät abzuschlieBen, das heiBt, das kleinere tbel zu wählen, na ja ... und so weiter, lieber Kollege, hehe! Mir ist es sehr unangenehm, selbstverständlich, hehe und ich bitte Sie, mir zu glauben, daB alle meine Sympathien auf Ihrer Seite sind, und wie sehr es mir auch peinlich ist, daB ich hier in der Rolle des Vermittlers erschienen bin, so glaube ich doch, daB Sie keinerlei Grund dazu baben, an meiner Freundschaft zu zweifeln (...). $(\mathrm{NRP}, 61 \mathrm{f.}) 33$

33 Ahnlich verfährt Krleža bel der Darstellung Domacinskis, Dr. Werners, Dizdars und Ijubičics (NRP). 


\title{
K A P I TE I II
}

\author{
D A R S TELIUNGS FOR Y EN \\ $D E R$ RE DE UND DER GE D A N K E N
}

1. Die Redeformen und ihr Verhältnis zueinander

Um Umfang und Bedeutung der Rede- und Gedankendarstellung für die Romane Krležas ermessen zu können, soll das Verhältnis der verschiedenen hauptsächlichen Redeformen zueinander betrachtet werden. Letzten Endes geht es hier un die Frage, ob der Erzähler mit den ihm verfügbaren Redeformen, Bericht und Schilderung, den meisten Platz des Textes für sich in Anspruch nimmt oder aber, ob er seinen Personen, das heißt ihren Monologen und Gesprächen, den größeren Anteil gewährt.

Die berichtenden und deskriptiven Teile der Romane Krlezas, insbesondere der letzten belden, sind von geringem Umfang. Hinzu kommt, daß der Bericht des Erzählers kaum je unbeteiligter, sachlicher Natur, sondern bäufig stark durch die Perspektive einer Person gefärbt 1st. Fast immer erscheint uns die Ungebung durch ein wahrnehmendes und betrachtendes kedium hindurch dargestellt. ${ }^{1} \mathrm{Be}-$ richt und ER sowie erlebter Eindruck liegen häufig 80 na-

1 Auch dann, wenn kein wahrnehmendes Medium vorgeschoben wird, ist der Bericht nicht unbeteiligt und objektiv. Krleza nimmt stets Stellung. Kritische Distanz, Spott, Ironie, bisweilen Sarkasmus, Empörung oder Zorn sowie Anteilnahme kennzeichnen seinen Erzählstil. 
he beieinander, daB man die tbergänge kaum wahrnimmt. ${ }^{2}$ Autorenperspektive und Personenperspektive wechseln unauffällig, gehen immer wieder ineinander über und überlagern sich streckenweise, so daB eine genaue Trennung nicht möglich ist. A. Neubert bezeichnet die Wirkung dieser Darstellungstechnik, die für Autoren bezeichnend ist, denen es vorwiegend auf die Introspektion ankommt, als ein "typisches Schillern 2wischen erlebender Person und berichtendem Autor." 3 Der Form nach dreht es sich hier 2war noch um Bericht, in der Wirkung geht er jedoch über den normalen Bericht hinaus.

Der Beginn des ersten Romans bietet sich als charakteristisches Beispiel für diese Technik der Darstellung an. Lediglich der erste Satz, in dem wir das Nötigste erfahren, wird in neutralem Ton berichtet. Bereits mit dem zweiten Satz wird die Perspektive in Filip gelegt, mit dessen Augen wir die Stadt seiner Kindheit und Jugend in den folgenden Kapiteln betrachten. Die affektive Haltung Filips gegenüber den inm vertrauten Gegenständen kommt unverhüllt zum Ausdruck. ${ }^{4}$

Dreiundzwanzig Jahre war er nachgerade nicht mehr in diesem Winkel gewesen, aber immer poch wuBte er, was alles kam: die morschen, schleimigen Dächer und der Turmhelm der Brüderkirche und das graue, verwitterte einstöckige Haus am Ende der düsteren Allee, das Medusenhaupt aus Gips über der schweren, beschlagenen Eichentür und die kalte Klinke.

(FL 9)

2 Der Vereinfachung halber werden im Rahmen dieses Kapitels außer den im Verzeichnis angeführten Abkürzungen noch folgende verwendet: erlebte Rede = ER; direkte Rede = $D R$; indirekte Rede = IR; direkter innerer Monolog = DIM; indirekter innerer konolog = IIX.

3

Die Stilformen der "Erlebten Rede" im neueren englischen Roman. Halle/S. 1957, S. 67 f.

4 Vgl. Frangě, Ivo: U potrazi za izgubljenim djetinjstvom. Nekoliko paralela uz "Povratak Filipa Latinovicza". In: Kolo, NS, 1, 1963, 6, S. 8 . 
Abgesehen von wenigen Sätzen, in denen der Erzähler - vor allem bei jedem neu einsetzenden Kapitel - die jeweilige Situation in berichtender Form angibt oder die Bewegung Filips innerhalb von Kaptol beschreibt, wechseln stark gefärbter Bericht mit Gedankenbericht, erlebtem Eindruck, ER und inneren Monologen miteinander ab. Auf diese Weise wird nicht nur die Umgebung Filips mit dessen Augen betrachtet, sondern auch ein Teil seiner Vorgeschichte in Form von Erinnerungen vergegenwärtigt. Die Gegenwart wird mit der Vergangenheit verflochten, obne daß die vor uns ablaufende "Handlung" unterorochen werden muB und ohne daB der Erzähler selbst ailzu sichtbar nervortritt. 5

Da Bericht und Beschreibung zum groBen Teil aus der Perspektive der Romanpersonen gegeben werden und Monologe und Dialoge dieser Personen einen groBen Anteil am Roman-Ganzen haben, stellt sich die Frage, wo und wie der Erzähler überhaupt in Erscheinung tritt und wie er der kritischen Distanz Ausdruck verleiht, die für seine Haltung mindestens ebenso charakteristisch ist wie Einfühlung und Miterleben mit seinen Personen. Aus den bisherigen Feststellungen könnte der Eindruck entstehen, Krleza überlieBe weitgehend seinen Romanpersonen das Feld. Genau das Gegenteil ist jedoch der Fall: Krleza ist ein eminent anwesender Erzähler, der nicht mit homerischer Ruhe und Gelassenheit, sondern sehr subjektiv und beteiligt erzählt. Lediglich die Stellen, die traditionellerweise vom Erzähler berichtet oder geschildert wurden und in denen es gar nicht auf seine Anwesenheit ankommt, verlegt er in die Perspektive seiner Gestalten. Lebendigkeit und Vielschichtigkeit sind das Ergebnis dieser Erzählweise. Obwohl er seine Personen sehr oft reden und noch mehr denken läBt, so daB Gespräche und vor allem Monologe den weitaus gröBten Raum einnehmen,

5 Handlung in Anführungszeichen, weil im ersten Teil des Romans kaum von einer solchen die Rede sein kann. 
kann von einem Verschwinden des Erzählers keine Rede sein. Wir verspüren seine Regie nicht nur in der IR, sondern auch in der ER, die in sämtlichen Romanen für die Darstellung von Rede und Gedanken eine überragende Rolle spielt. Am deutlichsten wird die Person des Erzählers jedoch in den vielen Kommentaren greifbar, die von iho allein ausgehen und neben den Monologen und Dialogen seiner Personen das dritte wesentliche Element der Romane Krležas bilden. Hier kommt die kritische Distanz des allwissenden Erzählers, der das gesamte Geschehen von seiner erhöhter Warte aus überblickt, unverhüllt zum Ausdruck. 6

2. Direkte Rede und indirekte Rede

Einleitend seien kurz die wesentlichen Charakteristika dieser beiden Arten der Rede angeführt.

W. Günther hebt hervor, daB die $D R$ "als reiner Abdruck des Einmaligen (...) das kittel ungetrübter Ubertragung eines gedachten oder gesprochenen Wortes ist. Sie erhöht den Wahrscheinlichkeitseindruck einer Erzählung und hat darum unter den drei Redeformen den gröBten Illusionsgehalt." 7 Was die Rolle des Erzählers bei der Wiedergabe der Worte oder Gedanken seiner Personen in der DR betrifft, so läBt sich durchgehend feststellen, daß er im Vergleich zu den übrigen Formen der Redewiedergabe hier am stärksten in den Hintergrund tritt. Er kann weitgehend auf die Redeankündigung verzichten und nur gelegentlich das Nötigste in Form von Regiebemerkungen anführen. Im Gegensatz zu dieser Form der Wiedergabe, die stark dramatischen Charakter besitzt, kann der Erzähler seinen Gestalten direkt das

6 Vgl. Kap. V, S. '204 ff.

7 Probleme der Rededarstellung. Marburg 1928, S. 5. VGl. dazu weiterhin: Iips, Uarguerite: Le style indirect libre. Paris 1926, s. 34. 
Wort erteilen oder den Inhalt von direkten Gesprächen vor deren Beginn in zusammengefaBter Form angeben - ein von Krleža immer wieder angewandtes Verfahren.

In Gegensatz zur DR tritt in der IR der Erzähler als Vermittler der Rede in den Vordergrund. Bezeichnend für die IR ist die Tendenz zur Konzentration und Raffung sowie der Einordnung der Rede in den Berichtston. Einerseits kann die IR die Form nüchterner und korrekter Berichterstattung sein, andererseits aber kann sie auf Grund der Tatsache, daß der Erzähler an erster Stelle steht, sich nicht mit den dargestellten Gestalten identifiziert, verschiedent rom Eszähler veabsicintigte Nuancen annehmen, die in der Form der DR nicht denkbar wären. Dem Erzähler steht die breite Skala von unbeteiligter, nüchterner Wiedergabe fremder Worte über ironische Brechung bis zur karikaturistischen Verzerrung offen. ${ }^{8}$ Es ist keineswegs so, wie $M$. Lips behauptet, daB die IR sämtliche affektiven und persönlichen Elemente ausschließen wïrde. ${ }^{9}$ Dies k a $n$ lediglich bei einer Wiedergabe in IR der Fall sein, m $u B$ es aber nicht. Ganz abgesehen davon, daß der Erzähler diese Form der Rede in seinem Sinne färben kann, zeigt es sich, daB die IR durchaus an die Ausdrucksweise des Sprechenden angenähert werden kann und nicht sachlịch und abstrakt sein muB. Direkte Einsprengsel, Nachahmung der Intonation, Verwendung von Dialekten und Fremdsprachen, sind auch in Rahmen der IR möglich. Gerade Krležas Romane bieten eine ganze Reihe von Beispielen für diese Art der stark persönlich gefärbten IR. Aus diesem Grunde wird der Ubergang von IR zu ER bei Krleža besonders leicht und unauffällig vollzogen.

8 Vgl. W. Günther, S. 56. Weiterhin: Bühler, Willi: Die "erlebte Rede" im englischen Roman. Ihre Vorstufen und ihre Ausbildung im Werke Jane Austens. Zürich, Leipzig 1937 , S. 84 .

9 s. 38 . 
Betrachten wir nun die einzelnen Romane, um festzustellen, an welchen Stellen und warum Krleža DR oder IR benutzt. Während wir in den verschiedenen Romanen im Hinblick auf die Funktion von DR und IR keine allzu großen Abweichungen feststellen können, da Krleza die oben angefübrten Stilwirkungen dieser beiden Arten der Redewiedergabe ziemlich erschöpfend ausnützt, zeigt sich jedoch, daß die Häufigkeit des Vorkommens dieser beiden Redearten in den einzelnen Romanen großen Schwankungen unterliegt.

Dies betrifft in erster Linie die DR. Während der erste Roman Krležas im Vergleich zu den folgenden ausgesprochen wenig $D R$ aufweist, die überdies auf eine Reihe von Kapiteln beschränct ist, verläuft ein groBer Teil von BB fast ausschlieBlich in DR. Im ersten Teil von FL ist der spärliche Gebrauch von DR insofern nicht ungewöhnlich, als Filip, abgesehen von seiner Pahrt mit dem Kutscher Joza, mit keinem Menschen ins Gespräch kommt und die "Szene" allein beherrscht. Bezeichnenderweise wird aber auch bei dem Zusammentreffen mit Joža die Gelegenheit zu DR nicht genutzt; abgesehen von ein par direkten Brocken werden dessen Worte in IR und vor allem in ER wiedergegeben. An den wenigen Stellen, wo wir DR finden, dient sie der Verlebendigung und Vergegenwärtigung im Rahmen einiger Szenen, die durch Filip wiedererinnert werden und die sowohl seine Kindheit als auch seine Mutter beleuchten. Dieselbe Tendenz, DR zu vermeiden und statt dessen IR und $E R$ zu benutzen, ist für die ersten Kapitel des zweiten Teils des Romans charakteristisch. Nur in Kapitel 14, in dem uns der Kreis um Liepach vorgefürt wird, spielt die $D R$ eine wesentliche Rolle. Die Szene läuft zum überwiegenden Teil in $D R$ ab, der hier ausschlieBlich charakterisierende Funktion zukommt. Erst im letzten Drittel des Romans nimmt die DR entscheidend an Umfang zu. Die vorwiegend theoretische Pragen berührende Debatte zwischen Filip und Kyriales ist größtenteils in DR gehalten. Die $D R$ wird jedoch vor allem in den letzten beiden Kapiteln des Romans, in denen fast die gesamte Hand- 
lung zusammengedrängt wird und sich ihrem dramatischen Höhepunkt nähert, eingesetzt, um die dramatisch gespannte Handlung vorwärts $z u$ treiben, die sich unmittelbar vor unseren Augen abspielt. Unmittelbarkeit, Lebendigkeit, Nähe zum Geschehen und vor allem Spannung sind die Folge dieser szenischen Gestaltung.

Obwohl der Schwerpunkt der Darstellung auf der Innenwelt Filips liegt und damit den Gedanken ein breiterer Raum gewährt wird als der Rede, spielt die DR zur wiedergabe von Gedanken kaum eine Rolle. Bis auf einige wenige Ausnahmen erscheinen seine Gedanken wie auch die der übrigen Personen in ER. Im Gegensatz $z u$ BB und $\mathrm{Z}$ haben wir in FL keinen DIM. ${ }^{10}$ Die wenigen Male, wo die Gedanken einer Person in DR reproduziert werden, geschieht dies in Form der sog. "fingierten direkten Rede". 11 In der "fingierten direkten Rede" werden die Gedanken in der 1. Person Singular wiedergegeben, in Anführungszeichen gesetzt und mit einer Formel wie "dachte $X "$ kenntlich gemacht, die die angeführten Norte als Gedanken einer Person kennzeichnen. Der einzige Unterschied zur DR besteht darin, daß es sich hier nicht um die Wiedergabe von artikulierter Rede handelt, sondern un die von Gedanken und Reflexionen, die mehr oder weniger klar formuliert sind und nahe an der Oberfläche des Bewußtseins liegen. 12 Die "fingierte direkte Rede" eignet sich somit zur Niedergabe von klaren Gedanken, die plötzlich das Gehirn durchzucken, von klaren Erkenntnissen oder Entschlüssen. Da diese Technik der Gedankenwiedergabe in allen Romanen in etwa der gleichen Art und Weise erfolgt und sowohl Funktion als auch Häufigkeit der "fingierten direkten Rede" kaum Schwankungen unterliegen, wollen wir uns hier

10 Der DIM soll erst im Zusammenhang mit den Monologen betrachtet werden.

$11 \mathrm{Vgl}$. W. Bühler, S. 24.

12 Vgl. A. Neubert, S. 46. 
mit einigen Beispielen begnügen und im weiteren Verlauf dieses Kapitels nicht mehr darauf zurückkommen.

In den meisten Fällen wird die "fingierte direkte Rede" nach Einschub der Pormel auch weiterhin in der 1. Person Singular fortgeführt. Manchmal folgt jedoch nach dieser Onterbrechung $\mathrm{ER}$, in die die "fingierte direkte Rede" somit übergeht. Längere Gedankengänge werden nie in "fingierter direkter Rede" gestaltet.

- Sieh mal an, ein netter, sympathischer und wie mir scheint, auch begabter Mensch - dachte Niels Nielsen, während er Patrizius Baltik nachsah, wie er durchs Cafe ging. (BB, 384)

Die hier vorliegende Situation ist bezeichnend für die Anwendung der "finglerten direkten Rede". Bei Betrachtung einer Sache oder einer Person taucht bei dem Betrachtenden plötzlich ein kurzer Gedanke auf. Wie nahe diese aufblitzenden Gedanken bisweilen an die Sprechsituation heranreichen, wind in einigen Pällen ganz deutlich:

- Das ist die Panik! Das sind die Nerven. Das ist die personfizierte Angst - sagte Nielsen halblaut vor sich hin, während er das Fenster schloB und die Vorhänge herablieB. (BB, 101)

In NRP wird DR bereits mehr verwendet als in FL, da sie als wesentliches Mittel der satirischen Charakteristik fungiert. ${ }^{13}$ während in FI die Rededarstellung, vereinfacht ausgedrückt, auf einige wenige Kapitel beschränkt bleibt und der Haupttell der Innendarstellung des komplizierten Helden gewidmet ist, finden wir in NRP genau umgekebrte Verhältnisse. Es geht hier weniger um den Helden des Romans und dessen

Die meist kurzen Begegnungen des Ich-Erzählers mit den verschiedenen Vertretern der bürgerlichen Gesellschaft, in deren Verlauf das wahre Tesen des jeweiligen Gesprächspartners durch seine Worte zum Vorschein kommt, laufen in vorwiegend direkten Szenen ab. 
Gefühle, als in erster Iinie um Kritik an der Gesellschaft. Die DR spielt aus diesem Grunde eine wichtige Rolle.

Der dritte Roman Krležas, $\mathrm{BB}$, besteht vorwlegend aus langen Monologen und nicht minder langen Gesprächen, die zum gröBten Teil in DR verlaufen. Streckenweise liest sich dieser Roman fast wie ein Dramen-Text. In keinem anderen Roman läBt der Erzähler seine Personen sich in solchem AusmaB mit ihren "eigenen" Worten äußern. Seitenlang vergessen wir die Anwesenheit des Erzählers völlig, denn Rede folgt auf Gegenrede, oder eine Person spricht ihren langen lionolog zu einem schweigsamen Partner, der nur als $\mathrm{Zu}-$ Lörer furgiert. Su die lange Rede des Paters Baltrubajtis oder die Knutsons.

In 2 wird die $D R$ nicht mehr so ausschlieblich verwendet wie in BB. Der Grund dafür ist sowohl in der differenzierten Redetechnik zu suchen, die ein Anwachsen der IR und vor allem der ER zur Folge hat, als auch in der Tatsache, daB der Erzäbler sich nicht mehr so im Hintergrund hält wie in BB. Bericht und längere Autor-Kommentare übernehmen wieder jene Funktion, die der DR in BB noch zusätzlich zukam, weil ein GroBteil der Geschehnisse in die Sphäre der Personen-Rede verlagert wurde. Trotzdem hat die DR an der Rededarstellung immer noch den weitaus gröBten Anteil.

Während Anwendung und Häufigkeit der DR in den einzelnen Romanen recht unterschiedlich sind, weisen Vorkommen und Anwendung der IR im Verlauf der Romane kaum Schwankungen auf. Aus diesem Grunde soll ein allgemeiner tberblick genügen.

In allen Romanen Krležas spielt die IR die geringste Rolle. Am häufigsten ist sie noch in NRP und $z$ anzutreffen. Betrachten wir die Stellen der Romane, wo Brleži IR verwendet, so stellt sich heraus, dab sie nur in den wenigsten Fällen zur Verkürzung und Raffung oder zur Mitteilung von inhaltilch Unwichtigem herangezogen wind. Die Untersuchung der Gespräche zeigt, daB diese fast ausschlieBlich in $D R$ verlaufen und daB IR nur ganz selten dazu dient, 
Ausführlichkeit und länge dieser Gespräche $z u$ vermeiden. Charakteristisch für Krležas Darstellungstechnik ist jedoch der indirekte Gesprächsbeginn. Die Gespräche, die in der Handlungsgegenwart stattfinden, setzen meist nicht mit $D R$, sondern mit $I R$ und $E R$ ein, in einigen Fällen aucb mit Redebericht. Nicht selten kündigt der Erzähler in einem einführenden Kommentar das folgende direkte Gespräch selbst an, indem er Thema und Inhalt angibt und auf diese Veise das Resultat des anschließenden Gesprächs vorwegnimmt. Im Prinzip ist dieses Verfahren Ausdruck der Erzählhaltung. Aus seiner allwissenden Uberschau über das Geschehen und aus seinem Streben nach Klarheit und Unmißverständlichkeit heraus faßt der Erzähler in geraffter Form den Inhalt des folgenden Gesprächs zusammen. Ein Beispiel:

Nach dem Abendessen, im Arbeitszimmer des alten Kamráth (...) entfernte sich das Gespräch von den Betrachtungen Amadeos über die Jesuiten und das Spielhaus und von den offenen Fragen der sozialen und moralischen Entwicklung der Menschbeit als solcher, und so bewegte sich die Unterhaltung auf die politische Situation in Kroatien $z u$ (...). Im Zusammenhang mit dem morgigen Leitartikel im "Madzarsko slovo" (...) über das Zagreber Attentat ging das Gespräch auf das überaus heiße Thema des serbisch-bulgarischen Krieges über (...). Lian begann von diesem unglücklichen Krieg als der hauptsächlichen Quelle aller ungarischen Unannehmlichkeiten zu sprechen, und was die Beurteilung des Verbrechens auf dem Balkan betrifft, waren sich alle Herren völlig darüber einig, daß dieser verrückte und blutige Krieg nichts anderes darstelle als den Untergang jedes normalen Verstandes sowie jeglicher Moral im europäischen, edlen und gebildeten Sinn dieses Wortes. $(2,2,269$ f. $)$

Häufig ist die Verbindung von Redebericht und IR. Die Formel "govoriti (oder "pricati") o..., o..., o..., i o tome kako", die Redebericht und IR miteinander verbindet, ist charakteristisch für eine Anzahl von Gesprächseinsätzen; vor allem dann, wenn eine Person spricht. Ein Beispiel aus FL: 
Während er seine dreiundvierzigste Zigarette rauchte und auf dem Zahnstocher herumbiB, erzählte der dicke alte specknackige Korngold von seinem Pett, von den gestörten Funktionen dieses Fettes, von Spargeln, von Pleisch, von Pischen, von seinen Waldgeschäften und davon, $d a B$ es eigentlich unfaBbar sei, daB er sich niemals das Kauen auf den Zahnstochern hat abgewöhnen können, dieses überflüssige Hölzchen, von dem die sogenannten wohlerzogenen Leute sagen, seine öffentliche Benutzung sel unanständig $(\ldots)$ ! $(235$ f.)

Andere Gründe sind für den indirekten Beginn aller jener Gespräche ausschlaggebend, die nicht in der Handlungsgegenwart stattinden, sondern im Rabmen eines Gedankenmonologs durch den Monologisierenden erinnert werden und auf diese Weise zur Darstellung gelangen. Der Ubergang von der Monologsituation zur Rede einer anderen Person läBt sich mit IR viel leichter hnd unauffälliger vollziehen als mit DR. IR paBt sich in Tempus und Pronomina dem in 3. Person Singular gehaltenen inneren $N o n o l o g$ mühelos an und geht absatzlos in diesen über. In all jenen Pällen, wo IR lediglich dazu dient, einen Ubergang oder eine Einleitung zu einem folgenden Gespräch zu schaffen oder wo thr kürzende Funktion zukommt oder wo sle Rede und Bericht miteinander verbindet, geht sie häufig bald in ER über. Längere Absätze in IR sind in diesen Fällen bel Krleža ziemlich selten. Während Krleza in den ersten Romanen zur Wiedergabe von Rede in Gedankenmonologen noch vorzugsweise IR verwendet, geht er in BB und vor allem in $Z$ dazu über, längere direkte Gespräche in die Monologe einzuschalten. IR hat hier nur mehr überleitende Punktion.

Vratill su se prošle jeseñ, poslije jednog regnikolarnog banketa kod "Engleske Kraljice" ovamo, u "Fiumu", u ovaj isti hotel, u ove istu sobu, 1 tu mu je Kamilo, sjedeti mu na krevetu, titao lekciju takoredi do jutra, kako treba da se stidi da kao hrvatski regnikolarac antigambrira kod onog Wekerlea (...) koji po srojim sposobnostima ne bi mogao biti butler ni u takrom bi- 
jednom hotelu kao sto je ova smrdljiva "Fiuma"

$(z, 1,280)$

Der innere Monolog Emerickis geht hier in die in IR wiedergegebenen Worte Kamilos über. Unmittelbar nach diesemAbsatz folgt das direkte Gespräch 2 wischen beiden, das jedoch bald wieder in den Yonolog Emeri

Verwendet Krleža IR selten in Gesprächen, um zu kürzen, so finden wir sie jedoch häufig in Verbindung mit dem Bericht. Auf Grund der bereits erwähnten Stilqualitäten paBt sie sich dem Berichtston an und eignet sich dazu, die Personenrede mit in den Bericht einzubeziehen. Oft werden Teile der IR in Anführungszeichen gesetzt oder zumindest stark an die Ausdrucksweise des Redners angenähert, so daß sie, obwohl sie sich in die Satzmelodie des Berichts einpassen, deutlich erkennen lassen, daB gesprochene Rede vorliegt. Ein Beispiel:

(...) a to je bilo jednog ljetnog predvečerja u Maksimiru (...) kada je Joja priznao Kamilu da je Żigman "socijalist", $i$ da su one gospodjice tamburašice u čamcu, sa krvavim crvenim kordonima na bijeloj svili, koje tako divno sviraju pohrvakenu i $2 a$ tamburice ukajdisanu barkarolu iz "Hoffmannovib prita" - socijalistice, "klasnosvijesno" organizirane u bojnim redovima hrvatskoga radniłtva, koje se bori za slobodu. $(z, 1,440 \mathrm{f}$.

Noch stärker wird der Eindruck erweckt, den Sprechenden unmittelbar zu hören, wenn die IR in einem Dialekt oder in einer Fremdsprache wiedergegeben wird. Krleza reproduziert in FL die Worte einer alten Frau in kajkavischer Mundart, ohne sie jedoch direkt darzustellen. Der Ubergang vom Bericht zur Rede im Dialekt geht ohne wesentlichen Sprung vor sich, da der Bericht des Erzählers bereits einige Barbarismen aufweist und sich damit der Personensprache bis zu einem gewissen Grade angenähert hat. 
Jedan $f i j a k$ e $r$ odvezao je gospodina geometra na komisiju, a kod drugoga našao je Filip u jednoj malenoj, svijetlozelenkastoj i z b $i$, kod goruće peći, staru krezubu b a b 1 c u i ta mu je, ¿ $v$ a č u $\varepsilon$ žemlju natopljenu kavom iz crvenkastog politrenog lonca, rekla, da se japica buju popoldan vrnuli, ali gda, da to ona reči nemre!

(FL, 53; Herv. v. mir)

In den bisherigen Beispielen diente die IR der Verkürzung, der Mitteilung von Unwichtigem oder bereits Bekanntem, der Einleitung in direkte Gespräche, der tberleitung vom Gedankenmonolog zur Gesprächssituation und vor allem dazu, um Rede innerhalb des Berichts wiederzugeben. Eine wesentliche Funktion, die die IR in den Romanen Krlezas erfüllt, wurde jedoch noch nicht erwähnt. Oft steht die IR im Zeichen der Ironie oder seltener der Karikatur. Manchmal drückt das verbum dicendi die Intonation der IR . aus, häufiger ein die IR einführender oder abschließender Satzteil oder ganzer Satz.

(...) i tako, još uvijek u jubilarnom raspoloZenju, Presvetli je ironizirao svoju vlastitu sigurnosnu službu, kako je u Katedrali bilo vise detektiva nego gradjanskog svijeta (...) $i$ to, kako je na banski prijem nagrnula sva bivša i buduca saborska bagra, titava falanga "politischverdächtigera", a kod Objeda , kako je promatrao jednog buduceg koalicionaskog "regierungsfähig" vožda, gdje oblizuje svoj nož, pa slušajuei svoga gospodina oca kako se obmanjuje vlastitom ironijom, kao da je doista nebeski vrhunaravno uzviłen iznad banskih politikanata $i$ "politischverdächtigera" sviju boja, Kamilo nikako nije umio da dodje do rijedi $(\ldots .$.$) .$ $(2,2,754)$

Das verbum dicendi der IR Emerickis "ironizirati" ist doppeldeutig, wie die Worte Emeri $X_{k i s}$ es zum Ausdruck bringen. Um keinerlei MiBverständnis über diese Doppeldeutigkeit aufkommen zu lassen, wird den Norten Emeričkis eine direkte Erklärung angefügt, die vom Erzähler ausgeht, aber bereits in die Perspektive Kamilos verlegt wird; kurz darauf folgen einige Gedaniken Kamilos in ER. 
Krleža verwendet häufig IR, um die Worte des Sprechenden zu verzerren. In folgendem Pall karikiert er nicht nur die Redeweise der betreffenden Person, indem er bezeichnende Floskeln mehrmals wederholt, sondern er erzielt einen besonderen Effekt durch die Menge der aneinandergereihten "kako".

Ovoga puta, u "Evropi", nije Prancek pritao o svom venecijanskom pakungu, ti boga, nego - tome, kako su ga bacill iz banke, kako sada rodi knjigovodstvo kod nekakrog carinskog posrednika, kako traḱt bolje 1 unosnije mjesto, kako bi trebao protekciju uglednog direktora jedne ugledne banke, kako svi ljudi kradu 1 varaju, ti boga, kako je sve sagradjeno na kradjama 1 na prevari 1 kako je svijet gadan, zloban 1 pokvaren. (NRP, 249 f.)

I. Prangez macht in seiner Untersuchung der ER auf diese für Krleza charakteristischen Sätze aufmerksam, in denen er mit Hilfe der zahlreichen Konjunktionen "da" und "kako" eine ganz spezifische Intonation erreicht, die häufig ironischer Natur ist. ${ }^{14}$ Diese Art der IR, die wir in Krležas Romanen besonders häufig antreffen, unterstreicht in einer Reihe von Fällen das Phrasenhafte oder Verlogene der Worte einer Person. In einigen Fällen wird das verbum dicendi weggelassen, und die IR nähert $\mathrm{sich}$ der ER. Frangeł bezeichnet diese Form der IR als tbergangsfall zur ER. ${ }^{15}$ Die spezifische Intonation wird auch hier wieder durch die Konjunktionen erreicht.

A zatim je pocelo dosadjivanje $s$ njenim portraitom.

Da je presvijetli Liepach titao jednu Pilipovu knjigu o slikarstvu ( 1 njoj donio, all ona nije dospjela dalje od trece strane), da je ona svima najavila, kada se njezin sin vrati iz inostranstva, kako ce naslikati njen portrait, kako je to prirodno da sin slika svoju rodjenu majku ("ako već ne 12 umjetnixkih,

14 Slobodni neupravni govor kao stilska osobina. In: UR, $7,1963,269,274$.

Ebd., S. 265, 274 f. 
a ono bar iz obiteljskib razloga - sebi na uspomenu"), da on njoj to ne smije da odbije $(\ldots)$. (PL, 87)

Der einleitende Satz bezeichnet mit "dosadjivanje" wiederum die Intonation der folgenden indirekten Sätze der Mutter Rilips. Wie nahe IR ohne verbum dicendi an ER herankommt, aber doch nicht ER ist, zeigen die in Klammern eingeschobenen Bruchstücke von ER an.

3. Erlebte Rede

Die ER ist eine Zwischenform zwischen IR und DR. Von der ersten übernimmt sie Pronomina und Tempus, von der letzteren die Intonation sowie gefühlsmäBige Elemente. In Unterschied zur IR fällt in der ER das für jene charakteristische übergeordnete Verb des Sagens oder Denkens weg. Während jedoch im Deutschen und in den romanischen Sprachen die ER nicht nur die 3. Person Singular, sondern auch die für den Bericht des Erzählers charakteristische Zeit, das Imperfekt, aufweist, und der vbergang vom Bericht zur ER aus diesem Grunde keine Veränderung der grammatischen Formen zur Folge hat, herrschen im Serbokroatischen andere Verhältnisse. Während in den genannten Sprachen nur eine Verschiebung des Blickpunktes eintritt, verändert sich im Serbokroatischen auch das Tempus. Die ER kann hier demnach nicht als "Rede in der Brechung des Berichts" bezeichnet werden. ${ }^{16}$ Der Grund für die verschiedenartige Ausprägung der ER liegt in der unterschiedlichen Behandlung der Zeitenfolge. Bereits $M$. Lips stellt rest, daB in den romanischen Sprachen in der IR die consecutio temporum obligatorisch ist. Im Deutschen und Englischen liegen die Verhältnisse ähnlich, wobel in Deutschen als Besonderhelt noch eine Umsetzung des Modus hinzukommt. Im Russischen

16 . Günther, s. 84 . 
dagegen wird weder der Modus verändert, noch tritt die consecutio temporum in Kraft. ${ }^{17}$ Die Untersuchungen von I. Pranges zur ER im Serbokroatischen bestätigen diese Beobachtungen von Y. Ifps. ${ }^{18}$ Als Grundproblem zum Verständnis der ER Im Serbokroatischen bezeichnet Franges die consecutio temporum. Zur Darstellung der Problematik fübrt er u.a. folgende Beispiele an:

On kaž da je bolestan On je rekao da je bolestan

Er sagt, er sei krank
Er sagte, er wäre 19
krank

Il dit qu'il est malade

Il a dit qu'il était

malade

Während die Zeit des abhängigen Verbs sich in der IR des Französischen und in der Regel auch des Deutschen nach der des einleitenden Verbs richtet, also eine consecutio temporum eintritt, ist dies im Serbokroatischen nicht der Fall. Hier bleibt das Verb des abhängigen Satzes auch dann

17 s. 38 .

18 I. Frangeš befaßt sich an Hand von Prosatexten Krležas in zwei Aufsätzen mit der ER; besonders ausfübrlich in dem bereits angeführten Artikel in UR (s. S. 68 Anm. 14). Während er hier die ER als Mittel der Redewiedergabe behandelt, geht er in "Stvarnost $i$ umjetnost u Krležinoj prozi" (in: Stilisticke studije. Zagreb 1959, S. 280283 über ER) in kürzerer Form auf die ER als Mittel der Gedankenwiedergabe ein. AuBer I. Franges ist noch $M$. Engelsfeld zu nennen, der in seinen Untersuchungen zum Stil Krležas ebenfalis die ER berücksichtigt, der spezifischen Erscheinungsform der ER im Serbokroatischen jedoch nicht Rechnung trägt (in: UR, 2, 1958, 19-22 über ER und UR, 6, 1962, 7-12 über ER). Als erster macht 4. Feller ("Kriticki fragmenti o Miroslavu Krleži". In: Republika, 9, 1953, 576-596) auf den für Krlezas Prosa bezeichnenden komplexen Stil aufmerksam, ohne aber das Hittel, das diesen Stil bewirkt, ER, zu nennen (S. 581585).

19 I. Frangeš berücksichtigt dabei allerdings nicht, daB im Deutschen auch 'er sagte, er $s$ e $i$ krank' möglich ist. Vgl. Slobodni neupravni govor kao stilska osobina, 266. 
in Präsens, wenn das übergeordnete Verb in der Vergangenheit erscheint. Für die ER im Serbokroatischen ist also nur die Umsetzung des Pronomens erforderlich, nicht aber die der Zeit. Statt der Vergangenheitsform, die für die ER in den romanischen Sprachen, im Deutschen und im Faglischen charakteristisch 1st, steht im Serbokroatischen das Präsens. I. Pranger stellt fest, daB die ER in Serbokroatischen gerade deswegen, weil die Handlung des abhängigen Satzes in einer "Art von gnomischem Präsens" steht, das selnen Wert durch den Hauptsatz erhält, zu einem "anderen Ausdrucksmittel" wird und eine "andere Psychologie" einschliebt als in den romanischen und germanischen Sprachen. 20

Aus der Tatsache, daB die Zeit der ER im Serbokroatischen das Präsens ist, ergeben sich zwel wichtige Polgerungen. 1. Da die Zeit des Erzählers im allgemeinen die der Vergangenheit ist, wird seine Anwesenheit in der ER des Serbokroatischen weniger spürbar als in den anderen erwähnten Sprachen, in denen sich Erzähler u n d Person derselben Zeit bodienen. Die Identifizierung ron Erzähler und Person errelcht einen höheren Grad, da das Imperfekt als Form der Distanzierung der Aussage vegfällt. Es bleibt jedoch die 3. Person singular als distanzierender Faktor bestehen. 2. Da die Zeit der IR dieselbe ist wie die der ER, fällt es oft schwer festzustellen, wo IR und wo ER vorliegt. Im Deutschen ist diese Onterscheidung leicht zu treffen, da der Modus der IR der Konjunktiv ist, der der ER jedoch der Indikativ. Im Englischen, das ebenso wie das Serbokroatische keinen Konjunktiv zur

20 Slobodni neupravnt govor kao st1lska osobina, 266. Das Beispiel, das D. Zivkovic in seiner "Teorija knjizevnostin (3. Aufl. Sarajevo 1960, S. 166 f.) für IR anfüht, ist ebenfalls im Präsens. R. Minde ("Ivo Andrit, Studien über seine Erzählkunst". Yïnchen 1962, S. 139 l.) nimmt auf Grund ihrer Beobachtungen an den Erzähiungen von I. Andrit auch an, das "die Vergangenheitsform nicht unbedingt als Voraussetzung für die 'erlebte Rede' empfunden wird." Ansonsten sind ihre Angaben über die ER im Serbokroatischen recht spärlich. 
Bezeichnung der syntaktischen Abhängigkeit kennt, nähert sich die konjunktionslose IR, die in der Vergangenheit steht, der ER und kann obne Schwierigkeiten in diese übergehen. Im Serbokroatischen ist die Situation insofern noch komplizierter, als beide Formen der IR, die im Präsens und die in der Vergangenheit, weder in Zeit noch Person von der ER unterschieden werden können, wenn die Konjunktion wegfällt. Mit zunehmender Entfernung von dem einleitenden Verb, das die Abhängigkeit bezeichnet, werden die Sätze immer selbständiger und können nicht mehr als von dem einleitenden Verb syntaktisch abhängig betrachtet werden, wenn die Konjunktion nicht wiederholt wird, die diese Abhängigkeit stets von neuem bekräftigt. Die Erlebtheit des Stils, Ausmufe, Fragen, umgangssprachliche Elemente, Wiederholungen und Demonstrativpronomina zum Beispiel können als Anzeichen für ER angesehen werden. 21

Die Verlagerung der Autorenperspektive in die Personenperspektive ist ein charakteristisches Merkmal der ER. Die für die ER bezeichnende Doppelheit von Erzähler und Person, die bis zur Identifikation gehen kann, schafft einen der ER eigenen "Stimmungswert". 22 Die Grenze zwischen Autor und Person ist entweder gar nicht oder nur sehr schwer festzustellen. "Ein Teil der Kriterien spricht für den Autor, die Authentizität des Wortlauts (Individualsprache) für den Belden (...). Die Stilwerte der erlebten Rede liegen demnach gerade in diesem Schwerbestimmbaren, VerflieBenden, mit Kalepky in ihrem 'Verschleiertsein'."23

Von wesentlicher Bedeutung für das Verständnis der ER und ihrer Stilwerte ist der ihr anhaftende paradoxe Cha-

$21 \mathrm{Vgl}$. I. Franges: Slobodni neupravni govor kao stilska osobina, 267.

22 Stephan, Doris: Der Innere Monolog in Hermann Brochs Roman "Der Tod des Vergil". Diss. Mainz 1957, S. 26.

23 Ebd. 
rakter: trotz aller Innenschau hat der Erzähler seinen Standpunkt außerhalb und über seinen Figuren nicht ganz aufgegeben. 24 Wenn auch "jedes Wort von der Pigur gesagt bzw. gedacht zu sein scheint, so ist der Erzäbler doch nicht ganz verschwunden: er bleibt in dem Gebrauch der 3. Person spürbar. 25

Diese ausführlichen Darlegungen, die dazu dienten, den bivalenten Charakter der ER zu beleuchten, sind deshalb so wichtig, weil häufig nur der eine Aspekt der ER in Betracht gezogen und der nicht minder wesentliche nicht beachtet wird. Vor allem aber sind es gerade diese Möglichkeiten der ER, die sie für einen Erzähler wie Krleža zu dem geeignetsten Darstellungsmittel überhaupt werden lassen. Ihm, dem es in erster Linie um die Darstellung des Inneren seiner Romanpersonen geht, aus deren Perspektive häufig erzählt wird, gleichzeitig aber darum, seiner kritischen Distanz Ausdruck zu verleihen, komen die Stilwerte der ER in geradezu idealer Weise entgegen.

Welch überragende Rolle die ER in den Romanen Krležas spielt, wird daraus ersichtlich, daß er sie nicht nur zur Gedankendarstellung heranzieht und nur gelegentlich zur Wiedergabe von Rede, sondern daß sie wesentlichen Anteil an der Rededarstellung hat. Die Perspektivenverschiedenheit von Erzähler und Person, die in ER in feiner, manchmal kaum merkbarer Form zum Ausdruck kommen kann, bestimmt weitgehend ihre Verwendungsweise in den Romanen Krležas und ist Ursache des für Krleža so charakteristischen komplexen Stils. Die ironische Brechung entsteht durch die scheinbare Annahme der Perspektive des Sprechenden (selte-

24 Vgl. W. Günther, S. 85 ff.

25 Kayser, Wolfgang: Das sprachliche Kunstwerk. 3. erw. Auf 1. Bern 1954, S. 147. Vgl. weiterhin: Ders.: Entstehung und Krise des modernen Romans. 4. Aufl. Stuttgart 1963, S. 32. Stanzel, Franz: Die typischen Erzäblsituationen im Roman. Wien-Stuttgart 1965, S. 151. Frangez, Ivo: Slobodni neupravni govor kao stilska osobina, 267. 
ner des Denkenden) durch den Erzähler, der gleichzeitig zu verstehen gibt, daß er selbst das Gegenteil des Gesagten (oder Gedachten) meint. Ch. Bally und M. Lips erkennen der ER jegliche ironische Ausdrucksqualitäten ab. ${ }^{26}$ Lips behauptet ähnlich wie Bally, daB die ER eine "attitude strictement objective du rapporteur" fordere. 27 DaB dies nicht der Fall ist, beweisen eine Reihe von Untersuchungen über die ER und nicht zuletzt der Gebrauch der ER bei Krleza. A. Neubert, der sich an diesem Punkt kritisch mit Bally auseinandersetzt, spricht für ein Vorhandensein dieser Ausdrucksqualität. ${ }^{28}$ Die der ER innewohnenden Möglichkeiten ironischer Gestaltung zu leugnen, heißt nur $e$ i $n$ e $n$ der beiden Aspekte der ER beachten, nämlich den der Identifizierung, und den besonders für Krleža bestimmenden, den der kritischen Distanz, übersehen. Als aufschluBreich für die ironischen Ausdrucksqualitäten der ER erweisen sich die Feststellungen R. Haumgarts, die er in Bezug auf den Gebrauch der ER bei Th. Mann trifft. Wie schwer diese Ironie zu greifen ist, so daß es sich des öfteren als unmöglich herausstellt, sie eindeutig zu bestimmen, geht aus seinen Darlegungen genau so hervor wie aus der Untersuchung der betreffenden Stellen bei Krleza. Kanchmal ist es "nur ein leiser Unterton, eine Nuance, die in die Worte der Person mit hineinklingt. Baumgart führt an, daB die ER, die "selbstloses Hineinleben in die Figur und überlegen lächelndes Beistehen verbindet" den "Bedürfnissen eines Ironikers einzigartig entgegenkomme. 29

26 Bally, Charles: Antiphrase et style indirect libre. In: A Grammatical 1:iscellany Offered to Otto Jespersen on his Seventieth Birthday. Kopenhagen 1930, S. 333, 340.

27 s. 133 f.

28 s. 89.

29 Das Ironische und die Ironie in den Werken Thomas Manns. Kinchen 1964, S. 63. 
Wit welchen Mitteln gelingt es Krleza nun, die in der ER verwirklichte ironische Note spürbar zu machen? An welchen Anzeichen merken wir, ob der Autor das Gegenteil des Gesagten meint oder sich sogar über die betreffende Person lustig macht? In manchen Fällen ist die ironische Distanz des Erzählers nur zu ahnen. Häufig kommt sie jedoch mehr oder weniger deutlich zum Ausdruck. Unverkennbar ist die ironische Färbung überall da, wo die ER vom Erzähler eingeleitet wird. Diese Einleitung ist bereits ironisch intoniert und zeigt die Richtung der ER an. So werden in folgendem Beispiel die in ER reproduzierten Forte der Frau Banalrat Rekettye durch den einleitenden Redebericht und vor allem durch den Begriff "fixe Idee" ironisch gefärbt.

Ona se micala svijetom i govorila o Casalsu, - besanicama, o bizarnim spiritistiłkim seansama, a zapravo je umirala od fiks-ideje, da nosi u sebi raka. I njen suprus, gospodin banski savjetnik plemeniti Rekettye, $i$ on je umro od raka prije tri godine, titavih njenih pet posljednjih godina nije bilo ispunjeno ničim drugim nego prisluskivanjem, kako to rak zapravo ždere tkivo gospodina banskog savjetnika (...). (FL, 92)

Konventionelle, phrasenhafte Reden werden häufig in ER wiedergegeben. In folgendem Beispiel geht die ironische Intonation wiederum von einer Einleitung aus, die unmittelbar in ER übergeht. Wortschatz und Hyperbolik unterstreichen den ironischen Ton.

Sekundu kasnije javio se Amandin glas iz telefonske školjke, Sirok, jovijalan, iznad davne, vec kao zaboravijene scene poslije Hortenzijina sprovoda plemenito uzvišen, pa kao da se 1zmedju tetke $i$ nećaka zaista nikada niłta nije desilo, Amanda se sva rastopila od slatke miline, vise od toga, od ushita కto joj se odmetnik javio, ona pozdravlja Kamila srdačnom dobrodoslicom, mogla bi se bila nadati glavnome zgoditku na lutriji prije nego da cuje njegov glas, gdje je odsjeo, kada je doputovao (...). $\{2,2,776)$ 
Phrasen, unaufrichtige, gewundene Worte, pathetische Reden, offensichtliche Lügen, Schmeicheleien und dergleichen werden in der Regel in ER wiedergegeben und kommen 80 weit besser zur Wirkung als in DR oder IR. Elnzelne Worte werden durch GroBschreibung hervorgehoben, in Anführungszeichen oder in Klammern gesetzt, die Titel der adeligen Personen werden häufig in ihrer vollen Länge wiederholt, der ironische Sinn mancher Worte enthüllt sich durch ungewöhnliche Satzstellung, so daB sie besonders hervorgehoben und damit betont werden. Des öfteren setzt der Erzähler auch Ausrufezeichen hinter die Aussprüche einer Person und verleiht diesen damit eine andere Intonation.

Wir räumten der ironisch gefärbten ER deshalb einen so breiten Raum ein, da ibr in Krlezas Romanen erstrangige Bedeutung zukommt. Selbstverständlich bleibt der Gebrauch der ER bei Krleza nicht nur auf diesen einen, wenn auch sehr wesentlichen Aspekt beschränkt. Sämtliche Möglichkeiten aufzuzeigen, würde zu weit führen, da Krlež die $E R$ in erstaunlichem MaBe zu differenzieren versteht. Heten wir aus diesem Grunde nur noch einige wesentliche Funktionen der ER hervor. Resignation, Distanz, Rälte, Kontaktlosigkeit sind häufig die Ursache, die Worte einer Person in ER wiederzugeben.

Potpuno siva u licu, all savrళeno hladnokrvna, Boba je odbila njegova pratnju odluxno. Zahvaljuje mu na ljubaznosti, ali ona putuje sama. Nju ne treba da prati nitko. Ona treba taj novac veceras, najkasnije do sedan! (FL, 244)

Weiterhin verwendet $\mathrm{Krlež}$ ER, um ausgesprochene Pakten durch eine Person berichten zu lassen. Auf diese We1se werden sie mehr in die Bericht-Sphäre gerückt, der Charakter der Mitteilung wird verstärkt. Gleichzeitig wird die Ausdrucksweise varilert, so dab die Unterredung nicht ausschlleBlich in DR verläuft. So beginnt das Gespräch 2wischen Barutanski und seinem Ninister Burgwaldsen zwar 
in $D R$, wechselt aber nach einigen Torten in ER über, als Burgwaldsen seinen Rapport über die außerhalb von Beauregard sich abspielenden Ereignisse beginnt. Erst nach diesem Bericht wird das Gespräch wieder direkt fortgesetzt ( $B B, 323$ ff.).

Im Zusammenhang mit dieser Art der ER steht eine andere, die die Redeform einer ganzen Erzählung einer Romanperson ist. Als Blithauer Nielsen die entscheidende Episode aus seinem Leben erzählt, werden seine Worte nicht mehr, wie bis zu diesem Punkt des Gesprächs, in DR, sondern in ER wiedergegeben:

Der einzige Sohn Egon Blithauers, der kleine Eugen (...) verschied eines Silvesterabends genau um sieben Uhr $(\ldots$.$) .$ $(\mathrm{F}, 96)$

Nach vier Seiten wechselt er, nachdem er seine Erzählung beendet hat, wieder in die 1. Person über:

Blithauer unterbrach seine Gedanken: übrigens sind das private Dummeiten. Intimes. Intimstes. Mit solchen Dingen soll man besser niemanden langweilen, und sie sind einer der wenigen, denen ich das erzählt habe (...). $(F, 99)$

Würde die Sprechsituation Blithauers nicht einleitend und abschließend - abschließend durch den Erzähler, der das Erzählte als Norte Blithauers ausweist - so deutlich angezeigt, entstünde der Eindruck, der Erzähler selbst würde das Erlebnis Blithauers berichten. Zeit und Person sind hier die des Berichts und überdies wird die vergangene Szene in solchem MaBe vergegenwärtigt, daB die Ausgangssituation in Vergessenheit gerät. Die Tatsache, daB die Erzählung Blithauers nicht mit dem Pronomen der 3. Person beginnt, sondern mit der Nennung seines vollen Namens, verstärkt diesen Eindruck weiterhin. Der Grund für dieses Verfahren ist wohl darin zu suchen, daB Krleža die Vergangenheit einiger Personen nicht in Form von Erzähler-Bericht 
darstellen will, der die handlung unterbrechen würde diese Technik finden wir in seinem ersten Roman -, sondern dab er die Person von sich selber erzählen lassen will.

Werfen wir abschließend noch einen kurzen Blick auf das Verhältnis von ER $z U$ IR und DR im Rahmen der Rededarstellung.

In FI spielt die ER vor allem im Vergleich zur IR eine verhältnismäBig große Rolle zur Wiedergabe von Gesprochenem. In fast allen Fällen ist sie deutlich zu erkennen, da ihr eine Einführung vorausgeht und sie meist von den anderen Redeformen abgesetzt wird.

In NRP finden wir verhältnismäßig wenig ER. Ähnlich wie in FI erscheinen die verschiedenen Redeformen im wesentlichen noch in deutlich voneinander abgesetzter Form. Dem satirischen Charakter des Romans gemäB dient ER vorwiegend der ironischen und sarkastischen Färbung der reproduzierten Worte sowie deren Karikierung. Als Beispiel sei die Szene zwischen Golombek und dem Ich-Erzähler angeführt. Die Szene beginnt unvermittelt in DR. Nach einigen Sätzen unterbricht der Ich-Erzähler Golombeks Rede, um diesen vorzustellen. Der tbergang zur abgebrochenen Gesprächsszene wird durch eine Reihe indirekter Fragen Golombeks vollzogen, die bereits ironisch intoniert sind. Anschließend spricht der Erzähler eine direkte Frage aus. Die Antwort Golombeks erfolgt bezeichnenderweise in ER:

On je Xitao u novinama, da sam na bijegu u Ameriku (...). Policija je izdala za mom tjeralicu, jer sam pod temeljitom sumnjom, da stojim $u$ vezi s jednom prepredenom $i$ razgranatom bandom krivotvoritelja banknota ... (NRP, 273) 30

30 Es ist keineswegs so, wie W. Bühler meint (s. $32 \mathrm{ff.}$ ), daB ER im Ich-Roman nicht vorkommen könne. D. Stephan betont ausdrücklich, daB ER theoretisch in allen Personen möglich sei (S. 23). In dem hier angeführten Beispiel liegt eindeutig ER vor. Golombek spricht von sich in der 3. Pers. Sg. und nicht in der 1. Pers. Sg. wie in der DR. Ebenso redet er den Ich-Erzähler nicht mit "Vi" an, sondern er verwendet für ihn die 1. Pers. Sg. Vgl. I. Franges: Slobodni neupravni govor kao stilska osobina, $268 \mathrm{ff}$. 
In den ersten beiden Büchern von $B B$ wird zur Wiedergabe von Gesprochenem fast ausschlieblich DR verwendet. Erst mit Buch III stellen wir ein starkes Anwachsen der ER fest. Ebenso wie in den beiden vorhergehenden Romanen geht die ER im allgemeinen nicht unmittelbar in die anderen Redeformen über, jedoch finden wir hier bereits mehrere solche ineinanderübergehende Formen, die in $\mathrm{Z}$ den Darstellungsstil kennzeichnen. In diesem Beispiel aus $B B$ folgen in einem Satz Bericht, ER einer Dame, Bericht, DR und $E R$ eines Leutnants unmittelbar aufeinander:

Nagradjen pretvorljivo uxtivim i nervoznim pogledom fantastilne crnke, zbunjene oxitom drskoscu ovoga mladića, koji tu razgovara 8 njom kao da ona nije - "dama u pratnji jednog visokog oficira", lajtnant se zapleo oko svoje pijane fraze, to jest, molit ku lijepo, u redu, ako mu je gospodja oprostila, onda je sve $u$ redu, ali ako gospodja misli da se vrati $u$ Monte Abato, to je veoma pametno, a on joj preporuča hotel "Lovoriku" (...). (F, $31 \mathrm{f.})$

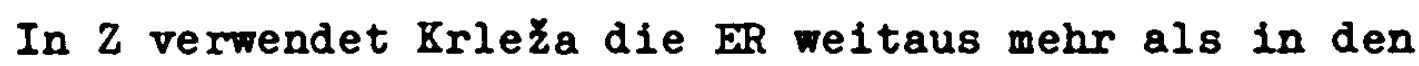
übrigen Romanen. Schneller und häufiger Perspektivenwechsel ist die Folge der ständig ineinander übergehenden Redeformen. Der Standortwechsel vom Erzähler zur Person und wieder zurück bewirkt einen lebendigen und äußerst komplexen Erzählstil, der nicht zuletzt auf die virtuose Handhabung der ER zurückzuführen ist. Die starke Beteiligung des ironischen Erzählers am Erzählvorgang ist ein weiterer Grund für den überaus häufigen Gebrauch der ER.

Das eigentliche Gebiet der ER ist Jedoch die Gedankenwiedergabe. Was die Redewiedergabe betrifft, so herrscht $D R$ in allen Romanen - auch dann, wenn $E R$ eine so wesentliche Rolle spielt wie in $Z$ - bei weitem vor. Die Gedanken der Romanpersonen werden dagegen in der überwiegenden Mehrzahl in ER dargestellt. DR wird lediglich in "fingierter direkter Rede" verwendet, die bei Krleža ziemlich sel- 
ten ist, und in den DIM, die ebenfalls in der Minderzabl sind.

Om tberschneidungen zu vermeiden, seien hier nur jene Fälle von ER behandelt, die nicht in Form innerer Monologe erscheinen. 31 Onter ER sollen primär alle jene Denkakte verstanden werden, die in unmittelbarem Zusammenhang mit der Handlung stehen, die von der Handlung abzweigen und deren dramatisches Gegenstück der Monolog ist. In ER gelangen demnach in erster Linie kurze Gedankengänge zur Darstellung wie etwa ein plötzlicher Einfall oder ein aufblitzender Gedanke oder eine momentane Empfindung, die durch den Anblick einer Sache ausgelöst wird. Gedanken und Gefüble, die nicht so sehr an der Oberfläche des Bewußtseins liegen wie die Inhalte der Monologe, werden in ER wiedergegeben. 32 Die Person, deren Gedanken in ER erscheinen, steht meist unter dem unmittelbaren Eindruck der Geschehnisse, hat also keine Gelegenheit zu ruhigen, wohlausgewogenen Reflexionen. Charakteristisch für die ER sind daher die vielen kurzen Frage- und Ausrufesätze, die dem

31 D. Stephan stellt fest, daB ER und IIM grundsätzlich verschieden sind. ER gehört in den "stilistischen Bereich und bezeichnet eine andere Form der 'Rede', als es die direkte und die indirekte Rede ist." Der IIM dagegen ist "eine besondere Art der stream of consciousness technique, also ein Darstellungsprinzip, das für das Romanganze verbindlich ist." (S. $26 \mathrm{f.}$ ) Stephan führt weiterhin an, daß der IIM außer der ER auch Bestandteile der DR und der IR sowie reinen Bericht absorbieren kann. Außerdem kann der IIM $n$ u $r$ Gedankenwiedergabe sein, ER dagegen dient zur Rede- u n d zur Gedankenwiedergabe (S. $27 \mathrm{f}_{\text {. }}$ ).

32 W. Neuse ('Erlebte Rede' und 'Innerer Monolog' in den erzählenden Schriften Arthur Schnitzlers". In: PLIA, $49,1934,343 \mathrm{ff}$. ) unterscheidet $\mathrm{zwischen}$ IM in der 1. Pers. und ER. Wichtig ist seine Feststellung, daß innerer Monolog und ER dazu dienen, verschiedene BewuBtseinstiefen voneinander abzugrenzen, und daB die im inneren Monolog dargestellten Gedanken bereits verstandesmäBig verarbeitet sind, also näher an der Oberfläcte des Bewußtseins liegen als die in ER. Unmittelbare Gedanken- oder Gefühlsreaktionen, Sinnesapperzeptionen, Gefülsvorstellungen, von Situationen angeregte Gedanken werden in ER wiedergegeben. 
Ganzen einen stark emotionalen Charakter sowie einen unrubigen, hastigen Rhythmus verleihen. Kurze Gedankenfragmente oder blitzartige Assoziationen werden in syntaktisch meist unvollständiger Form reproduziert. Häufig Beht die ER bei Krleža ohne einleitenden Hinweis aus Bericht oder Gedankenbericht hervor, und oft ist der Ubergang vom Bericht zur ER fließend. Manchmal beginnt die ER auch nach einem Doppelpunkt oder nach Pünktchen. Wird sie eingefüht, so geschieht dies durch sogenannte Einführungsverben, die etwa Freude, Schmerz, Angst, Zweifel oder andere Empfindungen zum Ausdruck bringen. Zwei Beispiele:

Protrnuvi i od tog ptiljeg glasa, bez daha, nepomitno, Filip se pripio uz jedan ogroman pojastuteni starinski naslonjac, osjeçajuci kako mu prsti polagano ulaze u staniol (...) kako ne zna కto da porne sa svojim zgužvanim cvjetićima (da ih baci), kako mama place preko u sobi, tiho, sasvim tiho, ali plače, a sojka ceprka po svojoj krletci (...) i sve je tako neugodno, zagušljivo, mračno, pretoplo, sve se lijepi kao rastopljena čokolada, sve zaudara po gadnoj krestavoj sivoj ptici. Bon jour, monsieur! $(\mathrm{FL}, 22 \mathrm{f}$.

Der tbergang vom Bericht zur ER Filips geht hier flieBend vor sich. Während das Attribut "ogroman" bereits aus der Perspektive des ängstlichen kleinen Jungen stammt, liegt ER, abgesehen von jenem kurzen Fragesatz in Klammern, erst ab "tiho, sasvim tiho" vor. Der Ubergang vom Perfekt zum für die ER charakteristischen Präsens ist in diesem Beispiel deutlich zu verfolgen. Uber Partizip und Verb im Perfekt wechselt Krleža zum Partizip Präsens und schlieblich zum Verb im Präsens über. Im folgenden Beispiel wird die ER sowohl eingefüht - wiederum durch das Verb "osjećati" - als auch abgeschlossen. Die Ausgangssituation ist bezeichnend. Filip hört Pacak sprechen, der Erzähler berichtet, was er dabei empfindet, und anschließend werden Filips Gedanken unmittelbar reproduziert. 
Bereits das erste Wort "konačno" zusammen mit dem Ausrufezeichen weist sich deutlich als von Filip Gedachtes aus.

Slusajuci ovog snoba pokraj sebe (...) osjecao je Filip kako mu nadire krv u glavu. Konalno! I on sam mislio je o tom istom "plebsu" na isto takav aristokratski način $($...): do vraga, kako je moguce, da bi on isto mogao da misli o tim pitanjima kao $i$ ovaj snob? (...) Osjećao je kako mu se nalila krv u glavu i kako mu na vrscima prstiju izbijaju kapljice znoja. (FL, 130)

In Krležas erstem Roman, aus dem die beiden Beispiele stammen, spielt die ER eine groBe Rolle zur Bewußtseinsdarstellung. Der gröBte Teil von Filips Gedanken, sowie die der übrigen Personen, werden teils in Form von Gedankenbericht, teils in Form von ER wiedergegeben. Der Grund ist darin zu suchen, daB die langen monologischen Reflexionen, die für die folgenden Romane charakteristisch sind, in FL noch wenig vorkommen. Das ständige Ineinanderübergehen von Bericht, Gedankenbericht und $E R$ ist für den Darstellungsstil von FL bezeichnend.

In NRP finden wir naturgemäB nur wenig ER. Die Gedanken des erlebenden Ich - und allein sie sind in dieser Form darzustellen - werden bei "temporaler Brechung (...) wäbrend des Geschehens nachträglich authentisch und ohne Einmischung des erzählenden Ich wiedergegeben." 33 Es ist allerdings nicht leicht zu unterscheiden, ob die in ER reproduzierten Gedanken auch wirklich vom erlebenden Ich ausgehen oder doch vom erzählenden, das von der Vergangenheit überwältigt, sich in das erlebende Ich versetzt, und dessen Gedanken sich in Form von spontanen Reflexionen in das vergangene Geschehen eindrängen. In folgendem Beispiel, in dem die Gedanken des Ich-Erzählers als Jüngling wiedergegeben werden, liegt eindeutig ein solcher Pall von ER vor. Da das vergangene Ereignis zum großen Teil aus der Retrospektive berichtet wird, stehen die Verben im Perfekt.

D. Stephan, S. $89 \mathrm{f}$. 
Die in ER dargestellten Gedanken des erlebenden Ich heben sich durch inre präsensform und auch durch ihren emotionalen Charakter deutlich vom übrigen Bericht ab. Der Ubergang von der Vergangenheitsform über das Partizip Präsens zur Gegenmartsform des Verbums und damit zum Tempus der ER ist hier jut zu beobachten. Nach Beendigung der ER geht die Zeit wieder in die des Berichts über.

Kad je na pestanskom kolodvoru nestalo crvene svjetiljke njenog posljednjeg vagona, ostao sam na peronu, ne shvacajuci niłta. U pet sati jučer poslije podne, to znati dvadeset i osam sati prije toga oprostaja na kolodvoru, stajao sam na istome mjestu, otekujuki debrecinski brzi, a veceras prolazi prokraj mene jedna grbava gospodja i nosi lakiranu kutiju za rešire ... Ta grbava dama nosi crvene ruze, bouquet crvenih ruza, njeni su kovtezi presviceni zelenkastom pustenom prevlakom, grbava je; kamo uopte moze da otputuje jedna grbava dama $i$ to to $t e$ joj ruKe? U dnu kolodvora, vani na otvorenoj pruzi, odjekivala je vojnitka pjesma (...) (NRP, $191 \mathrm{f}_{.}$)

Dais hier unzweifelhaft $\mathrm{ER}$ vorliegt, geht aus der Art und Weise hervor, wie die Gedariken dargestellt verden, die überdies nur in bezug auf das erlebende Ich sinnvoll sind. Scheinbar nebensächliche Dinge erscheinen bedeutungsvoll, werden vor allem affektiv wiederholt und in ihrer Simultaneität gesehen - alles typische Kennzeichen des Gedankenstroms, für den auch alogische Verknüpfungen wie "grbava je", das mit dem vorhergehenden Satzteil für einen Außenstehenden keinerlei Beziehung aufweist, charakteristisch sind.

In Zusammenhang mit der starken Zunahme der inneren lionologe in den letzten beiden Romanen, $B B$ und $Z$, verliert die ER an Bedeutung. Nur in jenen Kapiteln von $B B$, auf die sich die jandlung des Romans konzentriert, herrscht ER vor. Vährend der Gespräche oder Handlungen der Romanpersonen leuchten blitzartig Gedanixen auf, die Handlung und Gespräch nur kurz unterbrechen, sie aber um eine Dimension erweitern. Ein Seispiel sei angefübrt. Als Karin an der : Yohnungstür der alten Gallèn klingelt, bei der Nielsen sich 
verborgen hält, wird Nielsen von Angst und Zweifeln gepackt. Charakteristisch für die ER sind die kurzen und zum Teil elliptischen Frage- und Ausmufesätze, die den Affekt Nielsens anzeigen.

Kako je mogla doznati, da Nielsen stanuje kod Gallènke? Knutson? IskljuCeno! Stara Gallenka? Isto tako ... Otkrili su ga. Tu ce ga uhapsiti! Zaradit ce Karina dobru krvarinu!

$(\mathrm{BB}, 341)$

In 2 spielt die ER zur Gedankenwiedergabe, soweit sich das nach dem ersten Buch beurteilen läBt, eine noch geringere Rolle als in $B B$. Der tbergang $z u r$ ER ist in $Z$ unmittelbarer als in BB. Während die ER dort noch meistens eingeleitet und auch abgeschlossen wird und in der Regel mit einem neuen Satz beginnt, erfolgt der thergang in $Z$ oft völlig unvorbereitet und mitten im Satz. Manchmal ist die Grenze daher nicht festzustellen, aber meistens weisen spezifische stilistische Merkmale darauf hin, daB ER vorliegt. In folgendem Beispiel geht der tbergang flieBend vor sich:

Slura gospodja Hortenzija svoga supruga kako je povisio glas pred Visokim Domom, kako dokazuje nešto ovoj saborskoj marvi, to ona odbija s negodovanjem, rogobatno mumljajuci, te ne razaznaje kome njen Kamilo to zapravo prijeti, 1 zasto nasa banska, upravo nasa emericzijevska obiteljska Regnikolarna Deputacija ne ce biti u stanju da izidje iz nekog "provozorija" (...). $(z, 2,9)$

4. Gedankenbericht

Der Gedankenbericht entspricht der "internal analysis" L.E. Bowlings. 34 Er ist die traditionellste Form der Be-

34 "What is the Stream of Consciousness Technique?" In: PliLA, 65, 1950, 345. 
wuBtseinsdarstellung, findet aber trotzdem selbst in Joyce' "Ulysses" Verwendung. Im Gegensatz zu den anderen Formen der Gedankendarstellung, die die Dramatisierung der Gedanken zur Folge haben, erfahren wir im Gedankenbericht die Gedanken und Gefühle der Personen stets durch die Vermittlung des Erzählers, der sie uns berichtet oder beschreibt. Der Gedankenbericht ist somit der berichtenden Darstellungsweise zuzuordnen, die anderen Formen der Gedankendarstellung jedoch der Redewiedergabe. Beim Gedankenbericht steht der allwissende Erzähler in Vordergrund, wählt aus und formuliert. "The author intervenes in any way between the reader and the character's consciousness in order to analyze, comment or interprete." 35 Um über die Gedanken- und Gefühlswelt seiner Personen berichten zu können, muß der Autor fortwährend "Signale" setzen, "die das Berichtete als Rede bzw. Bewußtseinsinhalt oder als Gedanken einer Gestalt ausweisen." 36 Diese häufige Verwendung der Verben des Denkens und Fühlens ist für den Gedankenbericht charakteristisch.

L.E. Bowling stellt fest, daB sich die "innere Analyse" besonders fir die Hiedergabe des sogen. "non-language process" eignet. 37 Unbewußtes kann nur in Form von Analyse durch den Autor ausgedrückt werden, nicht aber. in Form von Gedanken durch die Personen selbst. Die Untersuchung der entsprechenden Verben in den Romanen Krležas ergibt ebenfalls, daß der Gedankenbericht in erster Linie zur Darstellung unformulierter Sinneseindrücke herangezogen wird. In etwa neunzig Prozent aller Fälle ist "osjećati" das Verb des Gedankenberichts. Neben den verschiedenen Formen

35 L.E. Bowling, S. 345. Vgl. ebenfalls: Humphrey, Robert: Stream of Consciousness in the Modern Novel. Berkeley and Los Angeles 1962, S. 33 . Humphrey bezeichnet den Gedankenbericht als "description by omniscient author." (S. 33).

36 F. Stanzel: Die typischen Erzählsituationen im Roman, S. 147 .

37 s. 345 . 
von "osjecati" sind lediglich noch "izgledalo mu je", "pritinilo mu se" und "bilo mu je" verhältnismäBig häufig anzutreffen. Des öfteren wird der Charakter des Unklaren, Unbestimmten besonders betont. So in Folgendem Beispiel:

Osjecala je ona spram alkohola litno konstantan otklon, ali je toliko toga popila u životu, te je mogla da pije tri noći, os jećajući nejasnu, ali duboku, upravo neodoljivu potrebu, da se napije do besvjesti (...). (FL, 172)

Gedankenbericht, der einen Gefühlsinhalt zum Gegenstand hat, dessen Verb also "osjećati" ist, geht in vielen Fällen in ER über. Manchmal fungiert er nur als Einleitung zur ER, oft geht er aber erst dann in diese über, wenn die unklaren Gedanken, Ahnungen oder Gefühle zu Einsichten, Erkenntnis oder klarem Bewußtsein geworden sind und von der vor-sprachlichen in die sprachliche Phase eingetreten sind.

Während Art und Weise des Gedankenberichts in den verschiedenen Romanen im großen und ganzen gleichbleiben, stellen wir jedoch beträchtliche Unterschiede fest, was die Häufigkeit des Vorkommens betrifft. In FL spielt der Gedankenbericht eine große Rolle für die Bewußtseinsdarstellung und wird häufiger verwendet als ER. Filips kompliziertes Wesen wird in erster Linie durch den Autor analysiert. Auch in dem Ich-Roman NRP finden wir noch ziemlich viel Gedankenbericht, wenn auch weitaus weniger als in FL. In NRP dient er vor allem dazu, das Innere des erlebenden Ich im Zusammenhang mit szenischer Darstellung zu beleuchten, da sich hier wenig Gelegenheit für ER oder Konolog bietet. Diese Tendenz, Gedankenbericht vorwiegend bei szenischer Darstellung zu verwenden, zeigt sich auch in den beiden folgenden Romanen, vor allem in $Z$. Im Gegensatz zu FL, wo Krleža die Personen noch verhältnismäßig wenig selbständig denken läßt, ist das Bewußtsein der Personen in den letzten beiden Romanen weitgehend dramatisiert. 
5. Monolog und Dialog als wesentliche Darstellungsformen der Romane Krležas

Bereits zu Beginn dieses Kapitels stellten wir fest, dar lionolog und Dialog den wesentlichen Teil der Romane ausmachen. Eine ganze Reihe von Kapiteln der letzten beiden großen Romane - und von diesen soll hier hauptsächlich die Rede sein - bestehen fast ausschlieBlich aus Monologen oder Dialogen oder beiden zusammen. Charakteristisch für diese Romane ist die Verschmelzung von Yonolog und Dialog. Im Rahmen der Monologe werden Gespräche dargestellt, und Dialoge werden durch Gedankenmonologe des geistig abschwe1fenden Gesprächspartners unterbrochen.

In $B B$ weist Krleža in einigen Autor-Kommentaren auf die Struktur dieses Romans hin, die durch die vorherrschende Stellung von Monolog und Dialog bestimmt ist. 38 so bezeichnet er $\mathrm{BB}$ als "romansjerska igra" oder "komedija" und deutet damit den szenischen und dramatischen Charakter dieses Romans an. Gleichzeitig hebt er die überragende Bedeutung des inneren Monologs hervor, den er ironisch mit "sich hinter den Kulissen abspielende, intime Geschichte der moralischen Kopfschmerzen der Hauptpersonen" umschreibt.

Was die Dialoge angeht, so werden wir uns hauptsächlich darauf beschränken, ihre verschiedenen Funktionen aufzuzeigen, da, was ihre Form betrifft, das meiste bereits im Zusammenhang mit den Redearten erwähnt murde. Bei den Monologen dagegen werden wir unser Augenmerk vor allem auf deren verschiedene Formen richten und erst in zweiter Iinie deren Funktion untersuchen.

Unter Monolog sollen hier jene stillen Selbstgespräche der Personen verstanden werden, die in räumlicher oder zu-

38 In $B B$ ist in erster Linie die Erzählhaltung ausschlaggebend für den ungewöhnlich breiten Raum, den Monolog und Dialog einnehmen. Vgl. Kap. V, S. $180 \mathrm{ff}$. 
mindest geistiger Isolation vor sich gehen und der Darstellung der Gedankenwelt der jeweiligen Figur dienen. Es ist kein Partner vorhanden, und die Absicht sich mitzuteilen fällt weg. Der Leser kann nicht als Gegenüber angesehen werden, da er der Realität angehört und nicht der fiktiven Vielt wie der lionologisierende. 39

Krlezas Helden erfüllen auf geradezu ideale Weise die Voraussetzungen der Monolog-Situation. Sie sind schlaflose Grübler, passive Träumer und von neurotischen Stimmungen besessene Einzelgänger. Das hervorstechendste Merkmal aller dieser Personen ist ihre innere und äußere Einsamkeit. Sie leiden unter Kontaktlosigkeit und ziehen sich in eine Welt zurück, die zum großen Teil aus Träumen und Erinnerungen besteht. Bei näherer Betrachtung der Gespräche fällt auf, daß eine ganze Reihe der Dialoge in Wirklichkeit versteckte kionologe sind. In keinem anderen Roman finden wir so viele und vor allem so lange konologe wie in BB. Acht von den zwölf Kapiteln der ersten beiden Bücher dieses Romans bestehen entweder ganz oder zum größten Teil aus Monologen, und Buch III ist abgesehen von einigen direkten Gesprächsszenen ein einziger langer Gedankenmonolog Nielsens. Während in den beiden ersten Romanen der innere Monolog noch auf eine Person beschränkt wird - abgesehen von einer Ausnahme in FL - treten in $B B$ und auch in $Z$ bereits mehrere Personen als Träger eises lionologs vor uns.

Betrachten wir die Monologe der Romanpersonen, so stellen wir fest, $d a B$ ein groBer Teil in der 3. Person Singular erscheint, daß daneben aber auch eine Reihe von Monologen in der 1. Person Singular gehalten sind, und daß weiterhin einige konologe sowohl die 1. als auch die 3 . Person Singular aufweisen. Wir haben es demnach mit zweierlei Arten von inneren kionologen zu tun. Der lonolog in der 1. Person stimmt im wesentlichen mit der direkten Redeweise über-

$39 \mathrm{Vgl}$. D. Stephan, S. 75. Sie bezeichnet den Leser als "Belauschenden". 
ein; Person und 2eit sind die der DR. Im Unterschied zu dieser wird er jedoch nicht ausgesprochen. Häufig wird unter innerem Monolog dieser direkte Typus verstanden. 40 R. Humphrey, der sich eingehend mit den beiden Typen des Monologs befaBt, definfert den DIM als jene Form des inneren Monologs "which is represented with negligible author interference and with no auditor assumed (...) it presents consciousness directly to the reader (...)" 41 völlig anderer Art ist der von E. Dujardin als "monologue intérieur indirect" bezeichnete Monolog. Die 3. Person Singular kann jedoch keinesfalls lediglich als "verkleidete erste Person" betrachtet werden, wie Dujardin meint. ${ }^{42}$ während sich der DIM auf DR stützt, ist ER die Stilbasis des IIM. DIM und IIM sind zwei verschiedene Techniken der Beruatseinsdarstellung, deren Wirkung unterschiedlicher Art ist. Der wesentliche Unterschied besteht darin, daß der Erzähler im DIM verschwunden ist, da er sich mit der Gestalt identifiziert hat, im IIM dagegen stets anwesend bleibt. "Indirect interior monologue is, then, that type of interior monologue in which an omniscient author presents unspoken material as if it were directly from the consciousness of a character and, with commentary and description, guides the reader through it. It differs from direct interior monologue basically in that the author intervenes between the character's psyche and the reader." 43 Im Gegensatz zum DIM, für den Wirklichkeitsnähe und dramatische Wirkung bezelchnend sind, ist der IIM auf Grund der 3. Person epischer, distanzierter. Der epische Charakter des IIN ermöglicht es, be-

40 So F. Stanzel, W. Neuse, W. Kayser, E. Lämmert.

41 S. 25. Vgl. ebenfalls: F. Stanzel: Die typischen Erzählsituationen im Roman, S. 147; Lämmert, Eberhard: Bauformen des Erzählens. Stuttgart 1955, S. 236 1.

42 Le monologue intérieur. Paris 1931, s. 391.

43 R. Humphrey, S. 29. Vgl. weiterhin: D. Stephan, S. 17. 
richtende Elemente wit einzubeziehen, was in DIM nicht möglich ist, da dieser nur Gedankenwiedergabe sein kann.

Was den Wechsel von Ich-Bezug zu Er-Bezug betrifft, der in einigen inneren Monologen der Romane Krležas stattfindet, so vollzieht sich der thergang von DR zu ER und damit vom DIM zum IIM meist allmählich, indem einige Sätze ohne Pronomen, ohne konjugiertes Verb oder mit unpersönlichem Pronomen aufeinanderfolgen.

Krleza verwendet den inneren Monolog in erster Linie zur Wiedergabe längerer Gedankengänge, die häufig Probleme allgemeiner Art berübren. Der innere Monolog wird in den meisten Fällen deutlich vom übrigen Text abgesetzt. oft beginnt ein neuer Absatz, und der Monolog wird überdies häufig durch einen Gedankenstrich bezeichnet.

Es zeigt sich, daß die inneren Monologe der Romane KrleZas in der Regel einen hohen Grad an Bewußtheit aufweisen. Logische Ordnung der Gedanken und rationale Kontrolle kennzeichnen diese Monologe, die mit den inneren Monologen der Bewußtseinsstrom-Romane kaum etwas gemeinsam haben. 44 Die Gedanken wirken fast nie so, als ob sie in statu nascendi wiedergegeben würden. Das Vokabular ist vorwiegend auktorialsprachlich, und nur in den wenigsten Fällen stoBen wir auf sprachlich Unvollständiges. Gedanken und Gefüble kommen in zusammenhängender Form zum Ausdruck, stehen letzten Endes im Dienst der Handlung und dienen nicht in erster Iinie der Seelenerforschung des denkenden Individuums. Eine Reihe innerer lionologe wird dazu benützt, um die Vorgeschichte nachzuholen, eine Person dem Leser vorzustellen oder den für Krleža bezeichnenden Gedankenballast in den Roman zu integrieren. Nicht selten wird sogar die Gesellschaftsanklage in den Monolog einbezogen oder der Reflektierende beschäftigt sich mit aktuellen politischen Fragen.

$44 \mathrm{Vgl}$. E. Dujardin, S. 59, und R. Humphrey, S. 24 f. Beide heben hervor, daß im IIM jene Gedanken zur Darstellung gelangen, die nahe am Unterbewußtsein liegen und die sich damit noch in der vor-sprachlichen Phase befinden. 
Besonders deutlich wird die vielfache Funktion der inneren Monologe in den letzten beiden Romanen, in denen sich der Erzähler weitgehend zurückzieht und damit ein groBer Teil dessen, was dem Erzählerbericht üblicherweise zufällt, von den monologisierenden Personen übernommen wird. Die Monologe Barutanskis (BB) und vor allem die Emerickis (Z) wirken zum Teil sehr zweckgebunden. So informiert uns Emericki ausführlich über seinen Sohn Kamilo, der erst im zweiten Kapitel des Romans auftaucht. Barutanskis erster langer Monolog führt uns ebenfalls unmiBverständlich in die blitwische Welt ein. Er charakterisiert sich nicht nur selbst, sondern macht uns mit mehreren später auftretenden Personen bekannt. Die funktionell bestimmte Auswahl dessen, was gedacht wird, ist nicht zu übersehen. Weiterhin entsteht in einigen Monologen durchaus der Eindruck, der Monologisierende wende sich an einen Leser - auch wenn er ihn natürlich nicht direkt anspricht. Der erste Monolog Barutanskis ist eine Art dramatisches Selbstgespräch mit stark rhetorischem Einschlag. Formal scheinen sich diese Monologe von den gesprochenen im wesentlichen nur noch durch den Wegfall der Inquitformeln zu unterscheiden und eventuell noch durch den höheren Grad an Aufrichtigkeit. Krleza benützt für einen großen Teil der Monologe dieselben typographischen Zeichen wie für die DR. Schon aus diesem Grunde kann von einer Identifizierung von Erzähler und Person keine Rede sein, da der Autor durch die Anführungszeichen oder den Gedankenstrich deutlich zu verstehen gibt, daB er die Gedanken der Romanpersonen lediglich übermittelt. Die für die Darstellung des Bewußtseins charakteristischen Eigenheiten wie Gleichzeitigkeit, Vieldeutigkeit, Nebeneinander, und eine bis zu einem gewissen Grade gehende Unverständlichkeit finden wir nur in einigen wenigen Monologen - vor allem dann, wenn Nielsen (BB) oder Kamilo (Z) von der Erinnerung überwältigt werden und ihre Monologe nicht der Mitteilung konkreter Tatsachen dienen. Assoziation und parataktischer Stil bestimmen den Verlauf dieser 
Monologe, die sehr persönlich gefärbt sind und eine lyrische, häufig schmerzliche Note besitzen.

Wir stellen somit folgende hauptsächliche Funktionen fest: 1. Charakterisierung des Monologisierenden; 2. Darlegung allgemeiner Probleme sowie unmittelbarer aktueller Pragen; 3. Darlegung von expositorischem Material.

Betrachten wir nun die bonologe der beiden Romane BB und $Z$ auf den zuletzt genannten Punkt hin, so zeigt sich, daB eine ansehnliche Reibe von Monologen vorwiegend dazu dient, die Vorgeschichte nachzuholen oder fenlende Handlungsteile miteinzubeziehen. Häufig werden die vergangenen Ereignisse szenisch vergegenwärtigt und im Rahmen dieser Szenen längere oder kürzere Gespräche wiedergegeben. Dies bewirkt, daß der Bezug auf die Monologsituation, die den Ausgangspunkt bildete, völlig verwischt wird. Hinzu kommt, daB diese Retrospektiven - vor allem in $B B$ - oft recht lang sind, so daB man erst durch einen nachträglichen Hinweis des Erzäblers wieder darauf aufmerksam gemacht werden muß, daß die soeben berichteten und geschilderten Teile von der reflektierenden Person ausgingen und nicht vom Erzäbler. In $Z$ ist die Situation insofern eindeutiger, als Krleza die vergegenwärtigte Gesprächsszene in jeweils nur kurzen Auszügen wiedergibt und immer wieder Monologstücke dazwischen legt. Das beste Beispiel für dieses Verfahren bietet das erste Kapitel von Z. Die Monologe Emerixkis werden immer wieder durch kürzere Gespräche mit Kamilo unterbrochen, die in der Vergangenheit stattfanden und an die Emericki sich erinnert. Ausdrückliche Hinweise erübrigen sich hier von selbst, da Monolog und Gespräch ständig einander abwechseln und ineinander übergehen. Anders in BB: die Verknüpfung von Monolog und vergegenwärtigter Szene ist äuBerst lose. Ein bestimmter Gedankengang Nielsens schlägt etwa das Thema des anschlieBend eingeschobenen Gesprächs an oder steht in irgendeiner Beziehung zu einer bestimmten Episode aus der Vergangenheit, die berichtet und vergegenwärtigt wird. Pällt auch 
noch der Hinweis auf Nielsen nach Beendigung der Retrospektive weg, so ist man sich völlig im unklaren, von wem die Episode erzählt wurde. Ein Beispiel: Nielsens Gedankenmonolog wird unvermittelt durch ein direktes Gespräch Nielsens mit Professor Burgwaldsen unterbrochen. Der Kommentar stellt dén Bezug zu Nielsen her:

- Sie irren sich in einer fundamentalen Voraussetzung - hatte ihm Dr. Burgwaldsen gesagt $(\ldots$.$) .$

$(\mathrm{BB}, 112)$

Daß das reproduzierte Gespräch durch Nielsen wiedererinnert murde, wird aber erst aus dem Bericht des Erzählers nach der Szene deutlich:

Indem er die Streifwache der Sturmtruppen beobachtete (...), erinnerte sich Niels Nielsen an dieses Gespräch mit seinem alten Professor Burgwaldsen (...).

(BB, 115)

Gleichzeitig wird der thematische Bezug geklärt. Nielsen erinnert sich beim Anblick eines verhafteten Blitwiers, der in Pesseln an ihm vorbeigeführt wird, an dieses Gespräch mit Burgwaldsen.

Sehen wir uns nun die Monologe an, um zu bestimmen, welche Form des Monologs Krleza bevorzugt und warum. Wir stellten bereits fest, daB Krleza in erster Linie den IIM zur BewuBtseinsdarstellung heranzieht. DIu finden wir in seinen Romanen nur sehr vereinzelt, und auch in diesen Fällen wechselt die 1 . Person bald mit der 3. Person ab. 45 DIM wird im Gegensatz zu IIM immer mit einem Gedankenstrich gekennzeichnet und ist stets kurz. In FL ist kein einziger DIM anzutreffen, in dem ersten Buch von $Z$ nur einer und in BB einige wenige. Häufiger als DIM ist die "fingierte direkte Rede".

45 Eine Reihe innerer Monologe, vor allem die Barutanskis, sind ohne konjugiertes Verb und ohne Pronomen, die eine eindeutige Bestimmung des Monologs ermöglichen könnten. Häufig ist das Pronomen auch das der 1. Person Plural. 
Diese wenigen DIU zeigen große Ahnlichkelt mit gesprochenen Monologen. Auf diese Weise werden klar erkannte Sachverhalte wiedergegeben, oder eine andere Person wird in Gedanken angesprochen. Folgenden DIM Kamilos kann maz kaum von gesprochenen Worten unterscheiden:

- Joja, mein Guter, mein Lieber, nie werde 1ch dich verlassen, Ehrenwort, Joja, du weiBt, ich bin hier, wir gehören zusammen, allons enfants, das 1st kein Geheimnis mehr, das wissen jetzt alle, wir marschieren an der Spitze eines $\mathrm{Zu}-$ ges, wir sind Bannerträger ... $(2,1,463)$

In einem der wenigen DIM Nielsens ist die Nähe zur Sprechsituation ebenfalls auffallend. Die Tatsache, daB Nielsen einen Auszug aus einem Brief an Rajevski liest und inn kommentiert, erweckt den Eindruck, daB Nielsen ein halblautes Selbstgespräch führt.

- All das sind Phrasen! Ich werde gegen diese Schurken doch nicht mit Phrasen auf den Lippen kämpfen? Andererselts wäre es auch dumm, sich erschießen zu lassen, ohne irgendein Zeichen von sich zu gebenl "Heute nachmittag (...) /Zitat des Briefausschnittes/Nein! So nicht! (...) all das sind Phrasen und dazu noch Phrasen in der ersten Person. $(\mathrm{BB}, 87)$

Die Möglichkeit, eine andere Person unmittelbar anzusprechen, und die aus dem Charakter der DR resultierende Klarheit und Sicherheit der Aussage sind ausschlaggebend für die Verwendung des DIM. DaB der Autor in diesen Fällen auf Grund der 1. Person kurzfristig in den Hintergrund tritt, ist hier ohne Bedeutung. Es geht Krleza an diesen wenigen Stellen darum, die Stilwerte der DR auszunützen. So wechselt in Barutanskis erstem Monolog ER dann in DR über, wenn Barutanski voller Pathos und voller vberheblichkeit von seiner eigenen Person spricht. In DR erscheinen seine Worte besonders betont und grell. In ER wären sie gedämpfter und unauffälliger, allerdings auch ironischer. Da Krleža jedoch den größten Teil jener 
selbstherrlichen Worte Barutanskis in DR wiedergibt, einige trotzdem in ER beläBt, kommt überdies die ironische Distanz des Erzählers zum Ausdruck. Außerdem ist die DR auch noch ironisch gefärbt, da die Pronomina groBgeschrieben und zum Teil in Anführungszeichen gesetzt werden (BB, 41). 46

Die IIM sind nur zum Teil durch Gedankenstrich gekennzeichnet, ein großer Teil bleibt unbezeichnet. IIM mit Gedankenstrich wird in erster Linie zur Wiedergabe von Uberlegungen, Denkprozessen, Fragen, Erkenntnissen und Feststellungen herangezogen, die der betreffenden Person verhältnismäßig klar sind. Es handelt sich weitgehend um die Wiedergabe bewußter tberlegungen und Gedanken, die nur deshalb nicht laut ausgesprochen werden, da die reflektierende Person allein ist und keinen Gesprächspartner als Gegenüber hat, dem sie ihre Gedanken mitteilen könnte. Hinzu kommt auch das Wissen, daB es sinnlos ist, sich einem anderen Menschen mitzuteilen. Mehrere Kommentare des Autors, die sich auf die Monologe der Romanpersonen bezienen, bringen diese spezifische Situation zum Ausdruck.

Während er /Barutanski/ so in seiner Bibliothek auf Beauregard $s a B$ und dem Rauch seiner Maryland-jaune Zigarette nachsah, verlor er, sich gewöhnlich in endlosen verworrenen Selbstgesprächen, wobei er an den erregenden Höhepunkten dieses intimen inneren Dialogs einzelne Worte laut aussprach, so dab ihn der Klang der eigenen Stimme gleich dem Knall einer überraschenden Detonation in die Wirklichkeit zurückrief.

( $\mathrm{BB}, 192)$

Aus diesem Autor-Kommentar wird ersichtlich, wie nahe die meisten Monologe an die Sprechsituation herankommen. Barutanski spricht genauso mit sich selbst wie Nielsen oder der Ich-Erzähler aus NRP. Nielsens Monologe werden vom Autor als "hoch erregtes, das Innerste aufwühlendes Selbstgespräch" und als "verworrener Monolog" bezeichnet (BB, 106). Der Ich-Erzähler sagt von seinen Monologen, sie seien

46

Vgl. Kap. VI, S.250 f. 
"intime, halblaute Selbstgespräche". (NRP, 9) 47

Was den unbezeichneten IIM betrifft, so dient er im allgemeinen der Wiedergabe von weniger klaren und bestimmten Gedanken, die tiefer im Unterbewußtsein liegen. Träume, Erinnerungsströme und Assoziationen erscheinen vorwiegend in diesen lionologen. Während die gekennzeichneten lionologe in der Regel nach einem Absatz beginnen, gehen diese oft unmittelbar aus dem Bericht hervor, so daß die Grenze nicht immer leicht $z u$ bestimmen ist. In fast allen Fällen, in denen im Rahmen eines inneren Monologs eine Retrospektive eingeschoben wird, geht ein solcher Monolog der Retrospektive voraus. Der Grund ist klar: der Ubergang von einem unbezeichneten Honolog zum Bericht der vergangenen Ereignisse läßt sich unauffälliger vollziehen, als dies in anderen Falle möglich wäre. Aufschlußreich sind auch hier wieder die Kommentare, die manche unbezeichneten Monologe einleiten.

Nielsen, der in die trüber Kreise der Erinnerung eindrang, um jenen Tag, jene Stunde und jenen Augenblick zu finden, als das nervöse Suchen nach einem Ausweg eigentlich begonnen hatte, dieses ununterbrochene, geradezu endlose Ausbreiten von immer undurchsichtigeren Geweben und Vorhängen, die ihn von der Gegenwart trennten (...) verlor sich in trügerischen Fernen, wo alles trübe und gleichzeitig unsagbar schwer von der schwermütigen Kelancholie eines vergifteten Traums zu trennen war (...). $(\mathrm{F}, 207)$

Auf Grund der Unterschiede, die zwischen den beiden Arten des Ini bestehen, leuchtet es ein, daB die inneren Monologe Barutanskis in den meisten Fällen gekennzeichnet sind. In langen Selbstgesprächen legt er seine "Philosophie" dar, beschäftigt sich mit Problemen allgemeiner Art und mit ganz konkreten Uberlegungen. Die Gedanien Nielsens dagegen, der sich vor allem in Buch III des Romans immer wieder neuen Erinnerungsströmen hingibt, der mehr in sei-

47 Vgl. Kap. IV, S. $155 \mathrm{f}$. 
nen Träumen lebt als in der ihm unerträglich gewordenen Wirklichkeit, und dem überdies die Aufgabe zufällt, fast alle Retrospektiven zu bewältigen, erscheinen zum gröBten Teil in Form von unbezeichneten Monologen.

Abschließend ist noch die Frage zu beantworten, warum Krleža die überwiegende Zahl aller inneren Monologe auf der Basis der ER gestaltet und warum er den DIN kaum zur Bewußtseinsdarstellung verwendet. Der Hauptgrund für die Bevorzugung des IIM scheint mir in der Tatsache zu liegen, daß der Erzähler in der 3. Person stets anwesend ist. In der 3. Ferson der ER und damit auch im IIM hören wir durch die Stime der Romanperson hindurch immer auch die des Erzählers, der sich nie restlos mit ihr identifiziert. IIM ermöglicht überdies die Einbeziehung vergangener Ereignisse und Gespräche, und außerdem kann der Erzähler den IIY mühelos und unauffällig aus dem Bericht herauswachsen oder inn in Bericht übergehen lassen, da beiden dasselbe Pronomen gemeinsam ist. Diesen Vorzug, den der IIM bietet, macht ihn zu d e m geeigneten Darstellungsmittel der letzten beiden Romane, die den Monologen einen breiten Raum einräumen und aus diesem Grunde darauf angewiesen sind, einen Teil der berichtenden Elemente in den Monolog einzuberiehen.

Zum Schluß soll noch ein tberblick über die verschiedenen Formen der Bewußtseinsdarstellung gegeben werden, um inre Anwendung in den Romanen Krležas zu verdeutlichen. Als Kriterium dient der unterschiedliche Grad von BemuBtheit, der den dargestellten Gedankeninhalten anhartet. An oberster Stelle steht selbstverständlich die Rede.

1. Gedankenbericht

2. ER

3. Unbezeichneter IIR

4. Bezeichneter IIM

5. DIU

6. Fingierte direkte Rede 
Das zweite wesentliche Darstellungsmittel der Romane Brležas ist der Dialog. Ebenso wie der innere Monolog spielt er vor allem in den letzten beiden Romanen eine groBe Rolle. Zwar ist $\mathrm{Z}$ nicht so weitgehend dramatisiert wie $\mathrm{BB}$, aber wir finden auch in diesem Roman einige Kapitel, die fast ausschließlich aus einer Reihe von Gesprächen bestehen. Im Unterschied zu BB ziehen sich die Gespräche in $Z$ nicht über ein ganzes Kapitel hin, sondern sie werden in mehrere Gespräche aufgelöst, oder sie wechseln mit Vonologen ab. Durchgehend ist festzustellen, daB die Gespräche größtenteils ganz in DR verlaufen und kaum gerafft werden. Charakteristisch ist der Beginn vieler Dialoge. Der Erzähler nennt das Thema des Folgenden Dialogs und gibt in einigen Worten dessen Inhalt an.

Auf Grund der Tatsache, daß Monologe und Dialoge in den letzten beiden Romanen Krležas einen so breiten Raum einnehmen, fallen ihnen mannigfache Funktionen zu. Die einzelnen Gespräche dienen nicht wie in den beiden ersten Romanen vorwiegend oder ausschlieBlich etwa der Charakterisierung, sondern sie erfüllen meist mehrere Funktionen gleichzeitig. Als Beispiel für die Verknüpfung mehrerer Funktionen sei der lange Dialog 2wischen Blithauer und Nielsen in BB erwähnt. Er dient sowohl der Charakterisierung beider Gesprächspartner als auch der Hitteilung von Handlung sowie deren Fortführung, ferner der Darstellung der Vorgeschichte Blithauers, die von ihm selbst erzählt wird, und schlieblich der gedanklichen Auseinandersetzung.

Wir unterscheiden somit drei wesentliche Funktionen: 1. Charakterisierung, 2. Darstellung von Handlung, 3. gedankliche Auseinandersetzung.

Dialoge, die ausschlieblich der Charakterisierung der Gesprächspartner dienen, finden wir vor allem in jenen Kapiteln, in denen Vertreter der kroatischen Gesellschaft auftreten. Charakterisierung kommt in all diesen Fällen einer Demaskierung gleich. Da wir uns im Zusammenhang mit der Technik der Personendarstellung ausführlich mit der 
Charakterisierung beschäftigt haben, sei hier nur mehr auf die charakterisierende Funktion der Gespräche hingewiesen. 48

DaB der Dialog eine wichtige Rolle für die Handlung spielt, zelgt sich vor allem in den letzten beiden Romanen - in erster Linie in BB. Da der Erzähler in BB kaum etwas berichtet, ist ein GroBteil der Vorgänge, die die Handlung ausmachen, in den Dialogen enthalten. Uberdies spielt sich in $\mathrm{BB}$ ein Teil der Geschehnisse im Hintergrund $a b$, so daß wir von innen lediglich vermittels eines Berichtes einer beteiligten Person erfahren. Am deutlichsten. kommt dies in II, 2 von BB zum Ausdruck, das den bezeichnenden Titel "Die Ereignisse überstürzen sich" trägt uná in dem die meisten Ereignisse des Romans zusammenlaufen. 49 Hier gewinnen wir den Eindruck, daß die Personen auf einer Bühne agieren. Während Barutanski als ruhender Pol in seinem Arbeitszimmer auf Beauregard weilt, treten die von inm telefonisch herbeibeorderten Personen der Reibe nach auf und verschwinden wieder, nachdem sie in jeweils verschledenen Versionen von den Geschehnissen berichtet haben, die sich außerhalb Beauregards abspielen. Kantorowicz beginnt seinen Bericht genauso wie Burgwaldsen. Beide sprechen sachlich und knapp und informieren Barutanski und damit den Leser in objektiver Berichtsform.

- Servus, Burgwaldsen, was gibt es Neues?

- Ich habe den Bericht von Kohlinis erhalten, Exzellenz, und ich war auch selbst an Ort und Stelle, um persönlich Einsicht zu nehmen und Ihnen über den Stand der Pakten zu berichten!

$(\mathrm{BB}, 323)$

$48 \mathrm{Vgl}$. Kap. I, S. $48 \mathrm{ff}$.

49 Vgl. Kap. III, S. 114 f. II 2 steht für Buch II, Kapitel 2. Grundsätzlich wi rd die römische ziffer für die einzelnen Bücher der Romane, die arabische für die $\mathrm{Ka-}$ pitel verwendet. 
Nicht zuletzt sind die vielen Telefongespräche zu erwähnen, die in $B B$ und auch in 2 geführt werden und denen dieselbe Punktion zukommt: die Verlagerung der Handlung ins Gespräch.

Neben den Dialogen, die die Handlung vorwärtstreiben, die an Stelle von Handlung stehen, und jenen, in denen uns ein bereits vorgefallenes Geschehen berichtet wird, treffen wir noch auf eine dritte Art von Dialogen, die der Orientierung des Lesers dienen. Personen werden vorgestellt, wir erhalten Auskünf te über sie, und Ereignisse werien berichtet, die zeitlich vor Einsetzen der Handlung liegen. So erfahren wir aus dem Gespräch Emeričkis mit dem Grafen, in dem der Graf sich eingehend nach Kamilo erkundigt, vieles über Kamilo. ( $\mathrm{z}, 1,294$ f.) Bevor dieses Gespräch beginnt, findet ein anderes statt, das der Vorstellung und Charakterisierung des Grafen dient. ( $2,1,271 \mathrm{ff}$. )

Vergleichen wir diese Gespräche, deren Funktion im Bereich der Handlung liegt, mit jenen, die der Charakterisierung der Gesprächspartner dienen, so stellen wir einen auffälligen Unterschied fest. Was die Dialoge betrifft, die für die Handlung eine Rolle spielen, so werden diese verhältnlsmäBig selten durch Kommentare des Erzählers unterbrochen. Die Inquitformeln fallen soweit möglich weg und der Erzähler, der sich im wesentlichen im Hintergrund hält, beschränkt sich weitgehend auf Szenenanweisungen. Vor allem dann, wenn das Geschehen sich seinem dramatischen Höhepunkt nähert, wie zum Beispiel in den letzten Kapiteln von FL, folgt Rede auf Gegenrede und die Anweisungen des Erzählers passen sich diesem dramatisch gespannten Stil an. Die Wirkung dieser Dialoge ist somit weitgehend szenisch-dramatisch. In all jenen Gesprächen jedoch, die der Charakterisierung dienen, tritt der Erzähler - vor allem dann, wenn die Vertreter der kroatischen Gesellschaft charakterisiert werden - mit einer ganzen Reihe von Kommentaren hervor, die seine Haltung gegenüber den Sprechenden unmiBverständlich zum Ausdruck bringen. 
"Es wäre vielleicht gut, sie beschriebe uns das Kostüm des seligen Grafen", sagte die einhundertundsieben Kilo schwere Gattin des Amtsarztes ganz rot vor Aufregung, daB auch sie an diesem geistreichen Geschehen teilhatte. (FL, 126)

Am auffälligsten ist die Tendenz des Erzählers, in den Hintergrund $2 u$ treten und nur noch die Romanpersonen sprechen zu lassen, jedoch in jenen Dialogen, die der gedanklichen Auseinandersetzung dienen und die in allen Romanen $d i$ e wesentliche Rolle spielen. Seitenlang treffen wir in diesen Dialogen weder auf Inquitformeln noch auf Kommentare. Entweder es folgt Rede auf Gegenrede, oder aber ein Partner spricht im wesentlichen ohne größere Unterbrechungen. In diesen Gesprächen liegt der Akzent auf der Darlegung wesentlicher Gedanken, die meist in DR und mit groBer Ausführlichkeit zur Darstellung gebracht werden, und nicht darauf, die Sprechenden zu verspotten und zu karikieren. Gemeinsam ist all diesen Dialogen, daß sie sich nicht auf die Handlung beziehen. Sie dienen der Integrierung ideeller Gehalte, sind also weitgehend essayistischer, theoretischer Natur. Noch viel stärker als in den Monologen integriert Krleza Probleme allgemeiner Art sowie ganz konkrete zeitgeschichtliche Fragen mit Hilfe der Dialoge in den Roman. Diese langen theoretischen Gespräche, in denen Zrlezas Weltanschauung nach dialektischem Prinzip zur Darstellung gelangt, neigen dazu, zu breiten Raum einzunehmen und die Form des Romans zu sprengen. Vor allem in FI erstrecken sich die problemgeladenen, weitausgreifenden Dialoge zwischen Kyriales und Filip (Themen: Malerei, der Mensch, Vergeistigung der Materie, Logik und Tod) über vier unittelbar aufeinanderfolgende Kapitel und hemmen den FluB der Handlung, zu der sie, abgesehen von den versteckten Andeutungen Kyriales' auf seinen Selbstmord, in keinerlei Beziehung stehen. Da weiterhin in erster Linie nur Kyriales spricht, wirken diese Dialoge im Grunde wie ein langer, le- 
diglich hin und wieder unterbrochener, didaktischer Monolog. Rrleža scheint diesen Mangel später selbst empfunden zu haben, denn in den folgenden Romanen werden die Auseinandersetzungen lebendiger und wirken nicht mehr ganz so abstrakt wie in FL.

Während in PL der Materialist Kyriales in Filip nur einen schwachen Gesprächspartner findet, der ihm nicht gewachsen ist und nur wenige Gegenargumente aufbieten kann - Filip vertritt gegenüber Kyriales den idealistischen Standpunkt - steht dem Doktor aus NRP ein Partner gegenüber, der letzten Endes dem Ich-Erzähler nur dazu dient, seine Thesen über die Kenschen, über die Tahrheit, über seine Teltanschauung und über die Gesellschaft zu entwickeln. In beiden Fällen kann von einer wirklichen Auseinandersetzung zweier gleichwertiger Partner nicht die Rede sein. Der eine dient vielmehr dem anderen in erster Iinie dazu, die Thesen Krležas in Form eines - allerdings ungleichseitigen - Gesprächs darzustellen. Anders ist die Situation in den beiden letzten Romanen. Zwischen Nielsen und Blithauer, und vor allem zwischen Kamilo und Emerički, sowie zwischen Kamilo und Amadeo entwickeln sich echte dramatische Auseinandersetzungen zwischen gegensätzlichen Gesprächspartnern. Im ZusammenstoB zwischen Kamilo und seinem Vater, der sich in einer ganzen Serie von Gesprächen immer wieder von neuem vollzieht, werden nicht nur zwei verschiedene Menschen einander gegenübergestellt, sondern zwei grundverschiedene Generationen, zwei Weltanschauungen, die sich gegenseitig ausschließen. 50 Emerički ist Anhänger der österreichisch-ungarischen Monarchie, Kamilo leidenschaftlicher Verfechter der kroatischen Sache. Bereits aus den diese Dialoge einleitenden Kommentaren des Erzählers wird der Charakter der streitbaren Auseinandersetzung und dialektischen Konfrontierung zweier gegensätzlicher Anschauungen ersichtlich.

50 Kamilo spricht dies mehrmals ganz deutlich aus. $\mathrm{Vgl}$. $z, 2,20,35,45$. 
(...) diese Gespräche über die politischen Krisen 2wischen der Annexion Bosniens und den Dummheiten des Banus und der Bommissare steigerten sich zu immer lauteren und erregteren Dialogen. $(2,2,16) 51$

51) Die Dialoge zwischen Amadeo und Kamilo werden wit ähnlichen Worten kommentiert ("ZusammenstoB", "nervöser Zweikampf mit Worten"). Vgl. Z, 2, 236 . 


\section{R A P I T E I III \\ KO O POS I T I O N}

Jeder Roman ist eine spezifische Ganzheit, deren Gesetze es aufzudecken gilt. Um diese Gesetze erfassen zu können, sind wir gezwungen, uns den "Einzelheiten" zuzuwenden, und somit den umgekehrten Weg $z$ u beschreiten wie der Autor. 1 Die Komposition des Romans umfaBt die Anordnung, Verknüpfung und Scheidung der einzelnen Teile und deren Verhältnis zueinander. Obwohl jeder Stoff eine andere, ihm gemäBe Form verlangt und jeder Roman aus diesem Grunde eine unterschiedliche Struktur aufweisen wird, stoBen wir in den vier Romanen Krlezas auf einige wesentliche Kompositionsprinzipien, die für jeden dieser Romane Geltung besitzen. Besonders aufscialußreich erwies sich hierfür die Untersuchung der Zeitverhältnisse. $\because$.

1. Einsträngigkeit des Erzählten ("Die Rückkehr des Filip Latinovicz", "Am Rande des Verstandes")

Der wesentliche Unterschied 2 wischen den beiden ersten Rowanen, die weit weniger umfangreich sind als die folgenden, und den beiden letzten besteht im Hinblick auf die Bauweise darin, daB nur die ersteren einen linearen liandlungsablauf aufweisen, der sich an einer Nittelpunktsfigur

$1 \mathrm{Vgl}$. Seidler, Herbert: Die Dichtung. Wesen. Form. Dasein. Stuttgart 1959. ( Kröners Taschenausg. Bd 283), S. 281. 
orientiert. Die zentrale Stellung Filips einerseits und des Doktors andererseits bestimmt die gesamte Werkstruktur. Die Bewegungen, Gefühle und Gedanken dieser einen Figur werden bis ins Detail eingefangen, und die Perspektive der Darstellung wird weitgehend durch sie bestimmt. Die übrigen Personen, die alle zu der Mittelpunktsfigur in Beziehung gesetzt werden, besitzen keine nur annähernd gleichwertige Bedeutung. Die ausgesprochen gesellschaftskritische Orientierung der beiden Romane bewirkt jedoch, daß diese Einsträngigkeit der Handlungsführung gefährdet und nicht immer ganz konsequent durchgeführt wird.

Der erste Roman, FI, dessen Titel bereits auf die zentrale Stellung einer einzelnen Person hinweist, besteht aus zwei Teilen. Teil I umfaßt mit acht Kapiteln etwa ein Fünftel des Romans; Teil II nimmt einundzwanzig Kapitel in Anspruch. Während Filip in Teil I ausschlieBlich im Mittelpunkt der Darstellung steht, wird er in Teil II streckenweise von den neu hinzukommenden Personen in den Hintergrund gedrängt. Abgesehen davon ist er jedoch von der ersten bis zur letzten Seite des Romans anwesend.

Teil I bietet die Exposition des Romans, Teil II das eigentliche Geschehen. In den ersten acht Kapiteln wird die Vergangenheit Filips, angefangen von seiner Kindheit bis zu seinem Leben der letzten Jahre vor Beginn der Handlung, an Hand von Erinnerungen Filips aufgerollt. Teil I ist die unerläBliche Voraussetzung für all das, was sich in Teil II abspielt. Krleža baut diesen Roman äußerst sorgfültig auf, schafft bis ins kleinste Bezüge und Entsprechungen. FL ist ein dramatischer Roman mit verhältnismäßig zielstrebigem Verlauf. Die gesamte Handlung ist auf das tragische Ende hin konzipiert; die Atmosphäre verdichtet sich mit fortschreitender Handlung in zunehmendem Maße. ${ }^{2}$

2 Der Erzähler bezeichnet das sich in Teil II abspielende Geschehen als "Drama", und kurz bevor der Roman sich seinem tragischen Ende nähert, heiBt es noch einmal "das Drama hatte begonnen, seinen Lauf zu nehmen." (FI, 186, 264). 
Die Kapitel des ersten Teils sind nach folgendem Schema verteilt: $3-2-3$. In Kap. 1-3 werden die entscheidenden Ereignisse aus Filips Kindheit vergegenwürtigt, in den folgenden 2 wei reflektiert Filip über Probleme allgemeinerer Art und über seinen Zustand in der letzten Zeit. Die letzten drei Kapitel von Teil I dienen vor allem da$z u$, die tyandlung vorwärtszutreiben, nachdem die ersten fünf Kapitel entweder völlig handlungslos waren $(4,5)$ oder die "Handlung" nur als Anstoß diente, vergangenes Geschehen zu vergegenwärtigen (1,2,3). Ganz ähnlich geht Rrleža in Teil II vor. Abgesehen von einem einführenden und zwei abschließenden Kapiteln, unterscheiden wir hier im wesentlichen drei Arten von Kapiteln: 1. Kapitel, in deren kittelpunkt Filip steht; meist sind dies ReflexionsKapitel; 2. Kapitel, in denen die Vertreter der Gesellschaft auftreten oder deren Vorgeschichte erzählt wird; 3. Kapitel, in denen die gedankliche Auseinandersetzung zwischen Filip und Byrieles vor sich geht. Folgendermaßen sind diese Kapitel verteilt: Einführung (1) - Gesellschaft (2) - Filip (2) - Gesellschaft (7) - Filip (2) - theoretische Diskussion (4) - Filip (1) - Schluß (2). Wie aus dieser Anordnung der Kapitel ersichtlich wird, ist Krleza darauf bedacht, die Gewichte sorgsam zu verteilen. Das längste Kapitel (14), Höhepunkt der Gesellschaftskritik, befindet sich in der Mitte des Komans. Erst nachdem Krleza die neue Umgebung geschildert und zu Filip in Beziehung gesetzt hat (9), führt er die Personen der Reihe nach ein. In Kap. 10 die Mutter Filips, in Kap. 11 Liepachs Schwester und vor allem Liepach selber. Bevor der ganze Kreis un Liepach jedoch in einem langen, szenisch angelegten Kapitel (14) auftritt, werden zwei kirzere Kapitel eingeschoben, in deren Nittelpunkt Filip und dessen Reflexionen stehen. Auf diese Heise wird ein gewisser Ruhepunkt geschaffen, nachdem nacheinander drei verschiedene Personen in die Handlung eingefübrt wurden, und Filip wird wieder etwas mehr in den Vordergrund gerückt. Bevor die letzte Person, Kyriales, 
eingeführt wird, stellt Krleža wiederum Pilip in zwei Kapiteln in den Mittelpunkt $(21,22)$. Nach vier Dialog-Kapiteln folgt ein abschließendes Reflexions-Kapitel, in dem Filip noch einmal das ganze Geschehen rekapituliert und über seinen augenblicklichen verhängnisvollen Zustand nachdenkt. Dieses Kapitel wirkt ausgesprochen retardierend, da die Handlung nach einer Lösung drängt und der Roman kurz vor seinem Ende steht. Die letzten beiden Kapitel steigern diese Spannung noch weiter, bevor sie endgültig im Schlußkapitel schrittweise gelöst wird.

Zweimal gerät die wohlausgewogene Komposition des Ganzen jedoch stark ins Schwanken. Das erste Mal, als die $\mathrm{Ne}-$ benhandlung Ksenija - BaloCanski in Porm eines zusammenhängenden sechs Kapitel langen Blocks die Haupthandlung unterbricht, und das zweite Mal - und dies ist viel schwerwiegender -, als die zum gröBten Teil theoretischen Gespräche zwischen Filip und Kyriales den Gang der Handlung stark verzögern. Hinzu kommt, $d a ß$ sich ein großer Teil der Reflexionen Filips ebenfalls nicht auf die Handlung beziehen und weitgehend abstrakt-theoretischer Natur sind.

Krležas zweiter Roman, NRP, weist einen ausgesprochen symmetrischen äußeren Aufbau auf. Der Roman hat insgesamt zwölf Kapitel. Das längste Kapitel und zugleich der Schwerpunkt des gesamten Romans liegt in der Mitte (6). Kap. 2, 3, 4 bilden eine Einheit: hier wird die "Tat" des Ich-Erzählers erzählt (2) und die Reaktion seiner Mitbürger geschildert $(3,4)$. Kap. 10 und 11 des zweiten Teils stehen inhaltlich in enger Beziehung zu diesen Kapiteln. Die Zusammenstöße des Erzählers mit seinen Bekannten werden fortgesetzt. Im zweiten Teil des Romans stehen Kap. 7, 8, 9 in engem Zusammenhang zueinander. Der Ich-Erzähler befindet sich im Gefängnis, reflektiert über seine Lage und seine Vergangenheit und führt mit Zelleninsassen lange Gespräche. In Kap. 12 gerät er wiederum für längere Zeit hinter Gitter (Gefängnis und Irrenhaus), um kurz vor Schluß des Ro- 
mans entlassen zu werden. Das erste Kapitel des Romans steht außerhalb der eigentlichen Handlung. Der Ich-Erzähler reflektiert über die menschliche Dummbeit und schlägt damit das Thema an, das sämtliche folgenden Ereignisse illustrieren. Ganz ähnlich wie in FL bringt das letzte Reflexions-Kapitel eine Art Zusammenfassung aller wesentlichen vorhergehenden Ereignisse. Der Ich-Erzähler reflektiert hier uber den Verlauf seines Lebens und vereinigt in einer Synthese sämtliche Anklagepunkte gegen die Gesellschaft. Die verschiedenen Fälle werden zu einem einzigen zusammengezogen und pathetisch erhöht.

Symmetrie, tbersicht, Klarheit der Anordnung und architektonische Geschlossenheit bietet dieser Roman jedoch nur in seinem äuBeren Bau. Das Romangeschehen selbst zerfällt in eine Reihe von Einzel-Episoden, die zum Teil durchaus selbständig sind. Sie werden lediglich auf Grund ihres Bezuges zum Thema und vor allem durch die Person des Ich-Erzählers zusammengehalten. Ein weiteres Bindeglied ist der gesellschaftskritische Bezug sämtlicher Geschehnisse. Krleža hat in NRP gar kein Interesse daran, wie in FI eine Handlung $z u$ entwickeln, die einzelnen Ereignisse sorgfältig vorzubereiten, eine durchgehende Spannung zu erzeugen und das Geschehen zielstrebig auf einen Höhepunkt hin anzulegen. Es geht ihm hier darum, möglichst viele Aspekte eines Themas darzustellen, um seiner Gesellschaftssatire eine breite Basis zu verleihen. In NRP entwirft er das moralische und psychologische Profil einer ganz konkreten Gesellschaftsklasse, die räumlich und zeitlich fixiert wird, indem er uns die verschiedenen Vertreter vorfürt. Eine Reihe von Parallelhandlungen ergänzen die Haupthandlung, die das Scheitern des Ich-Erzählers an der menschlichen Dummeit und Gemeinheit zum Inhalt hat. In drei Fällen erzählt die betreffende Person selbst ihr Schicksal, in einem Fall übernimmt der Erzähler diese Aufgabe. Die Funktion der Parallelhandlungen besteht somit darin, 
das Thema der Handlung $z u$ verstärken und $z u$ erweitern.

Das Konstruktionsprinzip dieses Romans beruht auf einem Nebeneinander und nicht auf einem Ineinander wie in FL. Von Kapitel zu Kapitel eröffnen sich neue Perspektiven, neue Figuren treten in Erscheinung, um anschlieBend wieder abzutreten und neuen Figuren Platz zu machen. Keine Person, außer der des Erzühlers, nimmt länger als ein Kapitel an der Handlung teil. Alle existieren sie nur als Demonstrationsobjekte, sie sind nicht um ihrer selbst willen da. Die einzelnen Abschnitte und Szenen sind formal verhältnismäßig selbständig, die einzelnen Kapitel in sich geschlossene Herkeinheiten mit bestimmten Raum- und Zeitverhältnissen und bestimmten Figuren.

Vier Interpreten dieses Romans gehen kurz auf die Komposition von NRP ein. Im wesentlichen stimmen sie darin überein, daß der Aufbau des Ganzen ziemlich uneinheitlich und zerrissen ist. Den Grund dafür berühren jedoch nur $\mathbf{M}$. Latkovic und vor allem I. Kozarcanin, der die Struktur des Romans in Zusammenhang mit dessen satirischem Charakter sieht. 3 S. Vucetić dagegen verteidigt die kompositorische Einheit von NRP, indem er feststellt, die architektonische Geschlossenheit des Romans werde durch den essayistischen Charakter nicht gefährdet. ${ }^{4}$ Er übersieht damit, daB die episodische Struktur von NRP die Folge des satirisch-kritischen Inhalts ist und nicht die Ursache nachlässiger Komposition.

3 Marginalija uz Krležino dramsko stvaranje, s. 9 f. Kozartanin, Ivo: Novi Krležin roman. In: Hrvatski dnevnik. Zagreb. 4.9.1938, 15. Vgl. ebenfalls: Kovacic, Ivan Goran: Najslobodoumnije Krležino djelo. In: Novosti. Zagreb. 16.2.1941, $18 \mathrm{f}$.

4 Krležino književno djelo. Sarajevo 1958, S. 268, 306. 
2. Zweisträngigkeit des Erzählten ("Bankett in Blitwien", "Banner")

Wesentlich komplizierter ist der Bau der beiden folgenden Romane. Die Ausweitung und Verzweigung des Geschehens zusammen mit einer Vielfalt von Personen bewirken, daB die für die beiden ersten Romane bestimmende Einsträngigkeit der Handlungsführung zugunsten einer Mehrsträngigkeit aufgegeben wird.

In $B B$ haben wir nicht mehr wie bisher e 1 n e zentrale Gestalt, an der sich die Struktur der Handlung orientiert, sondern $z$ e 1 . Das Strukturprinzip dieses "mittelalterlichen Spiels" richtet sich nach der dramatischen Polarität Held und Gegenspieler. 5 Die tragenden Figuren des Geschehens sind Niels Nielsen und Barutanski. Alle übrigen Figuren sind jeweils um einen der beiden gruppiert. Diese Polarität stellt besondere Ansprüche an die Komposition des Romans, denn es gilt zwei Handlungsstränge durchzuführen. Barutanski und Nielsen treffen sich nie während der gegenwärtig ablaufenden Handlung. Lediglich in den Erinnerungen und Träumen Nielsens vollzieht sich eine Begegnung der beiden. Barutanski hält sich in der Regel auf Beauregard auf und verläBt sein Arbeitszimmer nur höchst selten. Ein einziges Mal sind sich Nielsen und Barutanski räumlich ganz nahe. Allerdings ahnt keiner von beiden etwas davon. Nielsens Aufenthaltsorte wechseln im Gegensatz zu dem barutanskis ständig, da er sich vor dessen Häschern auf der Flucht befindet. Mit Ende des ersten Buches taucht Nielsen in der Wohnung einer alten Frau in Blitwanen unter. Zum Schluß von II, 4 verläBt er Blitwien endgültig und lebt in verschiedenen Ländern. Die beiden Handlungsebenen

Die mittelalterliche Polarität wird bereits im Prolog von $B B$ als wesentliches Element der dramatischen Handlung angekündigt. (BB, 24) (Vgl. Kap. III, S. 145.) 
berüren sich demnach nie direkt. Nielsen kommt lediglich mit einigen Leuten Barutanskis in Berührung, die eine Mittlerrolle zwischen den beiden Polen übernehmen. So erscheint Georgis nach der Gesprächsszene mit Barutanski (I, 1) im folgenden Kapitel bei Nielsen ( $I, 2)$. In Buch III trifft sich Kerinis mit Nielsen in Blatwien (4) und berichtet in III, 5 Barutanski von den Ergebnissen seiner Unterredung mit Nielsen.

Ein so umfangreicher Roman wie $B B$ erfordert eine andere Darstellungsweise als jene, die Krleza in der Novelle "In extremis" verwendet, um zwei gegensätzliche Charaktere einander gegenüberzustellen. Hier fübrt er zuerst den einen Handlungsstrang und dann den anderen bis zum Ende durch. In $B B$ dagegen nimmt Krleža die beiden Stränge im Wechsel auf, indem er in einem oder in mehreren aufeinanderfolgenden Kapiteln einen der beiden in den Vordergrund der Handlung stellt. Während Barutanski in den ersten beiden Büchern des Romans eine vorherrschende Stellung einnimmt, tritt er in Buch III nur noch in zwei Kapiteln auf. Folgendermaßen werden die beiden Handlungsstränge Barutanski - Nielsen auf den Roman verteilt: ${ }^{6}$

$$
\begin{aligned}
& B: \text { I, 1 II, 1-3; } 4,9 \\
& N: \text { I, 2-6; II, 4-5; III, 1-4, 6-11, Epilog }
\end{aligned}
$$

Diese Ubersicht scheint der Feststellung zu widersprechen, daB Barutanski im Mittelpunkt der ersten beiden Bücher steht. Bei näherer Betrachtung der einzelnen Kapitel stellt sich jedoch heraus, daß alle jene Kapitel, in denen Barutanski auftritt, entweder ausschlieblich oder vorwiegend auf seine Person konzentriert sind. Von den sieben Kapiteln der ersten beiden Bücher, in denen Nielsen aufritt, sind jedoch nur drei vorwiegend auf Nielsen bezogen. Umgekehrt sind die Verhältnisse in Buch III, das für die Persönlichkeit Nielsens von entscheidender Bedeutung ist, denn

6 Vgl. Schema Nr. 1 im Anhaug (S. 265 ). 
im Gegensatz zu Barutanski bleibt die Gestalt Nielsens in den ersten beiden süchern höchst unvollständig. Erst in buch III wird Nielsen nicht mehr als politischer Mensch, sondern als Individuum dargestellt.? Der wesentliche strukturelle Unterschied zwischen den ersten beiden und dem dritten buch besteht jedoch darin, daß an die Stelle der Handlungsgegenwart Reflexionen, Erinnerungen und Träume treten, die sich auf die Vergangenheit beziehen.

Neben jenen Kapiteln, die wechselweise barutanski oder Nielsen gewidmet sind, finden wir noch eine andere Art von Kàpiteln, die statischen Charakter aufweisen. Es sind dies die Gesellschafts-Kapitel, die in keinem der Romane KrleZas fehlen. In jedem dieser drei Kapitel, die auf die ersten beiden Bücher des Romans verteilt sind, läßt Krleža die Spitzen der blitwischen Gesellschaft sich anläßlich eines gesellschaftlichen Ereignisses versammeln. Zweimal ist ein künstlerisches Ereignis der Anlaß (I, 5; II, 3), einmal ein politisches, das jedoch mit der Person eines Künstlers zusammenhängt $(I, 7)$. Alle drei Kapitel sind im wesentlichen handlungslos und durch ein deutliches Hervortreten des sich in $\mathrm{BB}$ im allgemeinen im Hintergrund haltenden Erzählers gekennzeichnet.

$\mathrm{Da}$ in Buch III die Ebene Barutanski nur noch einmal aufgenommen und durch seinen Tod in Kap. 9 endgültig abgeschlossen wird, ergeben sich hier keine Probleme für die Darstellung; der eine handlungsstrang wird vorwiegend weitergeführt und der andere wird vorzeitig abgebrochen. Die sich nach Barutanskis Tod in Blitwien abspielenden Ereignisse erfährt

Vgl. Vidan, Ivo: Dvije razine "Banketa u Blitvi" (Fragmenti studije). In: Kolo, $1,1963,6,87,89$. Mir stellen in Buch III nicht nur eine eindeutige Verlagerung des Schwerpunktes fest, sondern auch eine hiodifizierung der ursprüglichen Konzeption des Romans. Eine der auffälligsten Anderungen ist der Schluß des Romans. Im Prolog wurde ursprünglich Nielsens Tod angekündigt. Vgl. I. Vidan, S. 85 . 
der in Ausland weilende Nielsen durch das Radio, aus Zeitungen und aus mündlichen Berichten. Nur einmal werden die beiden Handlungsstränge im Rahmen eines Kapitels nacheinander behandelt und am Schluß dieses Kapitels (III, 9) zeitlich synchron geschaltet. Der Erzähler raft im ersten Teil des Kapitels in groBen Zügen die Geschehnisse in Blitwien seit dem Zeitpunkt zusammen, als Nielsen Blitwien verließ. Anschließend schildert er die Situation in Blatwien während desselben Zeitraums. Auf den letzten beiden Seiten des Kapitels zieht der Erzähler den Bogen bis zur Gegenwart, bis zu jener Nacht, in der Bellonen seinen langgeplanten Putsch unternimmt und in der Barutanski erschossen wird. In Buch I ergeben sich ebenfalls keinerlei tberschneidungen, da Krleža einen Handlungsstrang nach dem anderen aufnimmt und die Handlung minimal ist. Nichts geschieht gleichzeitig. Anders in Buch II: hier spielt sich erstmals auf beiden Ebenen zu gleicher Zeit Geschehen ab. Krleža bedient sich zweier Mittel, um die Gleichzeitigkeit der Ereignisse darzustellen. Er greift auf die im Drama übliche Methode zurück, indem er Augenzeugen von der Hintergrundhandlung berichten läBt. AuBerdem bedient er sich einer ausgesprochen epischen Methode. Erst führt er den einen Handlungsstrang zu Ende, dann den anderen. Die Gleichzeitigkeit wird auf diese Weise in ein Nacheinander aufgelöst. Die Situation wird überdies noch dadurch kompliziert, daB während der ersten vier Kapitel von Buch II $v i$ e $r$ verschiedene Handlungsebenen nebeneinander herlaufen. Dies sind folgende: 8

I: Barutanski auf Beauregard und in Café "Kiosk" $(1,2,3)$ II: Knutsons Attentat und sein Tod $(2,4)$

III: Karins Besuch bei Niels und ibr Selbstmord $(2,4)$

IV: Niels in der Wohnung der Gallen und in Blitwanen (4).

Die Geschebnisse aller vier Ebenen spielen sich in einem Zeitraum von wenigen Stunden ab. Vereinfachend wirkt sich

8 Vgl. Schema Nr. 2 im Anhang (S. 266). 
jedoch aus, daß im wesentlichen nur zwei der vier Handlungsstränge direkt dargestellt werden: Ebene $I$ und Ebene IV. Ebene II bleibt ausschlieBlich auf den Hintergrund beschränkt. Die sich hier abspielenden Ereignisse erfahren wir durch Botenbericht. Die Ereignisse der Ebene III werden uns sowohl übermittelt, als auch direkt dargestellt. In Kap. 2 berichtet Pater Baltrusajtis Barutanski von dem Selbstmord Karins, in Kap. 4 wird uns ihr Tod ein zweites Mal mitgeteilt, als Nielsen in Karins Wohnung anruft und erfährt, daß sie sich erhängt hat. In Kap. 4 wird Ebene III außerdem kurz direkt dargestellt und berührt sich hier mit Ebene IV. Karin klingelt an der Kohnungstüre der Gallèn, Nielsen öfnet jedoch nicht. 9 Was die beiden direkt ablaufenden Ebenen betrifft, so wird Ebene I während der ersten drei Kapitel, Ebene IV in Kap. 4 dargestellt. Paradoxerweise geschieht gerade auf Ebene I kaum etwas. Säntliche Ereignisse gehen im Hintergrund vor sich, auf den Ebenen I, II und IV, und werden durch die Leute Barutanskis auf dessen Ebene übermittelt. ${ }^{10}$ Barutanski hält sich während

9 Die Rolle, die Karin in der Struktur des Romans spielt, ist bezeichnend; sie tritt bis zu ihrem Tod nur ein einziges kial auf, und auch dieses Nal wird sie nur von Nielsen wahrgenommen, der mit angehaltenem Atem hinter der Tür steht, an der Karin klingelte. Sie spricht kein Wort während der Handlung. Ihre Beziehung zu Nielsen liegt zeitlich vor Einsetzen der Romanhandlung. Dieselben Verhältnisse treffen wir auch in $Z$ an. Während der Gegenwartshandlung tritt Anna in Buch I kein einziges Mal aut. Eine in die Zukunft weisende Voraussage des Erzäblers läBt erkennen, daB Anna auch im folgenden Buch im wesentlichen im Hintergrund bleiben wird $(2,1,587)$. Selbst Isenija (FI) tritt nur wenig direkt auf, obwohl ihre Beziehung zu Filip ausschlieBlich auf die zeit der Romanhandlung beschränkt ist. So gering die Rolle der Frauen in den Romanen Krležas für das gegenwärtige Geschehen ist, so bedeutend ist sie jedoch auf der Ebene der Vergangenheit.

10 Abgesehen von Georgis' Tod und Nielsens Flucht spielen sich alle wesentlichen Ereignisse im Hintergrund der Handlung ab. Diese Tendenz ist mit Ausnahme von NRP in sümtlichen Romanen festzustellen und als charakteristisch für Krležas Darstellungstechnik anzusehen. 
der ganzen Zeit auf Beauregard auf und läBt sich erst gegen Ende des 3. Kapitels in das Café fahren, in dem Georgis umgebracht wurde. Nachdem in den ersten drei Kapiteln, während derer Ebene IV im Hintergrund verläuft, bereits sämtliche Ereignisse dieses einen Abends berichtet wurden, setzt Krleža mit Kap. 4 nicht nur noch einmal am Beginn dieser Zeitstrecke ein, sondern er nimmt im ersten Teil dieses Kapitels den Handlungsfaden wieder auf, der ab I, 7 liegengeblieben war. Bevor er jedoch in geraffter Form den Bogen von den ersten Tagen Nielsens in der Wohnung von Frau Gallèn bis herauf zum Spätnachmittag jenes ereignisreichen Tages zieht, nimmt er ein Ereignis vorweg, das erst gegen Ende des Kapitels stattfindet, das uns jedoch bereits in Kap. 3 auf Ebene I übermittelt wurde. Im ersten Satz des Kapitels teilt uns der Erzähler mit, daB Nielsen der Mörder von Georgis $w$ a $r$, und greift erst anschließend an diesen Satz in die Vergangenheit zurück, indem er ausdrücklich den Bezug zu I, 6 herstellt. ${ }^{11}$ Gleich mit dem ersten Satz wird das zeitliche Verhältnis des 4. Kapitels zu den vorhergehenden drei Kapiteln berihrt. Die Geschehnisse, die in Kap. 4 noch einmal szenisch vor unseren Augen abrollen, sind in den vorhergehenden drei Kapiteln bereits "geschehen". Krleža hält hier die Zeit auf und dreht sie zurück, um die Handlungsebene IV, die mit den anderen drei Zbenen zeitlich parallel verläuft, darstellen zu können. Als Folge davon weiß der Leser noch lange vor Nielsen, daß sowohl Rajevski als auch Knutson und Karin umgekommen sind. Von Georgis' Tod dagegen erfahren wir auf Ebene I nur das, was Barutanski mitgeteilt wird, also nur die Tatsache, nicht aber wer der Täter war, da Nielsen unerkannt entkommen konnte. Auf Jbene I wird von Georgis Tod nur berichtet, auf Ebene IV spielt er sich szenisch ab. Die zeitliche Parallelität

11 "Covjek, koji je ubio Georgisa, bio je Niels Nielsen." (BB, 332). 
der beiden Handlungsebenen I und IV kommt deutlich zum Ausdruck. Beide Ebenen ergänzen einander und verlaufen abschließend sowohl zeitlich als auch örtlich parallel. Am Ende des 3. Kapitels steht Barutanski an Bahnhof und betrachtet eine alte Lokomotive (s. 329 f.), dieselbe Lokomotive, die Nielsen zu Ende des 4. Kapitels ebenfalls wahrnimmt (s. 355). Außerdem sieht Barutanski den BlitwanenExpreB gerade abfahren (S. 330 f.), eben jenen Zug, mit dem Nielsen am Ende des 4. Kapitels kurz vor ein Uhr nachts Blitwanen verläBt (s. 355). 12

Der letzte Roman Krlezas, Z, soll in diesem Zusammenhang nur kurz gestreift werden, da sich aus dem ersten buch noch nichts Endgültiges über den Bau des gesamten Romans sagen läBt. Ziemlich sicher wird er ähnlich umfangreich wie BB werden, wenn nicht noch umfangreicher. Die Anlage des Geschehens, die Vielfalt der Personen und vor allem der Zeitraum der Handlung, die sich über ein Jahrzehnt erstreckt, legen diesen Schluß nahe.

Xhnlich wie in BB geht Krleža auch in diesem Roman von der einlinigen Darbietung des Geschehens ab. Zwar ist Kamilo ohne Zweifel die Mittelpunktsfigur, aber das gesamte Geschehen wird nicht ausschlieBlich auf ihn bezogen. Er ist in dreizehn der insgesamt vierzehn Kapitel des ersten suches anwesend, einige Male spielt er jedoch lediglich die Rolle eines Statisten. Hinzu kommt, daB ein großer Teil der vergangenen Ereignisse - vor allem die Geschichte Annas und ihres Mannes, das Verhältnis Annas zu Kamilo und umgekehrt - durch Kamilo wiedererinnert werden.

Der erste Handlungsstrang wird in Kap. 1 wit dem Auftreten Emeričkis aufgenommen, der zweite mit Kamilo in Kap. 3. Von Kap. 4 bis Kap. 8 einschlieblich verlaufen beide Ebenen im wesentlichen gemeinsam. Kamilo kehrt in sein Elternhaus

12

Vgl. Schema Nr. 3 und Schema Nr. 7 im Anhang (S. 267, 270). 
nach Zagreo zurück und verbringt die Zeit nach dem Begräbnis seiner lutter mit seinem Vater. Von Kap. 9 bis 13 hält Kamilo sich wieder in Budapest auf, um in Kap. 14 erneut nach Zagreb zurüickzukehren. Nach dem ersten Drittel dieses Kapitels fährt er nach Wien.

Im Verlauf des ersten Buches von $\mathrm{Z}$ kommt es im Gegensatz $z$ U $B$ zu keinerlei tberschneidungen der beiden Handlungsebenen Kamilo-Emericki. Ab Kap. 4 verlaufen sie eine Weile gemeinsam, und nach Kap. 9 wird nur noch die Ebene Kamilos weiter verfolgt. In Kap. 1 und 3 ergäbe sich die Höglichkeit, gleichzeitig ablaufendes Geschehen zur Darstellung zu bringen. Dies wird jedoch vermieden. Die Handlung des Romans setzt am 6 . Juli mit Telefongesprächen Emerickis und mit seiner Reise nach Budapest ein. Kamilo ist bereits am 5. Juli mit Anna abgereist, und Emerički trifft ihn nicht an. Ebene I (Emeri $\nearrow_{k i}$ ) wird bis zu den ersten Seiten des 3. Kapitels verfolgt. Anschließend wird Ebene II (Kamilo) aufgenommen, die mit Kamilos Rückkehr nach Budapest beginnt, wo er die Telegramme seines Vaters in seinem Zimmer vorfindet. Ebene II setzt zeitlich kurz n a $c$ b Ebene I ein. Die Ereignisse vom 5. bis zum 13. Juli, die sich gleichzeitig mit den Geschehnissen der Ebene I abspielen, werden nicht dargestellt. ${ }^{13}$ Erst später kommt Kamilo gelegentlich im Rahmen seiner Gedankenmonologe auf diese Tage zu sprechen.

Zwei weitere Handlungsstränge - wenn bier von Handlungssträngen überhaupt die Rede sein kann - verlaufen im Hintergrund. Uber die verschiedenen Aufenthaltsorte Annas erfahren wir in erster Linie aus den Gedankenmonologen Kamilos, der Karten und Briefe von ihr erhält. Ergänzt werden diese Angaben durch ein Telefongespräch Kamilos mit Annas Mann. Jojas schicksal wird in der zweiten Hälfte von Buch I mehrmals in Gesprächen zwischen Kamilo und anderen Personen berübrt.

Vgl. Schema Nr. 4 im Anhang (S. 267). 


\section{Zeitliche Strukturierung}

Jedes Erzählen vollzieht sich in der Zeit, und selbst der moderne Roman ist letzten Endes genau so wie der traditionelle Roman an "sein ursprüngliches, und wenn man will, primitives Urgesetz gebunden: der erzählerischen Auf reihung von Geschehnissen in einer - wie auch immer gearteten zeitlichen Ordnung." 14 Das Zeitproblem ist somit für die Struktur des Romans von wesentlicher Bedeutung. Aus diesem Grunde soll inm im Zusammenhang mit der Untersuchung der Komposition der Romane Krležas besondere Aufmerksamkeit gewidmet werden. Hierbei sind zwei verschiedene Aspekte zu unterscheiden: einerseits die zeitliche Gliederung des Geschehens, das Zeitgerüst, und andererseits die Reihenfolge der Geschehnisse, die Chronologie.

\section{a. Zeitgerüst der Romane}

Der Erzähler gliedert die erzählten Geschehnisse durch den Wechsel zwischen Dehnung, Raffung und Aussparung. Der Handlungsfaden läuft nie mit gleichbleibender Geschwindigkeit ab. Von wesentlicher Bedeutung für die Erfassung der ungleichmäBig ausführlichen Behandlung der Ereignisse ist das Verhältnis von Erzählzeit zu erzählter Zeit. G. Müller, der diese Unterscheidung erstmals vornahm, definiert die Erzählzeit als die Zeit,"die das Erzählen einer 'Geschichte' beansprucht", und erzählte Zeit als die Zeit, "die eine "Geschichte' nach Angabe ihres Erzählers dauert." Während das Erzählen "in ziemlich gleichmäBigem Tempo Satz um Satz" verläuft, wird der "erzählte Vorgang (...) keineswegs gleichmäBig Schritt vor Schritt dargestellt." ${ }^{15}$ Der Erzähler ist

14 Yandelkow, Karl Robert: Hermann Brochs Romantrilogie "Die Schlafwandler". Gestaltung und Reflexion im modernen deutschen Roman. Heidelberg 1962, S. 39.

15 Aufbauformen des Romans. In: Zur Poetik des Romans. Darmstadt 1965. (= Wege der Forschung. Bd 35.), S. 285. 
gezwungen, die erzählte Zeit ununterbrochen zu raffen, selbst dann, wenn die Erzählung nur einen Zeitraum von Stunden oder Tagen umfaßt. Erzäblzeit und erzählte Zeit kommen, wenn überhaupt, nur streckenweise zur Annäherung oder gar zur Deckung. Selbst im modernen Roman, für den die Verkürzung der erzählten Zeit charakteristisch ist, ist die Erzählzeit kürzer als die erzählte Zeit.

Entscheidend für den Wechsel der Erzählweisen und die Profilierung des Ganzen ist der Erlebnisinhalt der dargebotenen Ereignisse, denn Raffung ist zugleich auch Wertung. Inhaltlich Wichtiges wird durch einen geringeren Grad an Raffung von Unwichtigem geschieden, das stark gerafft, nur angedeutet oder ganz übergangen wird. 16

Die ersten drei Romane Krlezas erstrecken sich alle nur über einen verhältnismäßig kurzen Zeitraum. In jedem von ihnen gelangt nur ein Ausschnitt aus dem Leben der handelnden Personen zur Darstellung - Jeweils eine für sie entscheidende Phase. Die erzählte Ze1t des ersten Romans beträgt etwa ein halbes Jahr, die des zweiten etwa zwei Jahre und die des dritten etwa ein Jahr. Der letzte, únvollendete Roman Krlezas, $Z$, erstreckt sich im Gegensatz zu den übrigen Romanen über einen langen Zeitraum - über ein Jahrzehnt. ${ }^{17}$ Buch I von $Z$ umfaBt jedoch lediglich fünf Honate. Der Vergleich der ersten beiden Romane, FL und NRP, die beide annähernd gleichen Umfang haben, zeigt bereits die unterschiedliche Behandlung der erzählten Zeit. Einerseits werden auf 263 Seiten die Ereignisse eines halben Jahres dargestellt (FL), andererseits auf 266 Seiten die zweier Jahre (NRP). Um Gemeinsamkeiten oder Abweichungen

16 Vgl. G. Müller: Die Bedeutung der Zeit in der Erzählkunst. Bonn 1947, S. $19 \mathrm{f}$.

17 In I, 2 kündigt der Erzähler an, daß sich das Geschehen über ein Dezennium erstrecken wird $(2,1,438)$. 
feststellen zu können, sollen die Zeitgerüste der einzelnen Romane gesondert betrachtet werden.

FI setzt im Morgengrauen des Monats April ein und endet im Herbst desselben Jahres. Der erste Teil umfaßt nur wenige Stunden. Filip kommt um vier $\mathrm{Uhr}$ früh in Kaptol an, das er im Verlauf desselben Vormittags wieder verläBt. Mit der Pahrt nach Kostanjevec bricht die Erzählung zunächst ab, um nach einem Zeitraum von zwei dionaten wieder mit Teil II einzusetzen. Teil II erstreckt sich über die Zeit von Juni bis etwa September, also auf drei bis vier Monate. Die 200 Seiten und einundzwanzig Kapitel des zweiten Teils dienen jedoch keinesfalls ausschlieBlich der Darstellung der Gegenwartshandlung. In den ersten drei Kapiteln von Teil II werden einige Ereignisse nachgeholt, die sich seit der Ankunft Filips, also in dem übersprungenen Zeitraum von zwei Monaten abspielten. ${ }^{18}$ AuBerdem wird mehrere Kapitel hindurch die Vorgeschichte einiger Personen eingeschoben und die Handlungsgegenwart unterbrochen (15-20). Da Kap. 1-8 des ersten Teils einen Vormittag umfassen und Kap. 26-29 des zweiten Teils sich auf einen Zeitraum von einigen Tagen erstrecken, beträgt die erzühlte Zeit der restlichen siebzehn Kapitel fast ein halbes Jahr. Bei Betrachtung der einzelnen Kapitel stellt sich jedoch heraus, daß sie in der Regel nicht mehr als einen Tag oder den Teil eines Tages beanspruchen. Innerhalb der Kapitel erfolgt demach in der Regel eine nur geringe Raffung. Die Folge dieser Darstelluntsweise, die sich auf die Ereignisse einiger weniger Tage konzentriert, die aus dem Gesamtverlauf der Hand-

18 Der Erzähler holt das wenige, das ihm erzählenswert erscheint, in stark geraffter Form nach. Die Zeitbestimmungen bleiben unbestimmt und bringen den iterativdurativen Charakter der erzählten Vorgänge zum Ausdruck ("eines Abends", "vom ersten Tag an", "täglich"). Weiterhin werden imperfektive Verben, Steigerungsformen und der Konditionalis vervendet, un die Wiederholung der Handlung in der Vergangenheit anzuzeigen. 
lungszeit herausgegriffen werden, ist die, daB zwischen den einzelnen Kapiteln jeweils tote Strecken liegen, die stillschweigend übergangen werden. Nur zweimal holt KrleZa die ausgesparten Ereignisse nach.

Das Verhältnis von Erzählzeit zu erzählter Zeit ist demnach in FI starken Schwankungen unterworfen: Dehnung der Zeit zu Anfang und Schluß des Romans und in Mittelteil Raffung, die in erster Linie durch Auslassungen längerer oder kürzerer Zeitstrecken zwischen den Kapiteln bewirkt wird. 63 Seiten werden für die Darstellung eines einzigen Vormittags herangezogen, 38 seiten für die Nachholung der Ereignisse zweier Monate, 4, 8, 17, 9, 16, 11, 14 Seiten für die Darstellung jeweils eines Tages oder eines Abends, 11 Seiten für einen Tag bis in die Nacht hinein und für den Abend eines anderen Tages, 15 Seiten für die Nachholung einiger Tage, 30 Seiten für einen Tag und einen Abend.

Die Uhrzeit spielt nur in den letzten beiden dramatisch verlaufenden Kapiteln eine Rolle. Kap. 28 und 29 erstrecken sich über den Zeitraum eines einzigen Tages, insbesondere eines Abends, der bis in die kleinsten Zeiteinheiten aufgeteilt wird. Von S. 245 bis S. 266 wird zehnmal die genaue Uhrzeit angegeben. Die erzählte zeit dieser 22 Seiten beträgt eine Stunde und zwölf Minuten. In Teil I wird das stetige Verrinnen der Zeit durch die allmählich aufgehende und immer höher steigende Sonne angezeigt. Ebenso ersetzen in Teil II Verweise auf Erscheinungen in der Natur - meist zu Beginn der Kapitel - genaue Zeitbestimmungen. Neben diesen Hinweisen wird in der Regel noch die Tageszeit angegeben. Heist spielen sich die einzelnen Kapitel in der Abenddämmerung oder nachts ab.

Der zweite Roman, NRP, ist in besonderem Maße dazu geeignet, die für Krležas Romane typische Strukturierung der Zeit zu verdeutlichen, da die Ereignisse in NRP im Gegen-

$19 \mathrm{Vgl}$. Schema Nr. 5 im Anhang (S. 268 ). 
satz zu FI und zu $B B$ zeitlich verhältnismäBig genau fixiert sind und Krleža überdies gezmungen ist, in viel stärkerem Maße zu raffen, als dies in den beiden übrigen Romanen der Fall ist.

NRP umfaßt 283 Seiten und 12 Kapitel. Kap. 1 (17 Seiten) steht jedoch außerhalb des eigentlichen Geschehens, ist nicht Handlungsgegenwart, sondern Erzählgegenwart. Die ersten Kapitel sind im Vergleich zu den folgenden zeitlich ähnlich strukturiert wie die von FI. Kap. 2, 3, 4 umfassen einen Zeitraum von sechs Tagen, von Samstag bis einschließlich Donnerstag. 20 Kap. 5 setzt nach etwa vierzehn Tagen ein und umfaßt erstmals einen längeren Zeitabschnitt. Einerseits bleiben die vergegenwärtigten Tage zeitlich unbestimmt, und andererseits faBt der Ich-Erzähler die Zeit pauschal zusammen, da sie ereignislos verläuft. Da Kap. 5 etwa Ende September einsetzt und das folgende Kapitel an einem Februartag die Handlung wieder fortführt, vergehen mindestens vier Monate. Lit 45 Seiten ist das 6. Kapitel, in den die Gerichtsverhandlung gegen den Ich-Erzäbler von Anfang bis Fnde reproduziert wird, das längste Kapitel des gesamten Romans, das Kapitel, in dem die erzählte Zeit am stärksten gedehnt wird. Kap. 6 bildet den Schwerpunkt des Romans und damit den Höhepunkt der satirischen Gesellschaftskritik. Danach erfolgt ein tiefer zeitlicher Einschnitt: mit Kap. 6 ist die erste Hälfte des Romans und gleichzeitig ein Abschnitt im Leben des Ich-Erzählers abgeschlossen. Zwischen Kap. 6 und Kap. 7 liegen etwa sechs Monate. Genauso wie das vorhergehende Kapitel ist auch dieses Kapitel auf den Teil eines Tages beschränkt; ebenso die beiden folgenden $(8,9)$. Während Kap. 8 zeitlich ziemlich unbestimmt bleibt - wir erfahren nur, daB es Mitternacht ist und daB der Südwind weht -

20 Der starken zeitlichen Zusammendrängung kommt hier in erster Linie satirische Funktion zu. Innerhalb weniger Tage bricht die bürgerliche Existenz des Doktors zusammen. 
setzt Kap. 9 mit einer genaueren Zeitbestimmung ein. Es umfaBt einen Nachmittag im Oktober bis in die Nacht. Die Rede Valents, die den Hauptteil des 9. Kapitels ausmacht (21 Seiten), dauert von vier Uhr nachmittags bis zwel Uhr nachts. In Kap. 10 werden eine Reihe von verschledenen Vorfällen geschildert, die zu einem dreibigtägigen Krankenhausaufenthalt des Ich-Erzählers sowie zu einer achtzehntägigen Untersuchungshaft führen. Dieses Kapitel umfaßt im Gegensatz zu den vorhergehenden vier Kapiteln einen längeren Zeitraum, der in seiner gesamten Erstreckung unbestimmt bleibt. Kap. 11 setzt nach längerer zeit ein und spielt sich an einem Frühlingstag in Nal ab. Die ausgelassenen Ereignisse werden zu Beginn in geraffter Form nachgeholt. Das letzte Kapitel umfaBt wiederum eine längere Zeit, die unbestimmt bleibt. Es endet an einem Sommerabend - fast zwei Jahre nach Beginn der Frzählung. Nicht nur der Bau des Romans, sondern auch die zeitliche strukturierung ist im groBen sehr symmetrisch. Beide Hälften des Romans nehmen je fast ein Jahr in Anspruch. Das bedeutendste und längste Kapitel (6) liegt in der Mitte.

Da NRP zwel Jahre umfaßt, sind weitaus größere Zeitsprïnge nötig als in FL. Ahnlich wie in FI liegen auch in NRP die größten zeitlichen Einschnitte zwischen den Kapiteln. Weil die ersten drei Kapitel $(2,3,4)$ nur wenige Tage in Anspruch nehmen, erfolgt zum Ausgleich in Kap. 5 die Durchmessung einer langen Zeitstrecke. Nach Beendigung des ersten Teils des Romans wird wieder ein tiefer zeltlicher Einschnitt vorgenommen. Beide Phasen sind durch eine genaue zeitliche Orientierung kenntlich gemacht. Im Gegensatz zu FI rafft Krleža jedoch in NRP auch innerhalb der Kapitel längere Zeiträume zusammen $(5,10,12)$. V1el häufiger sind hingegen die Kapitel, die genauso wie in FL jeweils nur einen Tag oder den Teil eines Tages erfassen (2, $6,7,8,9,11)$. Zeitlich unbestimmt bleiben vor allem jene Kapitel, die einen längeren Zeitraum umfassen und in denen die ZusammenstöBe des Ich-Erzählers mit seiner Um- 
gebung geschildert werden $(3,5,10) .21$

Die Handlungsdauer des dritten Romans, BB, ist auf ein gutes Jahr anzusetzen. Obwohl die Erzählzeit etwa zwei bis dreimal so lang ist wie die des vorhergehenden Romans, ist die erzählte Zeit nur halb so lang wie die von NRP. Aus diesem Grunde sind keine so großen und vor allem nicht so häufige Zeitspringe erforderlich. Daß es dennoch zu recht großen Raffungen kommt, hat seine Ursache in der spezifischen zeitlichen Strukturierung dieses Romans, in dem noch mehr als in den beiden vorhergehenden die Handlung auf einige wenige ereignisreiche Tage konzentriert wird.

Buch I und II: Erzählzeit 356 Seiten (12 Kapitel) erzählte Zeit etwa zwei Monate

Buch III : Erzählzeit 242 Seiten (11 Kapitel + Epilog) erzählte Zeit ein knappes Jahr. 22

Dieser Vergleich zeigt, daB die erzählte Zeit in den ersten beiden Büchern ungleich weniger gerafft wird als in Buch III.

Buch I: Kap. 1 und 2 spielen sich an zwei aufeinanderfolgenden Tagen ab, am 1. und 2. September. Ebenso stehen Kap. 5, 6, 7 in zeitlich engem Zusammenhang. Während Kap. 5 und 6 auf einen einzigen Abend fixiert sind, folgt Kap. 7 in Abstand von zwei Tagen (am dritten Tag). Da Kap. 1, 2, 5, 6, 7 insgesamt lediglich vier Tage in Anspruch nehmen und zwischen diesen Kapiteln ein nur geringfügiger zeitlicher Abstand besteht, verfließt der Hauptteil der erzählten Zeit in den beiden Monolog-Kapiteln $(3,4)$, die verhältnismäßig unbestimmt bleiben und in denen die Zeit erstmals spürbar geraft wird. Ahnlich wie in den beiden vorhergehenden Ro-

$21 \mathrm{Vgl}_{\text {gl }}$ Schema Nr. 6 im Anhang (S.269).

22 Die Seitenzahl von Buch III läBt sich insofern nicht genau mit der von Buch I und II vergleichen, da Buch III in der Zeitschrift Forum erschien, die ein engeres Druckbild aufweist als das von dem Verlag Zora herausgegebene Buch. 
manen stellen wir auch in $B B$ eine zeitliche Konzentrierung zu Beginn des Romans fest. Im Unterschied zu Jenen Romanen wird dieses Prinzip der Konzentrierung jedoch auch weiterhin eingehalten und im Verlauf des zweiten Buches sogar noch verstärkt. Erst in II, 5 werden größere Zeitabschnitte durchschritten.

Buch II: Da Buch II mit einem zeitlichen Abstand von etwa zwei Wochen einsetzt, wird in II, 1 erstmals einiges nachgeholt. ${ }^{23}$ Die Handlungsgegenwart wird jedoch bald auf die Zeit der Abenddämmerung festgelegt (S. 203). Dieser Abend bis in die Nacht hinein ist die Zeiteinheit der ersten vier Kapitel ( 165 Seiten). Die ersten drei Kapitel schlieBen zeitlich unmittelbar aneinander an $(1,2)$ und überschneiden sich auf einer kurzen Zeitstrecke $(2,3)$. Zu Beginn des 4. Kapitels werden - ebenso wie in Kap. 1 - Ereignisse nachgeholt. Anschließend verläuft Kap. 4 mit Kap. 1, 2,3 zeitlich parallel. ${ }^{24}$ In Kap. 5 wird zum Ausgleich wieder eine längere Zeitstrecke durchschritten, deren Verlauf unbestimmt bleibt. Im wesentlichen werden jedoch 2 wei aufeinanderfolgende Tage vergegenwärtigt (S. 367-399). Buch III: Während der zeitliche Einschnitt zwischen Buch I und II lediglich etwa zehn bis vierzehn Tage beträgt, beläuft sich der 2 wischen Buch II und III auf mehrere Honate. Einige Ereignisse aus dieser Zeit werden in den ersten drei Kapiteln nachgeholt. In such III sind auch die Abstände zwischen den einzelnen Kapiteln erheblich größer als in den ersten beiden Büchern des Romans. Außerdem wird in Buch III auch innerhalb der Kapitel ein längerer Zeitraum $(2,7,9)$

$23 \mathrm{Da}$ Barutanski in I, 1 zim letzten lial auftrat, müssen in II, 1 die Ereignisse etwa eines Monats in geraffter Form nachgeholt werden.

24 Zur Veranschaulichung des simultanen Verlaufs sowie der Dehnung der Zeit in Kap. 1-4 vgl. Schema $\mathrm{Nr} .7$ im $\mathrm{An}-$ hang (S. 270). 
oder zumindest zwei oder drei Tage durchschritten $(4,6)$. Kap. 1, 3, 5, 10, 11 und der Epllog erstrecken sich jedoch auf nur jeweils einen Tag oder den Teil eines Tages. Nur wenige Hale wird die erzählte Zeit gedehnt und durch exakte Zeitangaben in ihrem Verlauf angezeigt. So wird Barutanski in III, 5 während einer Nacht und im Verlauf des darauffolgenden Nachmittags und Abends verhältnismäBig ausführlich in seinen Beschäftigungen verfolgt. Charakteristisch ist vor allem wieder die zeitliche Zusammendrüngung gegen Schluß des Romans. Die letzten beiden Kapitel einschlieBlich des Epilogs umfassen einen Zeitraum von etwa zwanzig Stunden. Abgesehen von diesen wenigen Kapiteln wird die Zeit entweder gar nicht oder nur sehr vage bestimmt. Häufig sind Angaben wie "vergangene Nacht", "eines Sonntags" oder "eines Nachmittags". Diese zeitliche Unbestimmtheit ermöglicht es, größere Zeitabschnitte unauffällig zu überbrücken. 25 obwohl in Buch III eine erheblich läggere Zeitstrecke bewältigt werden muß als in den ersten beiden Büchern, geht Krleza nur in einigen Kapiteln von seinem Prinzip ab und faßt mehrere Tage in einem Kapitel zusammen. Die weitaus längsten Zeitabschnitte liegen demnach zwischen den einzelnen Kapiteln und 2 wischen Buch II und III. Buch II endet im Herbst, in III, 2 ist es bereits Frühling und in III, 5 Sommer. Zwischen II, 4 und III, 7 vergeht fast ein Jahr, die Zeit, die Nielsen sich nach seiner Flucht aus Blitwanen (II, 4) in Blatwien aufhält. 26

Der Umfang des ersten Buches von $Z$ ist weit größer als der Gesamtumfang der beiden ersten Romane und auch etwas

\footnotetext{
25 Die zeitliche Unbestimmtheit in Buch III wird vor allem dadurch bedingt, daB hier Reflexion und Retrospektive vorherrschen. Die wenigen Kapitel, die in Buch III zeitlich genauer festgelegt sind, bringen Geschehnisse ( 3 , $4,5,10,11$, Ep1108).

26 Vgl. Schema Nr. 8 im Anhang (S. 271).
} 
größer als der der beiden ersten Bücher von BB. Die Erzählzeit von Buch I (2) beträgt 485 Selten (vierzehn Kapitel), die erzählte Zeit fün Monate. 27 Ein nicht geringer Tell der Erzählzeit wird jedoch der retrospektiven Darstellung gewidmet, die in $Z$ einen breiten Raum einnimmt. Im Gegensatz zu BB 1st die Handlungsdauer des ersten Buches von $Z$ genau datiert. Kap. 1 beginnt am 6 . Jull 1913 und Kap. 14 endet am 4. Dezember desselben Jahres. Erstmals gibt Krleža auch die Jahreszahl an. Weit mehr als alle übrigen Romane ist $\mathrm{Z}$ an ganz konkrete historische Ereignisse gebunden. Das Zeitgerüst von $Z$ ist damit wesentlich übersichtlicher als das von BB. Eine ganze Reihe von Ereignissen sind exakt datiert. Zeitlich unbestimmt bleiben vor allem wioder die Monolog-Kapitel (11, 12, 14). Zwar wird die erzählte zeit in $Z$ nicht mehr so einseitis gedehnt oder gerafft wie in $\mathrm{BB}$, jedoch zeigt sich gerade in diesem Roman die Tendenz Krležas, aus einer längeren Zeitstrecke jeweils nur einige wentge Tage herauszugreifen, besonders deutlich. Innerhalb der Kapitel wird in der Regel wenig gerafft. Dle unausgefüllten Zeltstrecken llegen auch hier wieder vor allem zwischen den Kapiteln. Ihnlich wie in den übrigen Romanen spielen sich die ersten Kapitel in einem engen Zeitraum ab. Die Zeitabstände werden mit den folgenden Kapiteln gröBer. Die erste Hälfte von Buch I (1-7) erstreckt sich auf nur eineinhalb Monate. Die restlichen dreieinhalb Monate beanspruchen die übrigen sieben Kapitel. Acht Kapitel werden zur Darstellung eines Tages herangezogen $(4,6,7,8,9,10,12,13)$, drel Kapitel für die zweier Tage $(1,3,11)$ und nur zwel Kapitel erstrecken sich über einen längeren Zeltraum $(5,14)$.

Da dieser Roman ein Dezennium umfassen 8011, in Buch I jedoch lediglich fünf Monate dargestellt werden, wird

27 Für das Druckbild von $\mathrm{Z}$ gilt dasselbe wir für Buch III von BB. Vgl. Anm. 22 S. 124 dieses Kapitels. 
Krleza in dem folgenden Buch (oder in den folgenden Büchern) ungleich größere Zeitsprünge machen müssen als bisher. ${ }^{28}$ Dies vor allem dann, wenn er auch weiterhin nach dem Prinzip vorgeht, nur einige Tage aus dem Gesamtverlauf der Zeltstrecke herauszugreifen. Der Beginn von Buch II zeigt, daB sich das Verhältnls von Erzählzelt zu erzählter zeit entscheidend wandelt, daß die erzählte Zeit ungleich stärker gerafft wird als in Buch I. Die ersten beiden Kapitel von Buch II umfassen berelts zweieinhalb Jahre. Kap. 2 endet im Juni 1916, also drei Jahre nach Beginn des Romans. Allein auf den ersten sieben Seiten von II, 1 zieht Krleža die Zeit von fast einem Jahr zusammen. Zwischen Kap. 2 und 3 liegt mehr als ein Jahr, und der zeitliche Abstand zwischen Kap. 3 und 4 beträgt Jahre. Bezeichnend für Krležas Darstellungstechnik ist, $d a B$ er selbst hier nur in einem der vier Kapitel (1) stark rafft und auch dies nur auf den ersten Seiten. Anschließend werden wieder nur zwei verschiedene Tage herausgegriffen, die ausführlich dargestellt werden. Die übrigen drei Kapitel spielen sich an einem Tag (4), an zwei aufeinanderfolgenden Tagen (2) und an drei verschiedenen, nicht näher bestimmten Tagen ab (3). Die groBen Zeitstrecken llegen demnach in Buch II von $Z$ noch viel auffälliger als in den drei vorhergehenden Romanen 2 wischen den einzelnen Kapiteln. 29

Vergleichen wir das Zeitgerüst der vier verschiedenen Romane miteinander, so stellen wir eine ganze Reihe von Gemeinsamkeiten fest. Das Verhältnis von Erzählzeit zu erzählter Zeit ist selbstverständlich von Roman zu Roman verschieden. Während in FI und in BB krasse Disproportionen

28 Da sich II, 4 bereits in Februar 1922 abspielt, ist anzunehmen, daB $Z$ nur aus $z$ wei Büchern bestehen wird.

29 Vgl. Schema Nr. 9 im Anhang (S. 272 ). 
auftreten, so daB Zeit und Geschehnisse in umgekehrt proportionalem Verhältnis zueinander stehen, sind NRP und Buch I von $Z$ in dieser Beziehung ausgeglichener gebaut. Gemeinsam ist jedoch allen Romanen, daB die ersten und letzten Kapitel elnen stets kurzen Zeltraum umfassen; lediglich der SchluB von NRP bildet hier eine Ausnahme. Weit aufeälliger 1st jedoch die Tatsache, daB Krleža die Darstellung auf elnige wenige Brennpunkte des Geschehens konzentriert, die plast1sch aus dem Ganzen herausgearbe1tet werden. Dies 1st ein wesentliches, für alle Romane gültiges Darstellungsprinzip. Krleža rafft die erzählte Zeit in der Regel nur wenig innerhalb der Kapitel, legt dafür zwischen die Kapitel und vor allem 2wischen die Telle oder Bücher des Romans jeveils längere Zeltstrecken. Charakteristisch für alle Romane ist somit die Häufigkeit zeitlich toter Strecken und die Dehnung der erzählten Zelt an den jewells vergegenwärtigten Zeitpunkten. Auch dann, wenn innerhalb eines Kapitels eine ganze Reihe von Tagen durchschritten wird, besteht die Tendenz, erst mehrere Tage, die unbestimmt bleiben, zusammenzuraffen, anschlleBend aber ein oder zwei Tage aus dieser Reihe zu vergegenwärtigen, die dann den gröBten Tell des Kapitels einnehmen. Krleža gibt also nicht den kontinuierlichen Zusammenhang elner Ereigntskette, sondern nur elne ausgewählte Folge von Ereignissen, die ausführlich vergegenwärtigt werden. therdies besteht die Neigung, mehrere Ereignisse auf einen verhältnismäBig kurzen Zeltraum zusammenzudrängen. Die Folge dieser Darstellungstechnik ist ein sprunghafter Aufbau. Die einzelnen Glieder sind stark für sich herausgestellt, es gibt keine durchgehende ruhige und flieBende Bewegung. 
b. Die gebrochene Chronologie

Nicht nur durch Dehnen, Raffen und Weglassen gestaltet der Erzähler den Stoff, sondern vor allem auch durch dessen Anordnung. Er lst nicht an das Gesetz der strengen Chronologie gebunden, "denn was er uns bringt, 1st nicht Gegenwart, sondern Vergangenheit. In dem Augenblick, da uns jemand eine Erzählung vorlegt, wissen wir, daß er bereits das Ende der Begebenheit kennt." 30

In keinem seiner Romane erzählt Krleza streng chronologisch. Charakteristisch für sein Erzählen ist im Gegenteil, daB die chronologische Folge der Geschehnisse ungestellt wird. Von wesentlicher Bedeutung für die Betrachtung seiner Romane unter diesem Gesichtspunkt ist die Auffassung Krlezas - und seiner Helden - von der Zeit, die zur Folge hat, das die Geschehnisse nicht in ihrem Nacheinander, sondern in ihrer Glej.chzejtigkeit erblickt werden. Es geht inm darum, die zeitliche (und räumliche) Kontinultät aufzulösen und die Ereignisse in ihrer Simultaneität darzustellen. Das Grunderlebnis des Malers Filip ist die Vielfalt der Ereignisse, die sich gleichzeitig abspielen, die jedoch obne innere Beziehung nebeneinander bestehen: "das eine im anderen, das eine neben dem anderen, das eine über dem anderen." (FL, 67). Filip träumt von der Verwirklichung eines Bildes, auf dew er gleichzeitig die Geräusche, Gerüche und Bewegungen darstellen will. Er meint, man müsse die Erscheinungen gerade in ihrer "grotesken Simultaneität" wahrnebmen und malen. 31

Letzten Endes geht es hier un die Totalität der Erscheinungen, die sich Filip und damit Krleža aufdrängt, elne Er-

30 Priedemann, Käte: Die Rolle des Erzählers in der Epik. Leipzig 1910, S. 99.

$31 \mathrm{Vgl}$. Kap. VI, s. 243. 
fahrung, die für den Schriftsteller des zwanzigsten Jahrhunderts von wesentlicher Bedeutung ist. Es 1st die Einsicht in eine Welt, die undarstellbar zu werden droht, da sie in eine Vieldimensionalität einander ausschlieBender Aspekte zerfallen ist. Die Folge dieser Erkenntnis schlägt sich in einer Handlungsführung nieder, die nicht einlinig und zielstrebig vorwärts schreitet, sondern die durch ein Neben- und Mitelnander verschiedener zeitlicher Ebenen gekennzeichnet ist.

Krleža geht in seinen Romanen jedoch nicht so radikal vor, er fübrt die Gedanken Filips "es gibt keine einheltliche Richtung, keinen Aufbau, sondern alles ist Verwicklung" (FL, 68) nicht ganz konsequent durch. Vor allem geht er nicht so weit, die Fabel völlig aufzulösen und die einzelnen Teile beziehungslos nebeneinander zu setzen. Der sorgfältig durchdachte Aufbau von FL und die vielfältigen Bezlehungen der Telle untereinander beweisen dies. Seln Streben, die Ereignisse in ihrer Gleichzeitigkeit zu erfassen, kommt, abgesehen vom Stil, vor allem in der Verflechtung und Durchdringung der verschtedenen Zeitebenen zum Ausdruck. Die Polge davon ist, daB die Chronologie zwar nicht aufgehoben wird, daB jedoch die natürliche Abfolge der Geschehnisse erheblich gestört wird und daB andere Ordnungsprinzipien als die der Zeit wirksam werden. Die Gleichzeitigkeit von Vergangenheit und Gegenwart wird dadurch bewirkt, das die Vergangenheit in der Gegenwart mit fortlebt, sie uberlagert und zu einem wesentlichen Bestandtell der Gegenwart wird. Die Vielschichtigkeit der Romane Krlezas ist in erster Linie auf diese Behandlung der Zeit zurückzuführen und nicht etwa auf eine komplizierte und verschlungene Fabel oder vielfältiges gegenwärtiges Geschehen.

Nicht nur der verhältnlsmäBig kurze Zeitraum, den die gegenwärtige Handlung umfaBt, sondern auch der medias-inres-Beginn der Romane lst die Ursache dafür, daB die Ge- 
schehnisse nicht in ihrer natürlichen Abfolge erzählt werden. Die Voraussetzung zu der unvermittelt einsetzenden Handlung sowie die Vorgeschichte der Romanpersonen muß im Rahmen der Gegenwartshandlung nachgeholt werden. Da ein groBer Teil der Geschehnisse aus der Vorvergangenheit durch die Personen der Romane selbst gebracht wird, und zwar vorwiegend in Form von Gedankenmonologen, ist die therlagerung und Vermischung der verschledenen Zeitebenen und damit die Zerbrechung der Chronologie eine naheliegende Polge. Im BewuBtsein sind Vergangenheit und Gegenwart vom zeitlichen Verlauf unabhängig und beide gleich gegenwärtig. Wesentlich für Krležas Erzähltechnik ist jedoch, daß nicht nur die Monologsituation für die tberlagerung von Gegenwart und Vergangenhelt verantwortlich ist, sondern daB die Chronologie auch dann durchbrochen wird, wenn die Geschehnisse aus der Perspektive des Autors dargeboten werden.

Da die Umstellung der Chronologie Pür sämtliche Romane Krlezas bezeichnend ist, seien in diesem Zusammenhang nur 2wel der markantesten Beispiele herausgegriffen: FI und Buch I von $\mathrm{Z}$.

Die Gleichzeitigke1t von Vergangenheit und Gegenwart, die tberlagerung der Gegenwart durch die Vergangenheit und die beiderseitige Durchdringung ist das charakteristische Merkmal des ersten Teils von FL. Filip erinnert sich in der Begegnung mit den Gegenständen seiner Jugend an die vergangenen Erelgnisse. In welchem Maße es Krleža hier um die Tatsache des Miteinanderexistierens der beiden Zeitebenen geht, beweist die Art und We1se, wie Filips Vergangenhe1t schrittweise und mosalkartig zusammengefügt wird. Die komplizierte, vielschichtige Darstellung ergibt sich gerade aus jenem ständigen Wechsel zwischen Vergangenheit und Gegenwart und vor allem aus der Tatsache, daB die vergangenen Ereignisse scheinbar wllkürlich und ohne Rücksicht auf den Zeitpunkt des Geschehens und auf Vollständigkelt auf dem Wege der 
Assoziation erschlossen werden. Es 1st kein bemuBtes Erinnern, sondern ein unwillkürliches Auftauchen von Erinnerungen, die durch den Anblick eines Gegenstandes, durch ein Wort, ein Geräusch oder einen Geruch angeregt werden. 32

Die Handlungsgegenwart des ersten Romantells umfaBt einen Frühlingsmorgen. Diese verhältnismäßig begrenzte Zeitschicht, in der kaum etwas geschieht, wird durch die Einbeziehung der Vergangenheit um ein Vielfaches erweitert. In die Gegenwartsebene verschlungen und sich mit ihr überschneidend, verläuft jene zweite Ebene, die zeitlich weit vor Einsetzen der Handlung liegt. Wir haben es hier jedoch nicht nur mit einer Vorzeithandlung zu tun, sondern mit mehreren. Der Reihenfolge nach sind dies folgende: 1. Filip als Zehnjähriger, 2. Filip als Sechzehnjähriger, 3. Fillp als Siebzehnjähriger, 4. F1lip als Neunundzwanzigjähriger, 5. Filip in der letzten zeit (kurz vor Einsetzen der Romanhandlung). Vergegenwärtigt werden die vergangenen Ereignisse jedoch nicht der Reihenfolge, sondern ihrer Bedeutung nach: 3., 1., 5., 4., 2. Greifen wir einige dieser Ereignisse heraus, um zu sehen, wie Krleža den Ubergang von der Gegenwart zur Vergangenhelt vollzieht und vor allem, mit welchen Mitteln er die Brücke zwischen den beiden Zeitebenen schlägt.

Der Roman beginnt mit der Evoziemung des bedeutendsten Ereignisses, jenem vor dreiundzwanzig Jahren, als der slebzehnjährige Filip von seiner kutter auf die Straße gesetzt wurde. Die Bezlehung zwischen dem Jetzt und dem Damals wird auf zeitlicher Basis hergestellt. Filip kommt an einem Morgen in Kaptol an, an einem Morgen wies inm auch seine Mutter die Türe. Dieses "ono jutro" durchzieht leitmotivisch das gesamte 1. Kapitel und dient zur Verknüpfung der beiden Zeitebenen.

Um die vergangenen Geschehnisse zu vergegenwärtigen, stellt

32 Vgl. Pranges, Iro: U potrazi za izgubljenim djetinjstrom. Nekoliko paralela uz "Povratak Filipa Latinovicza". In: Kolo, NS, 1, 1963, 6, 10. 
Krleža nicht nur die zeitliche, sondern auch eine räumliche Bezlehung her, die in weit stärkerem MaBe als Bindeglied dient. Bezelchnenderweise ist es P1lips stärkster Elndruck bel selner Rückkehr, daß alles noch so 1st wie damals (PI, 12). Alle jene Gegenstände und Ortlichkeiten, die für ihn voller Bedeutung sind, da sie eln bestimmtes Kindheitserlebnis symbolisieren, haben die Jahre seiner Abwesenheit unverändert überdauert.
Hier war vor langer Ze1t, vor dreiBig Jahren, die Trafik seiner Mutter, der Prau Regina, ge- wesen, und hier steht dieser Tabakladen auch heute noch wie in seiner Kindheit (...). Und das Rouleau am Penster 1st genauso zerrissen wie vor dreibig Jahren, und dort, hinter dem Rouleau, ist dieses feuchte, schimmlige Z1m- mer mit dem morschen FuBboden, auf dem er so oft hinter dem Eisenofen in der Ecke hat knien müssen. P1lip kniet im Halbdunkel und ist ganz allein im Zimmer, nur drauBen hört man die Schritte der Passanten (...) über die Kanal- rinne hinweg (...). Pilip schaute in diesen Kanal unter der kieinen Brücke (...). (FI, 17)

Die Vergangenheit nimmt für P1l1p den Charakter des Gegenwärtigen an, der zeltliche Abstand scheint aufgehoben zu sein, und die Darstellung wechselt folgerichtig vom Präteritum Ins Präsens über, um nach elnigen Sätzen wieder ins Präterlum der Erzählung zurückzukehren. Dieses Beispiel zeigt, we ausschnitthaft die vergangenen Freignisse jeweils nur beleuchtet werden. Sogleich erfolgt die Rückkehr in die Ausgangsituation, die Jedoch erneut alsbald verlassen wird.

Die Gleichzeitigkeit von Vergangenheit und Gegenwart wird sogar so weit hergestellt, daB nicht nur damals vor dreiundzwanzig Jahren ein Bäckerlehrling mit einem Netz voll duftender Semmeln an P1lip vorbeiging, sondern daB sich derselbe Vorgang auch am Morgen seiner Rückkehr wiederholt. Jegliche Distanz zwischen Vergangenhe1t und Gegenwart scheint beseitigt. 
Achronologische und zum gröBten Tell unzusammenhängende Vergegenwärtigung kennzeichnet die Darbletung der Vorgeschichte Filips, die durch dessen Gedankenassoziationen erschlossen wird. Betrachten wir nun die Art und Weise, we die Vorgeschichte Jener Personen zur Darstellung gelangt, die ausschlieBlich oder zumindest vorwiegend durch den Erzähler gebracht wird. Krleža geht hier von der schrittweisen Enthüllung der Vergangenheit ab und stellt die Vorgeschichte im wesentlichen in zusammenhängender Form dar, jedoch keineswegs immer chronologisch. Bevor in Kap. 16 zwe1 Episoden aus Ksenijas Leben in chronologischer Folge geschildert werden, wird inr Lebenslauf im vorhergehenden Kapitel ohne Rücksicht auf die zeitliche Ordnung berichtet. Die Affäre mit Baločanski, die zeitlich den AbschluB einer ganzen Reihe anderer Affären bildet, wird gleich zu Beginn des Kapitels erwähnt, anschließend lhre erste the mit Pavlinit, um nochmals ihre Geschichte mit Balotanski aufzunehmen, die bis in die Gegenwart hineingeführt wird. Danach wird in die Zeit zurückgeblendet, die vor der gegenwärtigen Situation liegt und die die drei Jahre umfaBt, in denen Balocanski im Gefängnis saB, bevor thn Ksenija bel sich aufnahm. In diese Zeit fällt die zweite Heirat Ksenijas. Von hier aus zieht Krieza einen weiten Bogen in die Zukunft und nimmt Ksenijas Ende vorweg. Anschließend greift er weder in die Vergangenheit zurück und zwar in jene Zeit, in der Ksentja Baločanski kennenlernte. Von hier aus wird wieder ein zeltlich früher liegendes Geschehen aufgenommen, die Scheldung von Pavlinit und Ksenijas Leben während dieser Zeit. Es ergibt sich folgende Linie:

1. Zusammenfassung aller Ereignisse: die beiden Fhen und die Affäre mit Baločansk1; 2. Affäre Baločansk1; 3. Ehe mit Pavlinić und Scheldung; 4. Affäre Baločanski; 5. Ehe mit einem Industriellen, während Baločanski im Gefängnis sitzt; 6 . Zukunft Ksenijas; 7. Beginn der Beziehung Baločanskis zu Ksenija; 8. Scheidung von Pavlinit (Balocanski lernt Ksenija im Zusammenhang mit dieser Scheidung kennen; er ist ihr Anwalt). 
Dieses Beispiel zeigt, daß Krleža sich nicht im geringsten an die Reihenfolge der Ereignisse hält und daß die vergangenen Geschehnisse auch dann, wenn sie nicht im BewuBtsein einer Figur auftauchen, sondern vom Erzähler vergegenwärtigt werden, nicht unbedingt in zusammenhängender Form dargeboten werden.

Buch $I$ von $Z$ unterscheidet sich insofern wesentlich von den drei vorhergehenden Romanen, als Krleža die Chronologie hier wirklich weitgehend zerbricht. In keinem anderen Roman wird soviel Retrospektive einbezogen und vor allem die als gegenwärtig ablaufende Handlung in solchem Maße umgestellt und verschoben. Für die Umstellung auf der Ebene der Handlungsgegenwart ist in erster Iinie die Haltung des allwissenden, immer wieder das Geschehen kommentierenden Erzählers ausschlaggebend, der souverän mit der Anordnung der Ereignisse verfährt. Der Erzähler von 2 bezieht sich immer wieder auf bexeits Geschehenes und zieht innerhalb weniger Sätze den Bogen von der Vergangenheit über die Gegenwart bis in die Zukunft hinein. Während in den übrigen Romanen eine chronologische Darlegung der Ereignisse in erster Linie durch die tberlagerung der beiden Zeitebenen der Gegenwart und Vergangenheit und die mehr oder weniger intensive Durchdringung dieser beiden Ebenen verhindert wurde, so gehen in $Z$ häufig drei zeitliche Ebenen auf engstem Raum ineinander über. Um das ther- und Nebeneinander der drei verschiedenen Zeitebenen sowie die Art und Weise, wie die Vorzeithandlung in die Gegenwartshandlung einbezogen wird, zu zeigen, sollen als Beispiel 2wei besonders charakteristische Kapitel $(3,9)$ angeführt werden.

In Kap. 3 versucht Kamilo am Abend des 13. Jul1 1913 Anna anzurufen, um ihr seine Abreise nach Zagreb mitzuteilen. Als er zum Hörer greift, schaltet sich der Erzähler ein und macht eine weit in die Zukunft reichende Voraussage. Er nimmt das letzte Treffen Annas und Kamilos vorweg, das in neun Jahren stattfinden und nur einige Minuten dauern wird $(z, 1,583)$. 
Unmittelbar nach dem Telefongespräch sitzt Kamilo im Zug nach Zagreb. Diese Zugfahrt nimmt drei Viertel des gesamten Kapitels ein und wird dazu benützt, die gemeinsame Vorgeschichte Annas und Kamilos nachzuholen, die zeitlich vor Einsetzen der Romanhandlung liegt. Zwei Assoziationskontakte lösen die Erinnerung an die vergangenen Ereignisse aus: der Zug führt am Geburtsort Annas vorbel, und Kamilo verspürt den Geruch von Heu, der ihn an jene Pfingstnachterinnert, in der seine Beziehung zu Anna ihren Anfang nahm.

Das Heu riecht, oh, es ist dasselbe feuchte, wohlriechende Heu wie Jenes, das in der Pfingstnacht mit Anna in der Mansarde unterm Dach geduftet hatte (...). $(2,1,584)$

Nach elnem Absatz beginnt die Erzählung mit fener Nacht:

Es war zu Pfingsten, vor drei Jahren, als

Kamilo noch im Francisco-Josephinum war und kurz vorm Abitur stand $(. .$.$) .$

(Ebd.)

Nach drei Seiten unterbricht der Erzähler Jedoch bereits wieder die Darstellung der vergangenen Geschehnisse und blendet in die Gegenwartsebene der Zugfahrt ein ("heute nacht im verrauchten Coupe"), um von hier aus in die $\mathrm{Zu}-$ kunft vorauszugreifen. Er nimmt Erelgnisse vorweg, die erst drei Jahre später eintreten werden $(2,1,588)$. AnschlieBend an diese Voraussage stellt er Anna und ihren Mann vor, faBt die Ereignisse zusammen, die sich bis zu diesem Zeitpunkt auf der Gegenwartsebene abspielten und greift ein zweites Mal in die Zukunft, indem er Geschehnisse vorwegnimmt, die erst in Kap. 5 und 6 sowle zum Schluß des 8. Kapitels eintreten: die Trauerzeit Kamilos und Emeritkis auf Ladanje Gornje und der Tod Jolandas Anfang September. AuBerdem erstreckt sich diese Voraussage noch über eine Reihe von Jahren. Hier kommt Krležas Bestreben, die zeitliche Reihenfolge aufzuheben und statt 
dessen inhaltliche Bezüge herzustellen, ganz deutlich zum Ausdruck. Er wendet sich an den Leser, erinnert diesen an bereits Geschehenes und eröffnet inm gleichzeitig einen Blick in die nähere und in die weitere Zukunft. Nach eineinhalb Seiten kehrt der Erzähler wieder zu der abgebrochenen Vergangenheitshandlung zurück, die im folgenden in zusammenhängender Form und im wesentlichen chronologisch vergegenwärtigt wird. Erst auf den letzten Seiten des Kapitels wird die Ausgangssituation wieder aufgenommen, nachdem die Vergangenheitshandlung szenisch geendet hatte. S. 584 sitzt Kamilo im Zug und beginnt sich zu erinnern, S. 604 wird wieder an die Gegenwartshandlung angeknüpft.

$\mathrm{Zu}$ erheblichen Umstellungen kommt es in Kap. 9. In der Uberschrift wird ein abendliches Zusammentreffen bei Kamrath angekündigt, das jedoch erst nach sechsundzwanzig Seiten szenisch dargestellt wird. Der Erzähler beginnt das Kapitel mit der Vorwegnahme zukünftiger Geschehnisse. Er berichtet von einem Selbstmordversuch der Frau Kamráths, ihrem Tod im nächsten Herbst und vom Tod ihres Sohnes, der in einigen Monaten an der Front fallen wird. Sodann wird die Gegenwartsebene wieder aufgenommen. Eines Morgens wird Kamilo von Amadeo angerufen, der ihn um jenes in der therschrift angekündigte Treffen bei Kamrath bittet. Nach diesem Telefongespräch unterbricht der Erzähler die Gegenwartshandlung und schiebt auf eineinhalb Seiten die Vorgeschichte Amadeos ein. Danach nimmt der Erzähler die Handlungsgegenwart jedoch nicht wieder an dem Punkt auf, an dem sie unterbrochen murde, sondern er holt einen Handlungsteil nach, der zwar auf der Ebene der Handlungsgegenwart liegt, jedoch auf einem zeitlich früheren Punkt. Von S. 236 bis S. 258 wird ein Gespräch Kamilos mit Amadeo nachgeholt, das vor etwa einem Lonat auf Ladanje Gornje stattfand und das in Kap. 5 oder 6 , die zu dieser Zeit spielen, nicht erwähnt wurde.

Die Betrachtung dieser beiden Kapitel zeigt, daB die 
vergangenen Geschehnisse in $\mathrm{Z}$ einen breiten Raum einnehmen und vor allem im ersten Teil die gegenwärtigen Ereignisse überlagern und in den Hintergrund drängen. Wesentlich ist, daß die Chronologie nicht nur bei der Darstellung der Vorzeithandlung, sondern auch im Rahmen der Gegenwartshandlung weitgehend ungestellt und zum Teil auch aufgehoben wird.

4. Prinzip der Kapiteleinteilung

Die den äußeren Aufbau bestimmende Gliederung in Kapitel ist im Gegensatz zu allen anderen Gliederungsfaktoren verhältnismäBig einfach zu erfassen, da sie unmittelbar nach außen sichtbar wird.

Für die Romane Krležas gilt, daß die Kapitel in der Regel eine abgeschlossene Einheit bilden und nicht ineinander übergreifen. Die Kapitelschlüsse sind wirkliche Abschlüsse und die Anfänge kommen jeweils einem Neueinsatz gleich. Abgesehen von FI tragen die Kapitel tberschriften, die auf das Mittelpunktsereignis hinweisen; manchmal geschieht dies in ironischer Form. 33 während die Kapitel der ersten beiden Romane, vor allem die von FL, kürzeren Umfangs sind und in der Regel ein Hauptereignis zum Inhalt haben, das sich an einem Ort abspielt, überwiegen in den beiden folkenden Romanen längere Kapitel, die öfter verschiedene Situationen umfassen und einen Ortswechsel mit sich bringen.

Die ersten Kapitel von PL beginnen in einer für Krležas Romane typischen Weise: ähnlich unvermittelt wie seine Romane setzen auch die einzelnen Kapitel ein. Krleža nennt den Namen der Person, die im Mittelpunkt des Kapitels steht

\footnotetext{
33 Das Kapitel, in dem die Gerichtsverhandlung gegen den Ich-Erzähler stattfindet, ist in ironischer Anspielung auf Dostojevskijs "Prestuplenie i nakazanie" "zlotin i kazna" betitelt (NRP, 108).
} 
und meist auch Ort und Zeit. Uberdies wird häufig auch mit den ersten Worten das Thema des Kapitels angeschlagen.

Die Sonne drang schon durch die Kronen der Iinden und der Maulbeerbäume, als Pilip die Brüdergasse hinab zurückkam. Die Trafik war offen, und Pilip fand sich vor der Theke (...). (FL, 27)

Mit jeweils wenigen Worten wird die neue Situation umrissen, um sofort mit szenischer Darstellung, monologischer Reflexion oder dem Bericht des Erzählers zu beginnen.

Auch die Kapitelschlüsse von PI welsen bereits die für die übrigen Romane bestimmende Form auf. Der Schluß des Kapitels fällt mit dem AbschluB eines bestimmten Geschehens oder einer Reflexion zusammen. Im ersten Tell des Romans geht Pilip zum Beispiel zu den verschledenen Orten, die mit seiner $\mathrm{Kindheit}$ in Verbindung stehen. Das vergangene Ereignis wird in diesem Zusammenhang vergegenwärtigt und Pilip verläBt den feweiligen Ort wieder, um sich zu einem anderen zu begeben. Ortswechsel und KapitelschluB fallen somit zusammen.

Die Kapitel von PL werden meist durch einige zusammenfassende und abschließende Sätze des Erzählers beendet und klingen ruhig aus. Reflexionen der Romanpersonen werden häufig durch einen Autor-Kommentar zum Abschluß gebracht. Besonders ausgeprägt kommt diese Tendenz, das Kapitel gleichsam mit einem Rahmen zu versehen, in Kap. 19 zum Ausdruck. Mit last denselben Worten, mit denen der Gedankenmonolog Balotanskis elngeführt murde, wird das Kapitel abgeschlossen. 34 Erst im letzten Drittel des Romans beginnen die Kapitel mit zunehmender zeitlicher Konzentrierung und dramatischer Zuspitzung zum Teil ineinander überzugehen. Elnige Kapitelschlüsse bleiben offen, und der Zusammenhang der letzten Kapitel 1st verhältnismäßig eng.

34 Vgl. FI, 156, 161. Mit einem ebensolchen Rahmen werden auch die Reflexionen des erlebenden Ich in Krankenhaus ungeben. VGI. NRP, 252, 2581 . 
Im allgemeinen enden die Kapitel auf der Ebene der Handlungsgegenwart. Wir finden jedoch in jedem Roman zumindest ein Kapitel, das mit der Vergangenheitsebene abschliebt. In FI sind dies Kap. 13 und die Kapitel, in denen die Vorgeschichte Ksenijas und Balotanskis gebracht wird (15-20). Erst mit dem letzten dieser Kapitel wird der AnschluB an die Handlungsgegenwart wieder vollzogen. In NRP sind dies Kap. 9, in BB III, 8, in ZI, 2.

Während in NRP die Kapitel meist durch das erzählende Ich begonnen werden, das hier die Aufgabe des Erzählers übernimmt und in die neue Situation elnführt, enden die Kapitel im Gegensatz zu FI in der Mehrzahl szentsch mit einem Gespräch oder einem Monolog des erlebenden Ich. Noch ausgeprägter als in FI sind die Kapitel des zweiten Romans für sich bestehende Einheiten. Die einzelnen Kapitel sind gleichsam die verschiedenen Stationen auf dem Teg des IchErzählers vom angesehenen Bürger zum Irrenhausinsassen.

Wesentlich häufiger als in den ersten beiden Romanen enden die Kapitel der letzten beiden Romane szenisch. Das Kapitelende fällt häufig mit dem Abschluß einer Gesprächsszene und mit dem Abgang eines oder mehrerer Gesprächsteilnehmer zusammen. Manchmal ist auch ein Ortswechsel AnlaB, ein neues Kapitel zu beginnen. Diese Schlüsse, die in den ersten beiden Büchern von $B B$ und in $Z$ sehr häufig sind, erinnern an den Szenenwechsel in Drama. In BB beginnen auch einige Kapitel unmittelbar mit einem Gespräch oder einem Monolog, der durch einen kurzen Autor-Kommentar eingerührt wird. Charakteristisch für $Z$ ist die Anwesenheit des Erzählers zu Beginn des Kapitels. In diesem Roman umreiBt er nicht mehr nur wie in FI oder in BB in wenigen Worten die Situation des neueinsetzenden Kapitels, sondern er nimmt zukünftiges Geschehen vorweg und wendet sich an den Ieser. In BB treffen wir lediglich auf einen solchen Kapitelbeginn (III, 9). 
5. Funktion und Integration der selbständigen Teile

In den letzten beiden großen Romanen Krležas stoßen wir auf eine ganze Reihe von Briefen und Zeitungsartikel, auf ein Tagebuch, einen psychoanalytischen Befund und vor allem auf das Drama "Puppen". Uns interessiert in diesem Zusammenhang lediglich die Rolle, die diese verhältnismäßig selbständigen Handlungsteile für die Struktur der Romane spielen, nicht jedoch das Spiel mit Fiktion und Wirklichkeit, dem diese fingierten Einheiten letztlich dienen.

Die meisten Erzähleinheiten dieser Art finden wir in dem weitgehend szenisch gestalteten Roman BB. Ihre Funktion ist damit bereits angedeutet: sie dienen der Mittellung von Geschehen und der Charakterisierung von Personen. In BB haben wir fünf Briefe, das Konzept zu einem Brief und den kurzen Briefwechsel zwischen Karin und Nielsen. Der kompositorisch wichtigste Brief ist der offene Brief Nielsens an Barutanski, der den AnstoB für alle folgenden Ereignisse gibt. 35 Georgis überbringt den soeben erschienenen Brief an Barutanski, der ihn liest. Wie sorgfältig Krleža diese selbständigen Einheiten mit der Handlung verbindet, beweist bereits dieser erste Brief. Barutanski liest den Brief nicht in einem Zug durch, sondern er bricht immer wieder mit seiner Lektüre ab, empört sich über dessen Inhalt und weigert sich weiterzulesen. Georgis muB ihn geradezu antreiben, den Brief zu lesen. Gespräch und Lektüre ergänzen einander. Ist der Empfänger eines Briefes allein, so tritt an die Stelle des Gesprächs über den Inhalt des Briefes und den Absender monologische Reflexion des Empfängers. So etwa reflektiert Nielsen über den Brief Blithauers.

Während in $\mathrm{BB}$ eine Reihe von Briefen in die Handlung in-

35 Dieselbe Rolle für die Romanhandlung spielt der Artikel von Kamilo in 2 . Krleža äuBert sich in Form eines ironischen Autor-Kommentars über die kompositorische Bedeutung dieses Artikels $(2,1,588$ f). Vgl. Kap. V, S. 195. 
tegriert werden und Zeltungsartikel eine untergeordnete Rolle spielen, ist es in $Z$ umgekehrt. Die wenigen Briefe oder Telegramme dienen in erster Linie der Handlung. Wesentlich vielschichtiger ist jedoch die Funktion der Ze1tungsartikel. Handlungsfördernde Punktion kommt lediglich dem ersten Artikel Kamilos zu. Viel wichtiger ist jedoch die Tatsache, daB diese in Zeitungen veröffentlichten Aufsätze Kamilos heftige Pamphlete sind, in denen er zeitgeschichtliche politische Institutionen und deren Vertreter angreift. Auf diese Weise wird die aktuelle politische Problematik in den Roman einbezogen und die Exponenten dieser Politik werden von einer Romanperson entlart. Außer den pamphletartigen Zeitungsartikeln Kamilos werden noch eine Reihe anderer Artikel aus verschiedenen Tagesze1tungen zitiert, die sich ausschlieblich auf politische Ereignisse beziehen und die Situation der Zeit widerspiegeln. Die Integrierung wird auf ähnliche Weise vollzogen wie bel den Briefen: eine Romanperson liest den Artikel und anschlleßend wird über den Inhalt diskutiert oder reflektlert.

Das Tagebuch Karins und der psychoanalytische Befund über die Persönlichkeit Nielsens sind von wesentlicher Bedeutung für die Beurteilung Nielsens als individuelle Gestalt. Uberdies erhalten wir durch das Tagebuch und die sich daran anknüpfenden Reflexionen Nielsens AufschluB über das Wesen und die Motive der geheimnisvollen Karin, von der wir hier erstmals etwas durch sie selbst erfahren. liehrmals wird hervorgehoben, daB das Tagebuch vertraulicher und intimer Natur sei (F, 154 f., 163). Nicht zuletzt dient das Tagebuch der Nachholung von Ereignissen, die vor Einsetzen der Romanhandlung liegen. Die Integrierung erfolgt dadurch, daß Nielsen das Tagebuch liest und darüber reflektiert. Zweimal unterbrechen Gedankengänge Nielsens die Lektüre des Tagebuches. Im folgenden Kapitel werden die Tagebuchnotizen Karins überdies noch durch Erinnerungen Nielsens an die gemeinsame Zeit ergänzt. Der psychoanalytische 
Befund wird ron Barutanski gelesen und kommentiert, wobei interessante Parallelen zwischen den beiden scheinbar so gegensätzlichen Romanpersonen sichtbar werden. Erstmals erfahren wir hier etwas über die Herkunft und Kindheit Nielsens. Als Kind weist Nielsen bereits die Eigenschaften und Merkmale des typischen Helden der Romane Krležas auf.

Im Gegensatz zu den bisher angeführten Erzähleinheiten, die jeweils nur der Nachholung, Zusammenfassung oder Auslösung der Handlung, sowie der Cherakterisierung der Romanpersonen und der Darlegung gedanklicher oder zeitgeschichtlicher Problematik dienen und somit im wesentlichen immer nur jeweils einen Aspekt der Handlung beleuchten, wrd in den "Puppen" die Struktur des gesamten Romans sichtbar. Dieses Spiel im Spiel bietet sozusagen das gedankliche Konzentrat von BB. ${ }^{36}$ Werfen wir einen kurzen Blick auf das spiel "Puppen", mit dem Buch II von BB abgeschlossen wird.

Nielsen lemt anläBlich seines Aufenthaltes in Blatwien den blatwischen Dichter Baltik kennen, der ihn zur Premiere seines Dramas "Puppen" einlädt. Noch bevor Nielsen der Aufführung beiwohnt, erklärt ihm Baltik ausführlich die Idee des Stückes. Es handelt sich um eine Komödie, ein'symbolisches Stück in fünf Bildern, Prolog und Epilog, die in einem Marionettentheater spielt und "Puppen" betitelt ist. Die Hauptrolle spielt die Marionette Yorik, eine Art blatwischer Till Eulenspiegel, der immer den kürzeren zieht. Als Puppe spielt Yorik immer ein und dieselbe Rolle, denn er ist an den Faden gebunden und damit gezwungen, diese Rolle auch gegen seinen willen zu spielen. Andererseits aber ist sich Yorik seiner Tragödie als Puppe bewußt und lehnt sich gegen den Faden auf. Im Prolog des Stückes, der hinter den Kulissen des Marionettentheaters beginnt, versucht Yorik, die anderen Puppen aufuwiegeln und den Faden zu zerschnei-

36 Vgl. Malic, Zdravko: Lutke. Pokušaj rekonstrukcije autorskog komentara u "Banketu u Blitvi". In: UR, ?, 1963, 185. 
den. Bevor es jedoch zu diesem Aufstand der Puppen kommt, ertönt der Gong und die Vorstellung im Marionettentheater beginnt.

Das Stück, das die Puppen vorführen, heiBt die "Komödie Yoriks". Hir haben demnach nicht nur ein Spiel im Spiel vor uns, sondern eine dreifache Staffelung: 1. die Handlung des Romans BB (Nielsen sitzt als Zuschauer im Theater); 2. das Drama "Puppen"; 3. die Marionettenvorstellung "Komödie Yoriks", die sich innerhalb der "Puppen"-Vorstellung abspielt. Drei Handlungsebenen gehen hier ineinander über. Krleža verknüpft das "Puppen"-Spiel, das eine in sich geschlossene Einheit darstellt, nicht nur im Hinblick auf den Gehalt mit der Handlung des Romans, sondern auch äußerlich. Nielsen ist Zuschauer der Aufführung und wir erfahren nur so lange, was auf der Bühne vor sich geht, wie Nielsen das Geschehen verfolgt. In dem Moment, in dem er mit seinen Gedanken abschweift, werden diese Gedanken wiedergegeben und die Ereignisse auf der Bühne vernachlässigt. Außerdem reagiert Nielsen unmittelbar auf das Stück selbst. Ein Satz Yoriks löst bei ihm eine kurze Gedankenassoziation aus (BB, 394).

In welchem Maße in den "Puppen" die Idee des ganzen Romans expliziert und die Auffassung Krležas von der Welt dieses Romans als großem Puppentheater konkret formuliert wird, zeigen die vielfältigen Bezüge, die zwischen Roman und Marionettenspiel bestehen. Nicht nur das Drama "Puppen" verfügt über Prolog und Epilog, sondern auch der Roman BB. Bereits im Prolog von BB definiert Krleža diesen Roman als "mittelalterliches Spiel, in dem zwei ritterliche Gestalten die Hauptrollen spielen." (BB, 24) ${ }^{-}$In Anknüpfung an das Theater des Mittelalters kündigt der Erzähler die Handlung des Romans mit folgenden Worten an: "Incipit comoedia blithuanica!" ( $B B, 25)$ Mit derselben Formel wird die "Komödie Yoriks" eröffnet (BB, 393). Baltik bezeichnet sein Stück als symbolisches Drama und als 
romantische Komödie in Versen. Krleža überschreibt den Prolog des Romans folgendermaBen: "Eine Art von Prolog oder sentimentaler Variation über die blitwische Frage durch die Jahrhunderte." Nielsen wird vom Erzähler im Prolog von BB als "Romantiker" bezeichnet, der in "dieser traurigen blitwischen Historie" eine wichtige Rolle spielt. (BB, 15 f.)

Der ganze Roman ist von solchen Hinweisen auf die Konzeption als Tragikfarce und politisches Puppentheater durchzogen. Dabei erweist es sich, daB die Vorstellung des Erzählers von der blitwisch-blatwischen Welt mit der der Romanpersonen identisch 1st. 37 Barutanski, der sich mit einem Schauspieler vergleicht, bezeichnet das Geschehen auf Beauregard als "blitwische Komödie" (BB, 37 f.).

Er glaubte an Dynamit, Kanonen und an die Gewait (...), er maskierte sich und verbarg sich hinter seiner Maske als Oberst Barutanski, und auch dieser "Oberst Barutanski" war nur eine Maske unter den vielen auf diesem Ball, der sich Blitwien nennt $(. .$.$) .$ $(\mathrm{F}, 77)$

Blithauers Worte 38 klingen ähnlich wie die Barutanskis, und selbst der ausgesprochen negativ gezeichnete Pater Baltrusajtis vergleicht das politische Geschehen mit einem Marionettentheater und definiert den Typ des Politikers, wie ihn Barutanski oder Bellonen darstellen, mit fast denselben Worten (BB, 196) wie der Erzähler, der Barutanskis Sicht der Dinge als "ritterliche Weltanschauung" bezeichnet (BB, 210). Ganz deutlich wird die Parallele am SchluB des letzten Kapitels von $B B$ gezogen. Masnov ist eine von den vielen "serienmäBig hergestellten Basarpuppen, die aufgezogen sind wie der Mechanismus der Blechritter auf dem

\section{$37 \mathrm{Vgl}$. Kap. V, S. $211 \mathrm{ff}$.}

$38 \mathrm{Vgl} . \mathrm{F}, 104$. Blithauers Xußerungen über die Wirklichkeit als Theatervorstellung stimmen mit denen des IchErzählers überein. Vgl. Kad. V, S. $211 \mathrm{ff}$. 
alten Stadtturm von Blitwinsk":

sie kommen, heben ihre Trompete mit einem

Fähnchen hoch und verschwinden, nachdem sie felerlich ihre Arie abgespielt haben, in die rechte Kulisse der dekorativen Bühne (...). $(\mathrm{F}, 236)$

Barutanskis Reflexion über die politischen Geschehnisse kurz vor Schluß des Romans, als er im Begriff ist, mit seinen Truppen den Nachbarstaat zu besetzen, beleuchtet den operettenhaften Charakter des Geschehens auf der politischen Bühne Blitwiens oder Blatwiens oder irgendeines anderen Staates und bestätigen die Worte des Erzählers im Prolog ( $B B, 13$ f.).

Wie die Herren bei einer Quadrille beim Damenwechsel linksum auf ihren Platz zurückkehren, so marschiert dann Bellonen nach Vajda-Hunnen und Barutanski nach Ankersgaden (...). $(F, 186)$

Der Staatsstreich Bellonens - "Bellonens feierliche Galavorstellung" ( $F, 192)$ - bildet den Gipfel dieses Melodramas. Es gelingt inm zwar, nach langen Vorbereitungen endlich die Regierung Blatwitzki zu stürzen, aber er kann sich nur eine Nacht lang an der Spitze Blatwiens halten Bereits am Morgen nach dem Putsch erscheint Blatwitzki auf Grund der Intervention der Großmächte wieder in seinem Amt. Dieser Staatsstreich ist nichts weiter als eine Farce:

So marionettenhaft wie er /Bellonen/ auf der blatwischen Bühne als Pantalone aufgetaucht war, so verschwand der Feldmarschalleutnant auch wieder, er empfahl sich telefonisch und rauschte mit seiner Hispano-Suisse Maschine über die hunnische Grenze (...). $(\mathrm{F}, 193)$

Das vom Erzähler als melodramatisch bezeichnete Ende Barutanskis ist dem farcenhaften Charakter des Spiels angepaBt. Barutanski wird auf dem Höhepunkt seiner Macht auf einem abendlichen Bankett gerade in Jenem Moment, als das Orchester die "Spanische Romanze" von Chabrier intoniert, 
durch einen einzigen RevolverschuB seines Adjutanten von der "blitwischen Bühne" hinweggefegt ( $F, 180)$.

Sind all diese Parallelen zwischen der Handlung des Romans und dem "Puppen"-Spiel bereits deutlich genug, so wird in den Monologen Nielsens in Buch III der symbolische Gehalt der "Puppen" ganz direkt zur Handlung von BB in Beziehung gesetzt und die Parallelen aufgezeigt. 39 Nielsen spielt die Rolle des blatwischen Till Eulenspiegels Yorik, der sich als einziger gegen den "unsichtbaren Inspizienten" aurlehnt, der sie alle zwingt, ihre immer gleiche Rolle zu spielen. Der "Faden" ("Nit") oder der "unsichtbare Regisseur" ("Nevidlfivi Redatelj") ist das Symbol für den geschichtlichen Determinismus. Hier kommt Krležas Auffassung zum Ausdruck, daß die Geschichte nur eine Wiederholung-immer gleicher Situationen ist. Der Mensch ist letztlich unfrei, denn sein Schicksal wird durch gesellschaftliche und historische Mechanismen bestimmt. ${ }^{40}$ Genauso wie Yorik erweist sich auch Nielsen als machtlos, denn Jegliche individuelle Revolte ist von vornherein zum Scheitern verurteilt. Nielsen muB am SchluB des Romans einsehen, daß Blithauer Recht hatte, als er behauptete, daB sich mit dem Sturz Barutanskis in Blitwien nichts ändern würde - selbst dann nicht, wenn der neue Machthaber Nielsen hieBe. ${ }^{41}$ Yoriks Worte über seine Rolle, die er als lächerlich empfindet - lächerlich im Hinblick auf die Wirksamkeit seiner Auflehnung - stimmen mit denen von Kyparis und Blithauer überein, die sich beide in diesem Sinn über Nielsen äußern. 42

Im "Puppen"-Spiel ist in nuce der gesamte Roman enthalten, und die Konzeption Krlezas von der Welt des Romans

\footnotetext{
$39 \mathrm{VGl} . \mathrm{F}, 152,205,224,225 \mathrm{f} ., 231,241 \mathrm{f}$.

$40 \mathrm{Vgl}$. BB, 383 f., 391 f. Vgl. weiterhin Kap. VI, S. 239 f. 41 Blithauer (F, 91), Nielsen (F, 153 f., 204, 241 f.).

42 Yorik (BB, 383, 391 f.), Kyparis (F, 237), Blithauer (F, 91).
} 
kommt hier in konzentrierter und fast überdeutlicher Form zum Ausdruck. Der imaginäre Staat Blitwien 1st eln relnes Symbol und das Geschehen, das sich in BB abspielt, ist auf die Ebene eines Puppensplels projiziert, das Krleža die adäquateste Form $2 u$ sein scheint, um die Erelgnisse der faschistischen Ara darstellen zu können.

6. Tberlagerung der Handlung durch Reflexion

Im Hinblick auf die Handlung seiner Romane ist Krleža ein ausgesprochen moderner Autor. Das auf Spannungserzeugung gerichtete Handlungsgerüst oder die Fabel verliert an Bedeutung und wird zugunsten essayist1scher Elemente zurückgedrängt. Der moderne Roman 1st gekennzeichnet durch die Infragestellung der Fabel und durch die Eliminierung des Romanhaften. Krležas Bemerkung in "Moj obračun s njima" (S. 205) - "mase opisnih popratnosti samo su instrumentativne sporednosti" - erinnert an die Worte, die Edouard in André Gides Roman "Les Faux-Monnayeurs" in sein Tagebuch einträgt: "Dépouiller le roman de tous les éléments qui n'appartiennent pas spécifiquement au roman $(.$.$) . Méme la description des$ personnages ne me parait point appartenir proprement au genre." 43 Edouard träumt davon, einen "roman pur" zu schre1ben, der an die Stelle des traditionellen Handlungsromans tritt und in den er a $l 1$ e $s$ einbeziehen will. Es wurde bereits erwähnt, daß Krleža bestrebt ist, die Geschehnlsse in ibrer Gleichzeitigkeit und Vielfalt darzustellen - eine Tendenz, die die "kunstvoll konstrulerte Verflechtung und Ineinanderschachtelung simultaner Handlungsabläufe" zur Folge hat. ${ }^{44}$ Es würde $z u$ weit gehen, bei Krležas Romanen

\footnotetext{
43 Paris 1929, S. 97.

44 Vgl. K.R. Mandelkow, S. 38.
} 
von Entfabelung zu sprechen, die Handlung wird in ihrer Bedeutung lediglich reduziert und durch Reflexion überlagert. Das Eindringen des Essayismus in den Roman des zwanzigsten Jahrhunderts und die damit verbundene Uberfremdung des Romans durch Reflexion kommt jedoch Krležas Haltung als Erzähler sowie seiner umfassenden Bildung und seinem allseitigen Interesse sehr entgegen. W. Jens' Worte, "die moderne Dichtung ist niemals nur Poesie, sondern immer zugleich Wissenschaft und Philosophie" 45 , die die wissenschaftsgebundene Haltung des modernen Dichters umreißen, gelten auch für Krleža, der folgendes in sein Tagebuch einträgt:

Der Schriftsteller mu3 in erster Linie Denker sein, der über die Dinge klar, sachlich und ganz logisch nachdenkt. Der Schriftsteller muß, wenn er seines Berufes würdig ist, (wie ein Gelehrter) die einzelnen Beispiele an Präparaten erläutern $(\ldots)$. (DD, $157 \mathrm{f.}$ )

Für elle Bomane Krležas gilt, daß der Schwerpunkt nicht auf der Handlung liegt und daB die reflexiven Elemente zumindest gleichberechtigt neben die erzählerischen Teile treten, wenn sie nicht sogar vorherrschen. Die langen Diskussionen und Reflexionen gehen häufig um philosophische, kulturhistorische, gesellschaftliche, politische, geschichtliche und allgemeinmenschliche Fragen, die zur Handlung in keiner oder nur in sehr loser Beziehung stehen. Das konkrete Geschehen wird auf weite Strecken zugunsten des Gedanklichen und Abstrakten verdrängt. Die essayistischen Teile erweisen sich als ein den großen Erzählstrom sprengendes Formelement, da sie das gesamte Romangefüge durchdringen. Der letzte Roman $\mathrm{Z}$ bietet das beste Beispiel für diese Tendenz. Andererseits hat die Einbeziehung von aktuellen politischen und gesellschaftskritischen Fragen sowie von Problemen allgemeiner Art eine Ausweitung und Vertiefung der

45 Statt einer Literaturgeschichte. Pfullingen 1957, S. 14. 
gedanklichen Problematik zur Folge. "Der Erzähler betätigt sich in diesen essayistischen Kapiteln ausschlieBlich als Denker; er behält die Erzählfäden in der Hand, webt aber an ihnen nicht weiter. ${ }^{46}$

Die problemgeladenen Monologe und Dialoge machen einen erheblichen Teil des Gesamtumfangs der Romane Krležas aus - in den letzten beiden Romanen verstärkt sich diese Tendenz - und drängen die romanhafte Handlung in den Hintergrund. Da Krleza jedoch keineswegs so weit geht, die Handlung bis auf einige wenige Reste zu eliminieren - im Grunde ist er ein großer und leidenschaftlicher Erzähler mit viel Sinn für dramatische Wirkungen -, groBo Teile der Romane jedoch auf Grund von Reflexion und theoretischer Diskussion handlungslos bleiben, konzentriert er die Darstellung stets auf einige wenige Brennpunkte des Geschehens und drëngt vor allem mehrere Ereignisse auf einen kurzen Zeitraum zusammen, wie dies die Untersuchung der Zeitverhältnisse in den Romanen zeigte. Diese Darstellungstechnik bewirkt, daB seine Romane trotz starker Theoretisierung den Eindruck erwekken, es geschehe viel, und daB immer wieder ihre Dynamik hervorgehoben wird. In Wirklichkeit geschieht wentg in KrleZas Romanen - vor allem auf der Handlungsebene. Ein Teil der gegenwärtigen Geschehnisse spielt sich überdies nicht im Vordergrund $a b$, sondern hinter der "Bühne". Erweitert und vertieft wird das magere Handlungsgerüst jedoch durch die Einbeziehung vergangener Ereignisse, die die Handlungsgegenwart durchdringen und überlagern.

46 Berger, Bruno: Der Essay. Form und Geschichte. Bern und München 1964. ( = Sammlg. Dalp. Bd 95.), S. 131. 
X A P I T E L IV

DER I C E - ROLA N

("Am Rande des Verstandes")

NRP ist der einzige Roman, den Krleža in der Ich-Form abgefabt hat. Eingangs sei kurz auf die besonderen Eigenheiten hingewiesen, die sich aus der Erzählsituation des Ich-Romans ergeben.

Im Ich-Roman tritt der Erzähler als Figur der dargestellten Welt auf, ist also Bestandteil der Fiktion. ${ }^{1}$ Die Verwendung des Pronomens der 1. Person Singular bekräftigt diese Identität des Erzählers mit einer Gestalt der fiktiven Welt. Im Gegensatz zum Er-Roman beruht die Illusion der Wirklichkeit im Ich-Roman nicht auf der objektiven Niedergabe von Geschehnissen, sondern gerade auf der Betonung der Subjektivität. Ein greifbarer Erzähler trägt seine eigenen Erlebnisse vor oder solche, von denen er auf irgendeine Weise erfahren hat. Er verbürgt sich für die Wahrheit der erzählten Geschehnisse. Der Anspruch des Romans, als wahre und nicht als erfundene Geschichte zu gelten, wird auf diese Weise weit stärker unterstrichen als im Er-Roman. ${ }^{2}$ Was den Autor im Ich-Roman betrifft, so hat

1 Vgl. Stanzel, Franz: Die typischen Erzäblsituationen im Roman, S. 61 .

2 Vgl. Forstreuter, Kurt: Die deutsche Ich-Erzählung. Eine Studie zu ihrer Geschichte und Technik. Berlin 1924 (= German. Studien. H. 33.), S. 48 . 
er sich hier am weitestgehenden objektiviert. "The author has vanished from the scene (...)." 3 Fr übergibt die gesamte Verantwortung für das Dargestellte an diesen Erzähler, der zwar die Rolle des Autors übernommen hat, nicht aber dieselbe Freiheit wie jener genieben kann.

Der besondere Reiz der Ich-Erzählung ergibt sich jedoch nicht nur aus der Subjektivität der Darstellung, aus der Brechung der Geschehnisse durch einen ganz bestimmten Gesichtswinkel. In all Jenen Romanen, in denen der Erzähler die Mittelpunktstellung einnimmt - und nur diese werden bier in Betracht gezogen - werden wir mit zwei verschiedenen Ich konfrontiert, die beide in der Figur des Erzählers vereinigt sind: dem erlebenden und dem erzählenden. Einerseits erscheint das Ich als "Gegenstand" der Erzählung, das die erzählten Ereignisse erlebt, andererselts als Ich, das diese Geschehnisse aus rückblickender sicht erzählt und betrachtet. Die Erzähldistanz, d.h. "der zeltliche Abstand des Erzählaktes rom Erzählten" und damit von den Erlebnlssen des erlebenden $\mathrm{Ich}^{4}$ bestimmt die Haltung der beiden Ich zueinander: groBe zeitliche Entfernung, d.h. Distanz, Obersicht und stärkere Objektivität, oder zeitliche Nähe, d.h. starkes Mitempinden und Miterleben von Seiten des erzählenden Ich. Es entsteht Infolgedessen eine doppelte Perspektive: die "unwissende", zukunftsungewisse des erlebenden Ich und die "wissende", retrospektive und daher überschauende des erzählenden Ich. Fntsprechend dieser Zwelpoligkeit sleht der Leser sich mit zwel verschiedenen Zeltebenen konfrontiert: mit der der gegenwärtigen zeit, die der Zeit des Erzählaktes und damit der epischen Situation des Erzählers entspricht, und mit der der vergangenen zeit,

3 Romberg, Bertil: Studies in the Narrative Technique of the Pirst-Person Novel. Stockholm 1962, S. 29.

4

Stanzel, Pranz: Die typlschen Erzählsituationen in Roman, S. 66 . 
in der sich der Erzähler als erlebendes und handelndes Ich bewegt.

In NRP, elner heftigen Satire auf die bürgerliche Gesellschaft Zagrebs der dreibiger Jahre, 1st der Ich-Erzähler zugleich Hauptheld des Romans, der sein eigenes Leben und Erleben erzählt. Er gehört selbst der angegriffenen Schicht ron Menschen an und hat 2wanzig (oder dre1Big) Jah$r^{5}$ lang nach dem erstarrten konventionellen schema des $\mathrm{ZJ}-$ linderträgers mitten unter seinen Mitbürgern gelebt. Er kennt sie somit gut genug, un die Berechtigung und Befähigung zur Kritik erlangt zu haben und um hinter die Masken blicken zu können. AuBerdem 1st er noch Doktor der Rechte und arbeitete jahrelang als Anwalt der Menschen, die er unerbittlich entlarvt. Die Befähigung zur Distanz, zu überlegener tbersicht und damit zur Kritik am Zjlinderträger als der Verkörperung der menschlichen Dummbeit erlangt der IchErzähler mit Hilfe des alten literarischen Motivs der inneren Omkehr. Als Zwelundfünfzigjähriger bricht er radikal mit seinem bisherigen Leben und gerät dadurch in Konflikt mit seiner Ungebung, die ibr Verhalten inm gegenüber schlagartig wandelt. Die Entlarvung seiner Mitbürger geschieht jedoch nicht nur durch seine direkten Angriffe und Enthüllungen, sondern auch auf lndirekte und weit wirksamere Weise. Sie zeigen ihr wahres Gesicht erst von jenem Moment ab, als der Ich-Erzähler die Wahrheit ausspricht und es wagt, sich gegen die Gesellschaft zu stellen. So lemt der Ich-Erzähler seine Prau in den wenlgen Tagen direkt nach seinem Um-

5 Mehrmals sagt der Ich-Erzähler, er habe dreiBlg Jahre lang als Zjlinderträger gelebt ( $\mathrm{S} .19,30,51,79,258)$. Andererseits behauptet er jedoch, daB es $81 \mathrm{ch}$ nur um zwanzig Jahre handelt (S. 81, 186, 190, 254). Der negative Umbruch des Ich-Erzählers zum Zylinderträger vollzieht sich anschlieBend an die Affäre mit Vanda, die sich 1916/1917 abspielte (S. 196). Es lst aus diesem Grunde kaum anzunehmen, daB das Bürger-Dasein des Ich-Erzählers dreiBig Jahre umfaBt, da NRP 1938 erschien. 
schmung wesentlich besser kennen als in den vierundzwanzif Jahren threr Ehe (S. 43).6

Die Erzählsituation wird glelch zu Beginn des 1. Kapitels angegeben, um im weiteren Verlauf immer näher präzisiert zu werden. Etwa zwel Jahre nach seinem Umschmung beginnt der Ich-Erzähler mit der Vergegenwärtigung seines ungewöhnlichen Lebenslaufes, der an einem Septemberabend bel Domacinsk1 seinen Anfang nahm. Außerdem erzählt er einlge Eplsoden aus seinem Leben, die zeitlich vor jenem einschneldenden Ereifn1s llegen. Die Erzähldistanz gegenüber dem gröBten Tell der Geschehnisse beträgt infolgedessen höchstens zwel Jahre, verringert sich jodoch mit dem Fortschreiten der Erzählung immer mehr, um schlleBlich völlig zusammenzuschrumpfon. Die Handlungsgegenwart mündet in etwa in die Erzählgegenwart ein.? Der genaue Zeitpunkt der Erzählsituation wird nicht angegeben, wir erhalten nur den unbestimnten Hinweis "nachts" und "in letzter Zeit" (S. 9).

Gleich auf der ersten Selte bezelchnet der Ich-Erzähler seine Erzählung als " 1 n t 1 mes, ha l b l a u t e 8 S e l b s t g e s p r ä C h ". Dieser Monolog des Ich-Erzählere rechnet in Gegensatz zum Normalfall, wo keine Hörer vorhanden sind, mit der Anwesenheit von Hörern oder Lesern. Er spricht sie ausdrücklich an und bezieht sle mit eln. Die $\mathrm{Ab}-$ sicht, sich mitzutellen und vor allem der Funsch, die inner-

6 In diesem Kapitel beziehen sich die in Klammern gesetzten Seitenzahlen ausschließlich auf den Roman NRP.

7 Die Zeitstrecke, die zwischen dem Finde und dem Beginn des Romans llegt, muB aus folgenden Grund kurz sein: gegen Fnde des Romans finden wr den soeben aus dem Irrenhaus entlassenen Ich-Erzähler an einem Sommerabend in seiner Wohnung wieder. Zu Beginn des Romans gibt er seine Erzählsituation mit. folgenden Worten an: "diesen Herbst werden es zwel Jahre her seln" (S. 26). Fr bezleht sich mit dieser Angabe auf das 1 bendessen bel Domarinski, das im September, knapp zwe1 Jahre vor der Entlassung des Ich-Erzählers aus dem Irrenhaus, stattfand. 
liche Betelligung des Hörers oder Iesers zu aktivieren, kommen unverkennbar zum Ausdruck. ${ }^{8}$ Ganz abgesehen von den Ansprachen an den Leser, geben die Interfektionen und rhetorischen Fragen, die der Erzähler an sich selbst richtet und beantwortet, sowie ein ganz persönliches, 1ronisch gefärbtes Spracheluldum innerhalb der Wortfolge den Anschein elnes Gesprächs, wenn auch eines Gesprächs mit sich selbst.

Obwohl der Ich-Erzähler eingangs eine mündliche epische Situation vorgibt, Finden sich im Roman auch mehrere Stellen, die auf die schriftliche, auf die epische situation der Niederschrift hinweisen:

Niederzuschreiben, daB mich diese Nachricht erschütterte, wëre unwahr.

(S. 286)

Vor allem jedoch deutet die Motivierung des Ich-Erzählers, warum er überhaupt erzählt, auf die Situation der Niederschrift:

(...) in einem Wort: über mich, über mein persönliches, privates oder öffentliches Leben hätte man keinen einzigen Satz schreiben können, der aus dem Rahmen der normalsten Vorschriften eines grauen, unpersönlichen Schemas gefallen wäre $(\ldots .$.$) .$

(S. 16 p.)

Die Befählgung und vor allem die Neigung des Ich-Erzählers, sich schriftlich zu äußern, die seiner gesellschaftskrit1schen Absicht entspringt, kommt mehrmals zum Ausdruck (S. 81 f.., 235, 268 f.).

Der AnlaB der Erzählung, das Generalthema des gesamten Romans und zuglelch der Ausgangspunkt der 1ronischen Reflexion des Ich-Erzählers, ist die menschliche Dummbeit. Mit gesplelter Ironie erklärt er, $d a \beta$ es keine so leichte Aufgabe sei, die menschliche Dumbelt zu enträtseln (S. 10). Andererseits betont er jedoch sofort seine Befählgung, sich über dieses Thema zu äußern. So sagt er, er habe die Dumm-

8 Vgl. Kap. V, S. 198 f. 
heit des Zylinderträgers "zlemlich genau studiert", denn er habe die "Ehre und das Glück" gehabt, sein ganzes Leben als Bürger und zjlinderträger zu verbringen (S. 11). Marum er erzählt und warum seine Erzählung gerade diesen Ze1tabschnitt von 2 wei Jahren umfaßt, wird aus folgender Yotivierung deutlich:

(...) die Tatsache, daß eln einziges Wort es
vermochte, ein ganzes Leben davonzutragen wie
einen luftbalion, der sich losgerissen hat
(.. ), das wäre auch mir mehr als unwahrschein-
lich und sogar ein wenig erlogen erschienen,
wenn ich es njcht selbst erlebt hätte und es
seit fast zwei Jahren immer noch erlebte ("da
ga nisam dozivio i da ga ne proživljavam skoro
već pune dvije godine") (...).
(S. 27)

Gleichzeitig betont der Ich-Erzähler damit, daB es sich um sein elgenes Erleben handelt - er infolgedessen befugt 1st, es wiederzugeben - und weiterhtn, daB die Handlungsgegenwart in die Erzählgegenwart einflieBt, der ProzeB noch nicht abgeschlossen ist und zur Zeit der Erzählsituation noch andauert. Das imperfektive Verb "prozivljavam" weist darauf hin, daB die Folgen, die für den Ich-Erzähler aus fenem Yoment der Wahrheit erwuchsen, noch kein Ende gefunden haben. Der SchluB des Romans mus infolgedessen offen bletben.

Der Erzähler führt sich nur schrittreise ein. Erst nach mehrmaligen Ansätzen ergibt sich ein Bild seines Lebens als Bürger, und erst nach zehn Selten erfahren wir, daB das Verhältnis des Frzählers zu seiner Ungebung sich irgendwie verändert haben muB. Auch was den Umschmung betrifft, präzisiert er nur allmählich und schreitet nur nach und nach von elnigen ziemlich unklaren Andeutungen auf die Ereignisse zu ihrer vollständigen Darstellung. Das Bild, das sich im Laufe der ersten Kapitel von der Persönlichkeit des Ich-Erzählers langsam herauskristallisiert, ist nur scheinbar zwlespältig. Dieser 2wiespalt beruht auf der Diskrepanz der Perspektive, ife 2wischen dem Erzähler und der Gesellschaft besteht. So 
werden in NRP wie auch in den anderen Romanen sämtliche positiven Personen auf Grund inrer Andersartigkelt von der Gesellschaft mit negativen und abwertenden Ausdrücken belegt. Da aber gerade die Vertreter der Gesellschaft aus der Sicht des Autors und seiner Helden negativ zu beurteilen sind, kommt eine Abwertung aus deren kund einer gegenteiligen Berertung gleich. Bezelchnend für diese Art der Darstellung 1st die Einführung von Katandic, den der Ich-Erzähler Im Irrenhaus kennenlernt und dessen Schicksal eine Art Parallele zu dem des Ich-Erzählers darstellt (S. 282 f.). KatanĊć und der Ich-Erzähler werden auf Grund 1hrer Menschlichkelt zu Schifforichtgen. Der Wille, sich der entstellten M1rklichkelt nicht anzupassen, verurteilt sle zum Sche1tern. Die satirische Verkehmung der natürlichen Wertordnung, die dieser Perspektivendiskrepanz zugrunde liegt, kommt in den Worten des Ich-Erzählers deutlich zum Ausdruck:

Alle Menschen rälschen Wechsel, elle lassen sich bestechen, um nicht die Wahrheit zu sagen (...), nur die Gestrandeten, die als Gerechte geboren wurden, das he1Bt als Menschen, deren Nerven so zerrütet sind, daB sich ihr Lebensinstinkt der Aufsicht des Gehirns unterordnet, diese werden getreten und bespuckt wie alte Lumpen, weil sie sich nicht in diesem $\mathrm{Zwin-}$ ger zurechtfinden konnten $(. .$.$) .$ (s. 283)

Es ergibt sich folgende verschiedenartige Betrachtungsweise der Person des Ich-Erzählers:

1. der Erzähler $v$ or seinem Unschwung in seinem eigenen Urtell (negativ) und in dem der Gesellschaft (positiv);

2. der Erzähler $n$ a c b seinem Unschrung in seinem elgenen Urte1l (positiv) und in dem der Gesellschaft (negativ).

Zur Veranschaulichung selen einige Belspiele angeführt: Zu 1. Der Ich-Erzähler bezelchnet s1ch als "wohlgeordnete Null in einer Masse wohlgeordneter und grauer Nullen" (S. 16), als "gutmütigen Schrachkopf" (S. 24) und als "eine der traurigen, schwachsinnigen Masken" (S. 48). Er ist der In- 
begriff des Durchschnittsbürgers, des "echten und unverfälschten 'homo cylindriacus'" (S. 283). Die Gesellschaft sieht im Ich-Erzähler einen "schweigsamen, passiven, gutmütigen" Mdtbürger (S. 51). Er wird von allen geachtet und ist allgemein bellebt (S. 18). Zu 2. Der Ich-Erzähler bezeichnet sich als "nervlich sensiblen Einzelnen" (S. 13), als Koralisten (S. 169) und als Menschen (Im Vergleich zur Puppe). Die Gesellschaft sieht in ibrem gewandelten Mitbürger "ein moralisch heruntergekommenes Subjekt" (S. 15), einen "geschlechtskranken Wüstling" (S. 19), "eine politisch gerährliche Person" mit "destruktiven Ansichten" (S. 44), einen "Schwachkopf" und "einen exaltierten, überspannten, närrischen, unzurechnungsfähigen Menschen", der reif fürs Irrenhaus 1st (S. 43 1.). Der IchErzähler führt diese Klischees voller Sarkasmus ad absurdum, indem er sie konsequenterweise in den amtlichen Meldezettel elnträgt, den er auszufüllen hat:

Beruf Doktor der Rechte, beschäftigungslos, Wüstling, Verleumder, Beischläfer, schuldig geschieden, überführter Ehebrecher, vorläufig unbescholten. Und in der Rubrik Bemerkungen: problematische Persönlichkeit, moralisch verkommene Erscheinung. (S. 107)

Die Baltung des Ich-Erzählers gegenüber seinem Ich nach dem Umschmung schwankt 2 wischen offener Anerkennung und ironischer Betrachtungsweise. Am unverhülltesten kommt die positive Beurteilung seiner Haltung jedoch in den XuBerungen des Bauern Valent und in denen des gescheiterten Intellektuellen Katantit zum Ausdruck. 9 Andererseits betrachtet or sich, d.h. in erster Linie die Rolle, die er spielt, ausge-

9 Valent (S. 201, 229); Katantić (S. 285). Ebenso 1st das Bild, das der Erzähler von sich als Jungem Yann zeichnet, fast zu positiv. Dieser Eindruck wird kaum dadurch gemildert, daB der Ich-Erzähler in der 3 . Person von $81 \mathrm{ch}$ spricht, sein eigenes Ich also objektiviert. Vgl. S. 83 I., 190. 
sprochen ironisch und distanziert. Der Grund hierfür dürfte wohl letzten Endes in der Erkenntnis zu suchen sein, daB sein einsamer Protest zu keinem konkreten Ergebnis rühren rann, da er den gesellschaftlichen Verhältnissen als Einzelner machtlos gegenübersteht. So äußert der Ich-Erzähler sich zu Beginn des Romans in elner Reihe von Bescheidenheitsfloskeln ironisch über die Aufgabe, die er sich gestellt hat, und gibt vor, nicht besonders intelligent zu sein.

(...) einer, der sich über die menschliche Dummeit aufregt, der wird wohl selbst nicht allzu reichlich mit Geistesgaben gesegnet sein. (S. 9)

Charakteristisch für den Ich-Erzähler aus NRP 1st, daß er sich trotz aller direkten oder indirekten Anerkennung, die er seiner Person und seiner Haltung zukommen läBt, stets der Bedeutungslosigkeit seiner selbst bewuBt ist. Sein Schicksal als Einzelner soll keinesfalls überbewertet, aber gleichzeitig nicht unterbewertet werden.

(...) all das hat eine besondere Bedeutung und gleichzeitig auch nicht.

(s. 159)

Nicht zu verwechseln mit dieser für den Ich-Erzähler und den Autor bezeichnenden Einstellung zur Rolle des Einzelnen im Verhältnis zu der ihn umgebenden Welt, ist ein anderer Zug des Erzählers, dessen Ursprung in der gesellschaftssatirischen Tendenz des Romans zu suchen 1st. Der Ich-Erzähler verharmlost seine Tat absichtlich. Die ungeheure Wirkung, die das Aussprechen der Wahrheit hat, die sich immer mehr häufenden Folgen, die daraus für den Erzähler erwachsen, stehen in keinem Verhältnis zum AnlaB. Die Betonung seiner Harmlosigkeit und Naivität läBt die Auswüchse, zu denen die Gesellschaft fähig ist, in immer groteskerem Licht erscheinen. Die Schilderung, die der Erzähler von jenem entsche1denden Augenblick gibt, als er an dem Abend bei Domaćinski die Wahrheit sagt, ist bezeichnend für diese Art der Dar- 
stellung (S. 35 I., 38 I.). Die unmittelbare Wirkung seiner Worte und vor allem alles folgende erscheint auf Grund der verharmlosenden Darstellung der Ursache in Riesendimensionen verzerrt.

Es liegt in der Tendenz dieses Romans, das die dargestellten Ereignisse mit dem Anspruch wirklicher und nicht erfundener Geschehnisse auftreten. Der Ich-Erzähler betont aus diesem Grunde seine intime Kenntnis der Verhältnisse Immer wieder und führt, obwohl dies gerade in seinem Fall gar nicht erforderlich wäre, des öfteren die elnzelnen Quellen seines Wissens an. Mehrmals sagt er, er wisse, whe es hinter den Kulissen der verschiedenen Personen aussehe, die entweder aus seinem Bekanntenkreis stammen oder mit denen er verwandt 1st. Bel seinem Angriff auf die Familie Sarvas führt er zum Belspiel an, daß er sie durch selne Frau gut kenne, die zu ihr in verwandtschaftlicher Beziehung stehe, und daB er Infolgedessen "zufällig" schon mehrere Jahre einen HinterlassenschaftsprozeB für seine Frau und gegen die Familie Sarvas führe (S. 42). Domacinsk1 kennt er natürlich ebenfalls gut, da er mehr als acht Jahre als "Person vollkommenen Vertrauens" die "allervertraulichsten Angelegenheiten" für diesen bearbeitete (S. 235).

Die vielen Male, in denen er sein Wissen sorgfältig motiviert, und die anfängliche Betonung, die er auf seine Menschenkenntnis im allgemeinen und auf die seiner Mitmenschen, der zylinderträger, im besonderen legt, rufen den Eindruck bervor, der Ich-Erzähler wsse auch dann stets Bescheid, wenn er sein Wissen einmal nicht motiviert. Dieser Eindruck wird auBerdem noch dadurch verstärkt, daß der Ich-Erzähler einige Male zu verstehen gibt, daB er über die betreffende Person eine ganze Reihe von unerfreulichen Tatsachen weiB, diese jedoch nicht wiedergibt.

Besonderer Hinweise auf sein Gedächtnis bedürfen selbstverständlich alle jene Stellen, wo er in selne weitere Ver- 
gangenheit zurückblendet. So rekonstrulert der Erzähler anläBlich eines Gespräches mit dem Exminister Javorళek eine Unterhaltung, die zwischen beiden vor sieben bis acht Jahren stattgefunden hatte. Der zeitliche Abstand vergröBert sich noch um zwei weitere Jahre, die den Erzähler auf Grund der Erzählsituation von dieser Szene mit Javorłek trennen. Der Ich-Erzähler, der sich der Unwahrscheinlichkeit einer so genauen Erinnerung durchaus berußt ist, motiviert sie durch die Stärke des Eindrucks, die ihm das damalige Gespräch und die damit verbundenen Umstände gemacht haben ( $S$. 69). Zwar trägt der Ich-Erzähler in der Art und Weise, wie er die Worte des Ministers wiedergibt, der ungefähren Erinnerung Rechnung ("so haben Sie mir ungefähr geantwortet", "ungefähr so haben Sie sich auszudrücken beliebt", (S. 72), nicht aber, was die detalllierte Schilderung der damaligen Atmosphäre und das Auftreten Javoršeks betrifft, an dessen Kleidung er sich aufs genaueste zu erinnern scheint. Krleža bedient sich hier eines besonders geeigneten Mittels, um die genaue Erinnerung seines Erzählers zu beweisen. Er läßt Javor̋̌ek die Worte des Ich-Erzählers bestätigen:

Ich leugne keines meiner Worte, die Sie wortgetreu wie eine Gramophonplatte wiedergegeben haben.

(S. 73)

Häufig kommt das Bemühen um die Zuverlässigkeit des Erzählers in dem Eingeständnis des Nichtwissens oder der ungenauen Erinnerung zum Ausdruck ("heute erinnere ich mich nicht mehr an den unmittelbaren AnlaB", S. 26). Die Schilderung des Abends bei Domacinski, der an Hand des mehrmaligen "ich erinnere mich" vergegenwärtigt wird, wird schlieblich mit "an weitere Einzelheiten erinnere $1 \mathrm{ch}$ mich nicht mehr" (S. 40) abgebrochen - eine Wendung, die besagt, daB der Erzähler die Geschehnisse bis ins kleinste Detail wahrheitsgemäB reproduziert hat. Die Bedeutung dieses Ereignisses rechtfertigt sowohl die genaue Erinnerung als auch die aus- 
fübrliche Darstellung des Erzählers. Auf Grund dieser Darstellungsweise gelingt es, den Leser vergessen zu lassen, wie unwahrscheinlich es ist, daB der Erzähler sich zum Beispiel genau an die Situation seines alten Bekannten, Dr. Walter, erinnert und sogar die Gefüble, die dieser vor achtzehn Jahren hatte, nicht vergessen hat.

Von wesentlicher Bedeutung für diesen Ich-Roman 1st das Verhältais des erzählenden Ich zum erlebenden Ich.

Der Ich-Erzähler beginnt fast zwe1 Jahre nach dem Ereignis bel Domakinski zu erzählen, das den Ausgangspunkt aller weiteren Ereignisse bildet. $\mathrm{Zu}$ diesem Zeitpunkt ist er zwe1undfünfig Jahre alt, d.h. zur Zelt der Erzählsituation vierundfünfzig. Er vergegenwärtigt die Geschehntsse dieser beiden Jabre in ungefähr chronologischer Reihenfolge, wobei sich die Ze1tebene der Handlungsgegenwart immer mehr der der Erzählgegenwart nähert, um schlieblich in diese überzugehen. Die erzählte Zeit umfabt in wesentlichen diese beiden Jahre. Einige Male blendet der Erzähler jedoch in seiner frühere Vergangenheit zurück. Der früheste Zeitpunkt dieser Retrospektiven, die mit einer Ausnahme den Ich-Erzähler als jungen Mann beleuchten, liegt im Jahre 1915. Die Zeit zwischen 1917 und 1937 etwa wird nicht vergegenwärtigt. Der Erzähler greift lediglich auf eine kurze sipisode zurück, die sieben bis acht Jahre vor dem Umschwung liegt und in erster Iinfe zur Entlarvung Javorకeks dient. Mit diesen zwanzig Jahren rechnet er pauschal ab. Der Grund liegt auf der Hand: die nur zusammenfassend erwähnte Zeitstrecke umschlieBt seine Existenz als Zylinderträger, d.h. es ereignete sich nichts Erzählenswertes. ${ }^{10}$ Erzählenswert erscheint ibm nur sein Leben $v \circ r$ seiner Existenz als Durchschnittsbürger und d a a c $h$.

Aus der spezifischen Situation dieses Romans resultiert eine mehrfache Staffelung des erlebenden Ich. Da das Leben des Ich-Erzählers, das sich auf der Handlungsebene abspielt,

10 Vgl. S. 156 dieses Kapitels. 
in drei Phasen zerfällt, ergibt sich folgendes Schema: Erzählebene: erzählendes Ich (der Erzähler als Vlerundfünfzigjähriger);

Handlungsebene: erlebendes Ich 1 (der Erzähler als junger Mann vor dem negativen Umbruch);

erlebendes Ich 2 (der Erzähler als Durchschnittsbürger);

erlebendes Ich 3 (der Erzähler als Zweiundfüfzig- bis Vierundfüfzigjähriger in der Rolle des einsamen Rebellen).

Das fur den Ich-Roman charakteristische Spannungsverhältnis zwischen erzählendem und erlebendem Ich kompliziert sich dadurch, daß wir es hier nicht mit einem, sondern mit drei verschiedenen erlebenden Ich $z u$ tun haben. Vereinfachend wirkt sich jedoch aus, daB die beiden erlebenden Ich 1 und 3 sowie das erzählende Ich weltanschaulich eine Einheit bilden. Der Ich-Erzähler als junger Mann (erlebendes Ich 1) unterscheidet sich vol Vierundfünfzigjährigen (erzählendes Ich) vor allem durch seine Unreife und Unerfahrenhelt. Der Unterschied 2 wischen dem erlebenden Ich 3 (der Erzähler in den zwei Jahren nach dem Umschwung) und dem erzählenden Ich besteht in der Tatsache, daB das erzählende Ich auf Grund seiner retrospektiven Sicht vollen Uberblick über die Ereignisse besitzt. Mit fortschreitender Erzählung nähert sich das erlebende Ich 3 dem erzählenden Ich immer mehr, d.h. auch sein Wissen nimmt ständig zu. Die Spannung besteht somit lediglich 2 wischen erlebendem Ich 1, erlebendem Ich 3 und erzählendem Ich einerseits und erlebendem Ich 2 (der Erzähler als Durchschnittsbürger) andererse1ts. Das tbergewicht des erzählenden Ich 1st jedoch so groB, und seine therlegenhelt tritt in solchem MaBe zutage, daB ungeachtet gegensätzlicher Haltung zwischen inm und dem erlebenden Ich 2 kein wirklicher Kontrast entstehen kann.

Während die Gedanken des erlebenden Ich 1 trotz der weltanschaulichen Nähe zum erzählenden Ich auch dann unschwer erkannt werden können, wenn sie nicht ausdrücklich als solche gekennzeichnet sind (Unerfahrenheit, Illusionen des erleben- 
den Ich 1), fällt es des öfteren schwer zu unterscheiden, ob ein bestimmtes Urteil oder eine tberlegung von der Ebene des erlebenden Ich 3 oder von der des erzählenden Ich ausgeht. Bezelchnenderwelse werden jedoch die Gedanken des erlebenden Ich 2, die sich krab von denen des erzählenden Ich abheben, ausdrücklich als solche bezelchnet, obwohl das gerade in diesem Fall nicht erforderlich wäre. Die konträre Perspektive des erzählenden Ich kommt in der Regel in den die Gedankenwiedergabe begleitenden Kommentaren zum Ausdruck. Zum Tell werden die Gedanken des erlebenden Ich 2 in Anführungszeichen wiedergegeben und dadurch in betonter We1se hervorgehoben und rom erzählenden Ich abgerückt.

Die starke tbertreibung der Denkweise des erlebenden Ich 2 weist darauf hin, daB es dem Autor hier in erster Iinie darum geht, das Bild des Bürgers durch tbersteigerung zu verzerren und zu entstellen. Aus dieser Tatsache ergibt sich das Hauptproblem für Krlež. Die Diskrepanz zwischen den beiden Ich wird auf diese Weise so groB, daB es schwerfällt, sie einem Menschen, dem Ich-Erzähler, zuzuordnen und dabel nicht unglaubwïrdig zu wirken. Die vielen Motivierungen, die den krassen Umschmung des Ich-Erzählers erklären und begründen sollen, weisen darauf hin, dab sich der Autor dieser Problematik wohl bewuBt war. Trotz der vielfältigen Motivierungen erscheint der Fall des Ich-Erzählers zu konstmulert. Einerseits muB er als typischer zylinderträger erscheinen, andererselts muß er als typischer held aufreten und infolgedessen einen radikalen Perspektivenwechsel durchmachen, um an Stelle des Autors seine Mitbürger demaskieren zu können. Die Kluft 2 wischen diesen beiden Ich ist zu groB, um überbrückt zu werden. Der Versuch dazu wird allerdings unternommen; er erscheint mir jedoch nicht besonders überzeugend, da eine Reihe von Widersprüchen bestehen bleiben. Zwar bemüht sich der Erzähler, eine gewisse Kontinultät zwischen seinem Bürger-Ich und den anderen Ich herzustellen, indem er sein erlebendes Ich 2 aus der allgemeinen Masse der Bürger heraus- 
hebt. So hat er sich auch schon $v$ o $r$ seinem Umschmung Gedanken über die menschliche Dummbeit gemacht (S. 15, 21, 25, 47). Außerdem erklärt der Ich-Erzähler, er hätte sich schon vor jenem Abend bel Domatinskl innerlich ron der Gesellschaft distanziert - wenn auch nur von Zeit zu Zeit (S. 24 f.). Um sich dem Dilemma zu entziehen, motiviert der Erzähler den Umschmung lediglich als einen Akt der BewuBtwerdung ( $\mathrm{S} .20,31$, 50, 109). Mehrmals drückt er dieses Verhältnis bildlich aus. So spricht er von sich als einem Menschen, der nach dreibig Jahren Schlaf erwacht ist (S. 258). Weiterhin bezieht sich der Ich-Erzähler auf sein erlebendes Ich 1, mit dessen Hilfe er die Kontinultät herzustellen sucht und den späten Umschwung erklärt. So trägt der Erzähler schon als junger Mann sämtl1che positiven Anlagen in sich, die ihn später zum Helden des Romans werden lassen. Schon damals ist seine Weltanschauung "negativ" und schon damals beweist er seine Distanz gegenüber der ihn umgebenden Wirklichkeit (S. 190).

Das Hauptmerkmal des Romans NRP scheint mir das starke Hervortreten des erzählenden Ich zu sein, das weltgehend auktoriale Züge aufweist. ${ }^{11}$ Das erzählende Ich durchdringt den gesamten Roman mit seiner subjektiven Gegenwart. Handlungsebene und Erzählebene überschneiden sich aus diesem Grund beständig. Das Anllegen des Ich-Erzählers, Gesellschaftskritik zu üben, ist so bestimmend, daB sich das erzählende Ich kaum für längere Zeit zurückziehen kann. Bezeichnenderweise steht es vor allem im ersten Tell des Romans im Vordergrund, wo es gilt, mit seiner Existenz als Durchschnittsbürger abzurechnen und den Typus des zylinderträgers anzugrelfen. Paradoxerweise spielen sich gerade in diesen Kapiteln die meisten Ereignisse ab; wir wirden erwarten, daß gerade hier das erlebende Ich im Mittelpunkt steht und nicht ungekehrt. Auch in den Kapiteln, in denen

11 Uber die Annäherung der Erzählsituation des Ich-Romans an die auktoriale Erzählsituation vgl. F. Stanzel: Die typischen Erzählsituationen im Roman, S. $63,164 \mathrm{ff}$. Vgl. Kap. V, S. $208 \mathrm{f}$. 
der Erzähler mit den Vertretern der Gesellschaft zusammenstöBt, nehmen die Dialoge nur verhältnismäBig wenig Raum ein. Die ausführlichen Charakteristiken der verschledenen Personen dagegen, die sich meist als direkte Entlarvangen durch den Ich-Erzähler erweisen, rücken das erzählende Ich in den Vordergrund. Die sorgfältigen Motivierungen seines Verhaltens gegenüber seinen Mitbürgern gehen ebenfalls vom erzählenden Ich aus, das seine Reaktionen nachträglich rechtfertigt und den Ieser auf diese Weise indirekt um Verständnis bittet. Selbst in Kap. 6, wo die Gerichtsverhandlung gegen den Ich-Erzähler in Form einer langen Szene vor uns abrollt, schaltet sich das erzählende Ich ein und unterbricht die szenische Darstellung. So motiviert der Erzähler auf mehr als zwei Seiten seinen Entschluß, sich im Gegensatz zu seiner ursprünglichen Absicht doch zu verteidigen (S. $130 \mathrm{ff.}$ ). Bereits eine Seite später schaltet sich der Erzähler wiederum ein, um über die Art und Weise zu reflektieren, wie er vor Gericht spricht (S. 133 f.). Zweimal unterbricht das erzählende Ich die Szene, um die Wirkung seiner Worte zu beurteilen, noch b e vor das erlebende Ich sie ausspricht (S. 143 f., 146).

Immer wieder werden wir an die Erzählsituation erinnert. Das erzählende Ich weist mit Ausdrücken wie "ich erinnere mich", "retrospektiv" oder unbestimmter "heute" auf seine Lage der vollständigen Kenntnis der Geschehnisse hin. Die Situation der Wiedererinnerung kommt mehrfach zum Ausdruck. In folgendem Beispiel sieht das erzählende Ich die vergangenen Geschehnisse gleichsam wie vor seinem inneren 1 uge abrollen. Es hat sich auf Grund der langen Erzähldistanz 80 weit von seinem erlebenden Ich entfernt,daB ibm dieses als objekt erscheint.

"Wie ich in diesen Zug geraten bin und in dieses Coupé, in dem die kitreisenden nach Wanzen suchten, das weiB $1 \mathrm{ch}$ auch beute noch nicht und ich erinnere mich nicht daran, aber ich sehe, wie der Zug durch betaute wälder donnert (...) und 
wie ein junger Offizier im schmalen Korridor des Waggons im rhythmischen Wiegen des Zuges wie ein lebloser Gegenstand hin und her schwankt (...). (S. 195)

Als der Ich-Erzähler Jedoch von seinem ehemallgen Zellengenossen Valent spricht, wird nicht die Ferne, sondern die Nähe zu dem vergangenen Erelgnis wirksam: das erzählende Ich wird durch die Erinnerung an die gemelnsame Zeit überwältigt. Bezeichnenderweise versetzt sich das erzählende Ich anläBlich dieser Wiedererinnerung nicht völlig in sein erlebendes Ich, denn es macht uns gleichzeitig seine überschauende Sicht der Erelgnisse bewuBt, Indem es weit vorausgreift und die Entlassung aus dem Gefängnis und den Abschied von Valent vorwegnimmt.

(...) nie im Leben habe ich soviel gelacht wie in diesen fünf letzten Monaten, die ich mit ihm zusammen verbracht habe (...), und $1 \mathrm{ch}$ verlieb Valent unter Tränen, und auch heute, wenn ich an diesen Viehdieb denke, spüre 1ch, wie es mir die Spelseröhre verengt: im groben Tuch des Sträflings gräbt er irgendwo in Zuchthaus Kartoffeln um und ahnt nicht, daB ich mit Sehnsucht an ihn denke, wie an die allerliebsten Kameraden und Freunde, die man verloren hat. (s. 200)

Die retrospektive Sicht des Erzählers kommt jedoch nicht nur in diesen direkten Hinweisen zum Ausdruck, sondern weit häuftger noch in der Anordnung der Ereigntsse. Der Ich-Erzähler erzählt zwar im groBen und ganzen chronologisch, weicht aber immer wieder von dieser Reihenfolge ab, indem er Zuküftiges vorwegnimmt und die Geschehnisse ohne Rücksicht auf ihren tatsächlichen zeitlichen Verlauf gemäB ihrer logischen Zusammengehörigkeit einordnet. Besonders deutlich kommt die souveräne Art des Ich-Erzählers gegenüber den Ereignissen zum Ausdruck, die sich zu beginn des 11. Kapitels in der Handlungsgegenwart absplelen. Er berichtet kurz über die Vorgänge, die sich inzwischen ereigneten und schliebt an die Handlungszeit dieses Kapitels, elnen Maimorgen, an. Er 
berichtet nun aber nicht der Reihe nach, was sich an diesem Morgen zutrug, sondern er schlldert uns die Folgen jenes Tages und greift den Ereignissen weit voraus. Fr teilt uns auf S. 260 bereits mit, $d a B$ er ins Irrenhaus eingelfefert und später wleder entlassen wird. Erst S. 281, bereits ein Kap1tel danach, tritt dies Jedoch eln; seine Entlassung sogar erst auf den letzten Seiten des Romans (S. 285). AnschlleBend an diese Voraussage glbt er vor, die Ereignisse so $\mathrm{zu}$ erzählen, wie sie sich zugetragen haben, also der Reihenfolge nach. Nach etwa zwei Seiten unterbricht er jedoch die Erzählung ein zweites $\mathrm{Mal}$, um erneut in die Zukunft vorzugre1fen. Erst jetzt folgt die bereits angekündigte chronologische Schilderung. Obwohl wir dem Ich-Erzähler die seiner Erzählsituation gemäBe überlegene tbersicht über die Geschehnisse zubilligen müssen, erscheint er doch, indem er seine Preihelt, die Geschehnisse nach seinem Ermessen anzuordnen, Immer wieder aufs nachdrücklichste bekräftigt, wit den Merkmalen des auktorialen Erzählers. Auch anläBlich des Auftretens der verschiedenen Personen mischt sich das erzählende Ich wie ein auktorialer Erzähler ein und unterbricht einfach die Szene, um die betreffende Person dem Leser vorzustellen. 12

Bezelchnenderweise überschreitet dieser Ich-Erzähler auf Grund seiner überlegenen Haltung einige Male beim suftreten der positiven Personen des Romans seine Perspektive. Er macht sich gleichsam zum Anwalt dieser Schiffbrüchigen und klagt die Gesellschaft in ihrem Namen an. Sein starkes Engagement verleitet inn dazu, uns Dinge mitzutelien, die er entweder gar nlcht oder nicht in solcher Genaulgkelt wissen kann. In Falle Valents und Katantićs umgeht er die Gefahr, indem er sie ihre Geschichte selbst erzählen läßt. ${ }^{13}$ Was

12

VGl. Kap. I, S. 22.

13 Nur der Tatsache, daB die "Lamentation" Valents szenisch vergegenwärtigt wird, ist es zu danken, daB dem Leser die Unmöglichkeit der wortlichen Reproduktion einer so langen Rede (S. 208-228) durch den Ich-Erzähler nicht beruBt wird. 
Jodoch die beiden anderen Personen betrifft, Jadviga Jesenska und Matko, so überschreitet er seine Befugnisse ale IchErzähler und teansprucht streckenweise die Haltung des allwssenden sutors. So vergegenwärtigt er die entscheidende Eplsode aus Matkos Leben, die ihn zum Kriminellen werden lieB, in Form einer detallilerten Szene und geht sogar 80 weit, zwel Sätze mit erlebter Rede Matkos einzurügen, die dessen Gedanken beinhalten ( $S$. 279). Mit keinem Fort erwähnt der Erzähler Jodoch, woher er so genau Bescheid weiB. Wir erfahren nur, daB er längere Zelt mit Matko zusammen im Gefängnis verbrachte.

Das erlebende Ich gewinnt erst im zweiten Teil des Romans an Gewicht, und zwar vorwlegend in jenen Kapiteln, die sich io Gefängnis oder Krankenhaus abspielen. Wir haben es hier mit einer ausgesprochen ereignisarmen Strecke zu tun, in der sich das erlebende Ich vornehmlich langen Reflexionen hingibt. Das Zurücktreten des erzäh?enden Ich gerade in diesen Kapiteln hat folgende Gründe. Nie bereits festgestellt, b1lden erzählendes Ich und erlebendes Ich (der Ich-Erzähler als Protestierender) - und allein um dieses Ich dreht es $81 \mathrm{ch}$ hier - weltanschaulich und perspektivenmäBig eine Einheit, sie sind insofern völlig ldentisch. Der Erzähler kann infolgedessen selne Gedanken über gesellschaftliche oder weltanschauliche Probleme obne weiteres dem erlebenden Ich in den Mund legen. Sein Dazwischentreten ist hier nicht erforderlich, und es gelingt ihm auf diese Weise, den ganzen Gedankenballast, der für sämtliche Romane Krlezas typisch 1st, unterzubringen, ohne auf welte Strecken seine Erzählsituation überzubelasten. Auch dann, wenn das erzählende Ich sich einschaltet, lst es schwer zu entscheiden, wem der entsprechende Passus zuzuschreiben ist, da die Identifikation der beiden Ich im Hinblick auf ibre Feltanschauung vollkommen 1st. Das erzählende Ich verschwindet aber auch in diesen Kapiteln nicht völlig. Des öfteren werden dem erlebenden Ich Dinge zugeschoben, die eher auf den Erzähler im Hintergrund weisen als auf 
das erlebende Ich. Das erzählende Ich mischt sich jedoch auch hier ganz unverhültt eln, und wir stellen einen ausgesprochen häufigen Wechsel von der elnen Ebene sur anderen fest. Als charakteristisches Beisplel für diese Technik des Hin- und Herschmenkens sel Kap. 9 angeführt. Das Kapitel beginnt auf der Handlungsebene, obwohl der erste lange Satz, in dem uns Valent vorgestellt wird, wiederum eigentlich nicht dem erlebenden Ich zuruschreiben ist. Bezelchnenderweise wird gerade in solchen Fällen, die auf das erzählende Ich deuten, aber offensichtlich vom erlebenden Ich ausgehen sollen,die Situation der Handlungsebene mit Hilfe von Adverbien der leit und des Ortes und Verben in Präsensform besonders betont.

Ein dämmriger Oktobernachmittag, regnerisch, langweilig, Kopfschmerzen verursachend. Valent Zganec, der noch in seinem Heimatort Gornje Vugersko Vudriga genannt worden war, eln armer Schlucker aus stubica, hatte sich bis zu selnem neunundoierzigsten Lebensjahr auf zreieinhalb Joch Grund als "verhältnismäBig wohlhabender" Teinbauer und Kuhhirt durchgehungert, sitzt jetzt in Ontersuchungsgefängn18 (...), rocht Tee auf meinem Spirituskocher und hört mir zu, während ich ing aus Buddhas Reden vorlese. (s. 198)

Nach diesem Absatz tritt deutlich das erzählende Ich in den Vordergrund und blickt auf die zelt wit Valent zurïck; das "heute" bezieht sich auf die Erzählebene. 14 Hach vier Selten wind weder der AnschluB an die Handlungsebene vollzogen, die bis zum Schlus des Kapitels beibehalten wird.

Die erste Oktoberdämmerung sinkt herab, und

1ch lese meinem guten Kameraden Valent die

Rede Buddhas über das Weltall vor (...). (S. 202)

Nur an ganz venigen Stellen versetzt sich das erzählende Ich 80 in das erlebende, daB es aus dessen Perspektive der Zukunftsungeribheit spricht. Kap. 10, das mit einem dreiBig-

VGl. S. 168 dieses Kapitels. 
tägigen Krankenhausaufenthalt des Ich-Erzählers endet, schlieBt mit einer Reihe von Fragen des erlebenden Ich ab, die dessen augenblickliche Situation der Unsicherheit und der Zweifel widerspiegeln. Wird die Handlungsebene und damit die Situation des erlebenden Ich so eindeutig bezeichnet, besteht kein Zwe1fel darüber, daB es sich bel der Wiedergabe von Gedanken um die des erlebenden Ich handelt. Der Ausgangspunkt der Reflexion des erlebenden Ich wird meist mit einem oder mehreren Verben in Präsensform angezeigt, die entweder eine passive Haltung des Ich bedeuten, wie sitzen oder liegen, oder die den Denkvorgang direkt nennen. In jenen Kapiteln, die sich vorwiegend auf der Ebene des erlebenden Ich abspielen, setzt der Gedankenmonolog meist unvermittelt und obne direkte Bezeichnung des Denkaktes ein. In allen anderen Kapiteln jedoch, in denen die Ebene des erlebenden Ich nicht dominiert und das Orientierungszentrum des Lesers nicht so eindeutig in das Hier und Jetzt des erlebenden Ich verlegt wird - und dies lst bel den meisten der Fall - bedarf die wiedergabe der Gedanken des erlebenden Ich 3 elnes ausdrücklichen Hinweises. Eine Reihe von Tendungen wie "ich fühlte", "es erschien mir", "es wurde mir klar" bezeichnen Eindrücke oder Gedanken als die des erlebenden Ich. Selten führen diese und ähnliche Wendungen auch wirklich zu einer echten Wiedergabe von Gedanken des erlebenden Ich. Melst liegt lediglich Gedankenbericht vor, so daB wir uns des erzäblenden Ich bewußt bleiben, das die Gedanken und Gefühle des erlebenden Ich anführt. Neben diese Art der Gedankendarstellung tritt in einigen wenigen Fällen eine direkte Bezelchnung mlt "1ch dachte", das die Gedanken des erlebenden Ich innerhalb einer Szene kenntlich macht. Häufiger als der direkt bezeichnete Denkakt des erlebenden Ich ist innerhalb szenischer Darstellung erlebte Rede anzutreffen. 15

NRP endet mit der Ebene des erlebenden Ich. Wir erfahren

15

Vgl. Kap. II, S. 82 f. 
den Inhalt dee "geheimnisvollen" Briefes aus Wien erst dann, als das erlebende Ich ibn öffnet und 11est, und 2war durch die in erlebter Rede wledergegebenen Gedanken des Ich ( $S$. 286 f.). Eine kurze Einschaltung des erzäblenden Ich unterbricht noch einmal die Handlungsebene, um anschlieBend über einen Satz in erlebter Rede in einen FluB unpersönlicher Sätze in Präsensform überzugehen. Die letzte XuBerung des persönlichen Ich betrifft den EntschluB, das Radio einzuschalten. Auf den drei, diesem Satz folgenden Seiten, mit denen der Roman abschlieBt, wrd die Ich-Porm keln elnziges Mal mehr gebraucht. Im Augenblick der gröBten Einsamke1t und Verzweiflung distanziert sich das Ich gleichsam von selner eigenen Person. Schmerz und Resignation, die den Ton dieser Selten bestimmen, werden auf Grund des unpersönlichen Pronomens der unangenehmen, weil persönlich bestimmten $\mathrm{Pa}-$ thetik entzogen.

Wie wäre es, wenn $1 \mathrm{ch}$ das Radio aufdrehte und In die Welt der Klänge flüchtete? Der Mensch hat die Möglichke1t, sich zu rerstecken, zu Fliehen, zu verschwinden (...). Der Mensch 1st allein, er leidet (...). Wenn man nur schlofen könnte. Einschlafen. Ruhig und endguiltig. Vergehen. (S. 288 f.)

Die Offenhelt des Romanschlusses wird durch das Verbleiben auf der Ebene des erlebenden Ich bewirkt, das auf dem tiefsten Punkt der Resignation angelangt ist. 16

16 D. Zetevit beschäftigt sich in ihrem Aufsatz "Krležina retenica" (1n: Kolo, NS, 3, 1965, 6, 43-54) mit dem Schlul von NRP. Sie meint, daB der Ich-Erzähler tot neben dem Ra. dio liege (S. 53). Der wiederholte Hinweis auf das nleere Zimmer" 1st meiner Meinung nach lediglich im Zusamenhang mit der Einsamke1t des Erzählers zu sehen. Wer anders als der Ich-Erzähler könnte denn am Knopf des Radioapparates drehen? Ganz abgesehen davon erscheint mir der Selbstmord des Ich-Erzählers mit seiner Haltung im Roman unvereinbar 
Wir stellten als besonderes Merkmal dieses Romans das starke Bervortreten des nit auktorlalen Zügen ausgestatteten erzählenden Ich lest, das in betonter Weise un die Herstellung der Illusion der Wirklichkeit bemüht ist und mit dem Anspruch auftritt, wabre Ereignisse zu erzählen. Beldes hat seinen Grund in der Form des Romans - einer gesellschaftskritischen Satire. Der Ich-Frzähler, der sein alptraumartiges Ieben der letzten beiden Jahre in einer für die Satire tJpischen Form, der des Yonologs, zu erzählen beginnt, entlarvt eine Gesellschaftsschicht und deren Weltanschauung an Hand ron typischen Erscheinungen, in stellvertretender Punktion für den Autor. Die Direktheit und OnmiBverständichkeit, mit der Kritik und Anklage in diesem Roman zum Ausdruck gebracht werden, erfordern die Anwesenheit elnes zugleich überlegenen als auch engagierten, leidenschaftlich beteiligten Erzählers. Einseltigkeit und Schärfe der Verurtellung, die in erregtem Ton vorgetragene direkte und unverhohlene inklage der Gesellschaft und die bittere Zeit- und Gesellschaftskritik, die der Ich-Erzähler teils aggressiv, teils resigniert und schmerzlich vorbringt, verleihen diesem Roman den Charakter einer zornigen Satire mit Zügen des Pamphlets. Absicht und Tendenz kommen in bekenntnishaften, polemischen und appellierenden Wendungen zum Ausdruck, vermittels derer der Leser zum yitvollzug und zur Aktivierung seiner persönlichen Stellungnahme aufgefordert wird. Mit besessener Intensität stürzt sich der Erzähler imer wieder auf die glelchen Themen mit dem Erfolg, daB der Leser wegen der daraus resultierenden geringen Variationsbreite - bel allem Respekt vor der Aufrichtigkeit und der Lauterke1t der Absichten des Erzählers - zu ermüden beginnt. Die starken Töne und die grellen Farben wirken sich auf die Dauer gesehen ungünstig auf die innere Anteilnahme des Lesers aus, der angesichts der in brutalen und direkten Sätzen geschilderten Welt von Abscheu ergriffen werden und sich damit dem Protest des Ich-Erzählers anschlieBen soll. Der anfänglich spieleri- 
sche, 1ronische Ton des Erzählers verschärft sich, sobald er sich seinem Thema, der menschlichen Dumbeit und inren Erscheinungsformen, nähert und geht alsbald in höbnische Verachtung und direkte Anklage und Verdammung über, die an Deutifichkeit nichts zu wïnschen übrig lassen. Schlmpfworte und direkte grobe Beleidigungen kennzelchnen seine Redereise gegenüber den Vertretern der Gesellschaft, die er mit Verachtung und $\mathrm{HaB}$ behandelt, die er lächerlich macht und die er schlieBlich alle ohne Ausnahme als menschllche Ungeheuer entlarvt. Der Titel des Romans gibt uns berelts zu erkennen, daB es dem Autor um ein bitterernstes Anliegen geht: der Held dieses Romans gerät durch die Schuld selner Mitmenschen an den Rand des Verstandes, er wird fast zun Wahnsinn getrieben.

Ironlsche 2weideutigke1t allein ist für diesen Erzähler ein zu subtiles Mittel. Bedient er sich der ironischen Verstellung als Mittel der Satire, um den Gegner durch scheinbare Anerkennung und scheinbares Lob zu entlarven, so übertreibt er den positiven Zug in solchem MaBe, daB der entgegengesetzte Sinn seiner Worte sogleich offenkundig wird. Meist jedoch - und dies 1st charakteristisch für sein Verfahren - Polgt einer indirekten, ironischen Wendung alsbald die direkte und unmiBverständliche Frklärung nach; häufis geht sie inr auch voraus, so dab die Zweideutigkelt nie wirklich zreideutig 1st. Die Tendenz zur UnmiBverständlichkelt und tberdeutlichke1t, die vorherrschend 1st, läBt keine MBBverständnisse aurkommen. Das Wesentliche wird vom Erzähler immer aufs neue wiederholt und an einfgen Stellen des Rowans, so im Gespräch mit Sinek oder in seiner Reflexion in Krankenhaus, in konzentrierter Form zusammengefabt.

Im Blick des Ich-Erzählers erscheinen selne Mltbürger zu Karikaturen verzerrt. In dieser Gesellschaftsschicht existieren ausschlieBlich lügner, Betrüger, Heuchler, Kriecher, Peiglinge, Opportunisten, elnfältige GröBenwabnsinnige und profitglerige, skrupellose Geschäftemacher. Der Ich-Erzäh- 
ler selbst verfügt in selner Unbelrrbarke1t und Ausdauer über fast übermenschliche Widerstandskräfte: er wird ron der Gesellschaft verfolgt, verliert fast sein Augenlicht, gerät Ins Gefängnis und Ins Irrenhaus und muB sich in einer Reihe von Prozessen verteldigen. Andererselts erhebt die Satire den Anspruch, die reine Wahrhe1t darzustellen; nicht die verzerte Wirklichkeit, sondern ihr getreues Abbild. " (...) satire - although it pretends to be telling the complete truth about life - in fact presents a propagandist distortion (...). Satire wishes to expose and criticize and shame human life, but it pretends to tell the whole truth and nothing but the truth."17 Der auf diese Weise entstehende Widerspruch wird am einfachsten in der Weise gemildert, das der Erzähler als Bestandtell der dargestellten Welt aurtritt, wie dies in der Ich-Erzählung der Fall 1st. Die negative tberstelgerung und Potenzlemung der Kritik, die Krleza als Satiriker in NRP beabsichtigt, wïde unglaubhaft wirken ohne diesen persönlichen Ich-Erzähler, der alles, was er erzählt, als seln elgenes Erleben ausweist und so selbst die unwahrscheinlichen Ereignisse vom Verdacht der Unwahrsche1nlichke1t oder gar Unwahrhe1t befreit. Nicht nur die Wahl eines Ich-Erzählers bestärkt in NRP die Illustion der Wirklichkeit, sondern auch das Thema. Selbst bel gröBter Ubertrelbung wird die Schilderung der Erschelnungsformen und Auswirkungen der Dummbeit nie unwahrscheinlich wirken, denn diese erreichen bekanntlich phantastische AusmaBe. Nicht umsonst ist gerade die Dummeit ein beliebtes satirisches Thema.

Die Ich-Form wurde also im Falle des Romans NRP ganz bemuBt gewählt, un die Darstellung zu verschärfen, sie glelchzeitig nicht unglaubwïdig erscheinen zu lassen und sie vom Autor abrücken zu kồnnen, d.h. sie einem Erzähler in den Mund zu legen, der es wagen kann, Dinge auszusprechen, die der Autor in dieser Schärfe unter Umständen nicht zur Sprache bringen wirde. Die Wahl der Ich-Form gestattet es dem Autor, die Satire formal zu verhüllen.

17 Highet, Gilbert: The Anatomy of Satire. Princeton 1962, S. 158. 


\section{K A P I T E I V}

\section{I E E R - RO Y A N E}

("Die Rückkehr des Pilip Latinovicz",

"Bankett in Blitwien", "Banner")

\section{Erzähler - Erzähltes - Leser}

In allen neueren Darstellungen zur Poetik des Romans werden Rolle und Haltung des Erzählers im Erzäblwerk als Jenes Formprinzip hervorgehoben, das für die Struktur des gesamten Romans von grundlegender Bedeutung 1st. 1 T. Kayser bezelchnet als "Ursituation des Erzählens", "daB eln Vorgängliches da 1st, das erzählt wird, daß ein Publikum da ist, dem erzählt wird, und daB ein Erzähler da 1st, der zwischen belden gewissermaBen vermittelt." ${ }^{2}$ Seine Definftion des Romans lautet demgemäB: "Der Roman ist die von elnem (fiktiven) persönllchen Erzähler vorgetragene, einen persönlichen Leser elnbeziehende Erzählung von Welt, soweit sie als persönliche Erfahrung fabbar wird." 3 Kajser hebt ausdrücklich hervor, daB der Erzähler eine erdichtete Gestalt 1st, eine "Rolle, die der Autor erfindet und elnnimmt", und daB er infolgedessen trotz aller hhnlichkeit nicht mit dem Autor verwechselt werden darf. ${ }^{4}$ Auch $P$. Stanzel stellt fest, daB "eine.

1 Vgl. Wellek, R. U. Warren, A., S. 231; Iubbock, Percy: The Craft of F1ction. New York 1957, S. 251; Priedman, Norman: Point of View in Fiction: The Development of a Gritical Concept. In: PMIA, 70, 1955, 1180; Priedemann, Käte, S. 26.

2

Das sprachliche Kunstwerk, S. 201.

3 Entstehung und Krise des modemen Romans, S. 26.

4 Wer erzählt den Roman? In: Kayser: Die Vortragsrelse. Studien zur Literatur. Bern 1958, S. 91. 
elgentümliche Verfremdung der Persönlichkeit des Autors in der Gestalt des Erzählers sichtbar" wird. "Er weiB weniger, manchmal auch mehr, als vom Autor zu erwarten wäre, er vertritt gelegentlich Meinungen, die nicht unbedingt auch die des Autors sein müssen." Der auktoriale Erzähler nimmt als "Mittelsmann der Geschichte einen Platz sozusagen an der Schwelle zwischen der fiktiven Welt des Romans und der Wirkl1chkeit des Autors und des Lesers" ein. ${ }^{5} \mathrm{Daß}$ der Erzähler Bestandeil der Fiktion ist, wird bereits daraus ersichtlich, dab er sich zu den Gestalten und zum Geschehen des Romans in Beziehung setzt. Am deutlichsten kommt dies im Ich-Roman zum Ausdruck, in dem der Erzähler selbst zu einer Figur der erzählten Welt wird.

Welcher Art ist nun dieser fiktive Erzähler? In welcher Rolle zeigt er sich uns in den Romanen Krlezas, und welche Haltung nimmt er dem Geschehen und dem Leser gegenüber ein? Es gilt, den Standort des Erzählers in den drei Er-Romanen $F L, B B, Z$ zu bestimmen.

In Gegensatz zu den beiden übrigen Er-Romanen tritt der Erzähler in FL kaum unmittelbar hervor. Nur wenig̀e Male spricht er in Form des Reflexivpronomens von sich, einmal tritt er durch eine in einem Zeitungsartikel eingeschobene Bemerkung hervor, die er mit "Anmerkung des Autors" (FL, 96) vom Text abhebt, einige Male kennzeichnet er durch die 1. Person Plural seine Position innerhalb der dargestellten Helt (FL, 93, 105, 141). Die Erzählergegenwart und somit die Erzähldistanz bleibt demnach ziemlich unbestimmt. Die Tatsache, daß der Erzähler in FL nicht zu einer deutlich faBbaren Gestalt wird, besagt jedoch keineswegs, daß wir uns seiner Anwesenheit nicht bewrußt würden. Ganz im Gegenteil: große Teile des Romans sind durch seine subjektive Anwesen-

5 Typische Formen des Romans. Göttingen 1964. ( ( Kleine Vandenhoeck-Reihe. 1872, S. 16. 
heit geprägt. Er führt die Vertreter der Gesellschaft ein und berichtet ihre Vorgeschichte, er kommentiert die Gedankenmonologe der Hauptpersonen und analysiert deren Wesen, er beurteilt Gedanken, Worte und Verhalten sämtlicher Personen, er fabt den Inhalt von Monologen und Gesprächen zusammen und gibt deren Themen an, er weis über das Innere aller Personen Bescheid und kennt sowohl thr Vorleben als auch ihre Zukunft. Dieser Erzähler besitzt tberblick über das ganze Geschehen. Er steht über seinen Gestalten, von denen er häufig mehr weiB als diese von sich selbst, und distanziert sich in Form von Kommentaren von ihnen. Deut$11 \mathrm{ch}$ kommt diese Distanz und tberlegenheit gegenüber den in das Geschehen verstrickten Personen zu Beginn des Kapitels 23 zum Ausdruck:

Sergije Kirilovit Krriales (...), der in diesem Drama von Kostanjevec für diese kränklichen Schwächlinge und konfusen Decadents eine so verhängnisvolle Rolle spielte, war vor dem Kriege aus RuBland emigriert (...). (PI, 186)

Zweimal weist der Erzähler in die Zukunft voraus und deutet das Ende zweier Romanpersonen an. Gleichzeitig mit diesen Vorausdeutungen, die als Symptom der erzählerischen Allwissenheit anzusehen sind und den in Verhältnis zum Erzählten nachzeitigen Standpunkt des Erzählers ins Berubtsein mfen, schränkt er diese Allwissenheit spielerisch ein. Er gibt damit vor, seine Higuren seien nicht von ihm geschaffene Phantasiegeschöpfe, sondern wirklich existierende Personen, deren Schicksal unergründlichen Gesetzen unterworfen ist und deren Inneres von ihm nicht ganz durchschaut werden kann.

(...) und wer weiB, ob nicht auch er /Kyriales/ irgendwo als versoffener Stabsleutnant oder schwachsinniger Konfektionshändler geendet hätte, wenn ihn nicht die Ereignisse eines Nachts aus St. Petersburg nach Tibet gewirbelt hätten und von Tibet durch alle Kontinente zu Bobocka Radaj und nach Kostanjevec, wo er in einer Regennacht ebenso furios im rebel verschwand, wie er 
erschlenen war. Es wäre schwer zu sagen, ob die Elgenschaften, durch die er eine so verheerende Wirkung auf Filip ausübte, wirklich magischer Natur waren, oder ob diese Beziehung bedingt war durch undeutliche und $8 \mathrm{chwach}$ ausgeprägte Neigungen bel Filip selbst (...). (FI, 187 f.)

Wichtig 1st, daB der Erzähler seine Allwissenheit nur geringfügig einschränkt und sie unmittelbar anschließend an sein fingiertes Nichtwissen wioder hervorkehrt. Er behauptet zwar, nlcht genau zu wissen, welcher Art die Elnflüsse Kyriales' auf Filip seien, zeigt sich jedoch aufs genaueste mit Filips Wesen vertraut. Einerseits gibt er nur das ungefähre Alter des Griechen on ("er hatte jedenfalls die Fünf21g hinter sich"), sagt, man könne von dem Gesicht Kyriales' nichts über dessen "unbekanntes" fünfzigjähriges Leben ablesen (FI, 186), und begleitet einige Angaben über dessen Herkunft mit einem "angebl1ch". Andererseits weiB er wieder detailliert über die Vorfahren Kjrialeg' zu berichten und kennt die charakterlichen Eigenschaften des Griechen.

Im Gegensatz zu FI haben wIr in BB eine fabbare Erzählergestalt, die sich im Prolog des Romans einführt, ihre Rolle bekanntgibt und inrer Haltung gegenüber der Welt des Romans und gegenüber den Figuren Ausdruck verleiht. Der Erzähler, der in der 1. Person Plural von sich spricht, bezeichnet sich als einen im "fernen und nebeligen Ausland" lebenden Beobachter, der nicht genügend Einblick in den "überaus verworrenen Komplex der blitwisch-blatwisch-hunnischen Fragen" besitzt (BB, 16). Die Distanz des Erzählers gegenüber dem Erzählten, die sich bereits in dem ersten Roman Krležas als wesentliches Kennzeichen herauskristallisierte, wird hier ausdruicklich und direkt in der Rolle veranschaulicht, die der Erzähler in BB spielt. Die erzählerische Grundhaltung der Distanz, mit der der Erzähler seinem Gegenstand gegenübertritt, kommt jedoch nicht nur in seiner Position als Ausländer zum Ausdruck, sondern vor allem auch 
in der ebenfalls im Prolog angedeuteten Konzeption des Romans als einer mittelalterlichen Komödie, eines politischen Marionettenspiels, das gleichermaßen komische und tragische Züge aufweist. Der Erzähler stellt uns die Welt des Romans als Bühne vor, auf der die Figuren agieren. Diese Distanz, die der Erzähler als Ausländer und Regisseur einer Welt von Puppen besitzt, bietet inm Spielraum für Ironje und Sarkasmus. Ausdrucksweise und Ton lassen deutlich erkennen, daB der Erzähler seine Figuren nicht ganz ernst zu nehmen gewilt ist. 6 Mit folgenden Worten kündigt er zum Beispiel im Prolog den Versuch von Kerinis an, Nielsen umzubringen:

Kerinis wird im dritten Buch dieses blitwischen Poems abreisen, um dem flüchtigen Tier den Garaus zu machen, er wird jedoch bel dieser ritterlichen und edien Arbeit selbst sein Leben einbüBen. (BB, 24 f.)

Belustigung und Ernst kennzeichnen den Ton des Erzählers in tbereinstimmung mit dem Charakter des Romans als Tragikfarce, der im Prolog angekrindigt und in einer Reihe von Szenen verwirklicht wird. Als es zum Beispiel bei "Dominik" zu einer SchleBerei kommt, wird nicht, we beabsichtigt, Nielsen getroffen, sondern einige andere Personen. Diese Szene wird jedoch nicht"realistisch" gebracht, sondern in grotesker Verzerrung. Als Knutson nach der SchieBerel zu Nielsen sagt, das er verletzt sel und inm blut aus dem Armel rinne, antwortet ihm Nielsen, jemand habe ihn mit Rote-Rübensalat begossen (BB, 166). Nicht nur in solchen Szenen läBt der Erzähler durchbl1kken, daB die Figuren Puppen sind, sondern er vergleicht sie überdies immer wieder ganz direkt mit Puppen. Am deutlichsten kormt der marionettenhafte Charakter des Ganzen jedoch in dem symbolischen "Puppen"-Spiel zum Ausdruck.?

6 Vgl. I. Vidan, 86.

7 Vgl. Kap. III, S. $144 \mathrm{fI}$. 
Die doppelte Distanznahme zum Geschehen läßt erkennen, $\mathrm{da} B$ gerade sie eines der Hauptprobleme für den Autor selbst ist. Er muß genügend Abstand von den Ereignissen gewinnen, um das Gräßliche und Ungeheure in ironischer irechung objektivieren und damit künstlerisch darstellen zu können. Er muß die Möglichkeit einer scheinbar unparteiischen Stellungnahme haben, darf sein inneres Getroffensein, seine Empörung über die menschenunwïrdigen Verhältnisse nicht direkt zum Ausdruck bringen. Wird diese Distanz zwischen Satiriker und objekt der Satire zerstört, so gerät die Darstellung in die Nähe polemischer Auseinandersetzung. Die unmittelbare Aktualität des Stoffes sowie die Tendenz Krležas, sich direkt zu engagieren, erschweren den Prozeß der künstlerischen Objektivierung in besonderem Maße. Wie sehr inn dieses Problem beschäftigt und wie wesentlich es für sein Schaffen ist, kommt nicht nur expressis verbis in der Einkleidung der Erzählsituation in BB zum Ausdruck, sondern noch deutlicher in der kurzen Erzählung "Dobrotvori" (G). Fijucek, der in einem büro für wohltätige Zwecke arbeitet, sammelt seit Jahren Miaterial - lauter Fälle aus der unmenschlichen Wirklichkeit, mit der er tagtäglich in berühmung kommt -, das er zu einer ivovelle in autobiographischer Form verarbeiten möchte. Er kommt jedoch nie über die ersten beiden Seiten hinaus, da er der Wirklichkeit, die er anzuklagen gedenkt, zu sehr verhaftet ist. Er kann sich nicht über die Dinge stellen, es gelingt ihm nicht, sich $2 u$ distanzieren. Gerade deswegen weil das Leben seines fiktiven Helden so "furchtbar" mit seinem eigenen übereinstimmt, weil der Held der Novelle und Fijucek ein und dieselbe Person sind, bleibt die Erzählung ungeschrieben. Die Gedankengänge Fijuceks, in denen er über den ProzeB der Objektivierung reflektiert, sind höchst aufschlußreich und berühren unmittelbar die Probleme Krležas selbst: 8

$8 \mathrm{Vgl}$. Krležas Eintragungen in seinem Tagebuch (DD, 85, $175 \mathrm{f}$. 250). 
Das Geheimnis der künstlerischen Gestaltung liegt in der Spaltung der Persönlichkeit (...). Er, Fijucek, der hier wie eine unbedeutende, hungrige, armselige Wanze in einem düsteren Zimmer verfault, er muß sich auf die Höhe künstlerischer objektivierung emporschwingen, er muß sich selbst erhöhen und muß aus der sogenannten Vogelperspektive auf sich selbst herabblicken. Solange ihn die Schmerzen dieses armen Tagelöhners Fijucek so unmittelbar aufwühlen, $d a B$ es ihm bei der Schilderung seiner eigenen Armut die Kehle zuschnürt, so lange ist all das Dilettantismus! $(G, 69)$

Die betonte Abstandnahme der persönlichen Erzählergestalt in $\mathrm{BB}$, die in ihrer Rolle versinnbildlicht wird, bietet die unerläBliche Voraussetzung für die Entfaltung von Ironie, die, als wesentliches Mittel des Satirikers Krleža, nur vermittels dieses Spielraums wirksam werden kann, den der Erzähler zwischen sich und das Erzählte legt. DaB diese Rolle des Erzählers als Spielleiter und ironisch-satirischer Interpret der Geschehnisse auf der imaginären Bühne Blitwiens jedoch nur eine Maske ist, beweisen jene Stellen im Prolog und vor allem auch im Roman selbst, wo der Erzähler in ernstem und zum Teil pathetischem Ton zu direkter Anklage übergeht - allerdings auch bier meist noch mit einem gewissen Vorbehalt in der Stimme.

Im Prolog tritt der Erzähler ausdrücklich seine Rolle als Vermittler des Geschehens vorübergehend an Nielsen ab, der einen besseren Einblick in die blitwischen Verhältnisse besitzt als er selber. Der Erzähler gibt vor, sich im Rahmen dieser "informativen Einführung" - des Prologs - "im wesentlichen" an eine "außerordentlich interessante, dokumentarische Studie" Nielsens über die blitwische Frage zu halten (BB, $15 \mathrm{f.}$ ). Vermittels dieser Fiktion distanziert er sich vom Stoff, und es gelingt ihm, eine Scheinobjektivität zu wahren. Durch die thernahme der Rolle eines ausländischen Beobachters hat er sich jedoch außerdem ein indirektes Mitspracherecht bei der Beurteilung der von ihm übermittelten 
Vorgänge erworben. Daß der Erzähler jedoch kelneswegs gewillt 1st, den im Prolog angekündigten AuBensichtsstandort elnzuhalten, zeigt sich bereits in 1. Kapitel des Ronans. Er sleht seine Gestalten auch von innen. Der Widerspruch 2wischen Einkleidung (beobachtender Ausländer) und Standpunktwahl (Innensichtsstandort und nur gelegentlich LuBensichtsstandort) wind Jodoch zum Tell dadurch verdeckt, daB der Erzähler hin und wieder vorgibt, nicht mehr zu wissen als die angeführten Gerüchte, oder dadurch, daB er zum Beispiel den ersten langen Gedankenmonolog Barutanskis mit einem "ungelähr" einleitet, mit dem er zu verstehen gibt, daß er nicht ganz genau we1B, was Barutanski in Wirklichkelt denkt (BB, 29). Manchmal schränkt er sein Wissen auch durch ein "vielleicht", "das ist unklar" oder "man weiB nicht warum" ein. Ein Beispiel:

(...) im mittleren und gröBten, dem sogenannten "Kolonnadensaal", der der mündlichen tberlieferung gemäB, man weiB nicht warum, "Kolonnadensaal" genannt murde, denn es befand sich In ihn keine einzige Säule, also in diesem sogenannten Gala-"Kolonnadensaal" von Beauregard fand beute ein Skripnik-Abend statt. $(\mathrm{BB}, 300)$

Hieraus wird ersichtlich, daB der Erzähler seine Allwissenheit nur in bezug auf völlig bedeutungslose Dinge einschränkt. Das wesentliche Anliegen dieser Elnschränkung ist jedoch ntcht die Fingierung von Wirklichkeit und die tberbrückung jenes Widerspruchs 2wischen Elnkleidung und Standpunktwahl, sondern die Bestätigung der Anwesenheit eines höchst subjektiven Erzählers, der hinter der Maske der Ironte zu uns spricht. Gerade dadurch, daß er selbst bei der Beschreibung eines augenscheinlich so nebensächlichen Ortes der Handlung, wie es der Kolonnaden-Saal ist, mit einer ironischen Reflexion hervortritt, läBt erkennen, wie wenig ihm daran gelegen ist, seine Anwesenheit zu verbergen.

GemäB seinem Standort als AuBenstehender registriert der Erzähler von Bo die Gesten der Personen, ihre Bewegungen, ihr 
ulenenspiel oder andere AuBerungen, die für einen Zuschauer oder Zuhörer ohne Schwierigkeit erkennbar sind. Charakteristisch für den Erzähler ist jedoch, daB er nicht nur konstatiert, sondern beurteilt, analjsiert, kommentiert und uns überdies auch die innerseelischen Vorgänge verrät. Noch bevor die erste Dialogszene zwischen Barutanski und Georgis beginnt, spielt der Erzähler sich als beurteilender und interpretierender Beobachter in den Vordergrund.

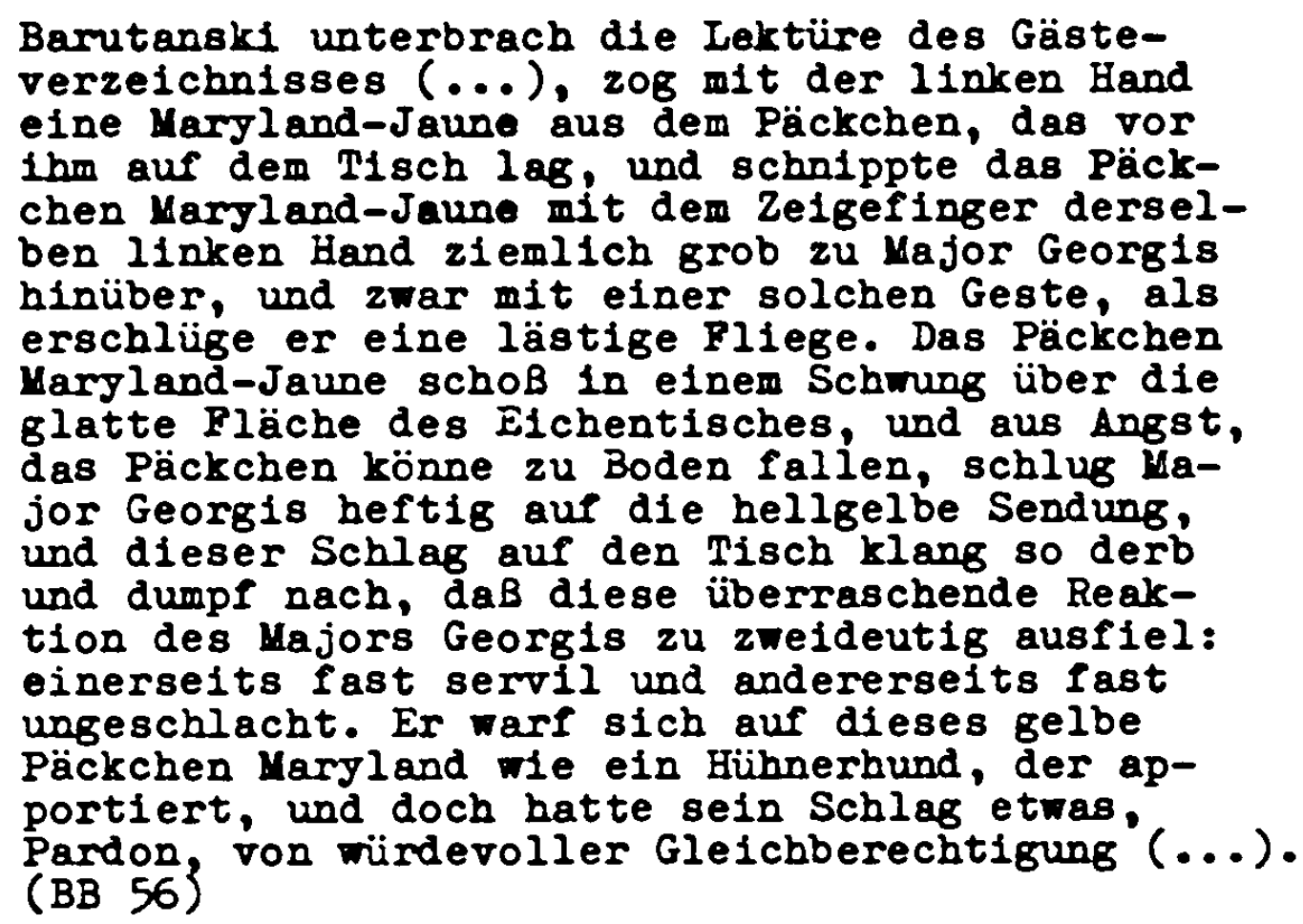

DaB der Erzäbler, der die Gesten der Anwesenden mit besonderer Genaugkeit registriert und seinen Beobachterstandort hier streng beibehält, ständig mit einem Blick auf den Leser spricht, wird vor allem aus der Hendung "Pardon" klar. Zwar läBt er die Gesten der Personen nicht für sich sprechen - er zieht sie zur direkten Charakterisierung der Gesprächspartner heran -, aber er gibt doch vor, ihr Wesen nur aus diesen Gesten erschließen zu können. Charakteristisch für ihn ist die überaus genaue Beobachtung. Man gewinnt den Eindruck, daB nicht nur die sprechenden oder monologisierenden Romanfiguren vor uns stehen, sondern daB sich stets auch noch eine andere Person auf der "Szene" aufhält. Besonders deutlich kommt dies 
in folgender kleiner Szene zum Ausdruck: Barutanski befindet sich allein in seinem Arbeitszimmer, d.h. Barutanski u n d der Erzähler, der die Telefonsignale hinter Barutanskis Rücken bemerkt, die diesem entgehen. Der Erzähler registriert sie jedoch nicht nur, sondern er knüpft eine kurze Reflexion an, die die Erwartung des Lesers auf das angekündigte Telefongespräch erregen und gleichzeitig den überlegenen Standpunkt des regieführenden Splelleiters bewust machen soll.

Hinter Barutanskis Rücken blinkte schon ziemlich lange das rote Licht an einem der Telefonapparate auf seinem Tisch. Da er sich in einem Lehnstuhl neben dem Kamin ausgestreckt hatte, konnte er nicht sofort bemerken, wie dieses intensiv rote Licht auf dem Schreibtisch erregt aufleuchtete und wieder erlosch, als wolle es aus der Ferne eine besonders wichtige Nachricht ankündigen. Aus dem blitwischen Schneesturm und Nebel versuchte jemand mit dem Kommandanten in Verbindung zu treten und 2 war über den Draht des Geheimtelefons, das (...) immer nur Dinge von erstrangiger Bedeutung übermittelte. Dieses rote Licht am Geheimapparat leuchtete weiterhin nervös auf, so als ob es in seiner taubstummen Beharrlichkeit ganz sicher wïBte, daB der Kommandant ( ...) nach allen Regeln der Logik früher oder später das Signal dieses geheimnisvollen Leuchtturms bemerken müBte. Und wirklichl Das Blinken hatte noch keine zwei Minuten gedauert, als Barutanski das Gefühl hatte, jemand berühre ihn mit unsichtbarer Hand von hinten am rechten Ohr; er richtete instinktiv seinen Blick auf den Schreibtisch und bemerkte das rote Signal, überzeugt davon, es handele sich wieder um eine unangenehme Nachricht. (Bष, 253)

Hier zeigt sich, daß der Erzähler keineswegs nur aus den Gesten der Personen auf deren Gedanken und Gefühle schlieBt. Weiterhin wird deutlich, warum der Erzähler immer wieder von neuem seine subjektive Anwesenheit bekräftigt und nicht hinter dem Erzählten verschwindet, wie er es im Prolog angedeutet hatte. Um die kritische Distanz und Freiheit gegenüber 
seiner erzählten Welt beibehalten zu können und sich damit Splelraum für seine Ironie zu schaffen, muB die Rolle des persönlichen Erzählers bemut vergröBert werden. 9 Die gelegentliche Elnschränkung des Wissens und der hin und wieder eingenommene Beobachterstandpunkt tragen spielerische Züge und dienen letztlich der Bestätlgung der Freihelt des Erzählers, der seinen Standort nach Belleben verändern kann. Besonders deutlich wird dies in all jenen Fällen, wo der Erzäbler seinen Bllckpunkt sowohl über und auBerhalb der Personen, als auch in ihnen hat. Das folgende Beispiel beweist, daB der Erzähler nicht nur über das Innere elner oder einiger Personen Bescheid weiB, sondern daß er sogar mit den Gedanken und Gefühlen eines Kollektivs, wie dies die Gesellschaft darstellt, vertraut ist.

(...) und in den Gedanken begann das ratlose UmherschieBen der kleinen Fische vor dem groBen Hecht, aber was die äuBere, konventionelle Erscheinung dieser Unruhe betrifft, so hätte, abgesehen von nervösem Hüsteln da und dort, nicht einmal das erfahrenste Auge eine besondere Bewegung in den Herzen dieser Hohlköpfe wahrnehmen können. (BB, 309)

Des öfteren welB der Erzähler sogar mehr als seine Gestalten und erklärt Dinge, die den Personen im Augenblick des Sprechens oder Denkens gar nicht bewußt sind. Obwohl der Erzähler Barutanskis Gedankenmonolog mit einem "ungefähr" elnführt, unterbricht er diesen mit souveräner tberlegenheit, kommentiert und beurteilt kritisch dessen Gedankengänge von seiner höheren Warte aus und macht sich überdies über Barutanskis gedankliche Entgleisung lustig:

Verwirrt von den Kontrasten verlor Barutanski trotz seines angeborenen Scharfsinns einen Moment lang die Kontrolle über dieses Bild, das in seinem Hirn aufgetaucht war, und er bemerkte

9 Vgl. Hielscher, Karla: A.S. Puskins Versepik. Autoren-Ich und Erzählstruktur. München 1966. (= Slavist. Belträge. Bd 22.), s. 110 . 
nicht, wie komisch er in diesem Augenblick eigentlich war. Die Wirklichkeit stimmte hier nicht mehr mit seiner Vorstellung von ihr überein, denn dies alles waren bereits Phantasmagorien an der Grenze des Opernkitsches, vor dem sich Barutanski Jahrelang so schrecklich gefürchtet hatte ... $(\mathrm{BB}, 48)$

Aus all diesen Beispielen wird ersichtlich, daB der persönliche Erzähler sich mit längeren oder kürzeren Kommentaren, Reflexionen, Urteilen, Vergleichen oder Redefloskeln und nicht zuletzt durch seinen ironischen und bisweilen sarkastischen Tonfall immer wieder in den Vordergrund spielt. Seine Anwesenheit wird vor allem in Kleinigkeiten sichtbar: kurze Kommentare in Klammern, die etwas ergänzen oder erklären und die mit einem Blick auf den Leser eingeschoben werden. R. Baumgart weist darauf hin, dab diese Stilmittel zweideutig sind, "denn aus solchen Ausrufen und Fragen spricht nicht die Geschichte selbst, sondern ein Erzähler, der die Spannungen seiner Gesckichte, halb ironisch schon, mit- und nachspielt, um für sie beim Leser um eine ähnlich zwischen Ergriffenheit und Belustigung schwankende Anteilnahme zu werben." 10 Während in FI die Anwesenheit des allwissenden Erzählers kaum auffallt - sie wird nicht besonders hervorgehoben und erscheint einfach als selbstverständlich -, macht der Erzähler in BB, ganz abgesehen von jenen längeren Kommentaren, in denen er in eigener Person zu uns spricht, gerade durch das Spiel mit seinem Wissen und seinem Beobachterstandpunkt immer wieder auf seine überlegene Anwesenheit aufmerksam. Andererseits tritt der Erzähler, was die Darstellung der Handlung und der Vorgeschichte betrifft, doch in den Hintergrund und verwirklicht damit die im Prolog angedeutete Dramatisierung des Geschehens.

Als besonders aufschluBreich für die Beurteilung der Person des Erzählers sowie für seine Erzählhaltung erweisen sich die ersten eineinhalb Seiten von III, 9. Ebenso wie im Prolog 
äuBert sich der Erzähler, der auch hier in der 1. Person Plural von sich spricht, über das Erzählte. ${ }^{11}$ Einerseits verleiht er der im Prolog dargelegten und im Roman verwirklichten Konzeption des Ganzen als tragisch-komisches Puppentheater Ausóruck, indem er das Erzähite ais "rcmanojezska igra" und "blitvo-blatvijska komedija" bezeichnet. Andererseits nennt er den Roman "kronika", "ljetopis" und "historija" und hebt den Bezug der fiktiven Geschehnisse zu den wirklichen politischen Ereignissen in Europa hervor. Fiktion und Wirklichkeit werden hier miteinander verflochten, und der reale Hintergrund dieser blutigen Komödie kommt zum Vorschein. Die auf einer Larionettenbühne sich abspielenden und von einem distanzierten Kommentator in ironisch-sarkastischem Tonfall erläuterten Ereignisse finden ihre Entsprechung in der Wirklichkeit des zwanzigsten Jahrhunderts und werden überdies von dieser noch übertroffen.
(...) diese unglückselige und elende blitwisch- blatwische Komödie erweist sich heute, aus der Retrospektive von zwei bis drei Jahrzehnten, als naives Vorspiel zu einer ganzen Reihe ge- spenstischer Gewitterstürme, die gegen Ende der dreibiger Jahre unseres Jahrhunderts als bluti- ge und tödliche Drohung über die gesamte westeu- ropäische $Z$ ivilisation hinwegbrausen sollten. $(F, 180)$

Der Erzähler gibt sich hier als der Autor und Zeitgenosse des Lesers zu erkennen, der die Ereignisse einer geschichtlichen Epoche niedergeschrieben und Kommendes vorweggenommen hat. Der fiktive Barutanski, Sinnbild des blutrïnstigen Tyrannen, findet eine Anzahl von "Imltatoren auf der polit1schen Bühne unseres kleinen Planeten." (F, 181). Blitwien

11 Im Gegensatz zum Prolog wird hier die Erzählergegenwart ausdruicklich realisiert. Der Erzähler, d.h. hier der Autor, beurteilt nach einem Zeitraum von über zwanzig Jahren - nach jenem Zeitraum, der 2wischen dem Erscheinen der ersten beiden Bücher und dem dritten liegt - die Geschehnisse aus rückblickender sicht. 
erweist sich als Symbol für die unmenschliche politische Wirklichkeit unseres Jahrhunderts, die durch zwei Weltkriege erschüttert wurde. Krleža spricht nicht nur von seiner fiktiven Welt als Bühne, sondern auch in bezug auf die Wirklichkeit.

Es ist der 2wiespalt zwischen Fiktion und Wirklichkeit, auf den wir hier in betonter Welse aufmerksam gemacht werden. Bereits im Prolog beginnt dieses doppeldeutige Spiel. Der Erzähler, der sich un Wahrheit der Darstellung und um Faktentreue bemüht, gibt vor, sich an Nielsens Studie zu halten, was die Darlegung der blitwischen Frage betrifft. Er betont ausdrücklich, daB diese Studie dokumentarisch fundiert sei, und unterstreicht den Charakter der Wirklichkeitsfinglerung noch dadurch, daB er in einer Anmerkung das Erscheinungsjahr des Buches von Nielsen angibt. In zwei weiteren Anmerkungen fügt er erklärende Ergänzungen für den Leser hinzu, die beide ebenfalls exakt datiert sind. Weiterhin gibt er in seinem kurzen tberblick über die blitwische Geschichte die genauen Jahreszahlen an und bezieht sich auf wirkliche historische Ereignisse wie die Friedensverhandlungen in Versailles. In II, 5 führt der Erzähler den Leser an Hand eines längeren historisch-soziologischen Kommentars in die blatwischen Verhältnisse ein und gibt unter anderem einige blatwische Volkslieder wieder. Er erklärt und übersetzt diese blatwischen Lieder und Sprüche und fügt mehrmals ein "ungefähr" ein. In den Anmerkungen, die den ersten beiden Büchern angefügt sind, führt er an, daB er die zitate der einzelnen blatwischen Volkslieder dem Buch "Blatvijas Kurtàla", einer Sammlung blatwischer Volksdichtung entnommen habe, die von einem blatwischen Dominikaner zusammengestellt worden sei. Sie seien nach Motiven von Volksliedern seiner eigenen Heimat ("po motivima naše narodne pjesme") bearbeitet worden, da sich hier ("kod nas") unter den vergleichenden Philologen ("medju našim komparativnim filolozima") nlemand gefunden hätte, der sie vom blatwischen Original hätte übersetzen können ( $B B, 401$ ) 
Was die Zeitungsartikel betrifft, die Barutanski liest, so behauptet der Autor in einer Anmerkung, daB sie Originaltexte seien, die er einem nordosteuropäischen diplomatischen Bulletin entnommen habe ( $B B, 401)$.

Alle diese Angaben dienen dazu, den Tatsächlichkeitsanspruch der dargestellten Ereignisse zu unterstreichen. Der Erzähler stellt in seiner Erzählung wirkliche Ereignisse dar - nicht erfundene. Andererseits aber steht ihm dieser, der Wirklichkeit entnommene Stoff als eine Piktion zur freien Verfügung. Die Illusion der Wirklichkeit wird dadurch zerstört, daß der Erzähler den literarischen Charakter des Ganzen hervorhebt, $d a B$ er uns darauf aufmerksam macht, daB die von ihm fabrizierten Gestalten Puppen sind, daB er das Geschehen in einem imaginären Raum ansiedelt und daB er es iberdies als "mittelalterliche Komödie" bezeichnet. Der Ton des Erzählers sowie seine Haltung haben nichts von einem Chronisten an sich, sie sind vielmehr seiner Rolle als Regisseur eines Spektakels angepaßt. Gerade in Jenen Partien, wo er sich auf die realen historischen Gegebenheiten bezieht, wie im Prolog, in II, 5 und III, 9, fällt die Verfremdung durch Ironie oder komödien- und märchenhafte Elemente besonders auf. In Buch III weist er uns auf die tbereinstimmung von Piktion und Wirklichkeit hin und läBt gleichzeitig das Bewußtsein erkennen, etwas Ifterarisches zu unternehmen. Ironisch reflektiert er über die Schwierigkeit, eine geeignete Methode der Darstellung zu finden, da die Angaben über die Geschehnisse im Zusammenhang mit Barutanskis Tod auf "mehr oder weniger schwachsinnigen Unwahrheiten" bemuhen $(F, 180)$. In keinem anderen Roman Krležas kommt dieses doppeldeutige Verhältnis von Fiktion und Wirklichkeit so zur Geltung wie in $\mathrm{BB}$.

In Buch I von 2 zeichnet sich die bereits in BB ersichtliche Tendenz, eine persönliche, faßbare Erzählergestalt in den Vordergrund der Erzählung zu rücken, in noch stärkerem Kaße ab. Dieser Erzähler tritt weit häufiger und vor allem 
weit souveräner auf als jener in 33 . Er ist allein schon deshalb freier und beweglicher, weil er sich nicht auf eine bestimmte Rolle festlegt. Er besitzt mehr inneren Abstand zum Geschehen und sein Ton ist dementsprechend weniger ernst als in $\mathrm{B} B$, wo der Erzähler sich um seine ironische Distanz ausgesprochen bemilhen muß.

Das erste Juch von $Z$ ist durch die Anwesenheit eines Erzäblers gekennzeichnet, der sich mit kïrzeren und auch längeren Komentaren in das Erzählte einnlscht, der seinen Standpunkt der iachzeitigkeit und damit seinen Uberblick iber das gesamte Geschehen in Form ron weit in die Zukunft hineiareichenden Vorausdeutungen immer wieder nachdrücklich ins zewuBtsein ruft, der den Leser des öfteren anspricht, der das Geschehen souverän unterbricht, um eine neue Person einzufihren, die Fersonen ironisch anspricht und unzeniert beurteilt und der schließlich die verschiedenen Teile der Handlung aufeinander beziebt und den jeser an bereits Geschehexes erinnert. Der Erzähler steht als Demiurg über der von ihm geschaffenen Welt, mit der er nach belieben schaltet. Er besitzt uneingeschränkte Eirsicht in das Innere aller Fersonen und verfügt überdies über mekr Distanz zu der Hauptperson Zamilo als der Erzäbler von BB zu Nielsen. Bezeichrend ist die Art und Teise, wie die Vorgeschichte einiger Personez eingeschaltet wird. In FL, wo der Erzähler genauso wie in $Z$ die Vorgeschichte selbst berichtet, geschieht dies vertältaismäkig unauffällig, indem nach oder vor dem Auftreten der vetreffenden Fisur ein oder mehrere Kapitel eingesctoben werden. In $z$ dagegen hält der Erzähler die Handlung mitten im Kapitel auf und macht den Leser ausdricklich darauf aufmerksam, das er jetzt die Jorgeschichte erziblt. So unterbricht er in höc.ist ironischem Ton einen Gedankenmonolog Emerickis über seinen Sobn Kamilo und macht sich unverhïllt über 5meriłkis sorgenvolle Gedanken lustig, bevor er inn uns auf mebreren Seiten vorstellt. 
Kada Presvetli De Emericzl ocajava nad svojim izgubljenim sinom, treba znat1 tko je On, odakle je stigao On u nake zbrkane 1 jadne prilike, od kakrih ponosnih antenata 1 ispod kakvih slavnih krovova, kada se na rubu bolecive tjeokobe gubi u bolnoj neizvjesnosti nad sudbinom svojom 1 svoga srca porodom, gdje se sve sudbonosnije ocrtava karakter njegova jedinca kao kobna prijetnja, koja ga moze strovaliti, 1 njega, 1 sve njegove, na dno najperverznifeg pakla, medju perverzne prokletnike, kojima je sudjeno da padnu od perverzne ruke svog vlastitog, perverznog djeteta ... $(z, 1,255)$

Die GroBschreibung, die dreimalige Wiederholung des Adjektivs "pervers" und vor allem das übertriebene Pathos der Worte des Erzählers lassen keinen Zweifel an seiner Haltung gegenüber Emericki, als typischem Vertreter des kroatischen Banalbeamten.

Häufig sind ironische Seitenhiebe der Art, daB der Erzähler sich ausdrücklich der Phraseologie einer Gestalt der Erzählung oder einer bestimmten literarischen Gattung bedient:

$$
\begin{aligned}
& \text { (...) Kamilo je zivio (da se 1zrazimo regni- } \\
& \text { kolarno-kurijalnim stilom njegova gospodina } \\
& \text { oca), razdrt "bilateralno" - na dvije strane (...). } \\
& (2, i, 445)
\end{aligned}
$$

Während der Erzähler in oblgem Beispiel nur einen charakteristischen Ausdruck einer Romanfigur in irontsche Anfübrungszeichen setzt, ahmt er in folgendem die pathetische, altmodische Ausdrucksweise der kritisierten Schicht von Personen über mehr als eine halbe Seite hinweg nach. Der erste Absatz soll als Belspiel genügen:

Kamráthova gospodja supruga slomila se, kao to se pişe u staromodnim romanima, pod teretom tragilnog dogadjaja, iskapivisi slabiju dozu veronala, pa kad se jedne dramatske noti sve sretno svrsilo 8 ispiranjem gospodjina želuca na klinici, otputovala u Beč, da se tamo pod okriljem nježne sukuti evoje još そ̌ive mame generalice vrati na trnovitu stazu stradanja 1 patnje, sa koje te je sudbina ukloniti ret slijedece jesent, kad joj budu javili da je njen ljubimac, jedina 
njena ovozemal jaka nada, Jenöke, Zrtvovao husarsku lajtnantsku karijeru za Grozdenu Slavu Dvoglavoga Orla. $(2,2,233)$

Diese für den Erzähler von $Z$ bezeichnende Haltung gegenüber den meisten Gestalten seiner Erzählung - er steht über ibnen, nimmt sie nicht ernst und macht sich sogar über ihre Krankheiten und ihren Tod lustig - findet ibren Ausdruck in der Konzeption des Ganzen als "gluma". Die Auffassung des Erzäblers von der Welt als Theater und von den Gestalten als Puppen kommt auch in diesem Roman zum Ausdruck, der ähnlich wie BB als "ljetopis" und "kronika" bezeichnet wird. 12 Wieder wird hier, wenn auch nicht so ausgeprägt wie in $B B$, der Zwiespalt zwischen Fiktion und Wirklichkeit ironisch ausgespielt. Einerseits sind dem Erzähltext eine ganze Reihe von 2 itaten aufmontiert, die kroatischen, ungarischen oder Wiener Zeitungen entnommen wurden, und die Personen diskutieren iber politisches Zeitgeschehen, wie die Balkankriege oder die politische Situation in Ungarn und Kroatien ganz allgemein oder über ganz konkrete Attentate. Die Schauplätze der Handlung sind genau lokalisiert: Agran, Wien, Budapest. Die erzählte Welt ist die der Gestalten und des Erzählers, und sie hat ihre Entsprechung in der zeitgenössischen Wirklichkeit Osterreich-Ungarns und Kroatiens. Andererseits hebt der Erzähler den fiktiven Charakter der Erzählung hervor, indem er die komödienhaften Elemente hervorkebrt und damit auf den literarischen Charakter der Erzählung hinweist.

Ahnlich wie auch schon in FL und BB treibt der Erzähler sein Spiel mit der Fiktion in der Weise, daB er über den Verlauf der Handlung reflektiert und Uberlegungen anstellt, was geschehen wäre, wenn dies oder Jenes Ereignis nicht einge-

12

Der Erzähler von $Z$ äußert sich mit einer ganz ähnlichen Pormel über das Erzählte wie der von BB. V8l. F, 180; Z, 1,438 . 
treten wäre. Er fingiert ein Eigenleben der von inm geschaffenen Gestalten. Das ironische Spiel mit der Wirklichkeit kommt in folgender Reflexion des Erzählers besonders gut zum Ausdruck und wirft ein bezeichnendes Licht auf seine Erzählhaltung:

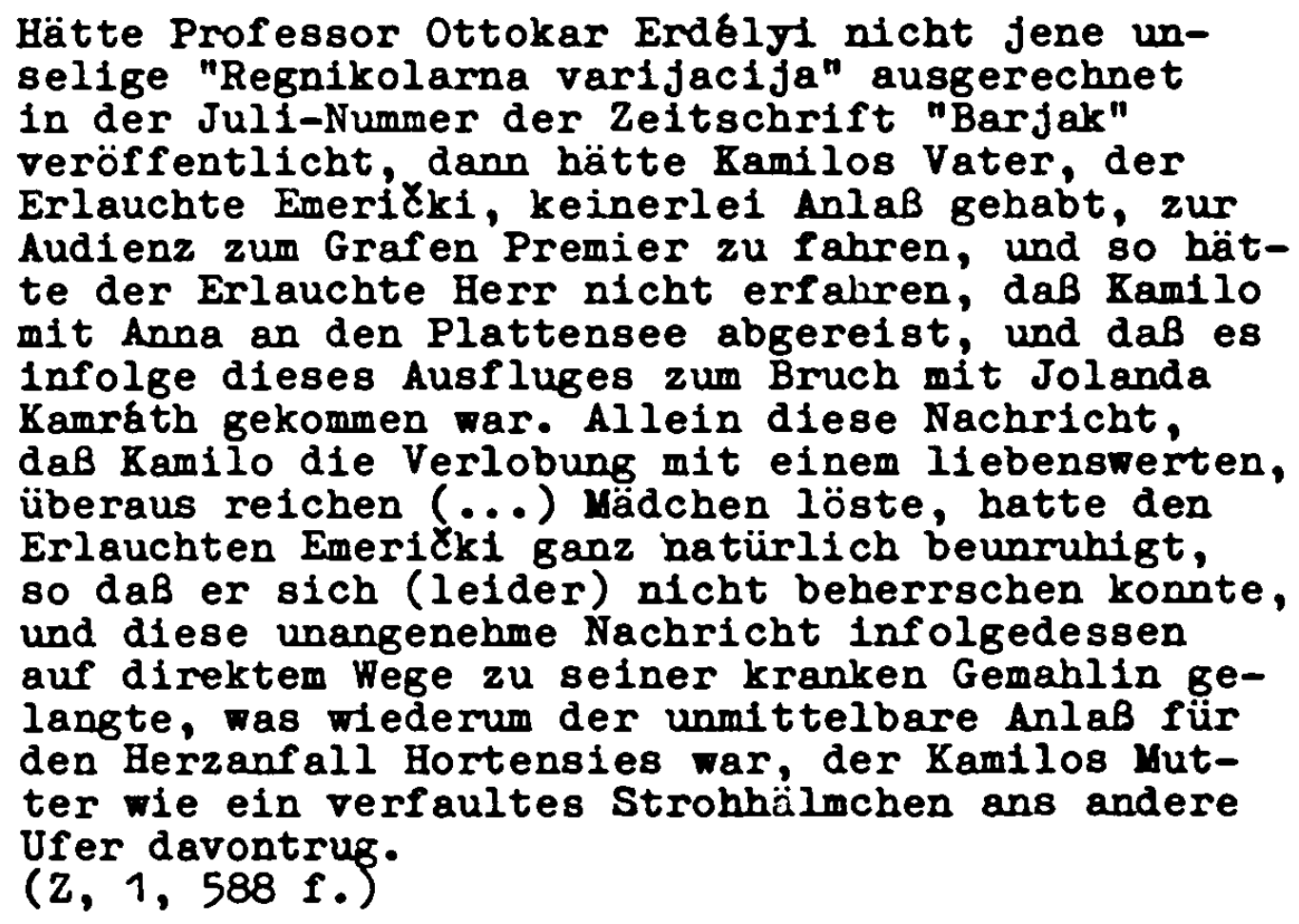

Der Erzähler rafft hier sämtliche Ereignisse der ersten Kapitel zusammen, nimmt zukünftiges Geschehen vorweg und gibt gleichzeitig vor, die Gestalten der Dichtung, auf die er aus groBer Distanz ironisch lächelnd herabsieht, seien wirkliche Gestalten.

Auffallend am Erzähler dieses Romans, der so souverän und willkürlich mit dem Geschehen verfährt, ist die Tatsache, daß er kaum Angaben über sich selbst macht und seine Person möglichst im Hintergrund hält. Er wird in erster Iinie durch seine Urteile, seine Abneigungen oder Vorlieben und durch seine Stellungnahme $z u$ den verschiedenen Ereignissen zu einer greifbaren Person, nicht jedoch dadurch, daB er wie in $B B$ eine bestimmte Rolle spielt und in der 1. Person Plural von sich spricht. 
Wenden wir uns nun dem zweiten Aspekt der Erzäblbaltung zu, dem Leser. Welche Haltung nehmen die Erzähler der Romane dem Leser gegenüber ein und welcher Art ist dieser Leser? Der Leser gehört genauso wie der Erzähler der Fiktion an. Er wrd vom Erzähler geschaffen und spielt eine bestimmte, von diesem vorgeschriebene Rolle. W. Kayser spricht von der Leserrolle, die jeweils vorgeformt wird. ${ }^{13}$ Je stärker der Erzähler hervortritt, desto mehr wird auch der Leser in die Erzählung einbezogen.

In Krležas Romanen, die alle mehr oder weniger ausgeprägt satirische Züge aufweisen und durch die ständige Anwesenheit eines ironisch sprechenden, persönlichen Erzählers gekennzeichnet sind, spielt der Leser eine wichtige Rolle. Die Ironische Sprechweise des Erzählers erfordert Mitdenken und Verständnis vom Leser. Es muß elne gemeinsame Basis geschaffen werden, damit der Erzähler in seiner Rolle durchschaut und der richtige Sinn seiner Worte erfaßt werden kann. "Diese gemeinsame Ebene 1st das Wissen um die Fiktion des Frzählten." 14 Es ist jedoch nicht nur dieses wissen un die Fiktion und das Verständnis für die Mehrdeutigkeit des Wortes, das vom Leser eines satirischen Romans gefordert wird. Von wesentlicher Bedeutung 1st eine grundsätzliche Ubereinstimmung zwischen Erzähler und Leser, was die Sicht der Wirklichkeit betrifft. Der Leser soll aus der gleichen Haltung der Vernunft und Koral urtellen wie der Erzähler. In Form des Gespräches bezieht der Erzähler den Leser in einen Bereich gemeinsamer Voraussetzungen ein und mobilisiert auf diese Weise dessen seelische Anteilnahme, d.h. er versucht, den Leser $g$ e $g$ e $n$ das objekt der Satire und $f \ddot{u} r$ seinen eigenen Standpunkt einzunehmen.

Der Erzähler der Romane Krležas scheint dem Leser nicht

\footnotetext{
13 Wer erzählt den Roman?, s. $88 \mathrm{f}$. 14 K. Hielscher, S. 20.
} 
allzuviel Vertrauen entgegenzubringen, was dessen Urteilsfähigkeit betrifft. Es wird ihm nie allein überlassen, eine Person oder eine Situation zu beurteilen. Stets urteilt der Erzähler, noch bevor dem Leser Gelegenheit gegeben wird, sich ein selbständiges Urteil zu bilden. D. Ze飞erit kommt anläBlich der Betrachtung der beiden Romane PL und NRP zu dem Schluß, Brležas Erzählweise führe dazu, daß die Frelhelt des Iesers - oder besser seine scheinbare Freiheit - bedroht sei. ${ }^{15}$ Bezeichnend für dieses Verfahren 1st die Art und Feise, wie die Vertreter der Gesellschaft elngeführt werden. ${ }^{16}$ Charakteristisch für die Erzähler sämtlicher Romane - am ausgeprägtesten in dem Ich-Roman NRP - ist, daB sie ständis mit einem Blick auf einen imaginären Partner, den Leser, sprechen. Die vor allem in BB und 2 häufig auftauchenden Ploskeln wie "wirklich", "in einem Wort", "man muB wissen" und andere, die ein auf den Leser hin gerichtetes Erzählen kennzeichnen, wurden bereits erwähnt. Auch Jene Wendungen, mit denen der Erzähler zuweilen Unsicherheit vortäuscht und vorgibt, nicht mehr zu wissen als die angeführten Gerüchte, oder im Ich-Roman das Eingeständnis der nicht mehr genauen Erinnerung, oder jene Wendungen, mit denen er eine Behauptung bestätigt oder beteuert, sind nur im Hinblick auf den Leser sinnvoll, dem auf diese Welse die Gewissenhaftigkeit des Erzählers bei der wahrheitsgemäBen und genauen Darstellung der Geschichte suggeriert werden soll. Häufig sind Einmischungen des Erzählers in der erläuternden Parenthese, wo er außerhalb des Textes zum Leser hin etwas bemerkt.

Es ist schon einige Jahre her (eigentlich seit Jenem Tag, als die Polizel wegen Joja Ins Haus von Emericki hineinplatzte), daB das Herz der Prau Hortensie we ein kleiner scharlachroter Teufel hin und herspringt $(\ldots)$. $(2,1,575)$
15 s. 44.
16 Vgl. Kap. I, S. $40 \mathrm{ff}$. 
Obwohl die Erzähler der verschiedenen Romane ständig im Angesicht des Lesers sprechen, sind direkte Leseranroden verhältnismäBig selten. In FI finden wir keine einzige und selbst in BB ist der Erzähler mit Leseranreden zurückhaltend. Zweimal nur wird der Leser direkt angesprochen. Das eine Mal im Rahmen des Prologs, der unmittelbar an die Zuhörer oder Zuschauer gerichtet ist und der dazu dient, die Beziehung zum Leser herzustellen und sein Interesse für die Geschichte $z u$ wecken. Unmittelbar nachdem der Erzähler sich mit zwei aufeinanderfolgenden rhetorischen Fragen an die Leser gewandt hat, spricht er diese mit "Citaoci" an. Das zweite Mal geschieht dies in III, 9, wo der Erzähler erstmals innerhalb des Romans mit einem längeren Kommentar hervortritt und seine Erzählgegenwart ausdrücklich vermerkt. Dieses Mal wendet er sich direkt an die Leser mit der Formel "poßtovani nałi Ztioci", die im Ton der Rolle des Erzählers als Ansager eines mittelalterlichen Spiels angepaßt ist. Der Erzähler von $B B$ vermeidet, ebenso wie der von $z$, eine unmittelbare Anrede an die Leser. Wird der Leser genannt, so in der Porm, als ob der Erzähler über ihn spräche: "die Leser werden es uns nicht verübeln" (BB, 15), "(was die Leser dieser Chronik höchstwahrscheinlich nicht aus dem Gedächtnis verloren haben)" ( $2,1,588)$. Anders der Ich-Erzähler aus NRP, der selbstverständlich viel unverhüllter hervortritt und sich keinerlei Zurückhaltung dem Leser gegenüber auferlegt. Er spricht den Leser häufig ganz direkt mit "Vi" an. Der Ich-Erzähler dieses satirischen Romans muB darauf bedacht sein, den Leser für sich zu gewinnen und ihn damit gegen die zylinderträger einzunehmen. Gerade hier ist eine Erzähler und Leser gemeinsame Betrachtungsweise der kritisierten Erscheinungen besonders wichtig, da sie die unerläBliche Voraussetzung lür die im Sinne des Erzählers und damlt des Autors richtige Aufnahme dieser Kritik bildet. Erst nachdem der IchErzähler sich der Zustimmung des Lesers versichert hat, beginnt er die Geschichte zu erzählen, in deren Verlauf er 
sich nur noch gelegentlich direkt an inn wendet. ${ }^{17}$ So schlieBt er die Geschichte des Einbrechers Matko mit einem direkten Appell an das Mitgefühl des Lesers ("Versuchen Sie einmal in der Teihnachtszeit durch unseren Schneematsch in zerrissenen Leinenschuhen ru wandern" NRP, 280) ab, der die Gesellschaft, die Matkos Scheitern verursachte, mit demselben Blick des Abscheus betrachten soll wie der Ich-Erzähler. Des öfteren fordert er den Leser auf, sich in seine Lage zu versetzen, und faßt überdies sich und den Leser in der 1. Person Plural zu einer Einheit zusammen.

Versuchen Sie einmal in so eine goldumrandete, "freiheitsliebende" Weltanschauung einzudringen, die da vor uns steht wie ein Vierfarbendruck (...), und machen Sie Ihrem Herm Mitbürger verständlich, daB seine Fiakerlogik auf Hühnerbeinen steht, und was wird er Ihnen antworten?

(NRP, 15)

Die Geschichte, die der Ich-Erzähler zu erzählen sich anschickt, bezeichnet er als "nała historija" (NRP, 26) und bringt damit das Erzähler $u$ a d Leser verbindende Interesse und Verstehen zum Ausdruck. Der Ich-Erzähler geht sogar so weit, eine der Romanpersonen ironisch als "unser lieber Dr. Werner" (NRP, 82) zu apostrophieren - ein Stilzug, der eigentlich nur dem auktorialen Erzäbler ansteht.

Wie wichtig dem Erzähler die richtige Aufnahme der Geschichte durch den Leser ist, beweist der Erzähler von BB, der sich Gedanken darüber macht, ob der Leser wohl imstande sein wird, den realen Hintergrund der imaginären blitwischblatwischen Welt zu erkennen, sowie darüber, ob die sich in erster Iinie auf Monolog und Dialog stützende Darstellungsform des Romans sich nicht hinderlich für das rechte Ver-

17 Allerdings läßt der Ich-Erzähler den Leser auch hier nie aus den Augen. Ständig motiviert er sein Verhalten und entschuldigt sich direkt und indirekt für die diversen

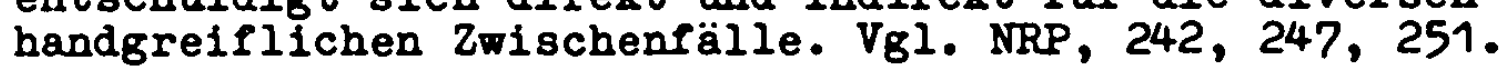


ständnis erweisen könnte. Die Monologe und Dialoge seiner Gestalten erscheinen inm als "zu schwaches Licht, als daB sie uns den finsteren und ausweglosen Pfad, auf dem sich fast alle Helden unserer Chronik verloren haben, erhellen könnten." ( $P, 181)$. Mlt halb ernster und halb verstellter Stimme ruft er den Leser schlieblich zu einem eigenen Urtell auf. Die Alternative, vor die er inn stellt, beweist jedoch, daB der Erzähler den Leser zwar zur MAtarbeit auffordert, daß or inm aber keine wirkliche Entscheidungsfreihe1t gewährt.

Wie es auch immer sei, auch ohne detaillierte Zenntnis der verborgenen Geheimnisse (...), wird es möglich sein, daB unsere verehrten Leser selbst beurteilen, ob diese Periode der blitwischen Geschichte, die durch Waffengeklirr und BlutvergieBen des Obersten Barutanski mit Schande bedeckt bleiben wird, ein Spuk aus einem Yärchen für Kinder lst oder Omen und Prophezeihung für lange Jahre des Leidens und der Qual, die sich ais Verhängnis und als Fluch nicht nur auf Blitwlen, sondern auf die ganze Welt herabgesenkt haben. (F, 181)

Was den Ton des Erzählers betrifft, so gibt er hier seine ironische Distanz, die sein Verhältnis zu den Gestalten der Erzählung bestimmt und die auch in dem Gespräch mit dem Leser zum Ausdruck kommt, in dem Moment auf, wo er sein Anliegen berïhrt - die Aufdeckung und Verurtellung einer geschichtlichen Epoche, von der seine Erzählung Zeugnis ablegen will. Die Leser, deren "Gedächtnis er aufrischen" will, sind die Zeitgenossen Barutanskis, wie er es formuliert $(F, 180)$. Erzähler und Leser gehören ein und derselben gesellschaftlichen und historischen Wiriclichkeit an, sind Zeitgenossen der Romanfiguren und wissen um die zeitgeschichtlichen Hintergrinde dieses politischen Romans. Die Verwendung der 1. Person Plural ("unser", "bei uns"), die dazu dient, Erzäbler, Leser und die Gestalten der dargestellten Welt im Rahnen eines gemeinsamen realen zeitge- 
schichtlichen Hintergrundes $z u$ sehen, ist vor allem in NRP und in 2 sehr häufig. Da der Erzähler in BB vorgibt, ein Ausländer zu sein, kann er sich kaum in die dargestelite Welt miteinbeziehen. Der Kommentar in Buch III läBt dies deutlich erkennen. Wird die 1. Person Plural in diesem Sinne benützt, so geschieht dies, um den Erzähler als zeitgenössischen Menschen ganz allgemein zu bezeichnen. In der Anmerkung zu den ersten beiden Büchern jedoch gibt sich der Erzähler in offensichtlichem Widerspruch zu seiner Rolle als Angehöriger der blitwischen Welt zu erkennen. ${ }^{18}$ Besonders deutlich kommt der reale Hintergrund des fiktiven Geschehens in 2 zum Ausdruck, wo der Erzähler als Bürger der Stadt Zagreb auftritt und die Leser als Bewohner Kroatiens miteinbezieht. So macht er aus seiner Vorliebe für die kroatische Nationalhymne ("ovaj nas slavni pastorale" Z, 1, 437) kein Hehl. Zagreb wird durchgehend als "Kleinstadt" oder als "rückständige, unzivilisierte Stadt" bezeichnet. 19 Auch der Ich-Erzäbler spricht von diesem Hintergrund aus zu seinen Lesern (NRP, 18).

Häufig sind Aussagen in 1. Person Plural, wodurch Erzähler und Leser zu einer Einheit zusammengeschlossen werden. Der Erzähler, der über der dargestellten Welt steht und aus dieser ilaltung der Distanz mit dem Leser über die Gestalten der Dichtung und die Geschehnisse spricht - gleichzeitig sind Erzähler, Leser und Gestalten jedoch auch Zeitgenossen macht den Leser auf kommende Ereignisse aufmerksam und weist auf bereits Geschehenes zurück. Er bezeichnet die Geschichte, die er erzählt, als "nała pripovijest" (BB, 16), "nała blit-

18 Vgl. S. 190 dieses Kapitels.

19 Die Sicht der kroatischen Hauptstadt und, etwas allgemeiner, der kroatischen Verhältaisse, ist in allen Romanen, in $G$ und in DD einheitlicher Natur. Vgl. NRP, 41, 47, 53, $78,95,232,236,260 ; \mathrm{BB}, 143,147 ; 2,1,439$ f . $813 \mathrm{f} .$, $810 ; Z, 2,41,459 ; G, 29,46,227 ; \mathrm{DD}, 92$. DaB mit "Kleinstadt" Zagreb gemeint ist, geht nicht nur aus der einheitlichen Bezeichnungsweise hervor, sondern auch aus ganz direkten Apostrophterungen wie "in der Kleinstadt Agram" ( $Z$, 1,810 ). 
vinska kronika" ( $P, 181)$ und "nała gluma" ( $(2,2,234)$. Indem der Erzähler seine Gestalten als "unser $X "$ bezeichnet, mit diesem Stilzug seine Anteilnahme und Vertrautheit sowie das Bemustsein des "Gemachtseins" der Figuren der Erzählung zum Ausdruck bringend, spricht er ein ähnliches Bewußtsein im Leser an, den er an seinem Verhältnis zu den fiktiven Gestalten ausdrücklich teilhaben läßt. ${ }^{20}$ Bezeichnenderweise wird das Possessivpronomen vor allem in $Z$ verwendet, dem Roman, in dem der Erzähler subjektiver und 1ronischer ist als in den übrigen Romanen. Das Possessivpronomen 1st hier als Ausdruck des willkürlichen Umgangs des Erzäblers mit den Figuren seiner Erzählung anzusehen. Die Anteilnahme an ihrem Schicksal ist gespielt und nicht echt. Nur zweimal wird in den insgesamt vier Romanen diese Bezeichnung vom Erzähler nicht zu ironischen Zwecken verwendet. Das eine Mal, als er in begeisterten Worten von Joja, der positivsten Gestalt von $Z$ spricht ("wundervoll war dieser unser Joachim Dijak-Zigman, genannt Joja" Z, 1, 440), und das andere Mal, als er von Nielsen als "unser Doktor Nielsen" spricht (BB, $106 \mathrm{ff}$.). AufschluBreich ist in diesem $\mathrm{Zu}-$ sammenhang, daß die Helden der Romane mit Ausnahme Nielsens nie als "unser Held" angesprochen werden. Noch deutlicher als in den Romanen kommt es in einigen Erzühlungen in $G$ zum Ausdruck, daß diesem Stilzug fast durchgehend ironische Funktion zukommt. 21 Gerade jene Gestalten, die er verlacht und die inm sogar verhaßt sind, nennt er "unsere liebe Charlotte" (G 35), "unseren berühmten Ritter oliver" ( $G$ 20) oder "unseren sympathischen Helden" (G 281). Auch dann, wenn der Erzïhler die Gestalten nicht als "unser $X$ " bezeicinet oder das Erzähler und Leser gemeinsame Interesse durch ein "nała historija" und dergleichen zum Ausdruck bringt, faßt er sich

20 VBl. K. Hielscher, S. 21.

$21 \mathrm{Vgl}$. v.a. "Svadio velikog župana Klanfara" (G, 281-295). 
und den Leser des öfteren in der 1. Person Plural zu einer Einheit zusammen ("die menschliche Dummeit ist eine finstere kraft unter uns" NRP, 16). Vor allem in BB, wo sich nicht nur der Erzähler, sondern auch der Leser in der Position eines Ausländers befindet, wird die gemeinsame Ebene besonders betont.

Aus all diesen direkten Hinwendungen an den Leser sowie aus der Miteinbeziehung des Lesers durch Wir-Aussagen wird ersichtlich, welche fialtung der Leser einzunehmen hat. Der Erzähler sieht in ihm nicht nur den Zuschauer eines auf der Bühne abrollenden Geschehens, der zum Mitspieler des Erzählers als Spielleiter wird, dessen laske es zu durchschauen und auf dessen Ton es einzugehen gilt, sondern auch denjenigen, der imstande ist, die zeitgeschichtlichen, politischen und gesellschaftlichen Fakten aufmerksam zu verfolgen, die inm von einem um die historische Wahrheit bemühten Chronisten dargeboten werden.

Für alle Romane Krlezas, in denen der Erzähler greifbare Gestalt annimmt, Bilt, daB zwischen Erzähler und Leser ein enges Verhältnis besteht und daB Erzähler und Leser in etwa auf einer Ebene stehen, die sich $\ddot{u}$ b e $r$ den Personen der Erzählwelt befindet. Es wird in erster Linie elne Gemeinschaft zwischen Erzähler und Leser hergestellt, in die die Romanpersonen nur gelegentlich miteinbezogen werden. Trotzdem blickt der Erzähler in gewisser Weise auch auf den Leser herab. Das Verhältnis Erzähler-Leser beruht nicht auf einer gleichberechtigten Partnerschaft, sondern vielmehr auf einer Vorrangstellung des Erzählers, dessen Diktat sich auch der Leser zu beugen hat. Er wird mehr oder weniger deutlich mit allen bitteln dazu gezmangen, sich die sichtweise und Aurfassung des Erzählers anzueignen. 
2. Die Kommentare des Erzählers

In Gegensatz zum modernen Roman, wo mit dem Zurücktreten des Erzählers und dem Verlust seines olympischen Standpunktes dessen Kommentare zum Geschehen wegfallen und der Leser infolgedessen "kommentarlos mit der Subjektivität des Erlebnisses einer Romangestalt ${ }^{22}$ konfrontiert wird, sind für die Erzähler der Romane Krležas und ihre Erzählhaltung gerade die zabllosen Kommentare charakteristisch, mit denen sie das Geschehen begleiten. Genauso wie die Vorausdeutung sind auch die Kommentare des Erzählers als Ausdruck der tberlegenheit nur von einem Standpunkt der Uberschau über das gesamte Geschehen aus möglich.

In erster Linie sind die Bommentare des Erzählers als Ausdruck seiner kritischen Distanz gegenüber der Welt se1ner Erzählung anzusehen. Der Erzähler der Romane Krležas geht nie ganz in seinen Gestalten auf. Gerade in bezug auf die Helden der Romane, die sowohl zu Trägern seiner Weltanschauung werden, als auch seiner Kritik an den Vertretern der Gesellschaft Ausdruck verleihen, zeigt sich die zwischen Annäherung und Distanz schwankende Haltung des Erzählers besonders deutlich. Ganz allgemein läBt sich folgendes feststellen: Je weniger sich der Erzähler mit der sprechenden oder denkenden Gestalt 1dentifizlert, desto häufiger sind die Kommentare, die deren Worte oder Gedanken begleiten.

Sehen wir die Kommentare des Erzählers in den Romanen Krležas nur als Ausdruck seiner Distanz gegenüber dem Erzählten an, so lassen wir eine für diesen Erzähler charakteristische Verhaltensweise auBer acht. Das auffällige Bedürfnis des Erzählers, das Verhalten der Romanpersonen sowie deren Gedanken und Worte zu kommentieren, ist auf sein Streben nach Klarhe1t, Eindringlichkeit und Unmibverständ-

22 Vgl. F. Stanzel: Innenwelt. Ein Darstellungsproblem des englischen Romans. In: GRM, 12, 1962, 285. 
lichke1t zurückzuführen. Der Erzähler läBt die Worte oder Gedanken seiner Figuren nicht für sich sprechen, er gibt dem Leser vielmehr immer wieder Anweisung, wie er sie aufgefabt haben will. Er füht den Leser in die Monologe oder Gesprëche der Romanpersonen ein, indem er das Thema vor Beginn dieser Monologe oder Gespräche nennt. Er unterbricht die Personen immer wieder, erklärt und beurtellt ihre XuBerungen, und er schlieBt die Monologe häufig in Form einer kurzen Zusammenfassung $a b$, die nicht selten eine Beurteilung der Gedanken der Gestalt mit sich bringt.

Da die erzählerische Zwischenrede sowohl in Zusammenhang mit der Rededarstellung als auch in Verlauf dieses Kapitels bereits mehrmals berüht wurde, sollen hier einige Beispiele für die häufigsten Formen genügen. Die Kommentare des Erzählers reichen von der einfachen anteilnebmenden Bemerkung bis zu längeren Kommentaren allgemeiner Art, wie zum Be1spiel der historisch-soziologische Kommentar zu Beginn von II, 5 in BB, mit dem uns der Erzäbler in die blatwischen Verhältnisse einführt. Im allgemeinen ist jedoch zu bemerken, daß längere Reflexionen des Erzählers in den Romanen Krležas vermieden werden. Zu diesem Zweck werden die Helden oder andere Hauptpersonen vorgeschoben.

Die weitaus meisten Kommentare des Erzählers führen in die Gedankenmonologe der Hauptpersonen ein. Besonders in FL finden wir eine groBe Anzahl solcher Kommentare. In folgendem Beispiel schlieBt der Kommentar des Erzäblers einen Gedankenmonolog Filips ab und leitet überdies in einen neuen Konolog ein:

Wenn Filip sich so in derartigen Reiben verschrobener und bizarrer Beobachtungen verlor,. muBte er selber, $d a B$ er sich in eine unmalerische Sehweise verirrte (...), aber dieser VerfallsprozeB, diese unaufhaltsame Entfremdung quoll immer üppiger und gebieterischer aus inm hervor. $(\mathrm{FL}, 40)$ 
Hier beurteilt der Erzähler die Gedankengänge Filips, gibt seine Vertrautheit mit Filips Innerstem zu erkennen und bringt abschließend zum Ausdruck, daB er mehr weiB als dieser. Bereits aus diesem Beispiel wird ersichtlich, in welchem MaBe der Erzähler sich als zusammenfassende, vorausweisende, beurteilende, gleichzeitis Einblick und Uberblick besitzende Gestalt ausweist, die die Führung auch dann nicht aus der Hand gibt und ständig anwesend bleibt, wenn eine Person der Erzähiung reflektiert. In den folgenden Komanen sind die Monologe der Figuren länger und die Kommentare des Erzählers bei weitem nicht so häufig wie in FI, sie sind jedoch trotz unterschiedlicher Häufigkeit für alle Romane charakteristisch. So werden die Monologe Barutanskis - vor allem in den ersten Kapiteln des zweiten buches - des öfteren von elnem allwissenden, höchst kritischen Erzähler kommentiert. Ein Beispiel:

In Barutanskis Inrerem war es in letzter Zeit immer finsterer geworden. Gegen seine erhabene Uberzeugung, man muisse sich blind an seinen eigenen Lebensstil halten und dürfe nicht "psychologisieren", versank er immer tiefer in dem Morast einer zersetzenden (...) Nervosität. Immer deutlicher fühlte er, wie er langsam die Sicherheit des blicks und der Uberzeugung einzubüBen begann, wie er sich in seinen eigenen Widerspruichen verfing, so daß ihm sein ganzes Leben wie ein nebeliges und unklares Gewirr offener Fragen vorkam (...). Vom Glutende seiner Zigarette stieg Rauch in Kringeln empor (...), der den ganzen Raum um Barutanski mit Schwaden einer truiben und verschwommenen Bildilchkeit überzog, die auf fatale Weise mit dem Begriff des Geschehens ganz allgemein übereinstimmte. - Auch das Geschehen als solches hat keinen tieferen Sinn als der Rauch einer zufällig angezündeten Zigarette! (DB, 192 f.)

Dieser etwas längere Kommentar führt nicht nur in den mit Gedankenstrich deutlich gekennzeichneten Monolog Barutanskis ein, sondern er dient der Analyse seines Zustandes, die in den folgenden lonologen ibre sestätigung findet. 
Der Erzähler läBt seine kritische Distans gegenüber der roPlektierenden Person nicht nur durch uberlegene Ortelle erkennen, sondern er manffestiert selnen Abstand zusätzlich noch durch einen ausgesprochen 1ronischen Ton. 23 Barutansk1 übernimmt in seinem Gedankenmonolog nicht nur das Stichwort. "Geschehen" aus dem Kommentar des Erzäblers, sondern er knüpft auch noch an das Bild mit der 21garette an. Das rom Erzähler gewählte Bild taucht somit im BemuBtsein der Romanperson auf.

In 2 dienen die weitgehend in 1ronischem Ton gehaltenen Kommentare weniger der Elnführung und Beurtellung der Monologe der Romanpersonen, als vlelmehr der Bestätigung der Anwesenbelt eines subjektiven Erzählers. So verbindet dieser zum Belspiel selnen Kommentar zum Tode der Frau Bmerickis mit elner ironischen Spekulation:

Die müden Augen der Frau Hortensie erloschen in Jahr ihrer silbernen Hochzelt, und wenn sie mit inrem Weggang noch b1s zum Herbst gewartet hätte, wäre dieses Jubiläum der Familien Habdelit-Emerizki ihrem Wunsch entsprechend mit dem größten Pomp gefelert worden, von dem sie dauernd 8 chwärmte (...). $(2,2,5)$

3. Der auktoriale Erzähler als tJpische Erzählergestalt der Romane Krlezas

Obwohl wir in jedem der drei Er-Romane Krlezas elnen jewe1ls anderen Erzähler vor uns haben, lassen sich trotzdem eine ganze Reihe wesentlicher züge feststellen, die ihnen

23 Auf den längeren Kommentar, in dem der Erzähler zu einem Bild Stellung nimmt, das in Barutanskis Gedanken auftaucht, rurde bereits hingewiesen ( $v$ gl. S. 187 f. dieses Kapitels). Der Erzähler korrigiert hier Barutanskis Vorstellung von der Wirklichkeit über dessen Kopf hinweg und macht ibn lächerlich, indem er uns auf dessen hohles Pathos ganz direkt aufmerksam macht. 
gemeinsam sind. Therspitzt formuliert: trotz der Unterschiede, die selbstverständlich von Roman zu Roman bestehen, kc̈nnen wir von einer für die Romane Krlezas typischen Erzählergestalt sprechen. 24 Selbst der Erzähler aus NRP, der auf Grund der Erzählsituation des Ich-Romans eine Sonderstellung einnimmt, weist gewisse Ahnlichkeiten mit diesem Typ des Erzählers auf. Da nicht das erlebende, sondern das erzählende Ich in den Vordergrund der Erzählung tritt, erfolgt eine Annäherung des Ich-Romans an die Erzählsituation des auktorialen Romans.

Fassen wir die für diese typische Erzählergestalt wesentlichen Züge noch einmal zusammen. Es ist dies ein persönlicher Erzähler, der vollen tberblick über das gesamte Geschehen sowie Einblick in das Innere aller Personen besitzt. Grundsätzlich ist es ihm jedoch möglich, die verschledensten Standpunkte einzunehmen. Im Prinzip allwissend - des öfteren weib er mehr über die Personen als sie selber - gibt er gelegentlich vor, dieses oder jenes nicht genau zu wissen; gleichzeitig mit dieser Einschränkung läßt er jedoch meist seinen olympischen Standpunkt durchblicken, indem er etwa künftiges Geschehen vorwegnimmt. Obwohl das fingierte Nichtwissen des Erzählers dazu dient, den Anschein zu erwecken, die Geschehnisse hätten sich wirklich zugetragen, ist die Einschränkung seines Wissens so willkürlich, daß der fiktive Charakter des Ganzen und damit das Spiel des ت̈r:ihlers mit der Fiktion in besonderem Maße bewußt wird.

Charakteristisch für diesen Erzähler ist, daß die Erzählung in ihrer Gesamtheit durch seine subjektive Anwesenheit gekennzeichnet wird. Nie spricht er als kalter, objektiver, unparteilscher Berichterstatter zu uns, der das Erzählte unbeteiligt übermittelt. Er spricht mit erhobener Stimme, nimmt Stellung, wertet und urteilt, bejaht ironisch und klagt di-

24 Interessanterweise treffen wir in einigen èrzählungen in $G$ auf eine ganz ähnliche Erzählergestalt wie in den drei Er-Romanen Krležas. 
rekt an. Er wendet sich gelegentlich unmittelbar an die Leser, faBt diese und sich selbst in der 1. Person Plural zu einer Einheit zusammen, bezeichnet andererseits sich, die Leser und die Gestalten der Erzählung als Angehörige ein und derselben gesellschaftlichen Wirklichkeit, spricht hin und wieder unter Verwendung des Possessivpronomens von den Romanpersonen und kennzeichnet sie dadurch als Produkte seiner Phantasie. Spricht er von seiner eigenen Person, so geschieht dies in der 1. Person Plural oder - häufiger - unter Verwendung des Reflexivpronomens. Obwohl die direkten Leseranreden selten sind, erzählt dieser Erzähler immer mit dem Blick auf den Leser, mit dem er durch die Zugehörigkeit zu derselben Wirklichkeit, durch das gemeinsame Interesse an der Geschichte, durch die Kenntnis der Welt, Verständnis für ironisches Sprechen und durch das beiden gemeinsame Wissen um die Fiktion des Erzählten verbunden ist. Durch Ausrufe, rhetorische Fragen und nicht zuletzt durch die Wortwahl verrät er seine Anteilnahme an dem Erzänlten, von dem er sich vermittels der Ironie distanziert. Ironie, Sarkasmus und bisweilen Humor verraten, daB er sich mit den Personen der Erzählung nicht auf eine Stufe stellt. Identifiziert er sich mit einer Person, so stets nur vorubergehend, um alsbald wieder durch persönliches Hervortreten und durch Kommentare seine Distanz gegenüber dem Erzählten zu manifestieren. Er steht Gleichzeitig über dem Erzählten und mitten in ihm. Distanz und Einfühlung kennzeichnen seine Erzählhaltung gleichermaBen. Obwohl wir in Krležas Romanen auf eine Reihe moderner Erzähltechniken treffen wie erlebte Rede, innerer Monolog, Reduzierung der Fabel, Eindringen des Essayismus in den Roman, Darstellung simultaner Abläufe und parataktischen Satzbau, weisen sämtliche angeführten Merkmale den Erzäiler dieser Romane als d e $n$ typischen auktorialen Erzähler aus, der trotz aller modernen Züge in der Erzähltradition des neunzehnten Jahrhunderts wurzelt. F. Stanzel füht als wesentliche Kennzeichen der auktorialen Erzählsituation an, daß der Erzähler 
trotz aller Annäherung immer auf "die Trennung der Seinsbereiche zwischen Erzähler und Erzähltem bedacht ist." 25 Diese Distanzierung von der dargestellten Welt ermöglicht es ihm, eine "Position der tberlegenheit über seine Gestalten einzunehmen" 26 , die die Voraussetzung für seine auktoriale Freiheit schaff. Er besitzt vollen Vberblick über das Erzählte, in das er fortwährend lenkend, regieführend und deutend eingreift. Charakteristisch für ihn ist das Spiel zwischen "auktorialer Freizügigkeit und augenscheinlicher Verleugnung derselben" 27, denn "das auktoriale Medium behält trotz der verschiedenen Einkleidungen etwas von seiner auktorialen Freizügigkeit, wodurch es sich als Maske und Erscheinungsform des Autors und Schöpfers der Erzählung auszeichnet. "28

Distanz, Uberlegenheit und Freiheit gegenüber dem Erzählten - all dies kommt den Bedürfnissen des ironischen und satirischen Erzählers in besonderem Maße entgegen. Die Grundvoraussetzung für Ironie und Satire ist die Anwesenheit eines persönlichen Erzählers, der immer im Erzählen anwesend ist, der sowohl Abstand hält als sich auch in seine Figuren hineinversetzt.

25 Die typischen Erzählsituationen im Roman, S. 42. 26 Ebd., s. 38 r.

27 Ebd., s. 41.

28 Ebd., S. 35. 
4. Romanfiguren, Erzähler und Autor in ihrem Verhältnis zur Wirklichkeit

Prüfen wir das Verhältnis des Erzählers zur fiktiven Welt seiner Erzählung und vergleichen wir seine Auffassung von dieser Wirklichkeit mit der der Romanpersonen, für die die Welt des Romans die einzige Wirklichkeit ist, so stellen wir fest, daß nicht nur die Erzähler der vier verschiedenen Romane ein und dieselbe Sicht dieser Wirklichkeit aufweisen, sondern auch die Figuren der Erzählung. Diese Sicht der Wirklichkeit findet ihren Ausdruck in einer Reihe von Schlüsselwörtern, die sowohl in den Kommentaren des Erzählers als auch in den Gedanken und Worten der Romanpersonen zur Bezeichnung der fiktiven Welt herangezogen werden. Ein e $1 \mathrm{n}$ h e 1 t 1 i$c h$ e 8 Weltbild liegt den XuBerungen der Erzähler über die Welt des Romans und denen der Figuren der Erzählung zugrunde. Wesentlich ist, daß diese tbereinstimmung nicht nur zwischen Erzähler und Held herrscht, sondern auch zwischen Erzähler und negativen Figuren, von denen seine Distanz weit gröBer ist.

Greifen wir einige der zentralen begriffe heraus, die die Einstellung der Erzähler und der Romanpersonen gegenüber der sie umgebenden Wirklichkeit widerspiegeln: "ludnica", "zvjerinjak", "blato", "kazalifte" ("scena", "predstava", "gluma", "igra", "komedija", "opereta", "cirkus", "daske", "glumac", "lutka", "maska", "uloga").

So verschiedene Personen wie Jadviga (NRP, 98), Barutanski, Nielsen ( $F, 198)$, Blithauer (, 91$)$, Emeriłki $(Z, 2,41)$ und Kamilo $(2,2,44,720)$ empfinden die Wirklichkeit, in der sie leben, als Irrenhaus ("ludnica"). Barutanski: ‘

"Ist denn all das, was sich angefangen von den Aragoniern bis zum heutigen Tag in olitwien abspielt, nicht ein Irrenhaus? (...) ist denn all das, was den Menschen heute hier zerfleischt, nicht Irrsinn, und wer ist schlieblich hier bei uns normal?

$(F, 77)$ 
In NRP erscheint die gesamte Welt des Romans unter dem Aspekt eines großen Irrenhauses. 29

Häufig wird auch der Begriff "blato" (Morast, Schlamm, Schmutz) zur Bezeichnung dieser Wirklichkeit verwendet. Filips Sehnsucht, diesem ihn umgebenden Morast zu entkommen, ist für alle Helden der Romane charakteristisch. 30 Selbst der von Nielsen als Henker bezeichnete Georgis stellt fest, daB man von falschen Voraussetzungen ausginge, wollte man in "diesem unseren Morast" einen wirklichen Menschen suchen (BB, 81).

Die Menschen, die dieses Irrenhaus bevölkern und die in diesem Morast leben, werden durchgehend mit Tieren verglichen und es wird dementsprechend "zvjerinjak" (Zwinger) als dritter wesentlicher Begriff zur Bezeichnung der Wirklichkeit verwendet. Filip sieht im Menschen ein in einem Käfig lebendes Tier, dessen Bewegungen die einer Hyäne sind (FL, 39). Für Kyriales steht der Mensch auf einer noch tieferen Stufe als der Affe (FL, 194), und der Ich-Erzähler aus NRP sagt, er lebe umgeben von zweibeinigen Tieren in einem stinkigen Zwinger (NRP, 21). Barutanski, der mehrmals vom Erzähler mit einem Tier verglichen wird - ebenso Georgis - (BB, 77, 194, 260 f., 268) siel sich in der Rolle des Tierbändigers. Für inn sind die Menschen Raubtiere und gehören als solche zu der "gefährlichsten Art von Fleischfressern" (BB, 37). Barutanskis Devise ("Der Mensch ist dem Menschen noch immer ein Wolf" BB, 194) lautet ganz ähn. lich wie die des Professors Burgwaldsen: "Sunt homines ex natu. ra hostes" (BB, 114). Für den Pater Baltrušajtis steht der Mensch trotz aller technischen Errungenschaften einem "diluvialen Menschenfresser näher als dem Begriff des Menschen" (BB, 226). Das Bild, das Nielsen in seinem offenen Brief von Barutas ski und dessen Kabinett und damit von der blitwischen Wirklich. keit zeichnet, stimmt mit dem Urteil des Erzählers, Barutanskis und der meisten anderen Personen des Romans überein:

29 Vgl. Kap. VI, S. 239.

$30 \mathrm{Vgl}$. PL, 71; NRP, 82 f., 188, 259; BB, 87 f.; Z 1, 807. 
Ihr Kabinett gleicht heute mit seinen kinistern einem Zirkuskäfig, in dessen kitte Sie in der lächerlichen Gala des Oberdompteurs von Blitwien mit einer Schreckschußpistole knallen, und Ihre Ministeraffen sitzen grinsend auf ibren goldenen Stühlen $(\ldots)$. (BB, 59 f.)

Weitaus am häufigsten aber sind die Begriffe, in denen der operetten- und farcenhafte Charakter der Wirklichkeit zum Ausdruck kommt. Die Welt ist ein groBes Puppentheater, eine zugleich komische und tragische Theatervorstellung, in der die Personen als Kasken und Puppen auf den Wink des unsichtbaren Regisseurs agieren. Am konsequentesten gestaltet Krleža diese Auffassung von der Wirklichkeit als Bühne in $\mathrm{BB}$; mehr oder weniger ausgeprägt kommt sie jedoch in allen Romanen zum Ausdruck. ${ }^{31}$ Sowohl die Erzähler aller Romane als auch die meisten Personen nehmen die Wirklichkeit des Romans und die darin lebenden Gestalten unter diesem Aspekt wahr. 32

Wie in chinesischen Volkstheater schlafen auch wir im Zuschauerraum, hier essen wir, hier leben wir und hier sterben wir auch. Wir wohnen einer verwunschenen Aufführung bei, bei der wir Schauspieler und Zuschauer in einer Person sind. Nicht imstande zu unterscheiden, wer Schauspieler und wer Zuschauer ist, können wir auch nicht herausfinden, wer wen betrachtet: die Schauspieler die Zuschauer oder umgekehrt? (NRP, 252 f.)

31

Vgl. Kap. III, S. 144 ff.

$32 \mathrm{Vgl}$. FL, 108, 135 (Filip); NRP, 22, 32, $36 \mathrm{f}, 48,50 \mathrm{f.}$, 254 (Ich-Erzähler); $\mathrm{BB}, 36 \mathrm{ff}, 240 ; \mathrm{F}, 77,186 \mathrm{f}$. (Barutanski); F, 152, $204 \mathrm{f}$., $225 \mathrm{f}$., 23i, 236, $241 \mathrm{f}$. (Nielsen); $\mathrm{BB}, 186$ (Knutson); $\mathrm{BB}, 196$ (Baitrusajtis); F, 104 (Blithauer); Z,2, 40 (Emeri $X_{k i}$ ); Z, 2, 246, 278 (Amadeo); $2,1,606 \mathrm{f} ., 793$ f., 803,$808 ; 2,2,45,53,62,256,287$, $435,443,449,714 \mathrm{ff}, 723$ (Kamilo). FL, 102; BB, 24 f $48 \mathrm{f} ., 72,106,261,275 ; \mathrm{F}, 180 \mathrm{f}, 187$; 192 f., 224,231, 236; $2,1,255$ f., 286, 606, $800 \mathrm{ff} ., 808 ; \mathrm{z}, 2,234 \mathrm{f}$., 281,459 (Erzähler). 
Wir stellten fest, daB die verschiedenen Erzähler der Romane groBe Ahnlichkeit untereinander aufweisen, so daB wir von einem typischen Erzähler sprechen können. Weiterhin ergab sich, daB die Auffassung dieses Erzählers von der Welt des Romans mit der der Romanpersonen übereinstimmt. Die Existenz nur eines Erzählers sowie die einheitliche Sicht der Wirklichkeit führt uns über Erzähler und Romanpersonen, also aus dem fiktiven Bereich, zurück in die Wirklichkeit, zum Autor der Romane, Miroslav Krleza. Nachdem die " M $i t t$ l e $r$ e $x 1$ s t e $n z$ des eingreifenden Erzäblers" bis jetzt nur nach einer Selte hin, nämlich "nach ibrem fiktiven Persönlichkeitswert als Vermittler zwischen Erzählgegenstand und Leser" geprïft murde, soll sie abschließend noch in ihrem "Verhältnis zur realen Persönlichkeit des Autors" betrachtet werden. 33

Irlezas Tagebuch bestätigt uns, daB dem einheitlichen Weltbild des fiktiven Erzählers sowie der fiktiven Figuren das Weltbild des Autors selbst zugrunde liegt. Einige Beispiele zu den angeführten zentralen Begriffen:

Die Telegraphendrähte überbringen Nachrichten, lauter schlechte Nachrichten, und ich denke mir: dies ist ein Irrenhaus. Wie kann man unter diesen Verruickten ein normaler Mensch bleiben? (DD, 102)

Krleza, der glaubt, von der "apokalyptischen Flut der Wirklichkeit" (DD, 214) davongetragen zu werden, verspürt genauso wie die Helden der Romane das Bedürfnis, diesem Irrenhaus zu entkommen ( DD, 41, 49 f., 53 f., 68). Das Mittelalter erscheint ihm angesichts dieser Wirklichkeit ("rasap diluvija", "rasulo Razuma, Uma 1 Pameti") geradezu als Paradies (DD, 332). Auch er glaubt, daß es bis auf den heutigen Tag nicht gelungen ist, "das Tier im Menschen zu zähmen" (DD, 32). Er schreibt in sein Tagebuch:

33

E. Lämmert, S. 69 . 
Um in diesem 2 winger mit den Affen zusammen leben zu können, benötigt man immerhin und trotz allem eine ziemliche Dosis Zynismus. (DD, 158)

Aufschlubreich erweist sich auch seine autoblographische Studie "Djetinjstvo u Agramu", in der wir auf folgende Definition der Puppe und des Puppentheaters treffen:

Der Mensch 1st den naheliegenden Weg der Verdummung und der Abstumpfung gegangen, und er wird als hölzernes Splelzeug enden, denn man hat begonnen, aus thm das zu formen, was man auf diesem Basar braucht: eine passive Figur in diesem Puppentheater, das man "gesellschaftliches Leben" (...) nennt (...). (S. 342)

\section{Der Satiriker Krleža}

Krleža leidet genauso wie seine Hauptpersonen, insbesondere seine Helden, an einer Wirklichkeit, die inm entstellt, verzerrt, irrsinnig und chaotisch erscheint. Seine Sicht der Welt ist die des Satirikers, der die Mangelhaftigkeit der Realität intensiv empfindet und der sich zutiefst getroffen gegen sie auflehnt. Ch. Heldemann bezelchnet als Satire "jene Art der Weltbetrachtung (...), deren BewuBtseinsinhalt der Kontrast von Ideal und Realität ist und die auf einer besonders starken Sensibilität für die 1rdischen Unzulänglichkeften beruht, welche sich ihr in riesenhafter VergröBerung des dem durchschnittlichen Sinn sichtbaren Formats aufdrängen." 34 Die Menschen sind für den Satirtker Krleža Puppen und Masken, und die Wirklichkeit ist ein chaotisches Irrenhaus, ïberreich an Kontrasten. In $B B$ ist die Welt des Romans die eines großen Puppentheaters, in NRP wird die Umkehrung aller Werte, der Aufbau einer verkehrten Welt radikal

34 Satirische und polemische s'ormen in der Publizistik von Karl Kraus. Diss. Berlin 1958, S. 42. 
demonstriert: der vernüntige und wahrheitsliebende Mensch wird für verrückt erklärt und ins Irrenhaus gebracht, und die sörder, Lügner und jetrüger werden als verdienstvolle Bürger gepriesen und genießen allgemein hohes Ansehen. Verkehrung und Verzerrung stehen im Dienst der satirischen $\mathrm{Ne}-$ gation.

In seiner Konzeption der Wirklichkeit sowie in seiner Haltung gegenüber dieser Wirklichkeit steht KrleZa Karl Kraus und George Grosz nahe, über die er Essays verfaßte, die sicn vor allem in bezuf auf Krleza als aufschlußreich erweisen. 35 Alle jene züge, die er an den beiden hervorhebt, kennzeichnen nicht nur diese, sondern genauso Krleža selbst und dessen satirische ieltbetrachtung. An K. Kraus, der es sich zur Aufgabe gemacht hat, die Lügen "einer kriminellen Zeit" aufzudecken und "der großen Zeit' die Maske abzureißen", bewundert hrleza vor allem die Schärfe der Sehweise (S. 349 f.). ifas G. Grosz betrifft, von dem Krleza sagt, er wäre vom Satiriker zum Chronisten und vom Chronisten zum tendenziösen Prediger geworden (S. 252), so hebt er besonders die "scharfsichtige Liebe zur Fahrheit und zur Wahrhaftigkeit" hervor(S.25 sowie die "nüchterne Kälte", mit der Grosz die zeitgenössische chaotische Wirklichkeit analysiert:

(...) alle dringen sie unter die haut, aber diese Anatomie ist bei keinem von ihnen (selbst bei dem extremsten von allen, bei Karl Kraus) so grausam wie bei George Grosz.

(S. 251)

Krleza liberträgt seine Haltung des Protests und der Verneinung auf die Selden der Romane. Protest und Rebellion seiner Helden - dies ist das zentrale Thema aller vier Romane. Keiner der Helden findet sich mit der wirklichkeit ab, alle

35 "Karl Kraus o ratnim stvarima", "Uspomeni Karla Krausa", "O njemačkom slikaru Georgeu Groszu". In: Krleža: Hrvatska književna kritika. VI. Zagreb 1953, S. 347-373, 251-60. 
engagieren sich mehr oder weniger ausgeprägt im Kampf gegen sie. Krleza und seine Helden sind leidenschaftliche Verfechter der Wahrheit, der Freiheit und der Menschlichkeit. Bezeichnend für die Haltung des Satirikers Krleza ist die Klage Nielsens, daß die Wahrheit nlemand hören wolle, da sie unbequem sei $(B B, 104) .36$ Aus dieser Haltung heraus wird verständlich, warum der Satiriker sich gezmungen sieht, die Wahrheit entweder durch übertriebene Verneinung oder durch direkte Aussagen und Wiederholungen sinnfällig zu machen. Dieselben Begriffe, die Krleza heranzieht, um seine Methode der Darstellung zu bezelchnen, finden wir bei den Helden der Romane wieder: "anatomlja", "skalpiranje", "1ci pod Ż za", "analitička metoda", "raskrinkati", "skinut1 masku". Folgende Worte schreibt Krleža in sein Tagebuch:

In der konventionellen Asthetik besteht eine bestimmte Grenze, bis zu der der Geschmack des zeitgenössischen, literarisch gebildeten Snobs die analytische Methode erträgt - auf keinen Fall jedoch darf man mit dem Messer bis unter die Haut vordringen! Das Skalpieren empfiehlt sich nicht und wenn möglich ebenso nicht der geringste anatomische Elngriff $(\ldots)$. tberschreitet man in seinen literarischen Forderungen diese Grenze, so heiBt es, man se1 "bizarr", "überspannt", "destruktiv" und "dekadent", ein "krankhaft veranlagter Mensch", ein "Schädiing der Gesellschaft" usw., usw. Ailes andere, nur nicht unter die Haut gehen und vor allem nicht bis in die Eingeweide vordringen und erst recht nicht bis in die Gedärme!

(DD, 190 f.)

Mit fast denselben Worten wendet sich der "sixtinische Schatten" an den Ich-Erzähler aus NRP, als dieser angesichts der ihn umgebenden Touristenherde zu sich sagt, daB man über all dies ein Buch schreiben müßte (NRP, 271). Nach derselben Methode geht auch Filip vor, wenn auch mehr unbewuBt, als er ein Porträt seiner Mutter malt, das nie vollendet wird, well

36 Vgl. ebenso NRP, 254; DD, 131. 
seine Mutter von dem, was unter Filips Händen entsteht, entsetzt 1st. Fillp dringt, je länger er an diesem Porträt malt, immer weiter zu dem wirklichen Gesicht seiner Mutter vor, das hinter einer Maske verborgen 1st. Der ProzeB des Malens kommt einer Demaskierung des Objektes gleich. Wieder wird dieser Vorgang mit demselben Vokabular beschrieben. Filip dringt mit seinem Pinsel bis "unter die haut", so daB sich die "Ep1dermis" unter den "scharfen Borsten des Pinsels" wie unter einem "Rasiermesser" öffnet. Wie mit einem "Skalpell" schneidet er das unter einer dicken Schicht von Schminke verborgene Gesicht seiner kutter heraus (FL, 89 f.). 37

Hinter aller Negation steht Jedoch der Wunsch nach Veränderung und Besserung der Verhältnisse. Krleza begehrt nicht nur gegen das thel auf, sondern er versucht durch Aufdeckung zu dessen tberwindung beizutragen. Er sieht seine Aufgabe als Schriftsteller darin, Zeugnis abzulegen von der ihn ungebenden unmenschlichen Wirklichkeit, damit die Greueltaten nicht. vergessen, sondern im Bewribtsein der Menschen wach erhalten werden. Kommende Generationen sollen gewarnt werden, in der Hoffnung darauf, daß sich das Schreckliche nicht wiederholt. 38 Nielsen gibt deswegen den Kampf nicht auf und begeht nicht Selbstmord, wel "ein Etwas, das stärker war als sein eigener Wille, es nicht zulieB, daB er als Zeuge gegen Dummelt und Iüge verschwand." ( $P, 146)$. Schreiben 1st für KrleŽa die einzige Möglichkeit, seinen Protest immer wieder von neuem vorzubringen. Er m $u$ B schreiben im Angesicht dieser Wirklichkeit, die inm keine Alternative bietet. 39 Schreiben, das heiBt

$37 \mathrm{~V}_{\mathrm{gl}}$. ebenso $\mathrm{Z}, 1,590 \mathrm{ff}$. über Kamilos Hethode zu schreiben, die als "chirurgischer Eingriff" bezeichnet wird.

$38 \mathrm{Vgl}$. DD, $180 \mathrm{f.,} 451 \mathrm{f.,} 480$ f.; F, 180 f.

$39 \mathrm{Vgl}$. DD, 41. Genauso wie Krleža reagieren auch der IchErzähler (NRP, 235 f., 268 f.), Nielsen (BB, 104), KJparis ( $\mathrm{OB}, 386 \mathrm{ff.}), \operatorname{Kamilo}(\mathrm{Z}, 2,736)$ und Fijucek $(G, 66$ ff.) auf die Wirklichkeit. 
anklogen, aufdecken, kämpfen. Seine einzige Waffe in diesem Kampf ist das Wort.

Auch in der Ifteratur muB man kämpfen. Wofür? Für eine menschenwürdige Lebensform. (DD, 172)

Was bedeutet es mutis $2 u$ sein? Mit der Feder kämpfen, das ist eine der gröBten Heldentaten. (DD, 110)

Diese Tagebucheintragungen bieten die Erklärung dafür, warum Nielsen im Prolog von $B \bar{B}$ als "mutige Person" ( $B B, 16)$ bezeichnet wird. Die Worte Nielsens, mit denen BB abschlieBt, können als Credo KrleYas selbst angesehen werden. In ihnen bringt er den festen Glauben zum Ausdruck, daB er mit Hilfe des geschriebenen oder gedruckten Wortes dazu beitragen könne, für die Freiheit und Würde des Menschen zu kämpfen:

(...) und was bleibt uns dann noch übrig? Eine

Schachtel voll Bleibuchstaben, und das ist nicht viel, wie Kerinis gesagt hat, aber es ist das einzige, was der liensch bis heute als Waffe zur Verteidigung seiner Menschenwirde erfunden hat.

$(F, 242)$

All das erklärt, warum Krleza ständig Stellung nimmt und leidenschaftich reagiert. Hinter jedem Satz steht seine Persönlichkeit, und seine Urteile geben sich betont subjektiv. Er engagiert sich voll und ganz für seine tberzeugunge Sein Wirklichkeitsverhältnis ist affektgeladen. Er muB sich aus diesem Grunde ausgesprochen um die Distanz bemühen, die 2wischen Satiriker und Objekt der Satire bestehen muB. 40 Folgende Eintragung in DD wirft ein bezeichnendes Iicht auf die für Krleza problematische Distanzierung:

Die Vögel singen so erhaben und indifferent, als ob sie sich nicht in kroatien befänden.

Wenn ich nur wie ein indifferenter Vogel zwitschern könnte. $(\mathrm{DD}, 250)$ 
Durch die Nähe zum Objekt wird der Abstand immer wieder zerstört, und die satirische Negation manifestiert sich in direkter und bitterer Anklage und nicht in Form von ironischer Verstellung. Die negative Wertung, die bei dem Ironiker in der Regel ausgespart wird, wrd von Krleža häufig direkt ausgesprochen. Charakteristisch für seine Romane ist die Mischung aus irontscher Verstellung und direkter Anklage. KrleZa lst seiner ganzen Haltung nach als polemischer Satiriker zu bezeichnen. Ch. Heidemanns Feststellung in bezug auf $\mathrm{K}$. Kraus trifft - trotz aller Verschiedenartigkeit der beiden auch auf Krleza zu. "Er steht den in seiner Sicht verzerrten Objekten nicht mit epischer Gelassenheit gegenüber (...), sondern er lebt wie der Lyriker in ständiger Erschütterung, in einer begeisterung mit umgekehrten Vorzeichen, die wie die lyrische in Superlativen schwelgt, die Dinge immer wieder als einzigartig und unübertrefflich empfindet, nur daB ibre Unerhörtheit eben einen negativen Grad hat." 41

41

s. 112 . 


\section{K A P I T E I VI}

D I E S U B J EK T I VE K O I PONEN T E I M S T I L KR I E Z A S

1. Erzählhaltung und Stil

Krlezas Haltung der Wirklichkeit gegenüber, die wir als die eines polemischen Satirikers bestimmten, erweist sich als ausschlaggebend für seinen Stil, der so unverkennbar ist, daß er vielfach mit dem Epitheton "krlezianski" bezeichnet und viel imitiert wurde. $Y$. Londar stellt in seiner Besprechung des zweiten Sammelbandes über die Werke Krležas nicht ohne Ironie fest, daB sich "die seltene Suggestion und die wirksame Magie" des Stils und der Sprache Krležas darin manifestiert haben, daB sich fast alle Autoren des Sammelbandes teils offen und absichtlich, meist aber unberußt und spontan seines Wortschatzes, der Form und des Rhythmus seiner Sätze und insbesondere seines attributiven Ausdrucks bedient hätten. 1

Wir definierten die Erzählhaltung Krležas als eine zwischen Distanz und Einfühlung schwebende Haltung. Die Distanz verschafft er sich durch eine Reihe von Kunstgriffen; seine Subjektivität, seine emotionale Anteilnahme am erzählten Geschehen kommt jedoch unverhiillt in seiner Sprache und seinem Stil zum Ausdruck. Die Emotionalität seines Stils resultiert aus dem Abscheu, mit dem er sich gegen die inm verhaBten Erscheinungen wie die bürgerliche Gesellschaft, die österrelchischungarische Monarchie, Dummheit und Krieg wendet, und aus dem

s. 198. 
Mitleid, das er mit den Unterlegenen empindet. Krležas Sprache, für die die "maximale Ausnützung emotionaler Ausdrucksmittel ${ }^{2}$ charakteristisch ist, ist subjektiv bestimmt, affektiv, expressiv, rhetorisch und weist barocke und groteske Elemente auf. Sein immer wieder als suggestiv bezeichneter $\mathrm{Stil}^{3}$ geht auf konkrete Wirkung aus. Die rhetorische ElnfluBnahme auf den Leser ist von wesentlicher Bedeutung für einen so stark gesellschaftskritisch orientierten Schriftsteller wie Krleža.

In dieser Arbeit soll keine erschöpfende Analyse der Sprache Krlezas gegeben werden. Es geht hier vielmehr darum, gewisse spezifische Merkmale seines Stils zu erfassen, die Ausdruck seiner Haltung der Wirklichkeit gegenüber sind. Denn es zeigte sich bei der Untersuchung der verschiedenen Erzähltechniken, daB gerade bel Krleza der Stil nicht ausgeklammert werden darf, wenn nicht ein wesentlicher Aspekt seiner erzählerischen Leistung außer acht gelassen werden soll.

\section{Krležas Stil in Urteil der Interpreten}

Gerade deshalb, weil dieser Stil so spezifisch ist, wurde keinem anderen Phänomen der Erzählkunst Krlezas so viel Aufmerksamkeit gewidmet wie diesem. Allerdings entstanden wirklich fundierte Untersuchungen über den Stil und die Sprache Krlezas erst in den letzten Jahren. Vorher beschränkten sich

2 z. Kal1E: Iutke, 172.

3 Vgl. Gligoric, Velibor: Pripovedacka proza M. Krlež, II. In: Izraz, 4, 1960, 8, 454, 462; I. Frangez: Stvarnost 1 umjetnost u Krležinoj prozi, S. 287; Engelsfeld, kladen: K. Krleza: "Baraka Pet Be" (Primjedbe uz stil). In: UR, 2, 1958, 31; Goj, Edvard: Problemi 1 raktura u Krlezinoj drami "Gospoda Glembajevi". In: Izraz, 4, 1960, 8, S. 1, 21; Sinko, Ervin: Istina M. Krleze. In: Republika, 8, 1952, 2, 139; Vuletic, Branko: 0 nekim elementima Krlezine irike. In: Kolo, NS, 1, 1963, 6, 130. 
die Kritiker und Interpreten der 海erke Krležas im wesentl1chen darauf, seinen Stil abzulehnen und inn als manieriert oder schlecht zu beurteilen oder aber ihn zu bewundern und inm Faszination, Suggestion und sogar magische Wirkung zuzuschreiben. S. Simie spricht von dem "unklaren, nicht zu enträtselnden Rauschen des Wortschatzes Krležas. ${ }^{4}$ R. Rotković, der Krleža unter anderem vorwirft, er gebrauche zu viele Germanismen, sagt, seine Sprache sei nicht einwandfrei, denn er habe in fieberhafter Elle gearbeitet. Er behauptet sogar, Krleza hätte mehr daran gedacht, " T a $s$ er zu sagen habe", als daran, "w 1 e er es zu sagen habe." 5 DaB Krleža gerade auf Grund seines "zlemlich schlechten Stils" so viele Bewnderer hat, führt Rotkovit auf die Emotionalität dieses Stils zurück. ${ }^{6}$ Die Ratlosigkeit Krležas Stil gegenüber hat am deutlichsten $M$. Bogdanovid eingestanden, der feststellt, daß Krleza zweifellos eln Schriftsteller se1, der den Leser faszinfert und thn durch "gewisse Elemente", die dieser nicht so leicht begreifen könne, einfängt. Bogdanovic fragt sich zwar, womit Krleža den Leser oder Hörer denn so fasziniere, wir erhalten aber nur die unbefriedigende Antwort, daB Krležas Wort "eine linm elgene ganz spezifische Magie" besitze, und daB von seiner Sprache "ein Element der Betäubung" ausgehe.? Auch D. Redjep spricht von dem Magnet1smus des Wortes bel Krleza und von der "ungewöhnlichen Vioration einer menschlichen Stimme." 8 M. Ristit

4 Krleza kao kritik. Zagreb 1933. Zit. nach M. Engelsfeld: Jos o stilu M. Krleže. In: UR, $6,1962,3$.

5 Dijalog o Krlezi. In: Knj1zevne novine. Beograd. 27.5.1954, S. 4 .

6 Krležin stil. In: Susreti, 2, 1954, 781.

7 o Krlezi, s. $23 \mathrm{ff}$.

8 Krležina reč. In: Savremenik, 9, 1963, 18, 5. 
äußert sich ebenfalls recht enthusiastisch über Krlezas Stil, der ihm jedoch rätselhaft erscheint: "Keine Aisthetik kann da etwas erklären. Daher ist es ausreichend, daB Worte, einfache Worte, zwei-drei Worte, eines neben dem anderen stehen, so wie sie die Erregung diktiert, wie sie das Gefühl verknüpft, wie sie die Eingebung hingesetzt, wie sie die Feinfühligkeit verteilt, wie sie die Musik gewollt hat." 9

In den füfziger und vor allem in den sechziger Jahren erschienen jedoch eine Reihe von Untersuchungen, deren Autoren sich nicht mit mehr oder weniger vagen Feststellungen begnügen, sondern die sich ganz konkret mit dem Stil KrleZas befassen, indem sie die einzelnen Phänomene seines Ausdrucks $z u$ erklären versuchen.

3. Der expressive Rhythmus

Von wesentlicher Bedeutung für die Intensität des Ausdrucks ist der spezifische Rhythmus der Prosa Krlezas. K. Pranjic schließt aus seiner Untersuchung des Prosarhythmus Krlezas, daß der "Rhythmus des künstlerischen Wortes KrleZas der Rhythmus des lebendigen, akustisch realisierten Wortes" sei. "Krleza ist kein Schriftsteller! Krleza ist ein Redner." Und 2 war in dem Sinne, daß "der Leser alle seine Worte als lebendige, zum Klingen gebrachte Bilder, als Sprechen erlebt."11

T. Maretic unterscheidet in seiner Grammatik 2 wei verschiedene Formen der Hortfolge: 1. die grammatische, in der

9 Fuga Krleziana. In: Republika, 9, 1953, 545.

$10 \mathrm{Vgl}$. S.12f. dieser Arbeit. Lediglich der Aufsatz von Pranjić uber die Pausentechnik erschien bereits im Jahre 1928. 11

o Krležinu proznom ritmu. In: UR, 7, 1963, 111. 
dem Sprecher oder Schreiber alle Worte gleich wichtig sind; 2. die rhetorische, in der der Schreibende oder Sprechende einzelne Worte oder Satzteile hervorheben will. ${ }^{12}$ Die Wortfolge hängt demnach davon ab, was hervorgehoben wird. Die Worte mit Satzakzent stehen gewöhnlich an der wichtigsten Stelle in Satz - an der ersten und der letzten. Abgesehen davon wird ein Wort oder ein Satztell allein dadurch betont, daB sie von ihrem üblichen Ort im Satz entfernt werden. Aus dem Gesagten geht hervor, daß die veränderte Wortstellung auch eine Ànderung des Satzakzents zur Folge hat. Pranj1c bezeichnet deshalb die Wortfolge als "rhythmusschaffendes Element par excellence." 13 Lj. Jonke macht darauf aufmerksam, daß eine andere Wortfolge nicht nur eine Veränderung des Satzakzents nach sich zleht, sondern im Zusammenhang damit auch eine leichte Bedeutungsverschiebung eintritt. 14 Der expressive Rhythmus der Prosa Krlezas wird somit dadurch bewirkt, daß Krleža von der normalen, genormten Wortfolge abweicht und eine rhetorische Wortfolge realisiert. 15

Bevor wir untersuchen, auf welche Weise Krleza die rhetorische Wortfolge verwirklicht, sind zwei Feststellungen zu treffen:

1. Da das Serbokroatische zu den Sprachen gehört, deren Tortfolge sehr frel ist, fällt die Beurtellung, ob eine Ab-

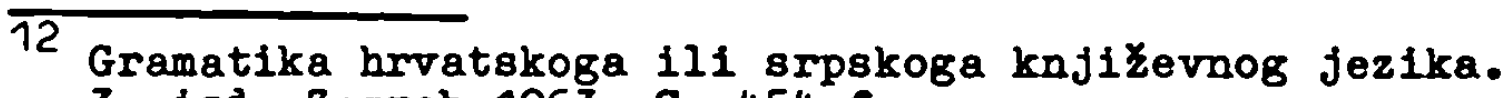
3. izd. Zagreb 1963, S. 454 1.

13 o Krležinu proznom ritmu, 103.

14 KnjiZerni jezik u teorij1 1 praksi. Zagreb 1964, S. 277.

$15 \mathrm{~K}$. Pranjic stellt fest, daB Krleža sich auch in der Poesie derselben Stilmittel bedient, um einen expressiven Rhythmus zu verwirklichen. ("O Krlezinu proznom ritmu", 111). Der Aufsatz von B. Vuletic über die Iyrik Krležas bestätigt dies (S. $130 \mathrm{ff}$.). 
weichung von der Norm vorliegt oder nicht, nicht immer leicht. $1 \epsilon$ Es läBt sich jedoch zumindest feststellen, wo der betreffende Satzteil üblicherweise steht. So befindet sich das Subjekt, obwohl es an zweiter, dritter oder letzter Stelle im Satz stehen kann, doch normalerweise an erster Stelle. Die gewöhnliche Wortfolge ist trotz allem Subjekt - Prädikat - Objekt. 2. Da es im Rahmen dieser Stiluntersuchung nur darum geht, eine Reibe von charakteristischen Kennzeichen der Sprache Krležas zu bestimmen, d.h. Merkmale, die in allen Romanen mehr oder weniger ausgeprägt sind, kann hier nur festgestellt werden, welche Phänomene diesen Stil bewirken - nicht jedoch, welche Funktion den einzelnen Kunstgriffen zukommt, da diese von Fall zu Fall verschieden sein wird.

Folgende überaus häufige Formen der rhetorischen Wortstellung kennzeichnen den Stil Krlezas:

1. Die Stellung des Enklitikums. Im Serbokroatischen steht das Enklitikum entweder an zweiter Stelle im Satz oder aber nach dem Verb, zu dem es gehört. Letztere Variante, die im Vergleich zur ersteren bei Krleza verhältnismäBig selten ist, bewirkt "eine ruhige, ausgeglichene Aussage, ein gesetztes Erzählen ohne Nervosität und Lebendigkeit." 17 Xußerst häufig bedient sich Krleza jedoch der ersten Variante, wobei das Enklitikum nicht selten weit von seinem Verb entfernt steht. Besonders charakteristisch für Krleza ist, daB er die Zweitstellung so konsequent einhält, daB syntaktisch zusammengehörige Satzteile häufig durch das Enklitikum auseinandergerissen werden. Normalerweise käme das Enklitikum erst nach

16 Im Serbokroatischen existiert nur eine verhältnismäßig geringe Anzahl von feststehenden Regeln für die Wortfolge, so z.B. für die Stellung des inklitikums, der Interrogativpronomen und der Präpositionen. Vgl. Ij. Jonke, S. 273 ff. über die Wortfolge im Serbokroatischen. Jonke führt sechs verschiedene Varianten für den einfachen Satz mit Subjekt, Prädikat und Objekt an (S. 111).

Ij. Jonke, S. 278. 
der ersten Akzenteinheit. Pranjic stellt als Folge dieser ungewöhnlichen Stellung des Enklitikums das Entstehen einer Graphisch nirgends bezeichneten Pause fest, die das Ergebnis der Längung des phonetischen Blockes ist. ${ }^{18}$ Jonke bemerkt, daB die Zweitstellung des Inklitikums charakteristisch für subjektives, lebendiges, unruhiges und nervöses Erzählen ist. 19 Einige Beispiele:

Naši s e političari cude alkoholu (...). $(\mathrm{F}, 37) 20$

Das Reflexivpronomen "se" steht hier zwischen dem Possessivpronomen und seinem Substantiv, die normalerweise syntaktisch eine enge Einheit bilden. Unauffälliger, farbloser und ohne die stilistisch realisierte ironische Nuance wäre die übliche Wortfolge: Naši politicari Cude $s$ e alkoholu. Im folgenden beispiel steht das Enklitikum zwischen Titel und Namen, die zusammen das Subjekt des Satzes bilden:

Pred javnołku čitavog civiliziranog svijeta pukovnik s e Barutanski zapitao (...). $(F, 220)$

Ein anderes Mal wird der an und für sich untellbare präpositionale Ausdruck durch zwel Enklitika gesprengt:

U posljednjem sam $s$ e trenutku probudio usred jednog ružnog sna!

(NRP, 233)

In folgenden Beispiel steht das erste Enklitikum, die Kopula "je", zwischen dem Subjekt und dem nachgestellten possessiven Adjektiv:

(...) a plamičac je svjetiljčin izgarao

1 micao se neprekidño $(\ldots)$.

(FL, 11)

18 o Krležinu proznom ritmu, $104 \mathrm{ff}$.

19 S. 278.

20 In diesem Kapitel sind sämtliche Hervorhebungen innerhalb der Zitate aus den Werken Krležas, wenn nicht anders vermerkt, von mir. 
2. Die Inversion von Subjekt und Frädikat, deren sich Krleža mit Vorliebe bedient. Als allgemeine Regel gilt, daB das Subjekt an erster, das Prädikat als seine Hauptbestimmung an zweiter Stelle steht. Bei Krleža dagegen befindet sich das Prädikat oft an erster Stelle im Satz - also vor dem Subjekt. Das Subjekt steht in diesem Fall meist an zweiter oder dritter, nicht selten jedoch auch an letzter stelle. Auf diese Welse wird sowohl das Prädikat hervorgehoben, da es an der wichtigsten Stelle im Satz steht, als auch das Subjekt, das sich nicht mehr auf seinem üblichen Platz beIindet. Des öfteren wird das Prädikat auch dadurch betont, dab es an letzter Stelle steht - und zwar im Gegensatz zur Regel manchmal weit von seinem Subjekt entfernt.

Ungewöhnlich häufig sind die Sätze, die mit dem Verb beginnen, "eines der auffälligsten Charakteristika der Volkssprache in Krležas Stil." 21 D. Brigljevit führt an, daB die Stellung des Verbs am Satzanfang dem ganzen Satz eine "besonders müde Akzentuierung" verleihe. 22 zum Beweis bringt er folgendes Beispiel:

S j e d I tako Filip u kavani i B 1 e d a ljude kako prolaze ulicom 1 m $i$ s 1 i o tom, kako je to micanje ulicama zapravo cudno 1 zagonetno.

(FI, 36; Herv. v. Briglijevit)

Die müde, resignierte Note wird in diesem Fall vor allem noch durch "tako" verstärkt. M. Engelsfeld beurteilt die Wirkung dieses Stilzuges ganz anders: Schnelligkeit, Tempo und Unruhe sind die Folgen der Stellung des Verbs am Satzbeginn. "Diese Unruhe verursachen die Verben, die Lebenselemente eines jeden Satzes, die - wenn sie an erster Stelle stehen nicht nur die gramatische Ruhe im Satz stören, sondern auch der Bewegung, der Handlung mehr Bedeutung beimessen als der

\footnotetext{
21 Brigljeviદ, Dragutin: 0 Krležinu izrazu. In: Republika, $11,1955,174$.

22 Ebd.
} 
Ruhe $(\ldots)^{n} 0^{23}$ Aus diesen beiden gegensätzlichen Urtellen wird ersichtlich, daß ein und derselbe Stilzug ganz verschiodene Wirkungen haben kann und $d a B$ es infolgedessen nicht zulässig ist, einen allgemeingültigen SchluB aus einem bestimmten Stilzug zu ziehen.

In diesem Zusammenhang sei noch kurz auf eine weitere Eigenheit von Krlezas Stil hingewiesen. Das Verb am Satzbeginn steht im Infinitiv und hat die Punktion des Subjekts.

S $j$ e $d j e t i$ tako nepomitno ver godinama po kavanskim izlozima, g $r i$ s 1 svoj nokat na lijevom kaziprstu 1 r a 2 b 1 ja $t i$ sebi glavi nad osnovnim pitanjem: treba il uopke slikati, a ako bezuvjetno treba, onda kako? (FL, 38)

Unveränderlichkeit und Dauer sowie eine resignierte Schmerzlichkeit werden hier nicht nur durch die unbestimmte Form zweier Zustandsverben in stilistisch adäquater Porm zum Ausdruck gebracht, sondern auch noch durch die Zeitbestimmung "godinama" (jahrelang) und durch das Adverb "nepomitno" (unbeweglich) unterstrichen. Wie aus diesem Beispiel ersichtlich, stehen häufig mehrere Infinitive, die als Subjekt fungleren, in einem Satz. Sieist werden die kurzen Hauptsätze mit jeweils einem Infinitiv als Subjekt, die asyndetisch aneinandergereiht sind, in einem abschlieBenden "to" zusammengefaßt.

P ○ 1 v je t 1 s kobilama 1 s mackama, $8 a$

- seoskim glasinama, 0 s $j$ e $t i t i$ hrapar jezik teleta na svom dlanu, 81 e d a $t$ biljke kako rastu (...), $t$ o su sve bill umirujuci motivi za Pilipovu neurasteniju. (FL, 75)

Nicht so häufig wie die Stellung des Prädikats am Satzbeginn ist die am Satzende. Die SchluBstellung bewirkt, daB das Prädikat in besonderem Laße hervorgehoben wird. Das Sprechtempo muß verlangsamt werden, so daß vor dem Prädikat eine Pause entsteht. In folgendem Beispiel wird diese Pause

23 k. Krleža: "Baraka Pet Be", 24. 
durch ein Komma bezeichnet:

(...) a Karina, koja mu se jučer (...) ispo$\forall j e d i l a$, da je Nielsen njen "put, istina 1 Zivot", Karina, nekoliko trenutaka prije jos pijana od zanosa, savijena u małjem klupku, $\left\{\begin{array}{l}\text { e } \\ \text { (165) }\end{array}\right.$

Das Prädikat steht hier weit entfernt von seinem Subjekt, das noch einmal aufgenommen wird. Oft steht das Subjekt auch an letzter statt, wie üblich, an erster Stelle:

Kristijana Barutanskoga sravaio je'sa zemljom, jednim jedinim revolverskim hitcem u zatiljak, njegor lični a d jut a $\mathrm{t}(\ldots)$. $(\mathrm{F}, 194)$

Hier findet nicht nur eine Inversion von Subjekt und Prädikat, sondern auch von Prädikat und objekt statt. 3. Die Nachstellung von Adjektiven und Pronomen. Die Stellung der Adjektive nach dem Substantiv, das sie näher bestimmen, ist $\in i n$ weiteres bezeichriendes Merkmal des Stils Krležas.

Da prozivi dolje kod majke na kostanjeveckom vinogradu jednu jesen, b 0 s a $t u$, m i r u, vinor o d n u !

(FI, 45)

oft finden wir das nachgestellte attributive Adjektiv in ironisch intonierten Sätzen:

Otac Pausto smatra se, to se $X_{1}$ teronske brbljavosti tice, vjestakom $p r$ or a $r$ e d $\mathrm{i} m$, vise od toga, virtuozom s a $v$ r 8 e $n 1 \mathrm{~m}(\ldots)$. $(F, 175)$

Die hinweisenden und besitzanzeigenden Pronomen stehen normalerweise vor dem Substantiv und dem zu diesem gehörenden Adjektiv. Bei Krleža befinden sie sich jedoch häufig 2wischen Adjektiv und Substantiv oder - seltener - nach dem Substantiv. Im folgenden Beispiel steht das Demonstrativpronomen 2wischen den beiden Adjektiven: 
(...) nesretna o $v$ a 1 bljedna blitvoblatvijska komedija (...).

(F, 180)

Oder aber das Demonstrativpronomen steht nach dem Subjekt und dem Enklitikum:

Napor je t a $j$ bespredmetan (...).

(NRP, 236)

Anstatt: 'taj napor je bespredmetan' oder, wie es drei Zeilen weiter heißt,

(...) t a $\mathrm{j}$ je napor bespredmetan.

4. Die Nachstellung des Komparativs, die fast ausschlieBlich in ironisch getönten Sätzen anzutreffen ist. In folgendem Beispiel wird die ironische Intonation durch die Voranstellung des vom Komparativ abhängigen "od" + Genitiv sowie durch die Iexik und die GroBschreibung verstärkt s

U predvexerje kumanovske bitke, od Slave Austrijskog Velicanstva samo se egipatski granit u oxima skromnib 1 poboznib smrtnika pri-

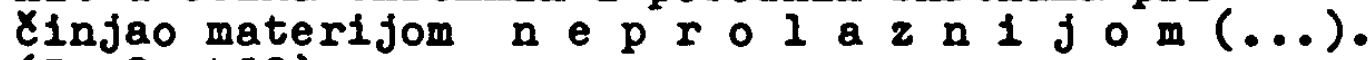
$(2,2,460)$

In sämtlichen bisher angeführten Beispielen murde die Pause und damit die Hervorhebung einzelner Worte oder Satzteile durch die von der Norm abweichende Satzstellung bewirkt. Die Pausen, die durch graphische Zeichen kenntlich gemacht sind, dienen ebenfalls der Intensivierung des Ausdrucks. Besonders bezeichnend für Krležas Stil ist die Setzung eines Gedankenstrichs und vor allem eines Doppelpunktes on einer Stelle, wo ein solches Zeichen nicht üblich ist. Logisch wäre eine Pause an dieser Stelle nicht zu erwarten, "denn sie 1st orthographisch nicht obligatorisch." Dieser Pause kommt eine ausgesprochen stilistische Punktion zu, sie "intensiviert den gedanklich-emotionalen Inhalt" der betreffenden Worte. 24 Ein Beispiel:

Prebaciti cijelo to pitanje drustrenog uredjaja na prostu mehaniku merkantilnih (...) odnosa, 24 K. Pranjić: Tehnika pauze kao stilski postupak. In: $\mathrm{KZ}$,
398 . 
znači pojednostavniti Zivotnu problematiku do onog okvira, sto ga zovemo stranackim programom, statutom, paragrafom, dogmom i uopce: katekizmom! (NRP, 171)

Der Oberbegriff "katekizam", der sämtliche vorhergehenden Glieder der sich in einer Klimax vollziehenden Aufzählung aufnimmt, wird durch den orthographisch nicht verbindlichen Doppelpunkt besonders hervorgehoben.

4. Funktion gewisser Partikeln

Bei der Lektüre Kirlezas füllt sofort die ungewöhnliche Häufigkeit von Worten wie "zapravo", "upravo", "uglavnom", "navodno" oder "takoreci" auf. Sie verleihen der Sprache eine ausgesprochen subjektive Wirkung und befinden sich häufig in ironisch intonierten Sätzen. In folgendem Beispiel dient das Adverb "upravo", wie sehr oft, der ironischen Steigerung:

Po tajanstvenom, svemirskom upravo zakonu. ljudske gluposti, ja bih po svoj prilici. bio pozivio u svojim vlastitim protuslovljima sve do groba $(\ldots$.$) .$ (NRP, 26)

Besonders häufig ist das Adverb "zapravo". In folgendem Beispiel wird es zweimal wiederholt:

Ovakar jedan propali brodolomac $z$ a $p$ r a $v o$, kao ovaj slikar tu pred njim, ovakav jedan biv$z_{1}$ Covjek 2 a $p r$ a $v o(\ldots)$ misli da je vrhunaravno vidovit, kako je to לalosno $z$ a p $r$ a $v \circ \quad$ (FL, 212)

Oft steht das "zapravo" in einer zusainmenfassenden Verallgemeinerung, die eine vorhergehende Aufzählung abschließt:

Sada je konazno krenuo, i sada sjedi tu pod tim strałnim ogledalom 1 teka na foringasa, a $s \mathrm{ve}$ je $\begin{aligned} & \text { j } \\ & \text { (FI, 51) }\end{aligned}$ 
Eine andere Funktion als die soeben angefürten Worte hat das für Krlezas Stil ebenso bezeichnende "tako". Dieser Stilzug, Ausdruck der Patalität und des geschichtlichen Determinismus, suggeriert die Sinnlosigkeit des Geschehens, das sich unabhïngig von unserem Willen vollzieht. 25 Unüberhörbar ist die resignierte Note, die dem Satz durch das "tako" verliehen wird.

T a $k$ o se je okrenuo, spustio niz stube 1 $t$ a $k$ je ostao na ulici dvadeset 1 tri godine potpuno sam. (PL, 15)

In diesem kurzen Satz wird in konzentrierter Form das Resümee aus dem Leben des neurotischen Malers Filip gezogen. Bezelchnenderweise wird das "tako" wiederholt. Des öfteren befindet sich "tako" auch am Satzanfang und suggeriert dadurch oine Beziehung auf Vorhergehendes, das jedoch nicht immer direkt erwähnt wird, sondern lediglich zu abnen 1st. ${ }^{26}$ Verstärkt wird dieser Eindruck noch dadurch, daB das Bindewort "i" vor "tako" tritt.

Bindeworte stehen ganz allgemein häufig am Satzanfang. Während bei "1 tako" der Bezug noch in den meisten Fällen gewahrt bleibt, werden die Konjunktionen "1" und " $a$ " oft abweichend vom üblichen Gebrauch verwendet. So stehen diese Konjunktionen, deren Aufgabe es ist, Wörter oder Sätze miteinander zu verbinden, am Anfang von Absätzen, die unvermittelt und obne direkten Bezug auf das Vorhergehende einsetzen.

25 Vgl. Kap. III, S. 148. Vgl. ebenso A. Flaker: Corjek 1 povijest u Kriezinim novelama. In: KZ, $153 \mathrm{fl}$. Plaker macht in diesem Zusammenhang auf die unpersönlichen Konstruktionen aufmerksam, die ebenso Ausdruck dieser Petalität sind ( $S .154)$. In den Aufsätzen "Nepoznat Netko'" (in: KZ, $68 \mathrm{ff}$ ) ) und "Kotivacija 1 stil" (in: UR, 6, 1962, $43 \mathrm{ff}$.) beschäftigt er sich ebenfalls mit dem geschichtlichen Determinismus bei Krleža; ebenso I. Franges ("Stvarnost 1 umjetnost u Krlezinoj proz:", S. 291 ff.). .

Vgl. M. Engelsfeld: H. Krleža: "Barake Pet Be", 25 l. 
Ein weiterer charakteristischer Stilzug ist die Verknüpfung von Erscheinungen oder Gegenständen, die in keinem logischen Zusammenhang zueinander stehen, mittels der Konjunktion "a" oder "i".

Tajna mesa, nezdrava tajna mesa u gnjilim djexjim tijelima, vani pada mokar snijeg, a iz matematike ga Zeka siguran popravak! (FI, 121)

Hier werden drei völlig verschiedene, logisch voneinander unabhängige Hauptsätze - der erste ist elliptisch - aneinandergereiht. Während der zweite unverbunden auf den ersten folgt, wird der dritte durch die Konjunktion "a" mit dem zweiten verbunden. Besonders auffällig ist die Verbindung von nicht zusammengehörenden Ereignissen dann, wenn die Konjunktion " 1 " verwendet wird, die normalerweise dazu dient, Gleichwertiges miteinander zu verbinden:

Boba putuje joß večeras, sedam hiljada lezi tamo u modroj kuverti na onom plis stolnjaku, 1 krave su se vratile, 1 kokołi su legle spavati, a jos je uvijek Xetrrt sedam 1 jedna minuta. $(F L, 246)$

Die einzige Beziehung, die hier zwischen den einzelnen durch " $i$ " verbundenen Lauptsätzen besteht, ist die der zeit.

5. Bildlichkeit der Sprache Krležas

a. Akustische und visuelle Elemente

Irlezas Sprache ist außerordentlich plastisch, anschaulich und bilderreich. Seine Empfindsamkeit für visuelle und akust1sche Hirkungen kommt unmittelbar in seiner Sprache zum Ausdruck. Auch Gerüche spielen hierbei eine nicht geringe Rolle. 27

27 Vgl. "Djetinjstvo u Agramu", 347 ff., 365, 369, 376 f. 


\section{Einige Beispiele:}

Sume vodovodne cijeri, plaču pipe 1 plinski kokoti, zvrndaju telefoni 1 bakrene Iice na krovovima, udara se vratima, zve laju psi, a negdje u zidu pjeva jednolizno jedna te ista kap, u pravilnim razmacima, kao otkucaj sata. Pjesme kapljica, odjeci koraka ljudskih u nerasvijetljenim hodnicima, daleki glasovi negdje u dubljini peterokatnice, plakanje crnalke plote na gramofonu 1 treperenje Filipovih Kivaca u tom zvulnom paklu zto zuji oko njega infernalno (...). (FI, 43 f.)

Bezeichnenderweise wird die Wirkung dieser Aufzählung von Geräuschen eines Stadthauses dem Leser nicht nur durch die einzelnen Detalls der Aufzählung suggeriert, sondern abschließend direkt ausgesprochen. Die Wirkung der Aufzählung wird noch dadurch verstärkt, daß die Verben, die ein Geräusch bezeichnen, an erster Stelle im Satz stehen. Krlezas ausgeprägter Sinn für Farben kommt in folgendem Beispiel besonders gut zum Ausdruck:

Jenseits der Promenade, wo unter Platanen Kreise roter und gelber Tulpen blühten, kroch langsam ein Metzgerwagen, schwer beladen mit blutigen Rinderkeulen, die Allee hinab. Ein bläulicher $\triangle a l b s f u B$ war in die Speichen geraten, und es sah aus, als werde das Rad diesen bläulichen KalbsfuB im Gelenk abbrechen. (FI, $16 \mathrm{f.}$ )

Des öfteren werden verschiedene Sinneseindrücke miteinander kombiniert. So in folgendem Beispiel Geruchs- und Gehörsempfindungen:

Hinter der Ecke waren Schritte zu hören. Ein Bäckerjunge mit einem Netz voll warmen Backwerks kam vorbei; die Semmeln dufteten und lange noch hörte man den Bäcker hinter der Straßenecke mit seinen Pantoffeln über den Asphalt schlurfen. $(F, 10)$

Gelegentlich kommt es auch direkt zur Synästhesie:

Und die Sonne spiegelt sich auf dem Samovar wie der klang der ersten Geige (...). (FI, 78) 
b. Vergleiche und Metaphern

In allen Romanen Erlezas finden sich viele, oft sehr ungewöhnliche Vergleiche, die ausgesprochen wirkungsvoll sind. Sie dienen der Veranschaulichung und Konkretisierung sowie der Bedeutungsverdichtung. Nicht zuletzt sind sie ein wichtiges littel der satirischen und grotesken Darstellung. Einige Beispiele:

Wie zerrissene Lappen flattern Bruchstücke der trüben und betrunkenen Sätze des Georgiers in Filips Kopf herum (...). (PI, 212)

Der Vergleich, der - wie häufig - am Satzanfang steht und dadurch besonders hervorgehoben wird, dient dazu, das Abstraktum "Satz" in einem konkreten Begriff ("Lappen") zu veranschaulichen. Sämtliche Adjektive stimmen in ibrem negativen Bedeutungsgehalt mit dem Vergleichsobjekt überein und färben in diesem Sinne auf das an und für sich neutrule Subjekt ab. AuBergewöbnlich viele Vergleiche dienen der Konkretisierung von Abstraktem:

Abscheuliche Bilder der Ausschweifung, dunkle Bilder der Wollust und des Fleisches, die dem Menschen wie alte Huren in unbeleuchteten Straßen im Schatten der Bäume zuzwinkern (...). (NRP, 155)

Des öfteren finden wir mehrere Vergleiche in einem Satz. Im folgenden Beispiel, in dem der Vergleich zum Bedeutungstrüger wird, ist wieder die für Krleža bezeicbnende Dichte des Ausdrucks zu beobachten, der enge Zusammenhalt aller am Satz beteiligten Worte, die den Grundeindruck lediglich variieren:

(...) und der Iift sah trübselig aus, wie die gläsernè Kứsche eines Begräbnisses zweiter Klasse: ein schwarzlackierter Kasten mit Polstern aus ducklem, abgewetztem Plüsch. (FI, 43)

in diesem Beispiel zeigt sich eine charakteristische Eigen- 
heit Krlezas. Er beläßt es nicht bei einem einfachen, kurzen Vergleich, sondern er spinnt diesen aus. Ahnlich im folgenden Beispiel:

Uber alle diese brennenden und blutigen Fragen sprach er scharf, wie ein Rabe, der menschliche Eingeweide zerreiBt und mit seinem schwarzen Schnabel das Gedärm anderer Lebewesen durch den Dreck zerrt. (FI, 190)

Der Vergleich wird $z u$ einem selbständigen Bild ausgeweitet. "Die sprachliche Figur des Vergleichs hat sich von ihrem Bezugspunkt losgelöst und gewissermaßen ein selbständiges Leben, eine eigene 'Wirklichkeit' erlangt." 28 Die Verwendung von mehreren Vergleichen für einen Gegenstand, die assoziative kortbewegung des Vergleichs, das Ausspinnen des Vergleichs $2 u$ einem Bild und die Ergänzung einer Metapher durch einen oder mehrere Vergleiche - all das ist bezeichnend für Krlezas barocken Stil. Ein Beispiel:

Keine letzten Worte glommen wie eine lunte,
zogen sich langsam hin, schwelten in einer
flimmernden langweiligen, eintönigen Hori-
zontale, und dann krachte alles wie eine
Sprengladung im Steinoruch. Es kam zur Haupt-
Detonation. Wie bei einem Feuerwerk, wenn al-
le denken, die letzte Rakete wäre schon abge-
brannt, und sich erst jetzt die Corona ent-
faltet, so daß die ganze Landschaft in einem
ubernatülichen Iicht aufflammt (...).
(NRP, 146)

Der hnlaB des Vergleichs, die Forte des Ich-Erzählers, treten hier völlig hinter dem detailliert ausgeführten Bild zurück. Bezeichnenderweise entstammen alle drei Vergleiche derselben Sphäre, und sämtliche Substantive, Verben und Adjek-

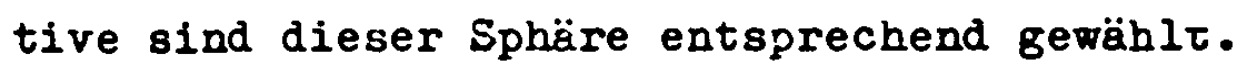

Krlezas Metaphern, die fast regelmäBig durch mehrere Vergleiche erweitert werden, so $d a B$ ein dichtes, geschlossenes

28 Günther, Hans: Das Groteske bei N.V. Gogol'. Seine Formen und Funktionen. Diss. Müncken 1967, s. $210 \mathrm{f}$. 
Gebilde entsteht, haben häufig eine erklärende Funktion. Ein abstrakter Begriff wird in einem konkreten, plastischen Bild veranschaulicht.

Dieser Gedanke tritt in den gestorbenen und
verfaulten Köpfen auf wie die Blase eines
trunkenen Traumbildes, er rollt uber den Grä-
bern wie eine durchsichtige Glaskugel, und in
dieser Kugel dampft in grünlichem Schein das
geheimnisvolle, warme, intensive Etwas, das
man süB hinunterschlürt wie einen heiBen
Punsch, das sich anühlt wie ein warmes Bett
und das angenehm ist wie ein gebadeter Leib,
das einzige HaB allen Lebens: der Tropen
lebenselexier, der so warm in unseren Adern
kreist.
(FI, 223)

Eine wichtige Rolle spielt der Vergleich auch im Rahmen der satirischen Darstellung zur Charakterisierung negativer Personen. Die zu charakterisierende Eigenschaft findet sich in höchster Potenz im Vergleichsobjekt. So wind der eitle und snobistische Phrasendrescher Pacak in FI zweimai mit einem Handlungsgehilfen auf dem Jahrmarkt verglichen, der seine Belesenheit und Bildung wie Stoffe vor seinen Kunden ausbreitet (FI, $134 \mathrm{f}$.).

c. Groteske Elemente

Viel bedeutender und aufschluBreicher für Krležas Stil sind jedoch jene verfremdenden Vergleiche, die zur Schaffung grotesker Gestalten gebraucht werden. Ungewöhnlich häufig werden eine Reihe von Romanpersonen - sie sind stets Vertreter der kritisierten Gesellschaft - mit Puppen, kasken und Tieren verglichen. Da im allgemeinen die grotesken Elemente im Herk KrleZas übersehen werden, soll in diesem Zusammenhang etwas ausführlicher auf dieses Phänomen elngegangen 
werden. 29

Krlezas Romane sind keineswegs durchgehend grotesker Natur, sie weisen jedoch in unterschiedichem AusmaB groteske Elemente auf, die sich vor allem im Stil und in den Motiven manifestieren. Das Groteske bel Krleza steht in erster IInie im Dienst der Satire. Krlezas Romane können schon deswegen nicht zu geschlossenen Grotesken werden, weil zu viel durch den Erzähler erklärt und gedeutet wird, der souverän über der Helt der Erzählung steht. "Der Gestalter des Grotesken darf und kann keine Sinngebung versuchen. " 30

Krleža bedient sich einer Reihe von grotesken Motiven. So wird in NRP die "Welt unter dem olickwinkel der Entfremdung als Tollhaus" 31 dargestellt. Es rindet eine Unkehr der wirklichen Verhältnisse statt: bel den "Irren" herrscht die Vernunft und nicht bel den "Normalen". Der Ich-Erzähler bemerkt über das Irrenhaus, in das er eingellefert wird, dab dort die "Sachverständigen durch ihre Handlungs- und Denkweise zweifellos ein gröBeres $\mathrm{MaB}$ an Irrsinn an den Tag legten als die Narren, die sie zu beobachten hatten." (NRP, 281). Der Topos des theatrum mundi - die Welt als Marionettentheater, Zirkus- oder Theatervorstellung - ist in allen Romanen KrleZas vertreten. 32 Dle Personen werden zu Masken und hölzernen Marionetten verfremdet, die nicht handeln, sondern sich me-

29 Lediglich 0. Bartoł ("Biljeske uz teoriju i tipologiju groteske." In: UR, 9, 1965, 82 ff.) sieht die grotesken Elemente in Krlezas Stil. Bartoz bezeichnet Krieza als Vertreter der "intellektuelien Groteske", in der sich Züge der kalten und der satirischen engagierten Groteske miteinander vermischen.

30 W. Kasser: Das Groteske in Malerel und Dichtung. München 1960. (= rowohlts dt. enzyklopädie. 107.), s. 138.

31 Ebd., s. 115.

32 Vgl. Kap. V, S. 213. 
chanlsch nach ihnen unfaBbaren Gesetzen bewegen. Etwas Fremdes handelt in ihnen und bewegt den Faden, an dem sie hängen. In FI sind es die "unsichtbaren Dekorateure", die sich im Hintergrund befinden und die den "wie in Schaufenstern" sitzenden Puppen "immer neue Schnittmuster und neue Gewobnheiten" anziehen (FI, 135). In BB sagt der Erzähler über Nielsen, daB sich dieser nur bis zu jenem "geheimnisvollen Augenblick" auf den "blitwischen Bühnenbrettern" bewege, bis der "unsichtbare Inspizient dieses blitwischen Dranas" den Mördern das verabredete Zeichen gebe (BB, 105). In dem "Puppen"-Spiel, dessen Auffübrung Nielsen beiwonnt, ist mehrmals ron diesem Faden die Rede, an dem die Puppen hängen und der sie zwingt, "ewig ein und dieselbe Rolle" zu spielen (BB, 391). 33

Während die Gestalten des Romans mit Puppen verglichen werden und die Handlung sich auf der Ebene eines Puppentheaters abspielt, werden die echten Puppen der blatwischen Marionettenvorstellung mehrmals als Menschen bezeichnet. Es tritt somit nicht nur eine Verdinglichung des Menschlichen ein, sondern auch eine Belebung des Unbelebten. Die Bereiche werden miteinander vermischt, und es vollzieht sich eine totale Umkehrung der normalen Verhältnisse.

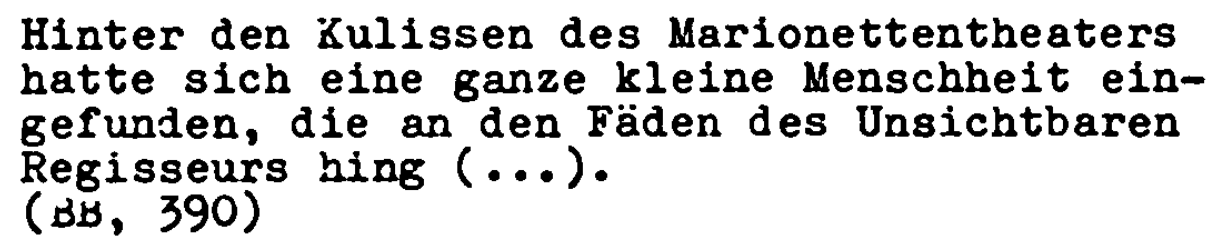

Die Puppen spielen ihre "Lebens-Rolle in diesem verrückten Theater (...)" (BB, 391). Yorik, der in Prolog des Stiickes zu dieser "kleinen denschheit hölzerner Puppen" (BB, 391) spricht, reflektiert darüber, wie sinnlos es ist, daB die "Puppe ein Mensch und der Mensch eine Puppe" ist (BB, 383). Eine andere Marionette, Doktor Faust, äußert:

$33 \mathrm{Vgl}$. Kap. III, S. 148. 
Unsere Theaterauffürungen wederholen $81 \mathrm{ch}$ bis in die Unendlichkeit, und unsere Menschheit spielt als Puppe am Faden ein und dasselbe Stück schon selt Beginn ihrer bürgerlichen Existenz!

(BB, 392)

In NRP vergleicht der Ich-Erzähler die Menschen in einem fast über elne Seite ausgeführten Bild mit Puppen auf Leierkästen, die sich nach dem "fremden Takt einer ihnen völlis unbegreiflichen und unverständlichen Musik" bewegen (NRP, 22). Der Ich-Erzähler bezeichnet die Menschen seiner Umbebung als Hanswirste, als Stroh- oder Holzpuppen, als Masken und Larven. In der Beschrelbung Domakinskis kommt die groteske Verfremdung des Menschen zur Fratze, zum Maskenträger und zur leblosen, mechanischen Puppe deutlich zum Ausdruck:

Ich erinnere mich, daß mir diese blöde apoplektische Maske des aufgedunsenen, alten Säufers (...) in der Tat wie ein dummer, stumpisinniger, leerer Gegenstand vorkam, daß ich den starken Eindruck von etwas künstilch Erzeugtem, Aufgezogenem, Temperiertem empland, von etwas, das nicht lebendig ist, sondern als solches zusammengesetzt ist und sich bewegt und spricht wie eine gespenstische Puppe, von etwas, das impersonal 1st, denn es stellt das Modell eines bestimmten Menschen dar, ist aber selbst kein Mensch $(\ldots .$.$) .$ (NRP, 32)

Noch weiter wird die Verdinglichung des Belebten im Vergleich der Menschen mit Wachspuppen aus dem Panoptikum getrieben. So schildert der Ich-Erzähler in einem weit ausgesponnenen grotesken bild mit groBer Ausführlichkeit eine Reihe von abstoBenden Details aus dem Panoptikum, um abschlieBend die Welt dieses Panoptikums mit der Wirklichkeit gleichzusetzen (NRP, 47).

Wir stellen in Krležas Romanen nicht nur eine Verfremdung des lienschlichen ins Puppenhafte, liechanische und damit ins Außermenschliche, sondern auch ins Tierische und Monströse fest. Menschliches und Tierisches wird miteinander vermischt, den "lienschenleibern" wird "etwas Tierisches" aufgesetzt. 34

34 W. Kayser: Das Groteske, S. 29. 
Die Vergleiche mit Tieren sind äußerst häufig:

(...) sie / die Kenschen/ nörgeln wegen jeder Kleinigkeit wie Dohlen auf dem Ast (...), wenn diese sich am Aas eines unbekannten Helden streiten, wer als erster das Recht hätte, sich an dem menschlichen Auge gütlich zu tun. (NRP, 23)

Hier wird der Vergleich wieder zu einem grotesken Bild ausgesponnen - ein für Krlezas Stil sehr bezeichnender Zug. Eine vom äußeren Erscheinungsbild her ausgesprochen groteske Gestalt ist die Schwester Liepachs (FL):

Ein ausgehungertes Gesicht, mit spanischem Unterkiefer, unverhältnismäßig hoch gewachsen, in altmodischen weißen Strümpfen, so bewegte sich die Erlauchte unter dem Sternenzelt wie ein völlig ausgedörrter Schatten in einer überaus pittoresken Welt $(. .$.$) . Von der letzten$ Hautrose im vergangenen Jahr war die Frau Banalrat kahl und trus eine reiche tiefschwarze Perücke, und um den Hals hatte sie ein schwarzes Samtband gebunden. So bewegte sie sich knochig und außergewöhnlich lang wie eine Vogelscheuche durch die Zimmer. Wie ein alter Rabe kaute sie ihre liedikamente und sprach dauernd davon, daß sie an Krebs sterbe. $(\mathrm{FL}, 91 \mathrm{f}$.

Ins Monströse und Froportionslose gesteigert erscheint die ebenfalls episodische Gestalt des Wiener GroBindustriellen Kornfold $(F L)$, der ungeheure liengen verschlingt und mehrmals mit einem riesigen Nilpferd verglichen wird. Außerdem wird der mit einem Tier auf eine Ebene gestellte Mensch durch ein Organ ersetzt, so daB Unbelebtes personifiziert wird:

Dieser alte asthmatische Balg, dieser Darm mit Verdauungsstörungen, dieses asthmatische behaarte Wesen (...) ist zum Erschrecken und gewaltig wie ein Gorilla (...).

(FI, 237)

Die Vermischung von Belebtem und Unbelebtem, Menschlichem und Tierischem manffestiert sich auch darin, daB nicht nur die Menschen tierische Züge annehmen, sondern daB die Tiere - ebenso wie die Marionetten in den "Puppen" in $B B$ - ver- 
menschlicht werden. So wird der Affe des Zardinals Armstrong (BB), der den Namen Giordano Bruno trägt, in seinem XuBeren beschrieben wie ein kiensch - und zwar ausfürlicher als die meisten der "menschlichen" Gestalten dieses Romans (BB, 136 f.). Anläßlich der Vernissage zum Tode Larsens erscheint er nicht zusammen mit dem Kardinal; da es regnet, fühlt er sich nicht besonders gut. ir sitzt währenddessen im geheizten Packard des Generals und lauscht der Radioübertragung der Fünften Symphonie Beethovens mit Toscanini als Dirigenten aus London.

Im ersten Roman (FL), dem einzigen, in dem der Begriff "grotesk" direkt verwendet wird, wird die Verfremdung der Realität am weitesten getrieben. 35 In Filips Sicht ist die Wirklichkeit kein sinnvolles Ganzes mehr; sie zerfällt in eine Reihe von disparaten Einzelheiten, die ohne inneren $\mathrm{Zu}-$ sammenhang gleichzeitig nebeneinander bestehen. Filip vermag nur noch die einzelnen Details zu registrieren, besitzt aber nicht die kraft, "diesen Details seiner Ungebung einen tieferen Sinn einzuhauchen" (FL, 32). Seine groteske Vision der Wirklichkeit, die Krleža mit Begriffen wie "Detailanalyse", "verschrobene und bizarre Beobachtungen", "VerfallsprozeB", "Entfremdung" und "Infernalisierung der Wirklichkeit" bezeichnet, findet ihren Niederschlag in Stil. Belebtes wird verdinglicht, Unbelebtes belebt, logisch nicht zusammengehörende Erscheinungen werden syntaktisch miteinander verknüpft oder einfach parataktisch aneinandergereiht, verschiedene semantische Bereiche werden nebeneinandergestellt, so daB "die qualitativen Unterschiede $z$ wischen Menschlichem und Dinglichem, Belebtem und Unbelebtem auf der dinglichen Stufe eingeebnet werden." 36 Für Filip zerfällt die Wirklichkeit nicht nur in Details, sondern es treten auch Teile als seIb-

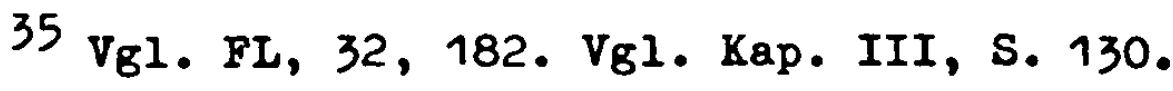

36 H. Günther, S. 85 .
} 
ständige Wesen auf:

Yenschen rennen in den Straßen, Gesichter bewegen sich in langen Zügen, gepuderte, bleiche Clownsgesichter mit Einschnitten von brennendem Karminrot um die Iippen, kurzsichtige Masken von Frauen in Schwarz, Gesichter von Buckligen, Unterkiefer, wächserne lange Finger mit bläulich schwarzen Nägeln, alles ziemlich häBi1ch. Ekelhafte Gesichter, Tierschnauzen, gebrandmarkt von Unzucht und Lastern, Bosheit und Sorgen, harzige, erhitzte Gesichter, Köpfe wie uöhren, Negerschnauzen, harte, scharfe Fleischfressergebisse, und alles ist grau wie ein photographisches Negativ. (FL, 34)

Die groteske Personifizierung wird hier mit der Verdinglichung von Belebtem kontrastiert. Die einzelnen menschlichen Gliedmaßen, parataktisch aneinandergereiht, erscheinen belebt und bewegen sich selbständig durch die Straßen. Die Isolierung der körperteile wirkt schon für sich unheimlich. Die Anhäufung von häBlichen und abstoBenden Einzelheiten verstärkt diese Wirkung. Bezeichnenderweise wird auch hier der Eindruck des HöBlichen und Grauenerregenden, der durch die einzelnen Glieder der Aufzählung suggeriert wird, abschlieBend jeweils direkt ausgesprochen.

Kamilos (Z) Sehweise ähnelt der Filips. Auf dem Begräbnis seiner Mutter oder auf dem Jolandas nimmt er die Menschen nicht als Ganzes wahr, sondern er sieht sie als eine bedrohliche Masse von Beinen, Nasen oder Augen. Noch ausgeprägter als in FI werden hier listenmäBige Aufzählungen von abstoßenden, ekelerregenden Details gegeben, die personifiziert werden. In folgendem Beispiel wird Belebtes und Unbelebtes in asyndetisch gebildeten Gruppen mosaikartig aneinandergereint und damit eine Verdinglichung des Belebten bewirkt:

(...) alle in Schwarz, Damen und Herren, Schleier und Frauenhüte, Zylinder und Lackschuhe, Strümpfe und Handschuhe, Krawatten und Regenschirme, alles schwarz in schwarz (...).

$(\mathrm{z}, 2,440)$ 
Einige Zeilen weiter nimmt die Verselbständigung der einzelnen Gliedmaßen ausgesprochen unheimliche Dimensionen an:

\begin{tabular}{|c|}
\hline 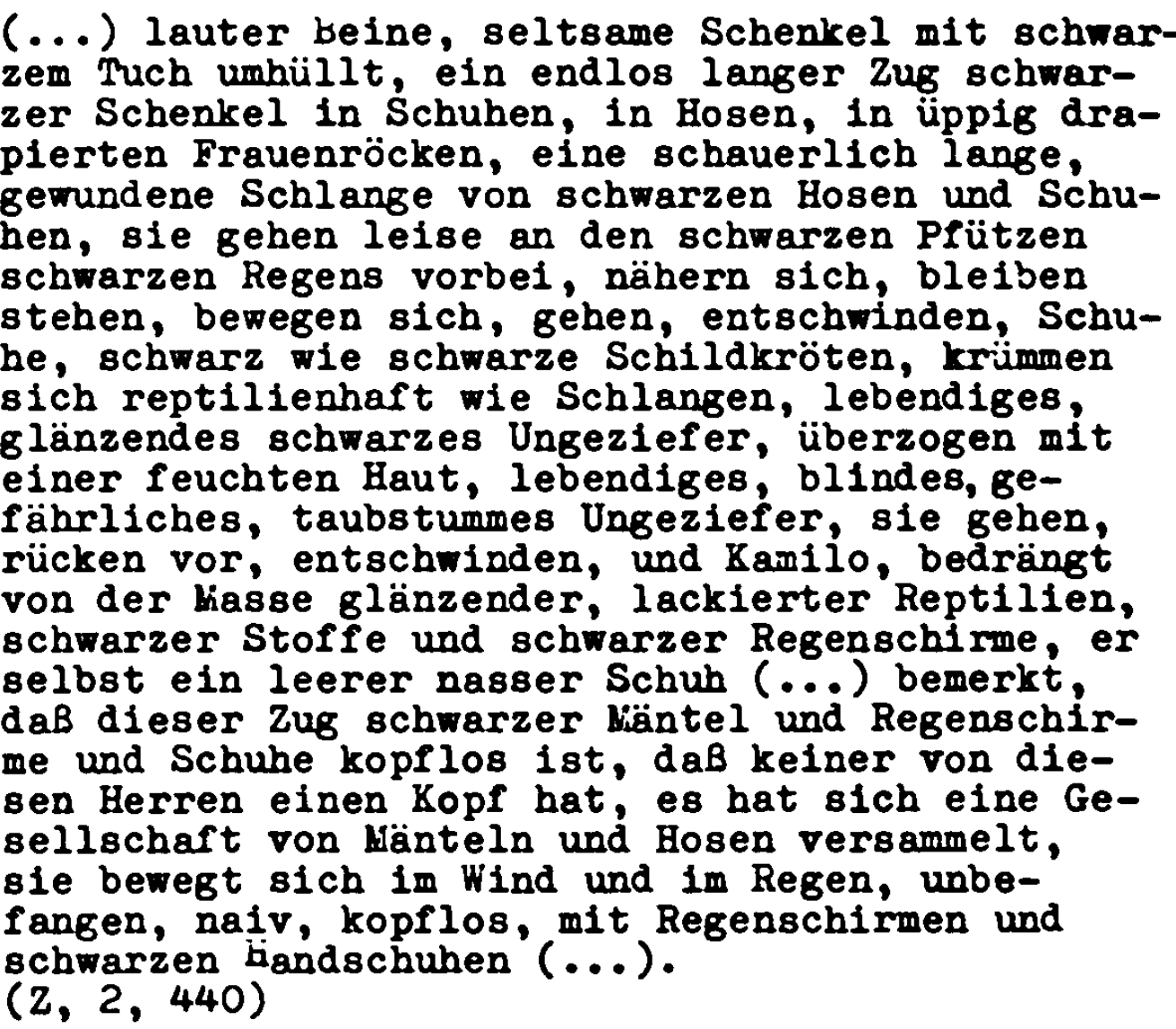 \\
\hline
\end{tabular}

Hier sind sämtliche Kerkmale des grotesken Stils vereinigt: Körperteile und Kleidungsstücke treten als selbständige Wesen auf, Unbelebtes (Schuhe) wird wit Belebtem (Tieren) verglichen, und Gegenstände treten an die Stelle der menschl1chen Gestalt. Die groteske Personifizierung geht so weit, daB die Kleidungsstücke sich zu einer Gesellschaft versammeln und sich wie lienschen bewegen. Es fehlt innen lediglich der Kopf. Die groteske Personifizierung wird durch die Reihung von Verben der Bewegung wirksam unterstrichen. Auf dem Begräbnis seiner Hutter, wo die Trauergesellschaft nur mehr als ein Heer von Augen, Nasen oder Schnauzen erscheint, schüttelt namilo nicht den Trauergästen die Hände, sondern ihren Hasen und Gedärmen ( $2,1,802$ I.).

Filips Vision der malerischen Darstellung des Sankt-RochusFestes trägt ausgesprochen groteske Züge. Kenschliches und 
Dingliches wird in turbulenter Häufung zu einem "höllischen Purioso" gesteigert, zu einem Chaos, in dem sämtliche Ordnungen aufgelöst werden (FL, $178 \mathrm{ff}$. ). Vor allem in FI, aber auch in den anderen Romanen zeigt sich, daB die grotesken Elemente im Romanwerk ärlezas im wesentlichen von der bildenden Kunst herkommen. Nicht zufällig werden im Zusammenhang mit Filips grotesken Visionen die Namen Bosch und Breughel genannt. 37 obwohl der weitgehend groteske Züge aufweisende Stil der Romane Krležas in erster Iinie im Dienst der satirischen Gestaltung steht, erschöpft er sich nicht in dieser konkreten Funktion. Ganz abgesehen von den grotesken Motiven, Vergleichen, Ketaphern, Wortmosaiken und Metonjmien trägt die Bildlichkeit der Sprache Krležas häufig groteske Züge. Sie ist üppig, muchernd, verzweigt, sinnlich-plastisch und tendiert zur tbersteigerung des jeweiligen Ausdrucks. Ein Beispiel:

D1s Träume wachsen und verzweigen sich geheimnisvoll und taubstumm wie heimtückische Baumstämme in nächtlicher stille: sie winden sich durch die finsteren Labyrinthe des Blutes und klimmen wie Rankenblattwerk an den Ruinen des Gefühls hoch, überwuchert vom Efeu des Leids und der Trauer wie auf einem vergessenen Priedhof, und die Phantasie klimpert mit dem feinen und todbringenden Summen eines giftigen Moskitos thre Kantilene über den faulig-morastigen Bereichen von Kamilos müdem BewuBtsein, indem sie wie ein tödliches gelbes Pieber auf jeden seiner Gedanken lauert. $(2,2,438)$

37 Vgl. PI, 67 f., 178. Vgl. 0. Dartoš: "Seine /KrleŽas/ widersprüchliche groteske Dildlichkeit murzelt in der bildenden Kunst." (83). 
6. Hyperbolik

Die Untersuchung der Vergleiche, Metaphern, Bilder sowie jener Stilelemente, die grotesken Charakter aufweisen, läBt das wesentliche Charakteristikum der Sprache Krležas bereits erkennen: die tberladenheit, das tberquellen, die wuchernde, strotzende Uppigkeit. Im gleichen Zusammenhang ist die Hyperbolik seines Stils zu sehen, die Vorliebe für Steigerungsformen, in denen die Gefühlsbeteiligung des Autors weit mehr zum Ausdruck kommt als in den bewertenden Adjektiven und Vergle1chen. Die ins Maßlose gehende tbertreibung, die vor allem für NRP charakteristisch ist, steht im Dienst der satirischen Darstellung.

Die einfachste Form der Steigerung ist der adjektivische Superlativ. Häufig wird hier eine übertriebene Steigerung positiver Züge oder Eigenschaften vorgenommen, hinter der das Gegenteil des Gesagten durchscheint. So in der hyperbolischen Lobrede Hugo-Hugos auf Domarinski (NRP):

Er ist einer der höchsten und angesehensten Würdenträger unserer heimischen Wirtschaft, er ist einer der weitsichtigsten Begruinder und geradezu seherischsten Lenker (...), dieser verdienstvollste unter allen Jubilaren und gleichzeitig der bescheidenste (...), dieser vorbildiliche Charakter (...), dieser groBe Mann mußte eines Tages erleben, bespien, beleidigt und verleumdet zu werden $(. .$.$) .$ NRP, 112) 38

Des öfteren erscheinen auch Adjektive mit negativer Bedeutung in der Form des Superlativs. Ebenso wie diese dienen auch die Schimpfwörter der Stelgerung des negativen Grades.

(...) und wer könnte diesem Herrn Stifter begreiflich machen, daB er (...) der gewöhnlichste und ordinärste kriminelle Typ ist, ein Mörder, ein moralischer Kretin, eine

38 Mehrmals spricht der Ich-Erzähler von den "phantastischen Superlativen" Hugo-Hugos über Domaćinsk1 (NRP, 122; vgl. ebenso NRP, 121, 123). 
verbrecherische Erscheinung!

(NRP, 33)

Nicht immer wind der Superlativ jedoch zur negativen Potenzierung herangezogen. In folgendem Beispiel schwelgt der Ich-Erzäbler aus NRP in Superlativen, um seiner geradezı pathetischen Begeisterung über die Tugenden Valents, des einfachen kajkavischen Bauern, Ausdruck zu verleihen:

(...) er ist mein weisester Ratgeber und Preund, er ist zweifellos einer der weisesten, erfahrensten und genialsten Menschen, denen ich je in meinem Leben begegnet bin. (NRP, 198)

Da die Substantive grammatisch nicht gesteigert werden können, werden sie entweder in form von Schimpfwörtern angehäuft - wie bereits erwähnt - oder aber sie werden in der Pluralform verwendet. Hohe Zahlen und groBe Mengenangaben dienen ebenfalls der hyperbolischen Steigerung.

Bettler, Intellektuelle Vagabunden, Narren, blaublütige Idioten, die sich einbilden, Nachkommen von Phantasie-Prätendenten auf irgendwelche Phantasie-Throne zu sein, von krankhartem Ebrgeiz verzehrte jchreiberlinge, Abschreiber fremden Blödsinns, iürdenträger, Redner, Vortragende, Schwachköpfe, die an den Bonbons ihrer traurigen Karrieren lutschen, alle diese lächerlichen klelnen Pinscher, die für ein Biskuit Jedem die Füße lecken, Säulen einer auf Einbildung beruhenden Gesellschart, Vertreter elner administrativ von oben befohlenen Wissenschaft, dieses ganze Pack (...), alle steckten sie wie zweibeiniges Klauenvieh die Köpfe zusammen (...). (NRP, $44 \mathrm{f.})$

Hier wird eine Henge von Schimpfwörtern aneinandergereizt, deren negative Bedeutung durch Adjektive und kurze Relavivsätze verstärkt wird. Die wenigen Substantive, die neutsal oder sogar positiv sind, erialten durch die negative Unzebung eberfalls einen negativen Yert. Die Pluralisierung des Subjekts wird häufig zur satirischen Verallgemeinerung der Typisierung herangezogen: 


\begin{abstract}
Alle Masnovs, so viele es ihrer auch gibt, und es gibt sie in unabsehbaren Haufen, fürchten sich nachgerade ständig, ununterbrochen und gleichermaßen panikartig vor verschledenen Gefahren, die ebenso pervers und ausdauernd auf diese Art von Masnovschen Existenzen lauern wie blutrünstige Ungeheuer. $(\mathrm{F}, 233)$
\end{abstract}

AuBer der Pluralisierung und der hohen Mengenangabe wird der hyperbolische Ausdruck noch durch die synonymen Adverbien und das Vokabular verstärkt. Hohe Zahlen und übertriebene Mengenangaben sind besonders häufig. In folgendem Beispiel werden sie mit chiastisch angeordneten Schimpfwörtern kombiniert:

(...) so pflegte ich die Geselligkeit und bewirtete in meinem Haus ganze Scharen von Schuften und Dummköpfen, Dummköpfen und Schuften in endlosen Reihen (...). (NRP, 23 f.)

Abschließend noch ein Beispiel, in dem hohe Zahlen- und Mengenangaben, der Genitiv, der Superlativ und das Gradadverb zur Steigerung herangezogen werden:

In dem Haus dieses gastfreundichsten aller Hausväter gingen Tausende ein und aus, an seinem reichen Tisch tafelten jahrelang ganze Prozessionen von Menschen, von seiner Wohltätigkeit erhalten Tausende Existenzen ihr Brot, sein Lebenswerk wird der unvergeBliche Stolz einer ganzen Nation sein (...). (NRP, 118)

Ein weiteres Mittel der Steigerung bietet sich in der mehrfachen Verneinung:

(...) biti bezidejna, bezlicna formula bezli ̌̇nog $i$ bezidejnog nełeg కto nikada nije htjelo ni vjerovalo ni sanjalo ni riskiralo nista, zto se nikada nije dalo zanijeti nikakvim pak ni najnevinijim proplamsajem bilo kakve nebanalne misli, to je lupismasnovljevsko klupko crijeva 1 bubrega u pantalonama (...) $(\mathrm{F}, 233)$

Die chiastisch angeordneten Adjektive werden durch die Vor- 
silbe "bez-" negativiert. Superlativische Adjektive verstärken die hyperbolische Verneinung.

Am häufigsten vertreten ist die fronische Steigerung mit "upravo", "gotovo" oder "viłe od toga", die sich in der Regel unter Verwendung von Synonymen und in der Form einer Klimax vollzieht. In diesem Pall erfolgt eine stufenweise Bedeutungssteigerung des Substantivs oder Adjektivs.

Ausdauernd und aufopferungswillig, geradezu samariterbaft liebte ich alle Menschen meiner Umgebung (...), 1ch tröstete und beruhigte mich mit mildem, fast christlichem Wohlwollen (...), lmmer fand lch irgendeinen guten, geradezu lobenswerten Charakterzus des Betreffenden (...). (NRP, 20)

Die entsprechende Wortwahl ist bei dieser Form der Steigerung außerordentlich wichtig. Das Grundwort, von dem die Steigerung ausgeht, weist zumindest eine übertrieben positive - seltener negative - Bedeutung auf; häufig ist es jedoch bereits ein hyperbolischer Ausdruck, der in seiner Bedeutung noch weiter gesteigert wird. Im folgenden Beispiel werden sowohl die synonymen Adjektive in ihrer Bedeutung gesteigert, indem das Subjekt, das sie näher bestimmen, mehrmals wiederholt wird, als auch die Substantive:

- Dieser Ausnahmezustand (...), dieser abscheuliche anarchische Zustand, als das Blut um uns in Strömen FloB, dieser in jeder Beziehung hochgradig unruhige, rebellische, ja geradezu abscheulich revolutionäre Zustand bot an und für sich die Möglichkeit, ja nicht nur die Möglichkeit, sondern geradezu das Recht und die Ermächtigung, noch mehr als die Ermächtigung: die Pflicht, die bürgerliche Ordnung und die Rechtssicherheit wiederherzustellen! (NRP, 119)

In diesem Zusammenhang sel kurz darauf verwiesen, daB KrleZa sich des öfteren der ironischen Grobschreibung bedient, um das Pathos des Sprechenden nicht nur durch den Wortschatz und entsprechende Kommentare anzuzeigen, sondern es überdies noch 
graphisch zu verdeutlichen. 39 Das, was hervorgehoben werden soll, wird im Gegensatz zur üblichen Rechtschreibung mit groBen Anfangsbuchstaben geschrieben. So etwa die Personalund Possessivpronomen im Monolog Barutanskis, der sich in übersteigerter Selbsteinschätzung mit Francesco sforza vergleicht und meint, ganz Blitwien sei ausschlieblich seine Schöpfung ( $B B, 41 \mathrm{ff}$. ). Oder die pathetisch phrasenhafte Rede Supilos:

On je stupio pred Omladinu da se nadahne najzdravijim eliksirom nase Narodne Egzistencije, naše Narodne Supstancije, nałe Zemlje, da se u Njenom zagrljaju obnovi kao Antej, pun snage za nove Borbe (...). $(2,2,773)$

Wichtig ist auch die Interpunktion. Abgesehen von den für Brleža charakteristischen Doppelpunkten, die bereits erwähnt murden, fallen vor allem die vielen Ausrufezeichen auf, die den Affekt des Autors anzeigen, der häufig mit erhobener Stimme spricht.

Wie der Klang eines nackten, silbernen Beiles, wie der Hall einer Dampfsäge, in der glänzenden metallischen Drehung des scharfkantigen Kreises, der im höheren, übernatürlichen Vibrieren unserer Zeit wie ein Rasiermesser die Dinge und die Vorstellungen zerschneidet, zitternd mit der hellen stimme eines hohen Aufschreies, wie das a auf der Stimmgabel, frech und siegreich ertönte hoch über Filips Haupt der Klang eines Propellers und ergOB sich wie der Schall der himmlischen Posaune! Zwei Welten: Iondon - Bagdad - Bombay in drei Tagen, und die Schnapsbude ron Kravoder mit den vollen Eierkörben der Nonnen! Pannonischer Schlamm und die vorrückende Zivilisation!

(FL, 71)

39 In einigen Kommentaren des Erzählers kommt deutlich zum Ausdruck, daB die GroBschreibung in erster Iinie in pathetischer Rede Verwendung findet. Vgl. Z, 2, 773 und F, 220. 
In diesem Absatz, in dem das Flugzeug über Filip als Symbol einer besseren, lichterfüllten Welt erscheint, manifestiert sich der Affekt des Sprechers nicht nur in der Betonung der Ausrufe, sondern auch im pathetisch gefärbten Vokabular und vor allem in den vielen Vergleichen (fünf). Die letzten beiden Sätze sind elliptisch und lassen damit ebenfalls die Gefüblsbeteiligung und Erregung des Sprechenden erkennen. Die Ellipse ist ein in den Romanen Krležas häufig verwendetes Stilmittel. In fast allen Fällen wird das Verb ausgelassen.

\section{Reihung und Hëurung}

Die Ausweitung und Oberstelgerung des Ausdrucks, die tberladenheit der Sprache Krležas wird zum großen Teil durch die Reihung und Häufung von Worten und Satzteilen bewirkt. Die barosken Mittel der suggestiven Worthäufung und Tortwiederholung dienen der Verstärkung der Aussage, der Variation des Ausdrucks und der Intensivierung des Gefühlsgehalts. So werden entweder verschledene Worte oder Synonyme aneinandergereiht oder dasselbe Wort wird wiederholt - meist mehrmals.

Einer der auffälligsten Stilzüge Krležas, der in fast allen Untersuchungen seines Stils erwähnt wird, ist die Häufung der Adjektive, die das jeweilige Substantiv geradezu überfluten. Die stets wertende haltung des Autors sowie die Tendenz, sich nicht mit einem Wort zu begnügen, um eine Person oder eine Sache zu kennzeichnen, kommt in diesem Stilzug deutlich zum Ausdruck. Meist dienen die verschiedenen Adjektivè der Verstärkung des Grundeindruckes, den sie varileren und intensivieren. Eine geradezu barocke Anhäufung von Attributen finden wir in folgendem Satz:

Svileni vjetar jutarnji, texki, bijeli, trudni travjanski oblaci (...). (FL, 16)

Vor allem dann, wenn Krleža verhaßte Personen beschreibt, 
sind Verbitterung und Abscheu häufig so groB, daB er immer wieder neue Adjektive aneinanderreiht, von denen jedes einzelne eine negative Bedeutung besitzt. Meist wird in solchen Fällen das Substantiv mehrere Male wiederholt. Im folgenden Beispiel wird das Substantiv "otin (Augen) viermal wiederholt, und zweimal erscheint das Synonym "pogled" (Blick), das eine Mal in dem diese asyndetische Reihung abschließenden verdinglichenden Vergleich.

Usred mase izvjedljivih otiju, osjeca Kamilo sive ljepljive, sitne, uvele, bezizrazne, mutne, Xinovnicke, umorne, bijjede poglede, kako $g a$ indiskretno diraju svojim staklenim sjajem, vodenoprozirne, mračne, tajanstveno hladne, Cudne oti, ptiłje oti, sive, grabežljive, gladne, podmukle, glupe, mrtve ofi, upale i sakrivene ispod niskih orbitalnih svodova, poluslijepe, kokoకje, pospane, tupe, lukave i zle oti, tako usasie, tako jadno utuljene kao pogledi tupih dikobraza (...). $(z, 1,792)$

Besonders hervorgehoben werden die Adjektive oft dadurch, daß sie sich nicht in der grammatisch üblichen Stellung vor dem Substantiv befinden, sondern danach. ${ }^{40}$ Auch durch die Stellung am Satzanfang werden sie betont:

Krvav, razderan, blatan, mokar kao utoplenik, Filip je utrtao u sobu. (FL, 271)

Zwar werden die Adjektivreihen besonders häufig in attributiver Form gebraucht, sie stehen jedoch des öfteren auch in der Satzaussage:

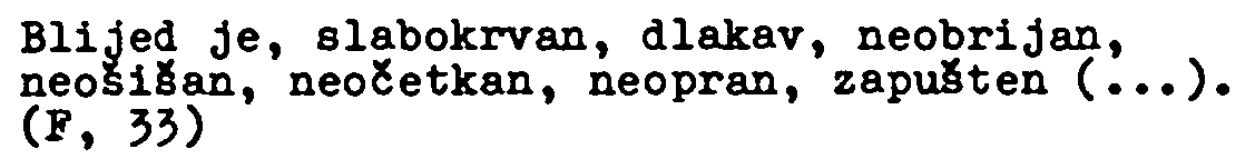

Charakteristisch für Krlezas Stil ist auch die Aufzählung vieler Begriffe, um eine Person oder eine Sacke zu kennzeichnen. Häufig sind die einzelnen Begriffe Träger einer negati-

$40 \mathrm{Vgl}$. S. 230 dieses Kapitels. 
ven Bedeutung, so daB dieser Eindiuck mit jedem neuen Giled der Wortreibe potenziert wird. In folgendem Beispiel wird das Objekt des Satzes fünfmal nacheinander aufgenommen und jedes hal durch ein Substantiv mit negativer Bedeutung bezeichnet:

Dobro sam poznavao tu hohrtaplersku obitelj (...) 1 znajue1 iza kulisa, kako to zapravo izgleda 8 tim opterećenim bijednicima, koji kao sucl sude po crt1 svojih zainteresiranih veza, kao odvjetnici gaze preko mrtvaca (...), ja te sluge stranih interesa, uvijek spremne na svaku uslugu svakome tko moze dobro da ih plati, te carske savjetnike, odlikovane najvizim redovima, te skrte kutevlasnike, koji se neprekidno tuzakaju sa svojim stanarima, nikada nisam volio (...). (NRP, 42)

Der einfache zweite Hauptsatz ("ja nisam volio") wird durch die mehrmalige Aufnahme des Objekts, sowie durch die an diese Objekte angeschlossenen Nebensätze, erweitert. Sämtliche Objekte samt ihren Nebensätzen sind zwischen das Subjekt ("ja") und das Prädikat des Satzes ("nisam vol1o") eingeschoben. Diese zum Teil beträchtliche Ausweitung eines einfachen Hauptsatzes durch die mehrmalige Wiederholung eines bestimmten Satzteils, an den fast regelmäßig Nebensätze angeschlossen werden, 1st sehr bezeichnend für Krlezas Stil.

Charakteristisch ist weiterhin die Häufung von Synonymen - ein beliebtes rhetorisches Stilmittel des Barock -, die Ausdruck des Bestrebens 1st, einen einzelnen Begriff durch eine ganze Reihe von Worten einer bestimmten Begriffskategorie möglichśt vollkommen zu erfassen und eine erschöpfende Bestandsaufnahme zu geben. Einige Beispiele:

Sjećam se, da ste se (...) osjetall potpuno

u zraku, bez podloge, bez uporizta, bez baze:

$u$ strahu pred Rmubom silom (...). u strav1 pred zelenokaderaskom anarhijom $i$ u panici pred nasim domatim, autohtonim vakuumom. (NRP, 84)

Die erste Reihe von Synonymen besteht aus vier Substantiven, 
die zweite, nach dem Doppelpunkt elliptisch angeschlossen, aus drei in einer Klimax angeordneten Substantiven, die sich wiederum in parallel gebauten Satzgliedern befinden. Die Reihung ist wie in vielen Pällen asyndetisch. Die Anordnung der Synonyme nach stufenweiser Steigerung im Aussageinhalt ist bei Krleza sehr häufig.

(...) posto je njfegora jednokatnica (...) sazidana na dradeset milijuna prorupljenih, prosviranih 1 proresetanih lubanja njegovih evropskih sugradjana (...), pozto se Xitava jedna Azija odvalila u krv, u kugu, u požar, u propast, u katastrofu ( ...), gospodin gradski vijecnik (...) protestira protiv upotrebe "teretnih automobila" (...). (NRP, 14)

Die erregte Anklage des Ich-Erzählers findet ihren stilistischen Ausdruck in der hyperbolischen Steigerung, in den Synonymen (drei Partizipien) und in der asyndetischen, in Form einer Klimax angeordneten Reihung von fünf Substantiven, von denen das letzte ("katastrofa") den Oberbegriff für die vorhergehenden bildet. In folgendem Beispiel erscheint die Re1hung der synonymen Substantive in der rhetorischen Plgur der Synekdoche:

(...) a jedini natin da se Xovjek probije 12 kaveza, to su, dijete moje, cekini, taliri, dukati, u jednu rijec, zlato $(. .$.$) .$ $(z, 2,258)$

Häufig wird auch dasselbe Wort einmal oder mehrmals wiederholt. Die Wortwiederholung bewirkt nicht nur eine emotionelle Färbung der Aussage, sondern sie erwelst sich des öfteren auch als ein geeignetes Mittel, den langen Aufzählungen, Reihungen und Häufungen Zusammenhalt zu verleihen. Oft wird das Subjekt des Satzes affektiv wederholt, wobel es beim zweitenmal durch eine Reihe von Adjektiven näher bestimet wird:

Još traje n o $\varepsilon$, duboka, nijema, zlokobnotamna, beskrajnoduga, beskonakna blatvifska $n \circ$ \& $(\ldots$.$) .$

$(8,1)$ 
In folgendem Beispiel wird das Akkusativobjekt zweimal wiederbolt und jedes $\mathrm{Mal}$ etwas näher bestimmt. Wiederum ist der Affekt des Sprechers ausschlaggebend für die Wortwiederholung.

(...) lesen Sie $(\ldots)$ wie man in unserer Zeitung auf e $\mathrm{n} s \mathrm{c}$ h $\mathrm{n}$ spuckt, auf zum Tode verurteilte $\mathrm{M}$ e $\mathrm{c}$ he $\mathrm{n}$, auf unschuldis verurteilte $u$ e $s c h$ e $n$ (...). $(P, 209)$

Eine beträchtliche Ausweitung erfährt der einfache, aus Subjekt, Prädikat und Objekt bestehende folgende Satz durch die geradezu schwindelerregende Wiederholung des Objekts. Bezelchnend ist die Satzstellung: Subjekt und Prädikat stehen am Schluß des sich über dreizehn Zeilen erstreckenden Satzes.

Ovaj $s$ n $i j$ e $g$ što pada, proljetni, februarski, novinarski s n $i j$ e 8 to prse kroz nałe nedjeljne feuilletone, ovaj nas domari, blitrinski, aragonski, mužikovski, autohtoni s n $i j e B$, naz rasni $s \mathrm{n} i j e g$, ovaj s n 1 je $g$ u garama $i$ u opancima, to pada kroz nału stampu (...), ovaj, u jednu riječ, nas "rodol jubivi", "Iirski s n $i$ e $g$ (...), ovaj poetski, karnevalski s $n i j$ e $B$ koji satirixno progovara na usta nałeg nacionalnog proroka (...), eto, ovaj "lanjski s n $i$ je $B$ " (...), ovaj, dakle, 1 ovakav hunsko-aragonski nostalgitan " $s \mathrm{n} i \mathrm{j}$ e 8 ", to, ja $(\ldots)$ zovem politi $\ldots$ ka onanija, da, onanija $(\ldots)$. $(\mathrm{P}, 209 \mathrm{f.})$

Immer wieder wird das Substantiv "snijeg" (Schnee) wiederholt - meist in Verbindung mit dem Demonstrativpronomen und immer wieder werden neue Adjektive aneinandergereiht. Bezeichnenderweise nimmt die Aufzählung auch dann noch nicht, wie erwartet, ein Ende, wenn das Vorhergenende mit der Nendung "u jednu rijel" (in einem Hort) zusammengefaßt wird. In folgendem Beispiel wird das Verb zweimal wiederholt, um die Gleichförmigkeit und Ereignislosigkeit der kläglichen Existenz Masnovs zu demonstrieren; ebenso zweimal die beiden Adjektive 
"prazan" (leer) und "glup" (dumm), die in der Form des Polyptotons erscheinen:

$$
\begin{aligned}
& \text { (...) hod a i hod a i hoda po } \\
& \text { p r a z n } \circ \mathrm{m} \text { i g l u p } \circ \mathrm{m} \text { Blitvanenu, } \\
& \text { p r a z n } i \mathrm{~m} \text { g l u p } i \mathrm{~m} \text { ulicama p } r \text { a } 2 \\
& n \text { o g g l u p o g, provincijalnog aragonskog } \\
& \text { gnijezda }(\ldots) \text {. } \\
& \text { (F, 232) }
\end{aligned}
$$

Nicht zuletzt erfolgt die Aufblähung der Sätze durch bloße Aufzählungen, durch Kataloge von Namen, Funktionen, Gegenständen usw. Meist sind diese Aufzählungen asyndetisch.

Die Leute haben sich Tapeten ausgedacht, Teppiche, Parkettböden, Röhren mit warmem Wasser, Glastüren, Goldfische, Kakteen (...). Die Leute haben unter ihren Dächern chinesische Majolika gestapelt, Aquarelle, Damasttischtücher, Seidenstrümpfe, Pelze und Juwelen. (FL, 44)

Beide Sätze beginnen mit demselben Subjekt. Die erste Aufzählung ist asyndetisch, die zweite monosyndetisch. Sämtliche aneinandergereihten Akkusativobjekte hängen von dem jeweiligen Prädikat des Satzes ab. In folgendem Beispiel münden die einzelnen Glieder der asyndetischen Reihung in einer satirischen Verallgemeinerung:

(...) und so belehrt er Kammern, Rektoren, Universitäten, die Presse, Wohltätigkeitsvereine, Delegationen, Partelen, Maler, die öffentliche Meinung, eine ganze Gesellschaft (...). ( NRP, 29 f.)

Häufig werden heterogene Begriffe nebeneinandergestellt:

Toplo meso (...) postavljeno na stražnje noge: u crkvu, u sudnicu, na kazalizne daske, na proporjedaonicu, na katedru, u pissoire, u krtme, u kasarne, to toplo meso obuteno po tajanstrenim pravilima raznolikih historijskih kostima (...), podrzarljeno ljudsko meso $(. .$.$) , to jad-$ no ljudsko meso izgubljeno je potpuno pred beskrajno velikom kolitinom otvorenih pitanja $(\ldots$.$) .$ (NRP, 21) 
Die Substantive "crkva" (Kirche), "sudnica" (Gerichtssaal), "proporjedaonica" (Kanzel) und "katedra" werden auf eine Ebene mit Begriffen wie ."pissolr" oder "krtma" (Kneipe) gestellt und dadurch mit negativer Bedeutung aufgeladen. Die nach dem Doppelpunkt beginnende asyndetische Reihung wird elliptisch an das vorhergehende Partizip ("postavljeno") angeschlossen. Ebenso typlsch wie diese Abhängigkeit vieler Glieder von einem 1st die mehrmalige wiederaurnahme des Subjekts, durch die der Aufzählung Zusammenhalt und toersichtlichkeit verliehen wird.

\section{Das Demonstrativpronomen}

Selbst bel flüchtiger Betrachtung der Romane Krležs fällt die ungewöhnlich häufige Verwendung des Demonstrativpronomens auf, dessen Leistung darin besteht, auf ein Ding oder eln Tesen hinzuweisen. Das bei einem Demonstrativpronomen stehende Substantiv wird dadurch in besonderer Weise hervorgehoben und betont. Bezeichnenderweise begnügt sich Krleza meist nicht mit nur einem Demonstrativpronomen. Wiederum ist eine stark affektive Pärbung des Textes das Ergebnis dieses 8t1lzuges.
$\mathrm{Da}, \mathrm{t}$ a $j$ ulaner, na bijeloj kobili (...), $t$ a $j$ cugsfirer Hitrec vom $k$. und $k$. Ulanen Regiment No. 12 Tolna, $t$ a $j$ nadcestar $u$ propnju na bijelojkobill (...), to je jedna 1sto tako nakinjena lutka, kao 1 o $v$ a $j$ njegor presvijetli veliki zupan (...). To je savr $\mathrm{x}$ ena tmina. I $t a$ b1 se tmina mogla rasvijetliti samo 8 nijagar- sk1m rodopadima (....). T o je inteligencija koja zapisuje sebi Tombola potpourri (...). (FI, 108)

Das Subjekt des ersten Satzes, der Bauer Hitrec, wird zwe1mal in Verbindung mit dem Demonstrativpronomen "taj" wiederholt. Die Zusammenfassung der einzelnen Glieder der Aufzählung durch die neutrale Form des Pronomens "to", das sich 
auf den gesamten vorhergehenden Inhalt der Reihung bezieht und deren Glieder in sich aufnimmt, ist auBerordentlich charakteristisch für Krlezas St1l. Häufig steht das Domonstrativpronomen in Verbindung mit Schimpiworten oder aber mit übertrieben positiven Bezeichnungen, so daB eine doppelte Verstärkung des Ausdrucks bewirkt wird.

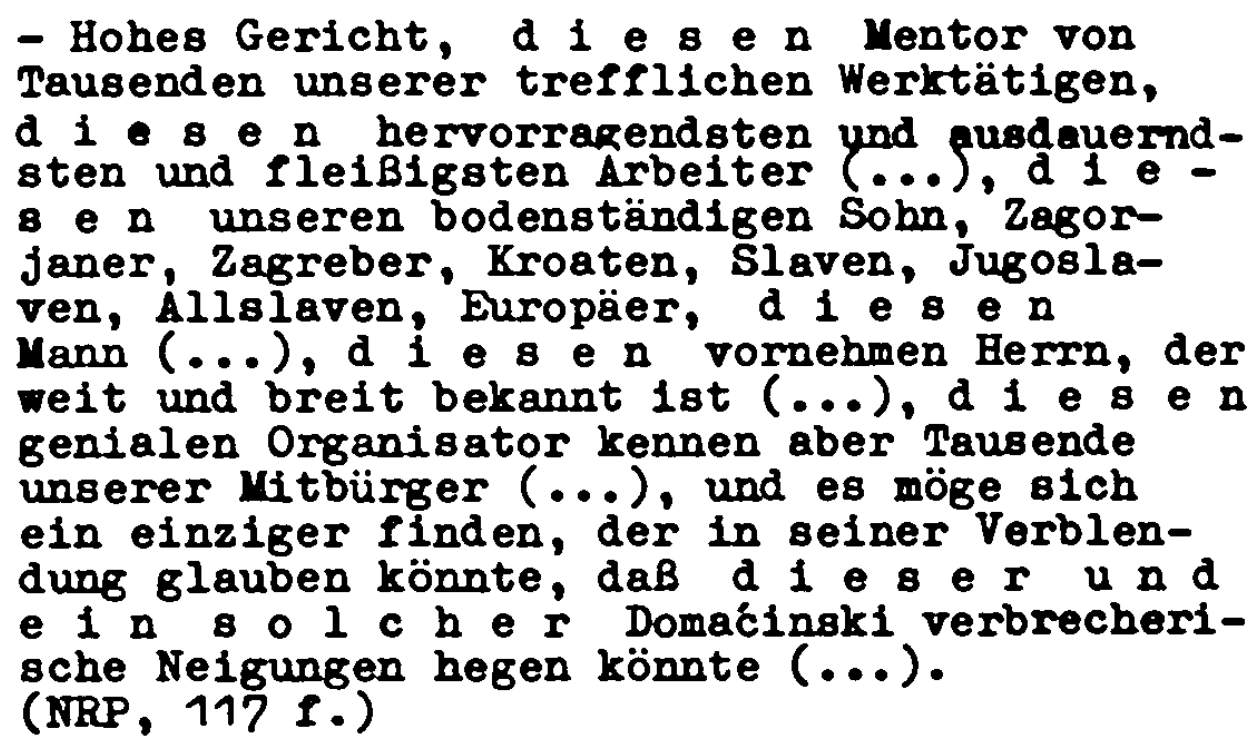

Dieser sich über siebzehn Zeilen erstreckende Satz ist trotz seiner Länge keineswegs unübersichtlich oder komplizlert. Er besteht lediglich aus einer Reihe von unverbundenen Akrusativobjekten mit Demonstrativpronomen, die zum Teil durch $\mathrm{Ne}-$ bensätze ergänzt werden. Charakteristisch ist wederum die Satzstellung. Erst in der elften Zeile folgt das Prädikat und in der zwölften das Subjekt des Satzes, von denen die vielen aufgezählten 'Akküsativobjekte abhängif sind.

Die neutrale Form des Demonstrativpronomens "to" wird auch dann verwendet, wenn das Gesagte besonders stark hervorgehoben und betont werden soll. Die Wirkung wird in folgendem Beispiel noch dadurch verstärkt, daB das "to" mehrmals wiederholt wird und daB die einzelnen Glieder der Aufzählung in ihrem Bedeutungsgehalt gesteigert und miteinander kontrastiert werden.

(...) jer Domaćinski nije Xovjek, $t$ o nije pojedinac, $t o$ nije odredjeno lice, $t o$ 
je pojam, to je slika, t $\circ$ je jedno Zitavo stanje uslovljeno drustvenim prilikama $(. .$.$) .$

(NRP, 126)

\section{Satzbau}

Abschließend seien noch einige typische syntaktische Konstruktionen erwähnt, die äußerst häufig sind und die im wesentlichen dazu dienen, die für Krlezas Romane charakteristischen "Sturzbachsätze" aufzufangen, zu gliedern und ihnen einen Zusammenhalt zu verleihen. Wir stellten als charakteristisches Merkmal seines Stils die barocke Weitschweifigkeit fest, die durch Wortfülle aufgeblähten Satzungetüme, die in immer neuen Ansätzen anschwellen und manchmal kein Ende zu finden scheinen. Der Verständlichkeit und Eingängigkeit des Gesagten wird dadurch jedoch im allgemeinen kein Abbruch getan. Der Satzbau ist in der Regel nicht kompliziert und meist auf ein einfaches Schema zurickzuführen. Der Hauptsatz wird oft durch eine Reihe von gleichartigen Nebensätzen oder durch Appositionen quantitativ erweitert; ebenso durch Wortwiederholungen, durch die Reihung und Aufzählung von Fakten, Namen, Titeln usw. Die Tendenz zur Verschachtelung und damit zur Bevorzugung des hypotaktischen Satzbaus ist für KrleZas Romane nicht charakteristisch. Im Gegenseit: seine Sätze wachsen nach dem Prinzip der Aneinanderreihung von oft gleichartigen Satzteilen und -gliedern an. Der parataktische Satzbau überwiegt bei weitem den hypotaktischen; lediglich in $\mathrm{Z}$ ist eine Zunahme der Hypotaxe $\mathrm{zu}$ bemerken. $\mathrm{Da}$ es Krleza stets um Klarheit, UnmiBverständlichkeit und Eindringlichkeit des Gesagten geht, bedient er sich abgesehen von der Neben- oder Beiordnung der Satzglieder einiger syntaktischer Konstruktionen, die die einzelnen Glieder immer wieder zusammenfassen und zu einem gut überschau- 
baren Ganzen ordnen. Den weitgespannten, stets neue Satzteile reihenden Perioden, die Ausdruck der Neigung Krlezas zur Expansion, zur tbersteigerung und zur Weitschweifigkeit sind, wird auf diese Weise entgegengewirkt, indem thnen ein fester Rahmen verliehen wird, der alle vorhergehenden Einzelteile in sich aufnimmt und sie gleichsam umschließt. D. Brigljević, der als Einziger auf eine dieser für Krležas Prosa so wichtigen Konstruktionen eingeht, bezeichnet KrleZas Stil im Hinblick darauf mit Recht als "analytisch-synthetischen Stil." 41

Ein Mittel, die einzelnen Teile miteinander zu verbinden, ist die Wiederaufnahme eines Wortes oder eines Satzteils nach der Aufzählung. 42 Wendungen wie "u jednu rijet" (in einem Wort) erfüllen eine ähnliche Funktion. Häufig wird die Aufzählung jedoch keineswegs nach einer solchen Zusammenfassung abgebrochen. Die häufigste und zugleich die charakteristischste Form der Zusammenfassung ist jedoch die durch das Indefinitpronomen "sve". Eine ähnliche Funktion erfült auch die neutrale Form des Demonstrativpronomens "to", auf das bereits verwiesen murde. Oft wird das Indefinitpronomen mit dem "to" kombiniert. Die ganze Vielfalt der aufgezählten Fakten wird in diesen Schluß mit "sve" oder "sve to" aufgenommen, zusammengefabt und zueinander in Beziehung gesetzt. So gibt der Ich-Erzähler eine sich über achtzehn Zeilen erstreckende Bestandsaufnahme der verschiedenen Erscheinungsformen des Zylinderträgers, die zweimal durch ein "sve to" zusammengefaBt wird. Die auf die Aufzählung der Substantive folgende Reihung von Prädikaten in Abhängigkeit von "sve je to potelo" - wird durch die Wendung "u jednu rijec" zusammengefaßt.

\footnotetext{
41 s. 175.

42 Vgl. S. 255 R. dieses_Kapitels.
} 
Dragul jari, zubari, bolj1 pokucarci, కefovi tehnirkih sekcija, romanisti, Celisti, trgovc1 cipelama, slobodni mislioci lamarkisti (...), $8 \forall$ e s s to uznemirilo kao vrapci na Valentinovo 1 i $v e j e$ $t$ o (...) pođelo da rezi, da laje, da se uzrujava, da klevece, da ogovara, da do-

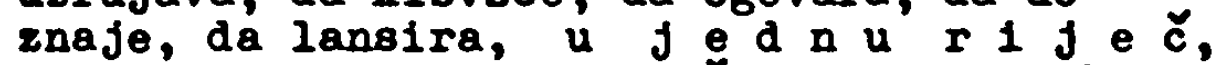
da se strastreno bavi sluçajem glavnog Domakinskovog advokata $(\ldots)$. (IRP, 45 I.)

Sämtliche Subjekte dieser langen Aufzählung werden in dieBem "sve" und in dem ibnen allen gemeinsamen einen Prädikat

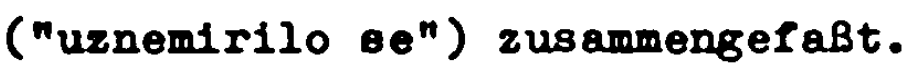

Besonders charakteristisch für Krležas Stil ist, daB mit dieser Zusammenfassung und Abrundung häufig ein allgemelnes Urteil, eine abschlieBende Verallgemeinerung verbunden ist. ${ }^{43}$ Eln Beispiel für diese in Krlezas Romanen sehr häufige induktive Methode:

(...) nach jenen zwe1, dre1 glücklichen Herbsttagen hat er schon lange nichts mehr erlebt, was überhaupt erlebenswert gewesen wäre: er schleicht in Cafte herum, lebt unter diesen Zweibeinern (...) die die Kiefer und Kautschukgebisse bewegen, $u n d$ a $11 \theta$ ist unfruchtbar, und es gibt keinen böheren Grund für das Dasein. (FL, 35 I.)

Krleza bringt diese Konstruktion auch in abgewandelter Form. Das Inderinitpronomen und im Zusammenhang damit das allgemeine Urteil steht nicht am Schlus des Satzes, also nach der Aufzählung, sondern am Beginn oder auch in der vitte des Satzes. Die Zusammenfassung oder die Verallgemeinerung bildet nicht den Endpunkt der Aufzählung, sondern den Ausgangspunkt :

$S$ ve je znao kako dolazi: 1 kraka u ruc1, 1 težak masivan otpor vratnica, 1 dugi neprozraCeni hodnik namazan sivom uljenom bojom, 1 drvene stube, i veliki, bijelouokvireni prozor u medjukatu s izgledom u vrt. (FI, 11)

43 VGl. D. Brigljerit, 171. 
Die elnzelnen Glieder der Reihung, die durch die Konfunktion "I" miteinander verbunden sind und nach dem Doppelpunkt stehen, wahren ihre Selbständigkelt und beziehen sich alle auf das eine, vor dem Doppelpunkt stehende Prädikat, an das sie elliptisch angeschlossen werden. Diese Abhänglgkelt vieler Glieder von elnem, so zum Beispiel eine ganze Reihe von Nebensätzen, die sich alle auf einen Hauptsatz oder einen Oberbegriff beziehen, die Relhung von vielen Subjekten, die alle in einem Prädikat aufgefangen werden, ist bezelchnend für Krležas Stil. Häufig hat der ganze erste Komplex des Satzes die Funktion des Subjekts, auf das sich alles Folgende bezieht, und ungekehrt. Trotz der Fiille und tberladenheit vieler Sätze macht sich dadurch ein Zug zur Konzentration bemerkbar.

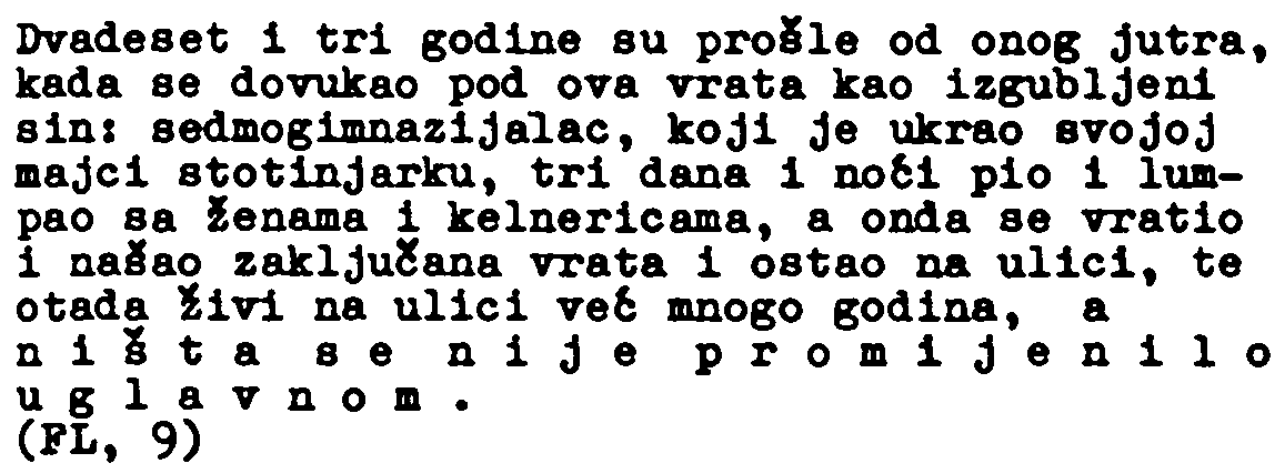

Alle sieben Prädikate beziehen sich hier auf das vor dem Doppelpunkt stehende Subjekt des Satzes ("on") und dessen Appositionen ("1zgubljeni sin", "sedmogimnazijalac"). In diesem Beispiel treffen wir aú einen weiteren für Krležas St1l bereichnenden Zug. Der SchluB des Satzes bringt die gedankliche Konzentration der Aussage, die den Rahmen des jeweiligen Satzes sprengt. In wenigen Worten wird die Quintessenz des Ganzen zusammengefabt, hier die Synthese aus sämtlichen Ereignissen gezogen, die Filips Lebensweg bestimmten. Ein Bild, eine Schilderung oder eine Aurzählung wird durch eine solche, sie abschlieBende Verallgemeinerung aus dem engen Rahmen der Umgebung herausgehoben und in einen höheren Zusammenhang hineingestellt. Ein weiteres Beisplel: 
Stajao je tiho taj stari vrt sa svoje četiri simetrið̌ne, bijele staze, sa rascvalim Žutim ruzama $i$ staklenim kuglama $i$ patuljcima $i$ vodoskokom i zlatnim ribicama kao netaknut, savrßeno uredan, poliven, obrezan, kao da se nije nitta dogodilo $i$ k a d a $s$ e u z $i$ vot $u$ u $\circ$ p \& e nit t a ne d o B $a$ d $j$ j $a$.

Ausgehend von der Beschreibung des Gartens, der sich seit Filips Kindheit nicht verändert hat, wird die Parallele zum Leben ganz allgemein gezogen. Von einem konkreten Einzelfall ausgehend wird der Bezug zu sämtlichen Erscheinungen de: Wirklichkeit hergestellt.

In folgenden Beispiel wird der Ausgangspunkt einer solchen auf Assoziation beruhenden Verallgemeinerung deutlich sichtbar. Der Ich-Erzähler aus NRP steht auf dem Bahnho: und betrachtet einen vorüberfahrenden Zug, dessen Fenstər beleuchtet sind, so daß es ihm scheint, als hätte sich eine Reihe beleuchteter Eisenbahnaborte in Bewegung gesetzt. Folgender Gedankengang schlieBt sich an diese Wahrnehmung in:

(...) und alles, was die lienschen bis heute im Lauf ihrer Zivilisation geschaffen haben, das ist nachgerade eine Reihe beleuchteter Eisenbahnaborte, die auf dem Globus in allen Richtungen fahren $(\ldots$.$) .$

(NRP, 193)

Aus all diesen beispielen wird ersichtlich, daß für krležas Stil nicht nur Ubersteigerung und Uberladenheit kenzeichnend sind, sondern daß er seine barock überquellende Sprache durch eine Reihe von syntaktischen Konstruktionen zu bändigen vermag und daß er überdies $z u$ einer starken Konzentration der Aussage fähig ist.

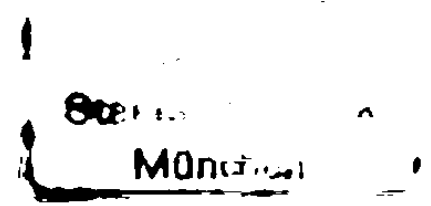




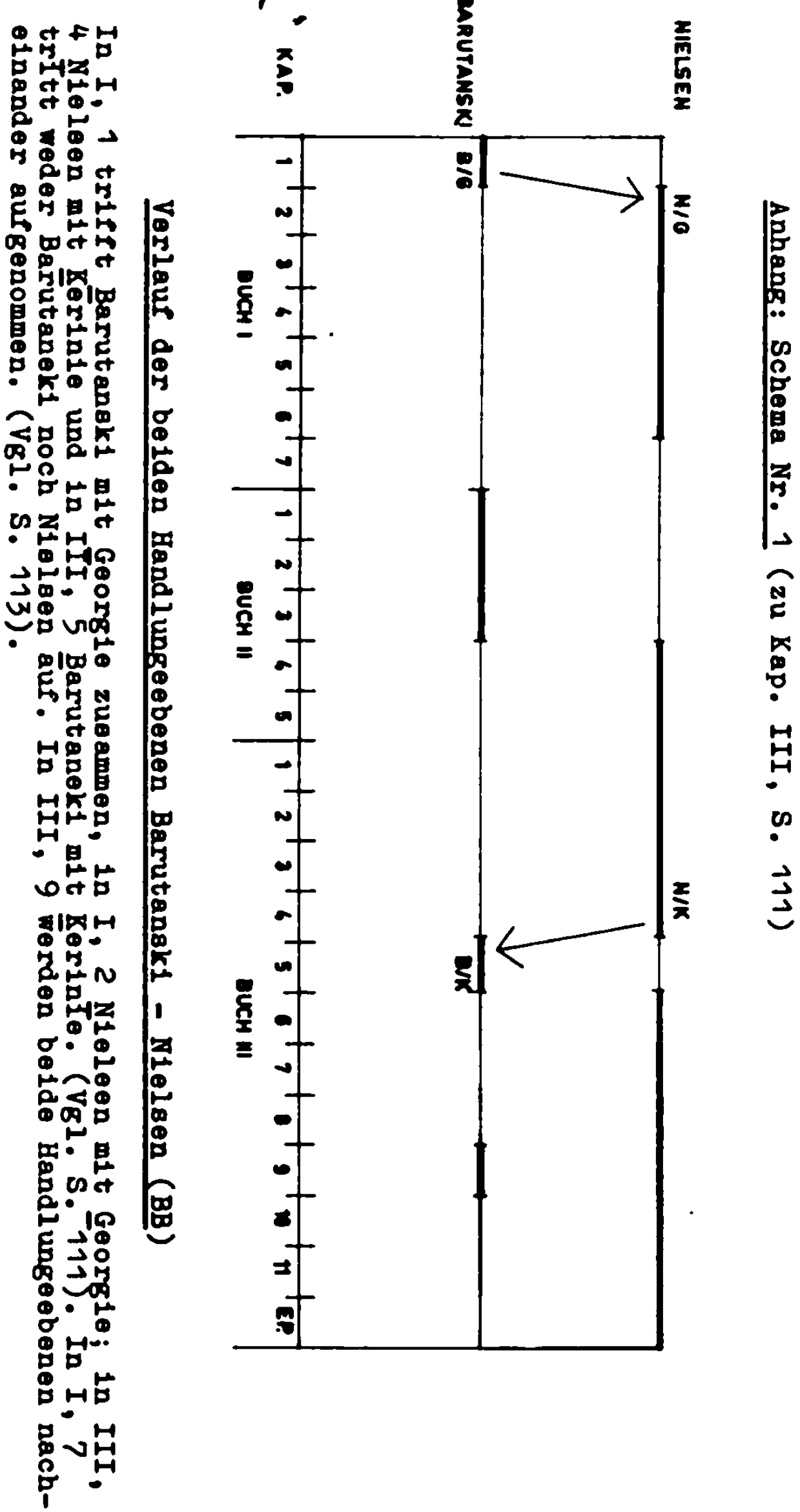


Schema Nr. 2 (2u Kap. III, S. 113)

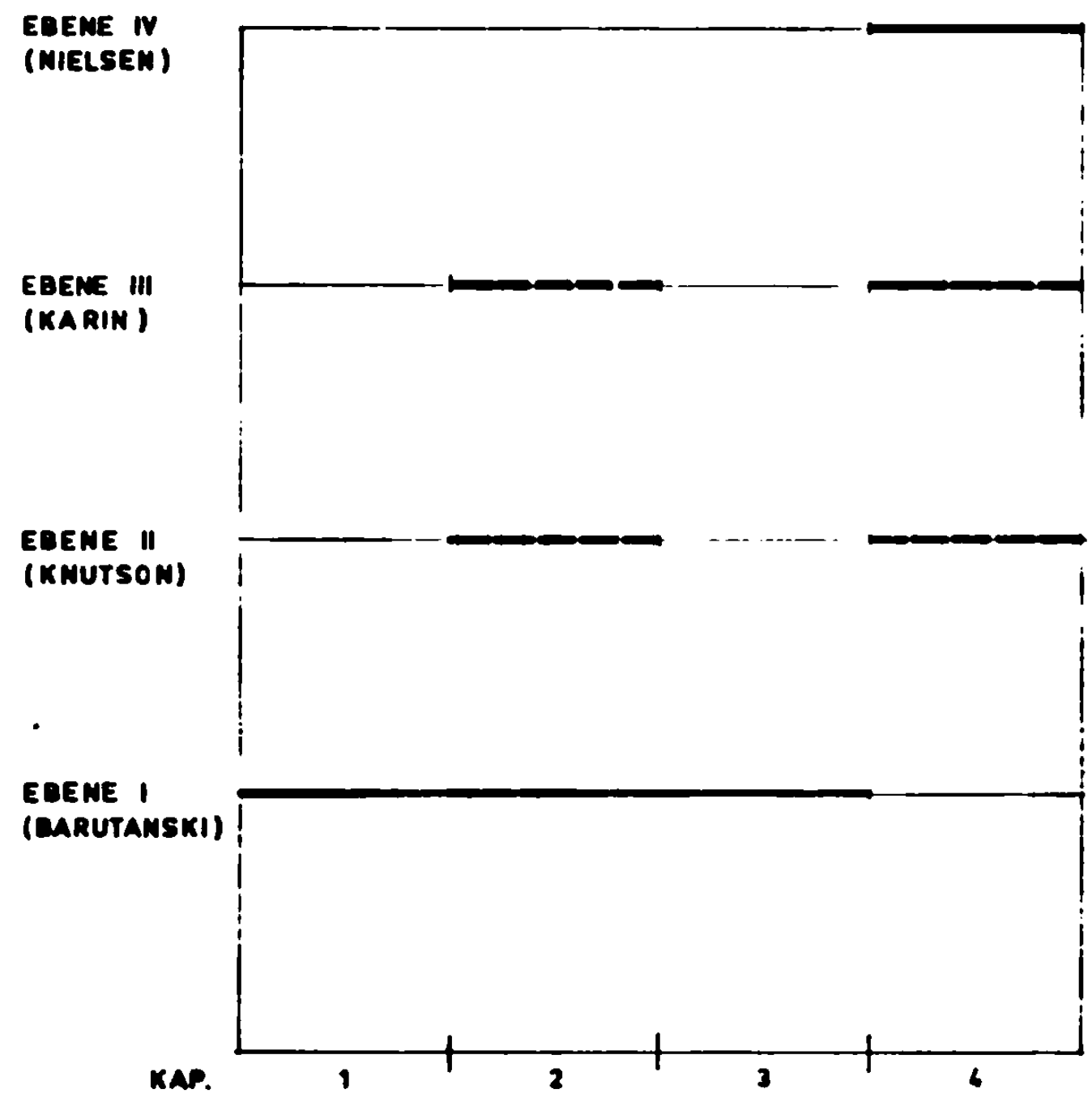

Verlauf der vier Handlungsebenen in $\mathrm{BB}$, II, 1-4

besagt, daB das Geschehen auf dieser Ebene direkt dargestellt wird. besagt, daß das Geschehen auf dieser Ebene sich im Hintergrund abspielt. 
Schema Nr. 3 (zu Kap. IlI, S. 116)

EBENE N

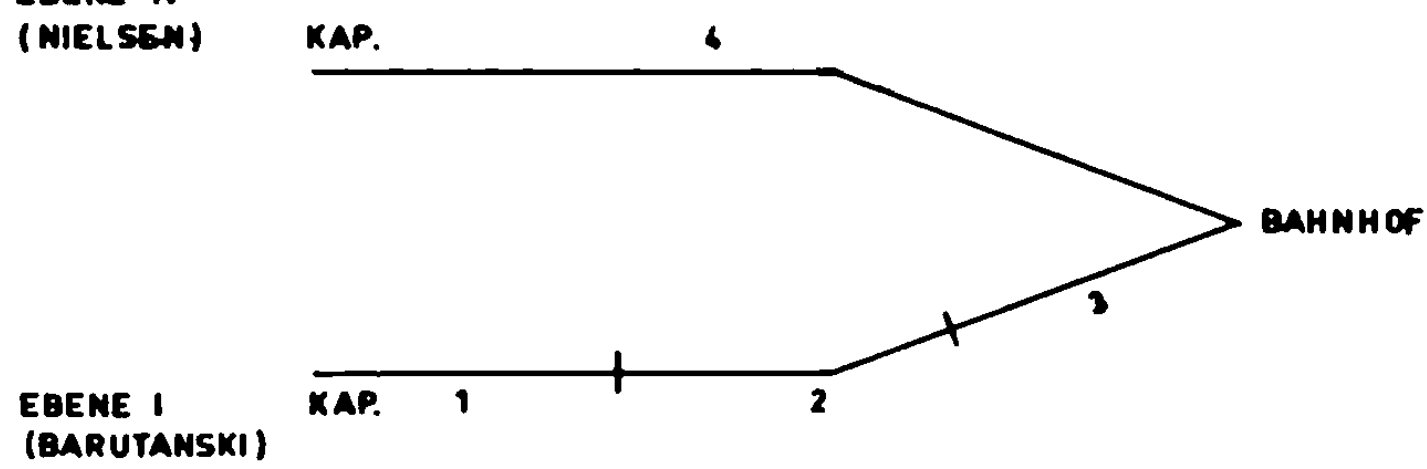

Verlauf der beiden Handlungsebenen I und IV in BB, II, 1-4 Dle beiden Ebenen I und IV verlaufen zum SchluB völlis synchron und schneiden sich.

Schema Nr. 4 (zu Kap. III, S. 117)

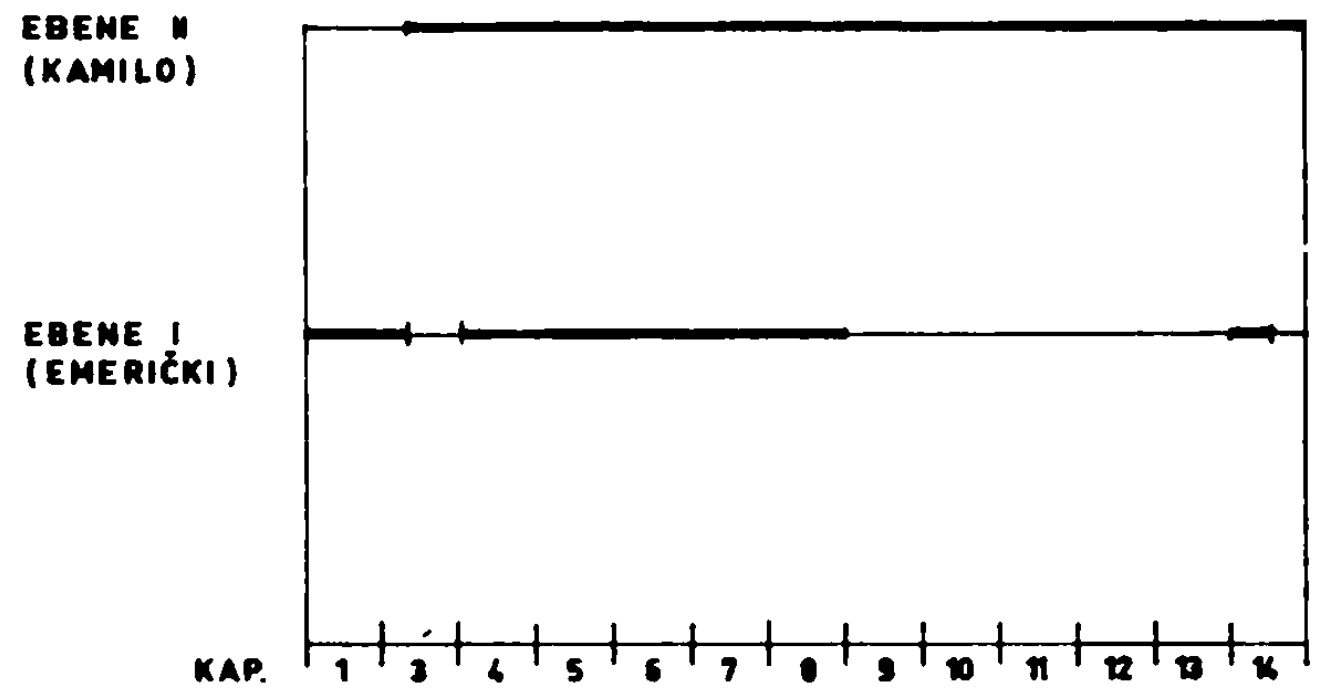

Verlauf der beluen Handlungsebenen Emerick1-Kamilo in Buch I Von 2

Da Kap. 2 ein reines Retrospektiven-KapiteI 1st, wird es hier nicht ${ }^{2}$ srücksichtigt. 


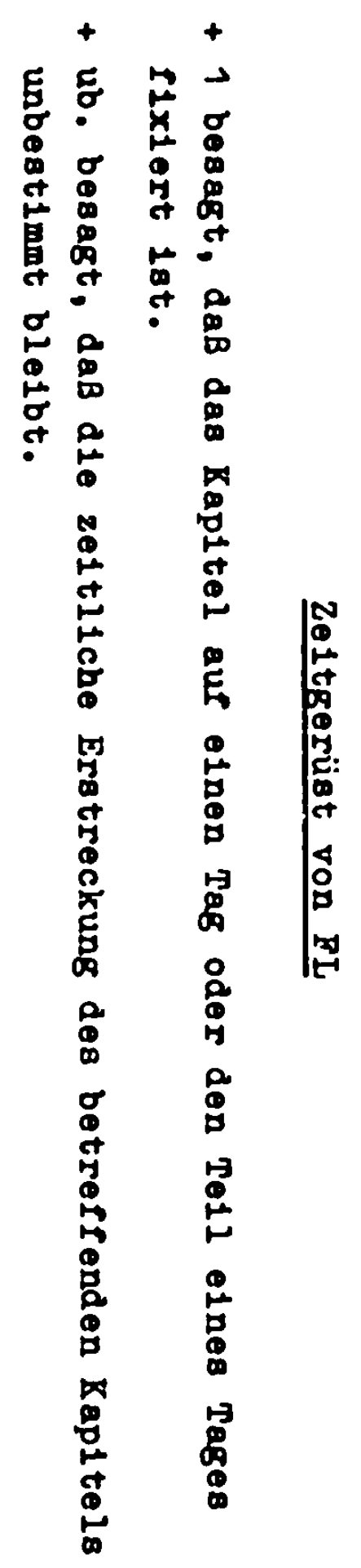

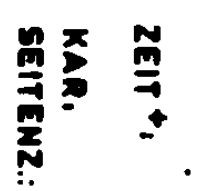

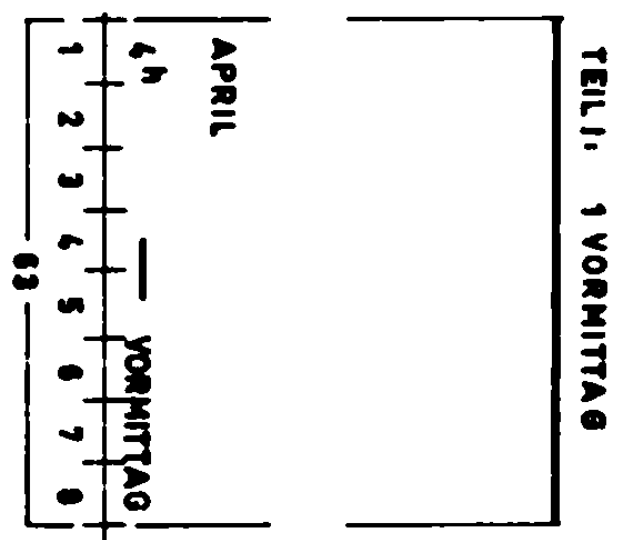

华

$\widetilde{E}$

茴

๑2

$\vec{J}$ 

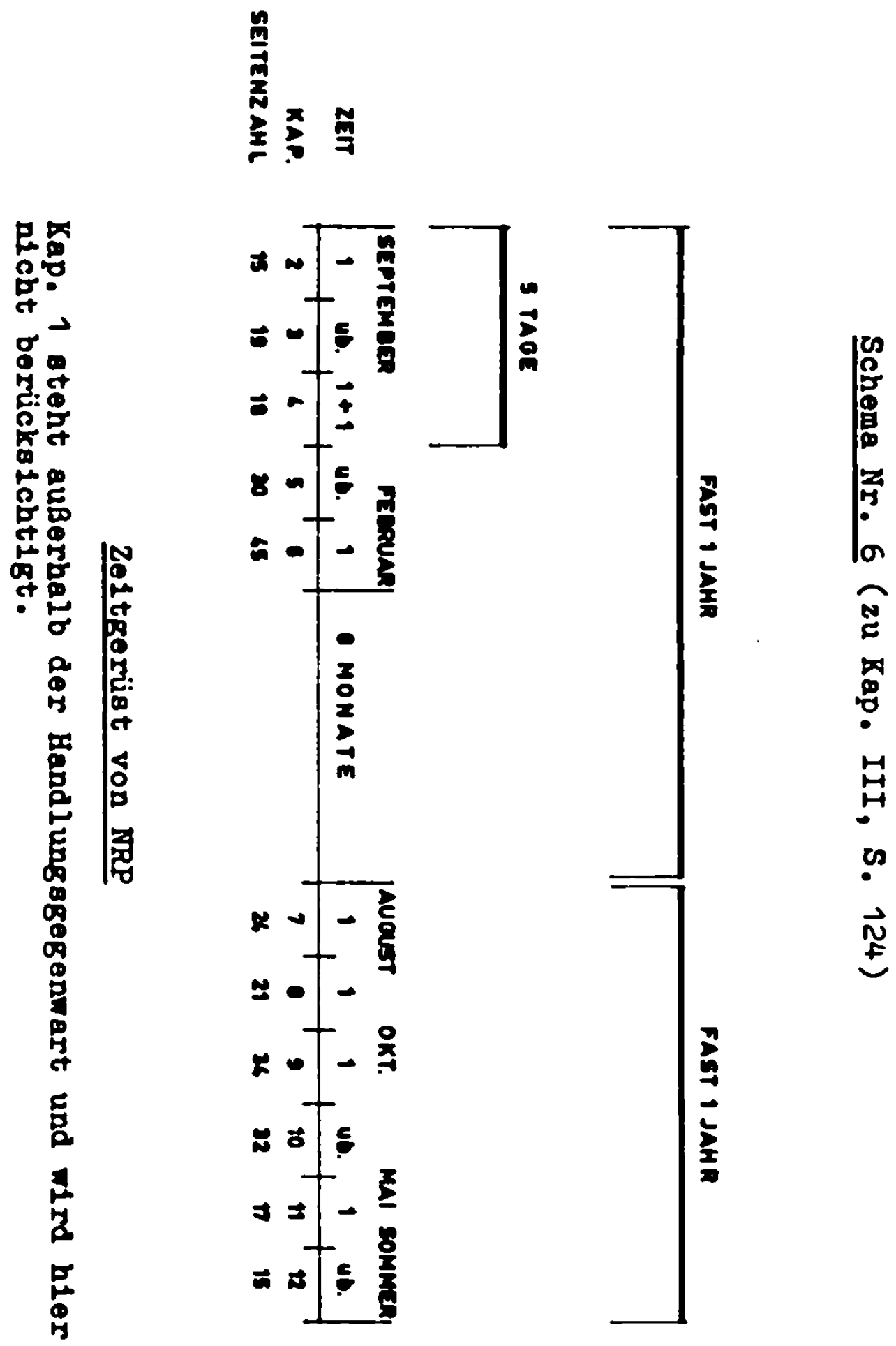
Schean Nr, 7 (zu Kap. III. S. 116, 125)

Istlcher Verlauf aer vier Bandiungecbenen in BB, II, 1 - 4

un 19 Uhr klingelt Kar In an vieleens

Wohnunget or
Kap.4.S.339, $19 \mathrm{Unr}$

119 unr 43:

Attentat Knuteons)

Kap.2,5.253, kurz nach 19 unr 43 (Georgle berlentet Berutanoki von dew Attentat)

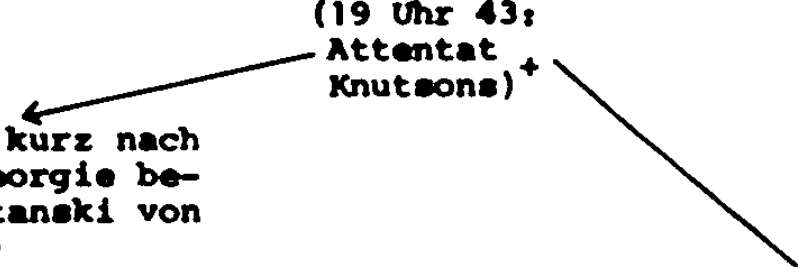

(awischen $20 \mathrm{Uhr}$

und 20 unr $3 \mathrm{O}_{2}$

Kap.2.5.282, etwa 20 Unr 45 (Barutanoki befiohlt Kerinie, Nielsen festzunehmen)

rap.2.5.282, etwa 20 Uhr 45 (Baltrulajtia berichtot Barutanoki von dem Tod Rarina)

Kep.2.S.296, zwinchen 21 Unr is und 21 Unr 30 (Rtickkehr von Kerlnis)

Kap.3. 5.300-323, zeltilich unbeetint (Berutanoki auf der Veraneteltung zu thren skripenike und im Gesprech ait Vanini)

Kap.3. 8.3278 etwe 24 Uhr 30 (Durgwaldeen berlchtet berutanek1 vow Tod Georgis')

Kap.3.S.329, nach 24 Uhr 30 (Barutaneki beobachtet die Lokomotive auf der Bahnhof)

iop.3. 8.330: 24 Unr 53 (arrutanoki eleht den altewanen-Exprese abfahren)

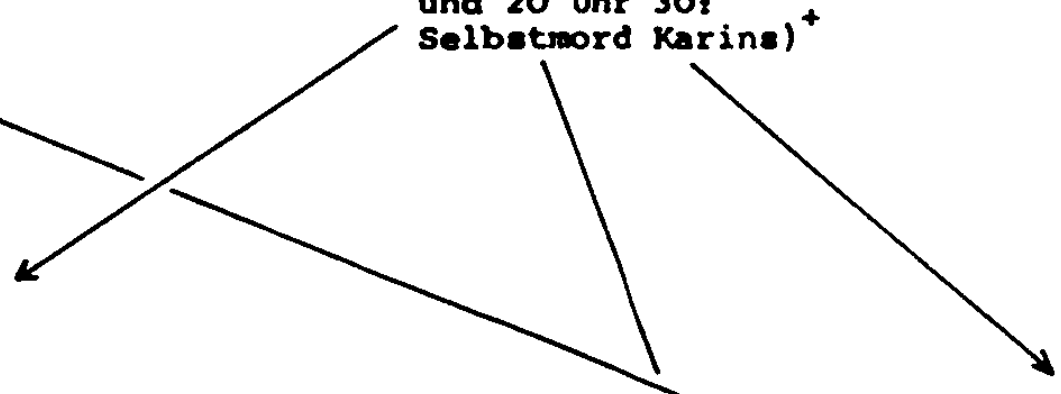

Kap.4.5.343, kurz nach 2 (Nieleen verlast die Woh nachdem er von dew Atten erfahren hat!
Kap. 4.5.345, 21 Unr 50 Kap. 4,5.345, 22 Unr 55 Kap. 4.5.349, Mitternach Kap. 4.5.349, 24 Uhr 03 Kap. 4.S.350z 24 unr o4 Kap. 4.S.351: 24 unr os (Niel sen erfihrt von Kar Tod)

Kap. 4. S. 354. 24 unr 17 (Nielsen bringt Georgia ।

beegt, das dae Geschehen elch im Hintergrund abepielt. 


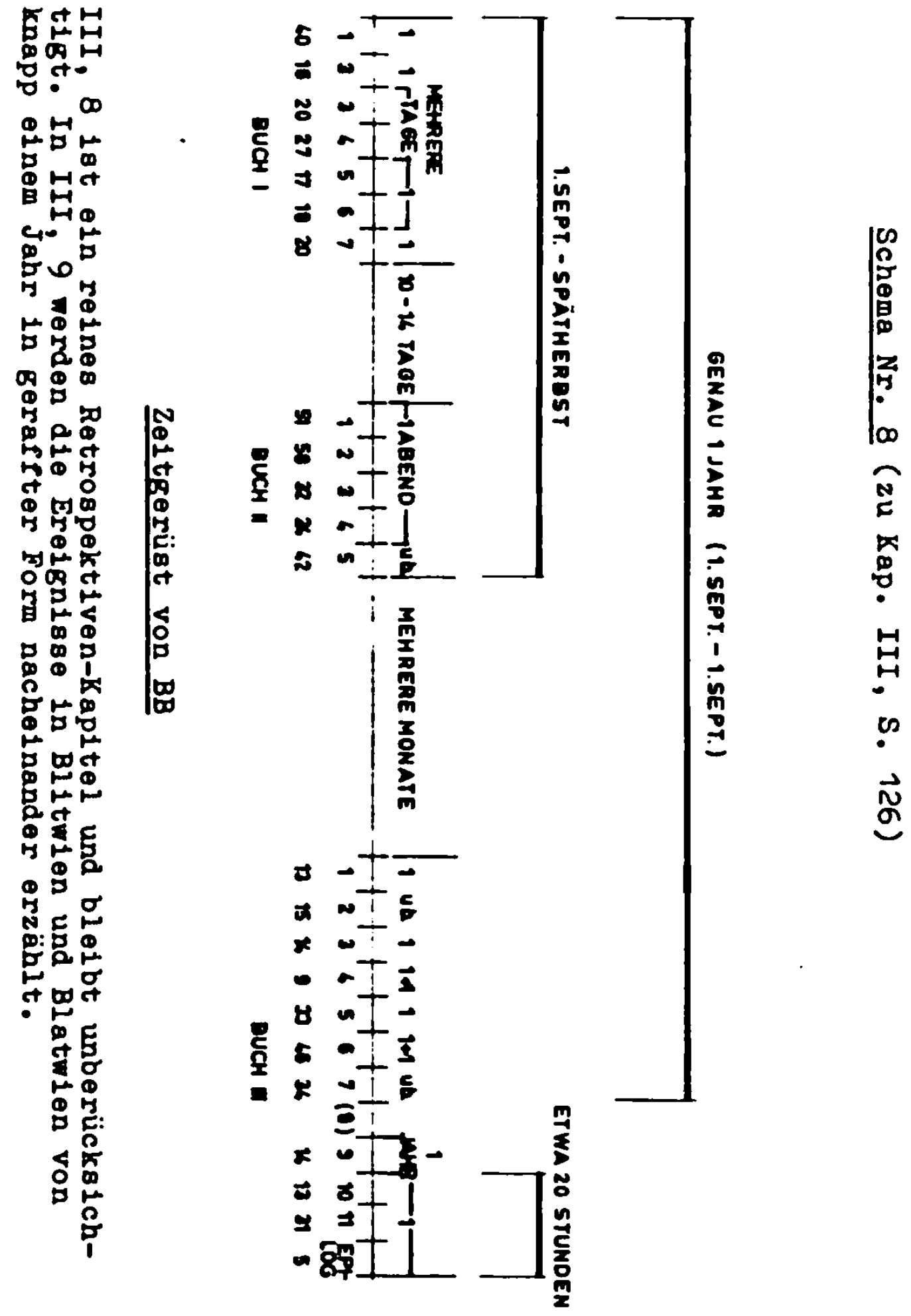




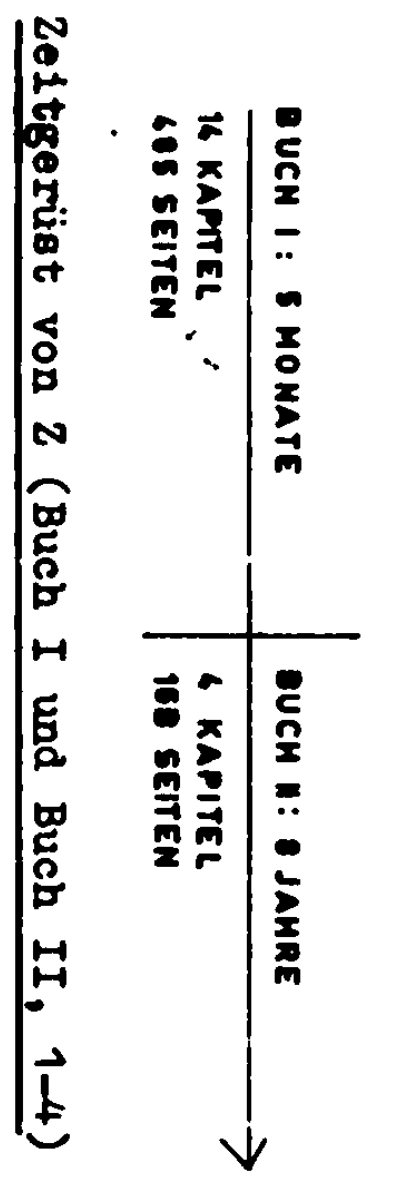

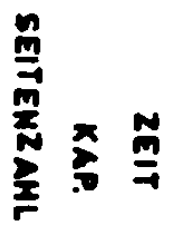

둥

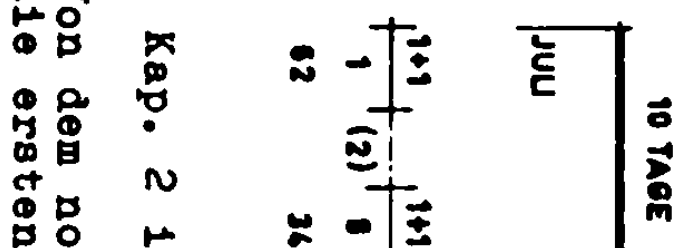

<客

号占

造

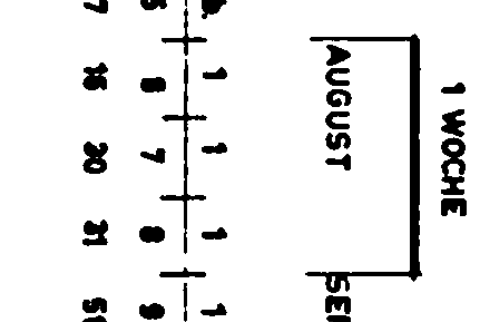

茴

苗思

声 饮

为星

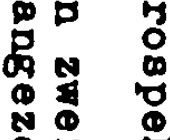

号 究

思思

藏

\&

๑

兑

品

范

\&

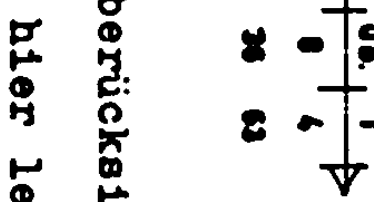

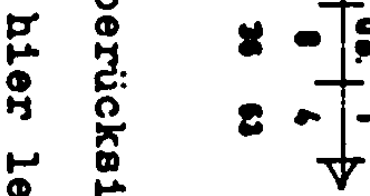

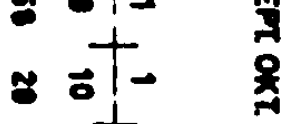

$8= \pm$

疍

\& $\mathrm{N}$

ห む十 ?

$5 \times$ 邪
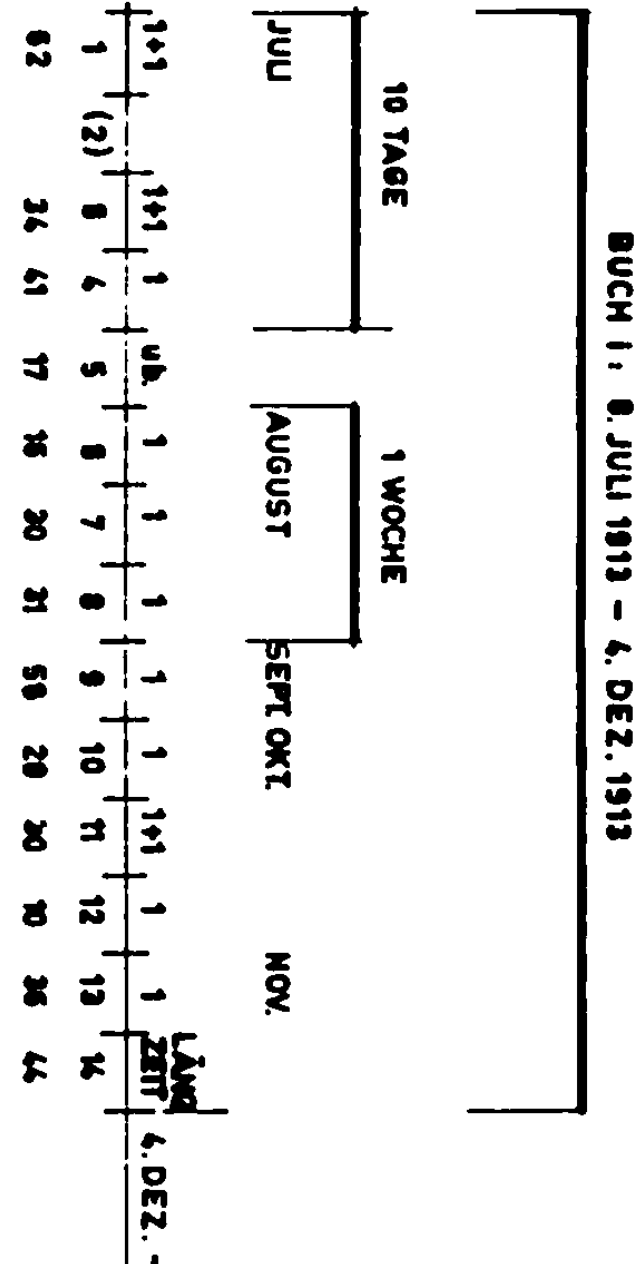

م

若 总

م 


\title{
IITERATURVERZEICENIS
}

\author{
Werke Krležas*
}

Sabrana djela Miroslava Krleže. (Bisher:) Sv. 1-25. Zagreb: Zora 1953-1967.

Djetinjstvo u Agramu. In: Republika, 8, 1952, 2, 337-379. Hrvatska književna kritika. VI. Miroslav Krleža. Zagreb 1953.

Banket u Blitvi. Treea knjiga romana. In: Forum, 1, 1962, 1, 1-242.

Zastave. (Buch I.) In: Forum, 1, 1962, br. 3-12.

Sekundärliteratur

I. Zur Literaturtheorie

ALEWYN, R., H.E. Hass, C. Heselhaus (Hrsg.): Gestaltprobleme der Dichtung. (Festschrift G. Müller 2. 65. Geburtstag.) Bonn 1957.

ALIEMANN, Beda: Ironte und Dichtung. Pfullingen 1956.

ARNTZEN, Helmut: Der moderne deutsche Roman. Voraussetzungen, Strukturen, Gehalte. Heidelberg 1962.

BALIY, Charles: Le style indirect libre en français moderne. I, II. In: GRY, 4, 1912, 549-556, 597-606.

- Figures de pensee et formes linguistiques. In: GRY, $6,1914,405-422$.

BARTEL, Norbert: Untersuchungen zur Romantechnik bei Maksim Gor'kij. Diss. Künchen 1955.

BAULGART, Reinhard: Das Ironische und die Ironte in den Werken Thomas Wanns. München 1964. (- Literatur als Kunst. 13.)

BEACH, Joseph W.: The Twentieth Century Novel: Studies in Techntque. New York 1932.

Es werden hier nur die Titel angefuhrt, die in unmittelbarem Zusammenhang mit dieser Arbeit stehen. Die vollständige, bis 1963 reichende Bibliographie der Werke Krležas ist in dem Sammelband der Jugoslavischen Akademie der Wissenschaften (2MK) zu finden. 
BEREND, Eduard: D10 Techntl der "Darstellung" in der Erzäblung. In: GRU, 14, 1926, 222-233.

- Die Namengebung bel Jean Paul. In: PMAM, 57, 1942, 820-850.

BERGER, Bruno: Der Essas. Form und Geschichte. Bern u. München 1964. (- Sammlg. Dalp. Bd 95.)

BOCKouNN, Paul (Hrsg.): Stil- und Pormprobleme in der Literatur. Heidelbers 1959.

BOGDANOV, M.B.: Serbskaja satiriceskaja proza konca XIXnacala $\bar{a}$ veka 1 nekotorye roprosy teoril satiry. Moskra 1962.

BOHNKE, Jutta: Thomas Manns Romantechnik. Diss. Tuibingen 1950.

BOSTH, Warne C.: The Rhetoric of Piction. Chicago 1961. BOWLING, Lawrence E.: "What is the Stream of Consciousness Technique?" In: PKI , 65, 1950, 337-345.

BROOKS, C., R.P. Warren: Understanding Piction. New York 1943.

BUEHER, Karl: Sprachtheorie. Die Darstellungsfunktionen der Sprache. 2. Aufl. Stuttgart 1965.

BUHLER, Willi: Die "erlebte Rede" im englischen Roman. Ihre Vorstufen und ihre Ausbildung im Werke Jane Austens. Zürich u. Leipzig 1937. (- Schweizer anglistische Arbeiten. Bd 4.)

BECKER, Heinz: Der Innere Monolog. Zur Analyse des "Ulys8e8". In: Nkzente, 2, 1961, 99-120.

DUJARDIN, Edouard: Le monologue interieur. Son apparition, ses origines, sa place dans l'oeuvre de James Joyce et dans le roman contemporain. Paris 1931.

DUWE, Wilhelm: Ausdrucksformen deutscher Dichtung vom Naturalismus bis zur Gegenwart. Eine Stilgeschichte der Moderne. Berlin 1965.

EDEL, Leon: The Psychological Novel. Nen York 1953.

EICHENBAUY, Boris: Aufsätze zur Theorie und Geschichte der Iiteratur. Frankfurt 1965. (= edition suhrkamp. 119.)

EI'SBERG, Jakov E.: Voprosy teori1 satirJ. Moskava 1957.

PISCHIR, Herbert: Die literarische Form des Essajs und se1ne besondere geistesgeschichtliche Bedeutung. Diss. Hüchen 1950.

PIAKER, Aleksandar: N.V. Gogolj: Mrtve duse (I. d10). Interpretac1ja. In: UR, 2, 1958, 9-18.

PLEakiING, W1ll1: Epik und Dramatik. Versuch Ihrer Wesensdeutung. Bern 1955. (- Dalp-Taschenbücher. Bd 311.) 
FORSTER, E.M.: Ansichten des Romans. Prankfurt 1962. (- Bibl. Suhrkamp. Bd 30.)

FORSTREUTER, Kurt: Die deutsche Icherzählung. Bine Studie zu ihrer Geschichte und Technik. Berlin 1924. (- German. Studien. H. 33.)

FREITAG, Gudrun: Die Entwicklung der Satire in den Erzähiungen N.V. Gogol's. Diss. Iolpzig 1957.

FRIEDEMANN, Käte: Die Rolle des Erzählers in der Eplk. Leipzig 1910. (- Untersuchungen zur neueren Sprachund If teraturgeschichte, hrsg. v. Oskar Walzel.)

FRIEDMAN, Melvin: Stream of Consciousness: 1 Study in Iiterary Kethod. New Haven 1955.

FRIEDMAN, Norman: Point of View in Fiction: The Development of a Critical Concept. In: PUA, 70, 1955, 1160-1184.

FRIEDRICH, W.H., W. KillJ (Hr8g.): Literatur. 2/1, 2/2. München 1965. (- Das Fischer Lexikon. 35.)

FUNKE, Otto: Zur "erlebten Rede" bel Galsworthy. In: Funke: Wege und Ziele. Bern 1945, S. 157-182.

GERIGK, Horst-Jürgen: Versuch über Dostojevsk1 js "Jüngling" . Fin Beitrag zur Theorie des Romans. München 1965. (- Forum Slavicum. Bd 4.)

GESEXANN, Wolfgang: Epische Studien. Der Roman bel Ivan

- Vazov. Dis8. Müchen 1956.

GLAUSER, Lisa: Die erlebte Rede in englischen Roman des 19. Jahrhunderts. Bern 1948. (- Schweizer anglist. Irbelten. Bd 20.)

GRAMICH, Rudolf: Formprobleme der Erzählkunst: Wilhelm von Scholz. Dis8. Minchen 1958.

GRIMM, Relnhold: Romane des Phänotjp Ir: Akzente, 5, 1962, $463-479$.

GtNTHER, Hans: Das Groteske bei N.V. Gogol'. Seine Formen und Funktionen. Diss. Künchen 1967.

GUNTHER, Terner: Probleme der Rededarstellung. Untersuchungen zur direkten, indirekten und "erlebten" Rede im Deutschen, Französischen und Italienischen. Marburg 1928.

HÄUFLER, Wolfgang: Zeitkritik und politische Satire in den Werken E.T.A. Hoffmanns. Diss. Marburg 1955.

HAMBURGER, Käte: Die Logik der Dichtung. Stuttgart 1957. HEIDERANN, Christel: Satirische und polemische Formen in der Publizistik von Karl Kraus. Diss. Berlin 1958.

HEINERUANN, Theodor: Die Arten der reproduzierten Rede. Muinster 1931. (= Forschungen zur roman. Philologie. H.2.) 
HIELSCHER, Karla: A.S. Pułkins Versepik. Autoren-Ich und Erzählstruktur. Hünchen 1966. (= Slavist. Beiträge. Bd 22.)

HIGHET, Gilbert: The Anatomy of Satire. Princeton 1962.

BONIG, Lnton: Andrej Belyjs Romane. Stil und Gestalt. Ninchen 1965. (- Forvm Slavicum. Bd 8)

HOLTHUSEN, Johannes: Erzählung und auktorialer Kommentar im modernen russischen Roman. In: Die Welt der Slaven, 8, 1963, 252-267.

HULPHREY, Robert: Stream of Consciousness in the Modern Novel. Berkeley and Los Angeles 1962.

INGARDEN, Roman: Das literarische Kunstwerk. Eine Unterslchung aus dem Grenzgebiet der Ontologie, Iogik und Iiteraturwissenschaft. Halle (Saale) 1931.

JAMES, Henry: The House of Fiction. Essays on the Novel. Iondon 1957.

JAUSS, Hans Robert: Zeit und Erinnerung in Marcel Prousts "A la recherche du temps perdu". Ein Beitrag zur Theorie des Romans. Heidelberg 1955. (= Heldelberger Forschungen. H. 3.)

JENS, Walter: Statt einer Ifteraturgeschichte. Pfullingen 1957.

JUNGER, Friedrich G.: Uber das Komische. Prankfurt 1948.

KNAEPKY, Theo: Zum "Style indirect libre" ("Verschleierte Rede"). In: GRY, 5, 1913, 608-619.

RASACK, Wolfgang: Die Technik der Personendarstellung bel N.V.Gorol'. Wlesbaden 1957. (- B1bliotheca Slavica.)

KAYSER, Wolfgang: Das sprachliche Kunstwerk. Eine Einführung in die Iiteraturwissenschaft. 3. , erw. Aufl. Bern 1954.

- Entstehung und Krise des modemen Romans. 4. Aufl. Stuttgart 1963.

- Das Problem des Erzählers in Roman: In: The German Quarterly, 29, 1956, 225-238.

- Das Groteske in Malere1 und Dichtung. München 1960. (= rowohlts dt. enzyklopädie. 107.)

- Kleist als Erzähler. In: Kajser: Die Vortragsreise. Studien zur Ilteratur. Bern 1958, S. 169-183.

- Ter erzählt den Roman? Ebd., S. 82-101.

KEITER, H., und T. Kellen: Der Roman. Geschichte, Theorie und Technik des Romans und der erzählenden Dichtkunst. Essen 1908.

KIIIY, Walter: Wirklichkeit und Kunstcharakter. Neun Romane des 19. Jahrhunderts. Hinchen 1963. 
KLOTZ, Volker (Hrsg.): Zur Poetik des Ronans. Darmstadt 1965. ( = Wege der Forschung. Bd 35.)

KOSKIMIES, Rafael: Theorie des Romans. Helsinki 1935.

IÄbatERT, Eberhard: Bauformen des Erzählens. Stuttgart 1955.

IASIC, Stanko: Roman Senoina doba (1863-1881). In: Rad JAZU, knj. 341. Zagreb 1965, s. 163-230.

IAZAROWICZ, Klaus: Verkehrte Telt. Vorstudien zu einer Geschichte der deutschen Satire. Tübingen 1963.

IEISI, Ernst: Der Erzählerstandpunkt in der neueren englischen Prosa. In: GRM, 37, 1956, 40-51.

LERCH, Eugen: Die st1listische Bedeutung des Imperfektums der Rede. In: GRM, 6, 1914, 470-489.

LIDDELI, Robert: Some Principles of Fiction. Iondon 1953.

- $\quad$ A Treatise on the Novel. Iondon 1953.

LIPS, Marguerite: Le style indirect libre. Paris 1926.

IOCKERiANN, Fritz: Iiteraturwissenschaft und literarische Wertung. Minchen 1965.

IORCK, Etienne: Die "erlebte Rede". Eine sprachliche Untersuchung. Heidelberg 1921.

IORENZEN, Brigitte: Justus Mösers Patriotische Phantasien. Studien zur Erzählhaltung. Diss. Göttingen 1956.

IU

IUKACS, Georg: Die Theorie des Romans. Ein geschichtsphtlosophischer Versuch über die Formen der groBen Epik. Berlin 1920.

MANDELKOW, Karl R.: Hermann Brochs Romantrilogie "Die Schlarwandler". Gestaltung und Reflexion im modernen deutschen Roman. Heidelberg 1962. (- Probleme der Dichtung. H. 6)

MARTINI, Fritz: Das Wagnis der Sprache. Interpretationen deutscher Prosa von Nietzsche bis Benn. 2. Aufl. Stuttgart 1956.

LENDIIOW, Idam L.: Time and the Novel. Diss. Iondon 1952.

MEYER, Hermann: Zum Problem der epischen Integration. In: Trivium, 8, 1950, 299-318.

- Das Zitat in der Erzählkunst. Zur Geschichte und Poetik des europäischen Romans. Stuttgart 1961.

YEYSR, Kurt R.: Zur erlebten Rede im englischen Ronan des 20. Jahrhunderts. Bern 1957. (= Schweizer anglist. Arbeiten. Bd 43.)

MIGNER, Karl: Formprobleme der Erzählkunst Werner Bergengruens. Dis8. München 1956. 
MIIJSR, Norbert: Erlebte und verschleierte Rede. In: Akzente, 3, 1958, 213-226.

- (Hrsg.): Romananfänge. Versuch zu einer Poetlk des Romans. Berlin 1965.

MINDE, Regina: Ivo Indric. Studien über seine Erzählkunst. Hünchen 1962. (= Slavist. Belträge. Bd 8.)

VULLER, Günther: Die Bedeutung der Zeit in der Erzählkunet. Bonn 1947.

- Erzählzeit und erzählte Zeit. In: Festschrift für Paul Kluckhohn und Hermann Schneider. Tübingen 1948, S. 195-212.

- Uber das Zeitgerüst des Erzäblens. In: DVjs. 24, 1950, 1-31.

MUIR, Edwin: The Structure of the Novel. Iondon 1929. NEUBERT, Albrecht: Die Stilform der "Erlebten Rede" im neueren englischen Roman. Halle (Saale) 1957.

NEUSE, Werner: "Erlebte Rede" und "Innerer Monolog" in den erzählenden Schriften Arthur Schnttzlers. In: Pula, 49, 1934, 327-355.

PETSCH, Robert: Der epische Dialog. In: Euphorion, 32, 1931, 187-205.

- Mesen und Formen der Erzählkunst. Halle (Saale) 1934. POUILION, Jean: Temps et roman. Paris 1946.

RASCH, Wolfdietrich: Die Erzählweise Jean Pauls. Metaphern8piele und dissonante Strukturen. Hünchen 1961.

RIDGE, Helga: Studien zur Satire in Bertolt Brechts "Dreigroechenroman". Diss. Jena 1956.

ROMBERG, Bertil: Studies in the Narrative Technique of the First-Person Novel. Stockholn, Göteborg, Uppsala 1962.

RUP, Heiner: Die Kunst der Erzählung in den letzten Prosawerken Gerhart Hauptmanns. Dis8. Nünchen 1957.

SCEILIDAEIT, Jost (Brsg.): Interpretationen. Bd III. Deutsche Romane von Grimmelshausen bis Musil. Frankfurt u. Hamburg 1966. (- Fischer Büchere1. 716.)

SCHNEEGANS, Heinrich: Geschichte der grotesken Satire. Strabburg 1894.

SCBNITZIER, Pelix Th.: Die Bedeutung der Satire für die Erzählform bei Grimmelshausen. Diss. Heidelberg 1957.

SCHORER, Mark: "Technlque as D1scovery", Forms of Modern Fiction. Minneapolis 1948.

SCHWIMaER, Helmut: Erlebnis und Gestaltung der Wirklichkeit bei Alfred Döblin. Dis8. Künchen 1960. 
SEIDLER, Herbert: Die Dichtung. Wesen. Porm. Dasein. Stuttgart 1959. (= Kröners Taschenausg. Bd 283.)

SEUBERT, Burkhard: "Die Blechschmiede" von Arno Holz. Ein Beitrag zur Geschichte der satirischen Dichtung. Dis8. München 1955.

SPIELEAGEN, Friedrich: Beiträge zur Theorle und Technik des Romans. Loipzis 1883.

Neve Beiträge zur Theorle der Epik und Dramatik. Leipzig 1897.

STANZEI, Pranz: Die tjpischen Erzählsituationen im Roman. Dargestellt an Tom Jones, Yoby-Dick, The Ambassadors, Ulysses u.a. Wien-Stuttgart 1965. (= Wiener Beiträge zur engl. Philologie. Bd 63.)

- Innenwelt. Ein Darstellungsproblem des englischen Romans. In: GRY, 43, 1962, 273-286.

- Typlache Formen des Romans. Göttingen 1964. (- Kle1ne Vandenhoeck-Reibe. 187.)

STEPHAN, Doris: Der "Innere Monolog" in Hermann Brochs Roman "Der Tod des Vergil". Dis8. Mainz 1957.

STEPHAN, Joachim: Satire und Sprache. Zu dem Werk von Karl Kraus. Künchen 1964.

STROBSCENEIDER-KOHRS, Ingrid: Die romantische Ironte in Theorie und Gestaltung. Phil. Habil. Schrift. München 1959.

THIBAUDET, Albert: Reflexions sur le roman. Paris 1938.

WALZEI, Oskar: Das Wortkunstwerk: Mittel seiner Erforschung. Ieipzis 1926.

HEIMUNN, Robert: "New Criticism" und die Entwicklung bürgeriicher Literaturwissenschaft. Geschichte und Kritil neuer Interpretationsmethoden. Halle (Saale) 1962.

WEINRICH, Harald: Tempus. Besprochene und erzäblte Welt. Stuttgart 1964. (= Sprache und Iiteratur. 16.)

WELLER, René and Austin Warren: Theory of Literature. New York 1949.

WeSTON, Harold: Porm in Ifterature. A Theory of Technique and Construction. Iondon 1934.

WIESE, Benno von (Hrsg.): Der deutsche Roman vom Barock bis zur Gegenwart. Struktur und Geschichte. Bd 1,2. Dissseldorf 1963.

- Immermanns "Müuchhausen" und der Roman der Romantik. In: Formenwandel. (Festschrift für Paul Böclomann, hrsg. V. Vüller-Seidel u. W. Preisendanz). Hamburg 1964, S. 363-382.

WILPERT, Gero von: Sachwörterbuch der Iiteratur. 3. Aufl. Stuttgart 1961. (= Kröners Taschenausg. Bd 231.) 
ŽEGAC, Viktor: Opazanja o strukturi suvremenoga romana. In: UR, 2, 1958, 1-8.

II. If teratur zu Krleza

BARAC, Antun: Krleza straralac (Povodom proslava 60-godiznjice Zivota 140 godina lojizernog rada Krleze. Referat na svetanoj akademiji). In: Naprijed. 11.12. 1953, 6-7.

BARTOS, Otakar: Biljeske uz teoriju 1 tipologiju groteske. In: UR, 9, 1965, 71-87.

BENESIC, Julije: Miroslav Krleza. In: ZMK, 183-187.

BERKOVIC, Zvonimir: Neke osobine Krlezine dramaturgije. In: 2lik, 379-386.

BOGDANOVIC, Milan: Pripovetke Mroslava Krleze. In: Srpski kojizevni glasnik, iss, 5, 1922, 131-143.

- U znacaju arame u delu Mroslava Krleze. In: Letodis Matice srpsks, 130, 1954, 373, 363-368.

- 0 Krlezi. Beograd 1956.

BOGICEVIC, Miodrag: Dosljednost angaY̌ovanosti. In: Izraz, 6, 1962, 12, 290-294.

BOROZAN, Braslav: Jezik 1 psihofiziłko osetanje க̈rlezinih ijkova. In: Moguknosti, 4, 1957, 924-928.

BRIGLJEVIC, DRAGUTIN: 0 Krlezinu izrazu. Na marginame romana "Povratak Filipa Latinovicza". In: Republika, 11, 1955, 169-175.

CESARIC, Dobriła: Prije trideset godina. Prve moje uspomene na Krlezu. In: Republika, 9, 1953, 602-605.

CVITAN, Dalibor: Mitska interpretacija romana "Povratak Filipa Latinovicza". In: Kolo, NS, 1, 1963, 6, 54-65.

DAIMA, Alfons: Ein verhinderter Nobelpreisträger wird entdeckt. Lï̈nchen und Graz drucken den kroatischen Autor virosiav Krlež. In: Münchner Merkur. 12./13.9.1964, 16.

Aus der umfangreichen Krlezaliteratur werden nur solche Titel angeführt, die für diese Arbeit wichtig waren. Heitere Arbeiten sind in den beiden Sammelbänden über das Werk Krležas zu finden. 
DRAGOJEVIC, S.: Miroslav Krleža: "Na rubu pameti". In: Mlada hultura, 1, 1939, 2, 124.

DŽADŽIC, Petar: Pubunjent Covjek u Krlezinom romanu. Uz ponorno objarljivanje "Banketa u Blitvi", "Na rubu pameti" 1 "Filipa Latinovica". In: Zak, 405-409.

ENGEISPELD, Mladen: Miroslav Krleza: "Baraka Pet Be" (Primjedbe uz stil). In: UR, 2, 1958, 19-32. Joß o stilu Miroslava Krleže. In: UR, 6, 1962, 5-16.

FELCER, Miroslav: Kritiðki fragmenti o Miroslavu Krleži. In: Republika, 9, 1953, 576-596.

o Miroslavu Krlezi protiv Marka Ristica. In: Život, 5, 1956, 505-513, 570-576.

FINK, Humbert: Serbokroat1sche Temperamente. In: Süddt. $2 t_{g} \cdot 14 . / 15 \cdot 12.1963$, Feuilleton.

- Eine österrelchische Elegie. In: Süddt. Ztg. 29./ 30.8.1964, Feuilleton.

FLAKER, Aleksandar: Motivacija i stil. In: UR, 6, 1962, $17-49$.

- "Nepoznat Netko" (0 jednoj analognoj pojavi u ruskoj 1 hrvatskoj knjiZevnost1 20. stoljeca). In: KZ, 53-74.

- Covjek 1 povijest u Krležinim novelama. In: KZ, 153169.

- In extremis (Krleza u svjetlu književnih poredjenja). In: UR, 7, 1963, 31-45.

FRANGES, IVo: Strarnost 1 umjetnost u Krlezinoj proz1 (Novela: "Veliki mettar sviju hulja"). In: Frangez:

Stilistikke studije. Zagreb 1959, s. 271-294.

Slobodni neupravni govor kao stilska osobina (Krležini "Davai dani"). In: UR, 7, 1963, 261-275.

O potrazi za izgubljenim djetinjstrom. Nekoliko paralela uz "Povratak Filipa Latinovicza". In: Kolo, NS, 1, 1963, 6, 6-20.

- Rijed okrenuta zvijezdama. In: Republika, 19, 1963, 281-285.

FRANICEVIC, Marin: Krlezina doba u naroj knjiZevnosti. In: Republika, 9, 1953, 606-608.

GAVELILA, Branko: Miroslav Krleza 1 kazalizte. In: Republika, 9, 1953, 569-575.

GIIGORIC, Velibor: Pripovedacka proza Miroslava Krleže. I, II. In: Izraz, 4, 1960, 8, 283-296, 447-463.

- U viboru. Beograd 1962.

- U olujnim vremenima. Prva knjiga romana "Zastave" Miroslava Krleze. In: ZMK, 559-562. 
GOJ, Edvard: Problem1 1 laktura u Rrlezinof dram1 "Gospoda Glembajeri". In: Irraz, 4, 1960, 8, 1-30.

GUBERINA, Petar: Teorija o ritmu 1 primjena na jedno KrleEino djelo. In: Republika, 9, 1953, 613-634.

IVANISIN, Nikola: Rasprava o Krlezinu zborniku. In: Izraz, 9, 1965, 1194-1213.

JEIXIC, Dubravka: Poetsko-refleksivaa esejistika. In: Izraz, 8, 1964, 16, 63-65.

JENNY, Urs: Weltliteratur von der Peripherie. IV. Miroslav Krleza - der Hecht im Karplenteich. In: Du - Atlantis, 5, 1964, 8, 66-67.

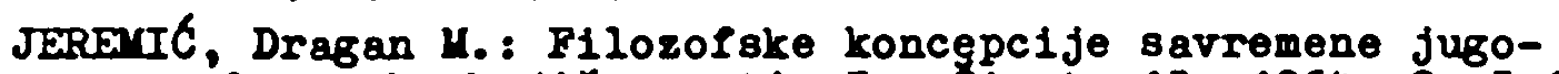
slavenske knjizevnost1. In: Z1vot, 13, 1964, 2, 3-15.

KAIE, Eduard: Pobuna Xovjeka. Iz "Marginalija uz djelo Kiroslava Krleže." In: danas, 1, 1961, 1, 103-110.

kruIE, Bratoljub: Ieksiðke biljełke uz jedan Krležin tekst. In: Republika, 19, 1963, 324-327.

KOIJEVIC, Svetozar: "Gradsko" I "seosko" u književnosti. In: Izraz, 9, 1965, 748-757.

KOVACIC, Ivan Goran: Najslobodoumntje Krležino djelo. In: Novost1. Zagreb. 16.2.1941, 18-19.

KOZARCANIN, IVO: Novi Krlezin romar. In: luratski dnernik. Zagreb. 4.9.1938, 15.

KREFT, Bratko: Pragmenti o Miroslavu Krlez1. In: Kreft: Portreti. Ljubljana 1956, S. 27-86.

- Spremna beseda. In: ZMK, 517-523.

KRKCLC, Gustav: Knjifevni lik Miroslava Krleze gledan ir tri vremenska usla. Sezdesetogodirnjica Zivota nałeg najvereg knjiZevnika. In: Zivi, 366-371.

KRIIC, Jovan: Mroslar KrleZa: "Porratak Fillpa Latinovicza". In: Pregled, 6, 1932, 486-487.

IEOVAC, Slavko: Plameni intelekt lifroslava Krleze. In: Izraz, 7, 1963, 13, 1-7.

IOHCAR, Hate: Ljetopis lomova doba 1 sudbina. In: Izraz, 7, 1963, 13, 337-343.

- Pred knjizevaim dielom Miroslava Xrleze. In: Izraz 9, 1965, 190-199.

LiLGIC, Milivoj: KrleZina estetika. In: Socijalna misao, $6,1933,2,65-71$.

iulIC, Zdravko: Vlastita imena kao stilska kategorija "Banketa u Blitvi". In: KZ, 211-225.

- Iutke. Pokusaj rekonstrukc1je autorskog komentara u "Banketu u Blitv1". In: UR, 7, 1963, 171-185. 
unŠTROVIC, Ijubomir: Kajizevaik-borac. In: Zadaraka revija, 2, 1953, 3, 105-109.

MATKOVIC, Marijan: Marginal1ja uz Krlezino dramsko stvaranje. In: Matkovit: Dva eseja. Zagreb 1950, S. 5-89.

- 0 knjizi Miroslava Krleze "Davni dant". In: 2MG, $484-488$.

MCTREV, Dimltar: Miroslav Krleža: Knjlga eseja. In: ZMK, 537-542.

NEVISTIC, Ivan: Slikar disolucije 1 novelista Miroslav Rrleza. In: Pokret, 2, 1922, 55, 4.

NOVAKOVIC, Boßko: Roman Miroslava Krleze ("Porratak Fillpa Latinovicza"). In: K18ao, 14, 1932, 40, $452-457$.

PAKIC, Vitomir: Drije knjige Miroslava Krleže. ("Povratak Filipa Latinovicza", "Esej1"). In: Jadranska vila, $6,1933,1,14-15$.

PAVIETIC, Vlatko: Hrvatski pjesnici 1emedju dva svjetska rata. Miroslav Krle8a. In: Republika, 19, 1963, 344345.

PETRIC, Vladimir: Dramatixnost Zrležlnog dijaloga (0 mogucnostima savremenog natina interpretiranja konversac1je u dramama "Gospoda Glembajevi", "U agonif1", "Leda"). In: Republika, 11, 1955, 973-980.

PETROV, Aleksandar: Pozoritte lutaka u Krlezinon ronanu ("Banket u Blitv1"). In: Savremenik, 8, 1962, 16, 87-94.

POInNŚcAK, Antun: 0 Miroslavu Krlez1. In: Zar, 301-304. POPOVIC, Bruno: Vrijeme, Covjek, pjesnik. "Davni dani" k1roslava Krleze. In: ZMK, $478-483$.

PRANJIC, Krunoslav: Tehnika pauze kao stilski postupak ( $\nabla_{2}$ tekst Miroslava Krleze: "Slon Frana Supila"). In: ZZ, 395-401.

- 0 Krlezinu proznon ritmu. In: UR, 7, 1963, 101-112. REDJEP, Drałko: Krlezina reX. In: Sarremenik, 9, 1963, 18, 5-13.

RISTIC, Marko: Fuga Krlezlana. In: Republika, 9, 1953, 537545.

- Krleza. Zagreb 1954.

ROTKOVIC, Radoslav: Dijalog o Krleż. In: Knj1ževne novine. Beograd. 27.5.1954, 4 .

- Odnos kvantiteta 1 kvaliteta u Rrležinom djelu (Odlomak). In: Susret1, 2, 1954, 186-194.

- Krlezin 8til. In: Susreti, 2, 1954, 767-783.

SINEON, RIkard: Novele lifoslava Krleze. In: Savrenenik, $27,1938,4,389-392$. 
SICEL, Mroslav: Literarni estetsko-programatski i idejni otavovi Miroslava Krleze (Nacrt 2a studiju). In: $\mathrm{KZ}, 331-339$.

SINKO, Ervin: Istina Kiroslava Krleze. In: Republika, 8, 1952,2 , 133-144.

- Marginalije uz Krlezin obračun s "nauknom estetikom". In: Republika, 9, 1953, 551-568.

- Krvavi mit (I-VI). In: Delo, 2, 1956, 995-1028, 1195$1241,1467-1491,1659-1686$; 3, 1957, 481-503, 684-718.

- Palanga antikrista 1 drug1 komentari. Zagreb 1957.

- Poet koji pripada svima nama. U povodu proslave sedamdesete godiznjice rodjenja Miroslava Krleže. In: 2MK, 548-558.

TATIC, R. - A.I. Spasie: Osvrt na stranu kritiku o krleži. In: Izraz, 7, 1963, 13, 27-33.

TAUTOVIC, Radojica: Anti - Makijaveli 111 poetska ideja o viast1. In: Zivot, 11, 1962, 592.

TORBERG, Friedrich: Jugoslawische Premiere in Graz. "Die Glembays" - Schauspiel von Miroslav Krleż erstmals in deutscher Sprache. In: Süddt. Ztg. 3./4.7.1965, 11. TRIPKOVIC, Risto: Pred vrhovima Krlezina djela. In: Zivot, $12,1963,5,79-83$.

VAUPOTIC, Miroslav: Socijalni smisao Krležina djela. In: KZ, 19-35.

- Siva boja smrti. Interpretacija Krlezine novele "Crreak pod rodopadom". In: Kolo, NS, 1, 1963, 6, 66-84.

- Krlezini knjizevni Casopisi. In: Republika, 19, 1963, 331-339.

VERES, Sała: Da se Cuju satiritari. In: Vjesnik u srijedu. Zagreb. 29.12.1954, 7 .

- Pojzaz u djelu Kiroslava Krleze. In: Kolo, NS, 1, $1963,6,46-53$.

VIDAN, Ivo: Dvije razine "Banketa u Blitvi" (Fragmenti stud1je). In: Kolo, NS, 1, 1963, 6, 85-104.

VIDMAR, Josip: 0 Krlez1. In: ZMK, 567-570.

vUCETIC, Sime: Krlezino knjizevno djelo. Sarajevo 1958. (- Pogledi. Biblioteka za domacu 1 stranu esejistiku. Knj. 5.)

vUCKovIC, Radovan: Legenda o fatumu mrznje (Uz Krlezin roman "Banket u Blitvi"). In: Zivot, 12, 1963, 7-8, 82-86. 
VULETIC, Branko: 0 nekim elementima Krlezine 11rike. In: Bolo, NS, 1, 1963, 6, 127-140.

ZANINOVIC, Vicko: Odabrane novele savremene hrvatske prose ("Bitka kod Bistrice Lesne"). In: Misao, 13, 1931, $36,101-109$.

ZBORNIK o Miroslavu KrIeK1. Hrsg. V. Marijan Matkovit. Zagreb: JAZO, Odjel za suvremenu knjikevnost 1 Inst1tut za knjizevnost, 1963.

Krlezin ZBORNIK. Hrsg. V. Ivo Pranger, Aleksandar Flaker. Zagreb 1964. (- Institut 2 a nauku o knjikernost1 Pliozofskog fakulteta sveutilizta u Zagrebu. Knj. I.)

ZECEVIC, Divaa: Krlezina reZentca (Drije primjodbe o Krlozinoj prozi u romanima "Na rubu pameti" 1 "Porratak Pilipa Latinoviczan"). In: Kolo, NS, 3, 1965, 6, 43-54

ZUPPA, Vjeran: Jezik 1 smisao. Stilska analiza novele $Y$. Krleže: Bitka kod Bistrice Iesne. In: danas, 1, 1961; $1,71-83$. 


\section{(3)}

(40)

(40)

40.

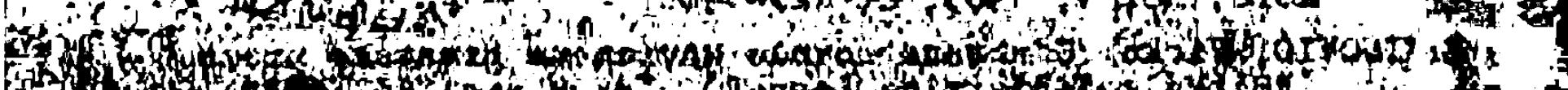

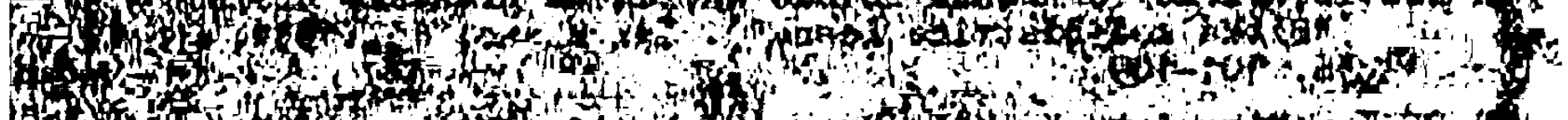

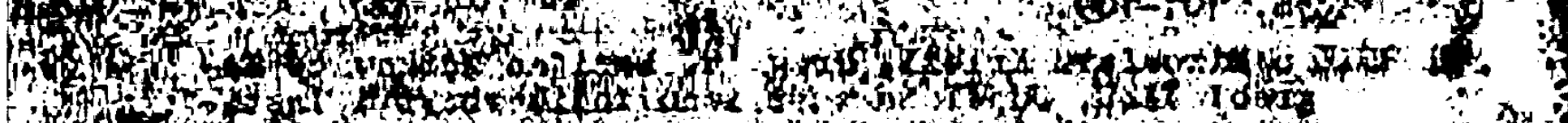

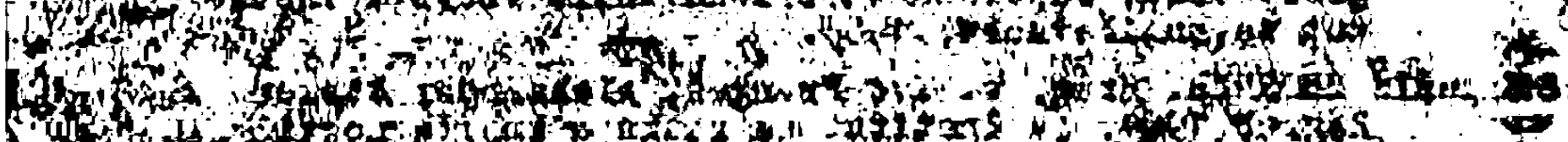
Wh (n)

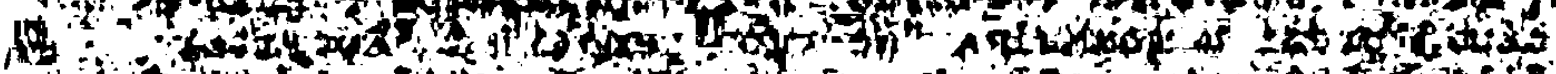

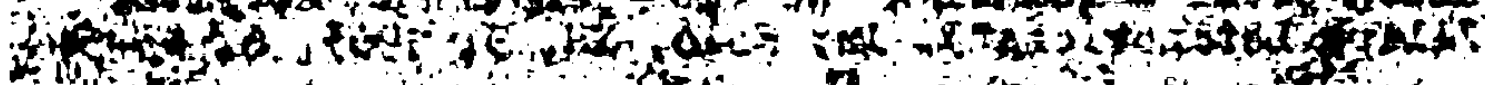

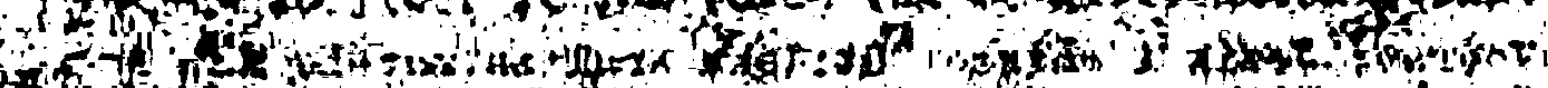

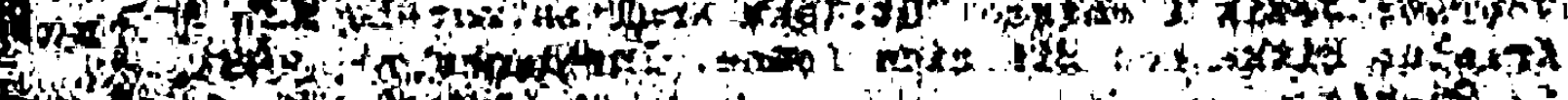

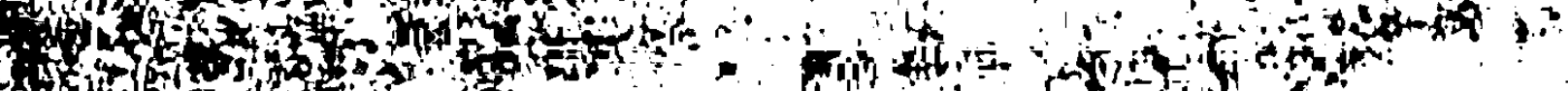
Fiflif

15y

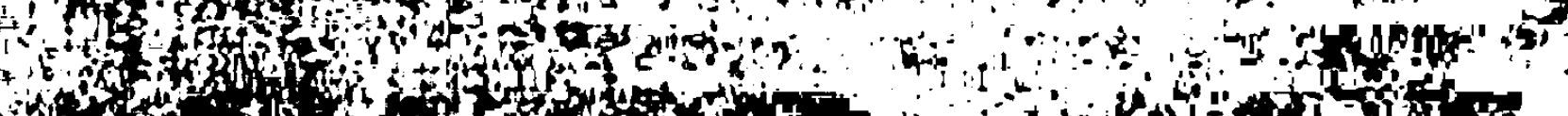
Why

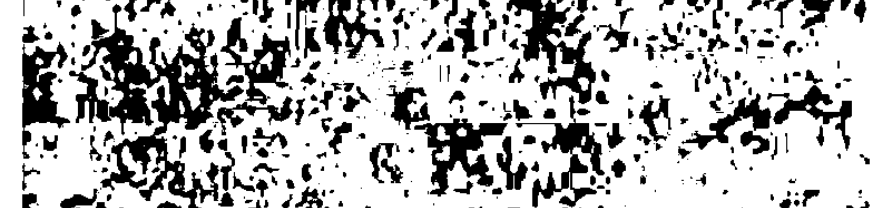

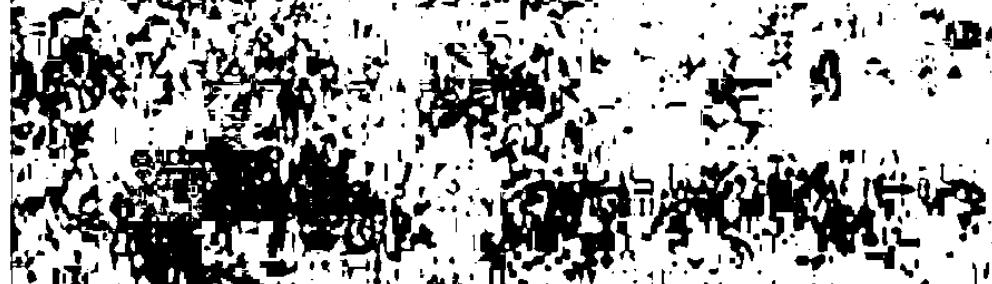
1 the 1.

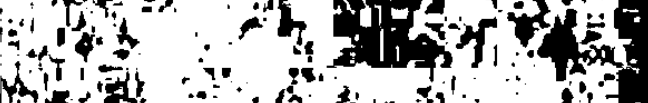

citis

i. nofing

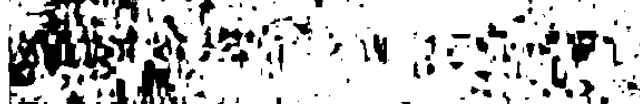

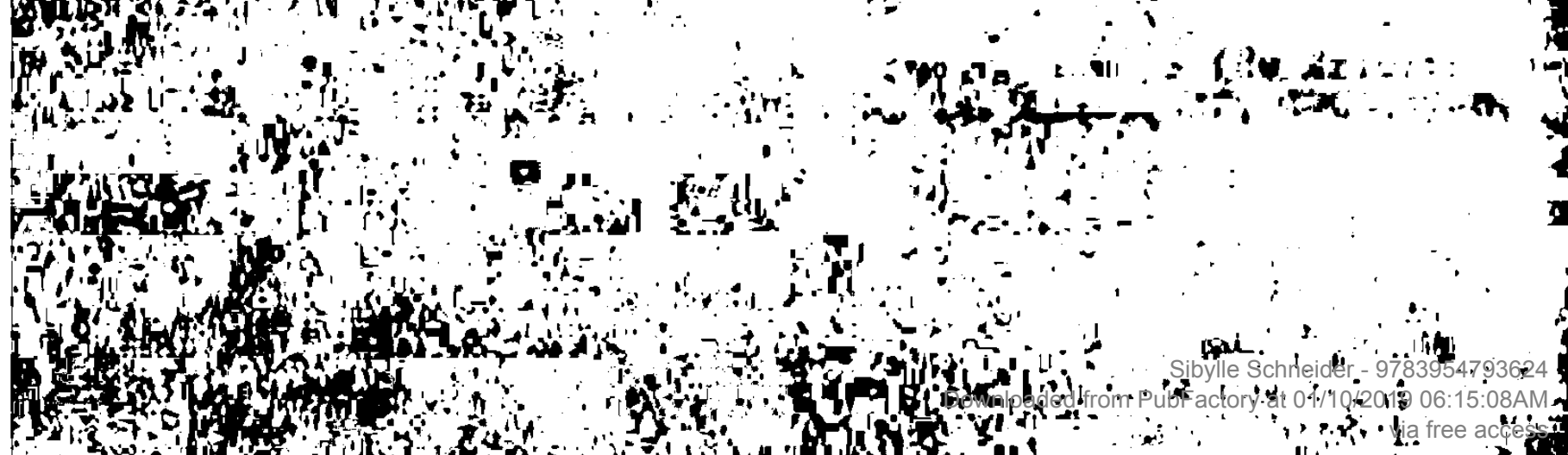

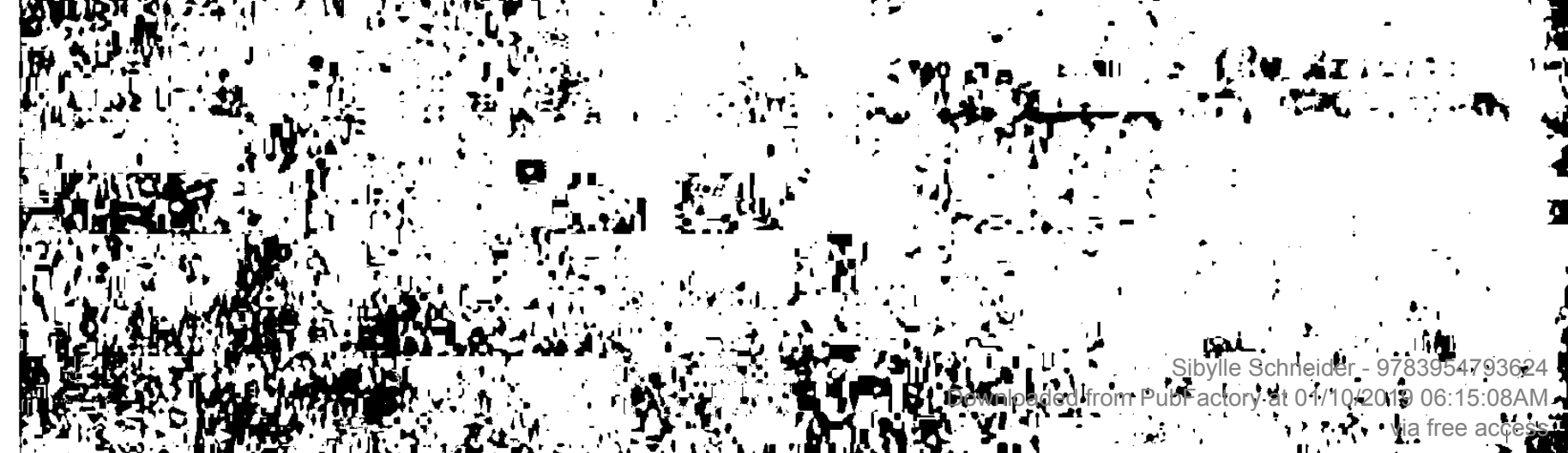

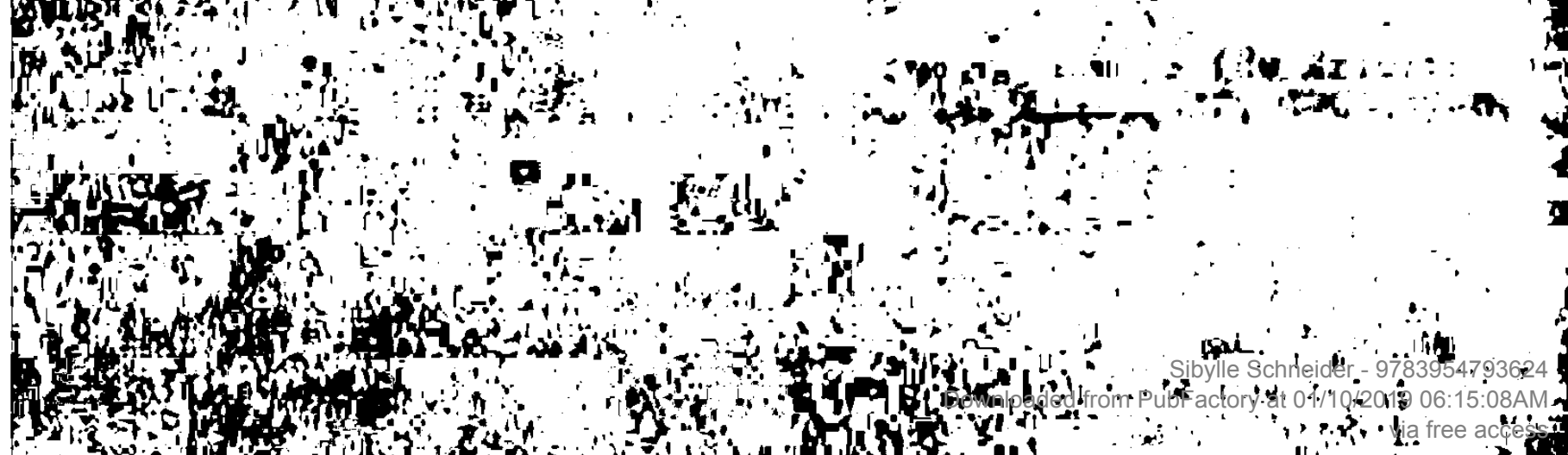

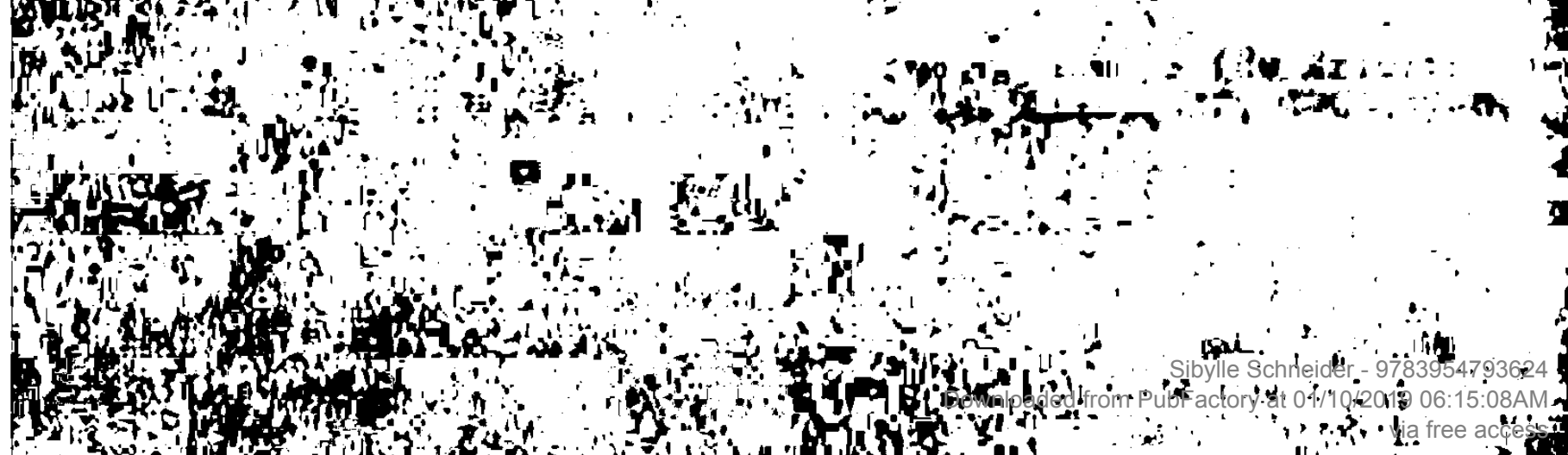

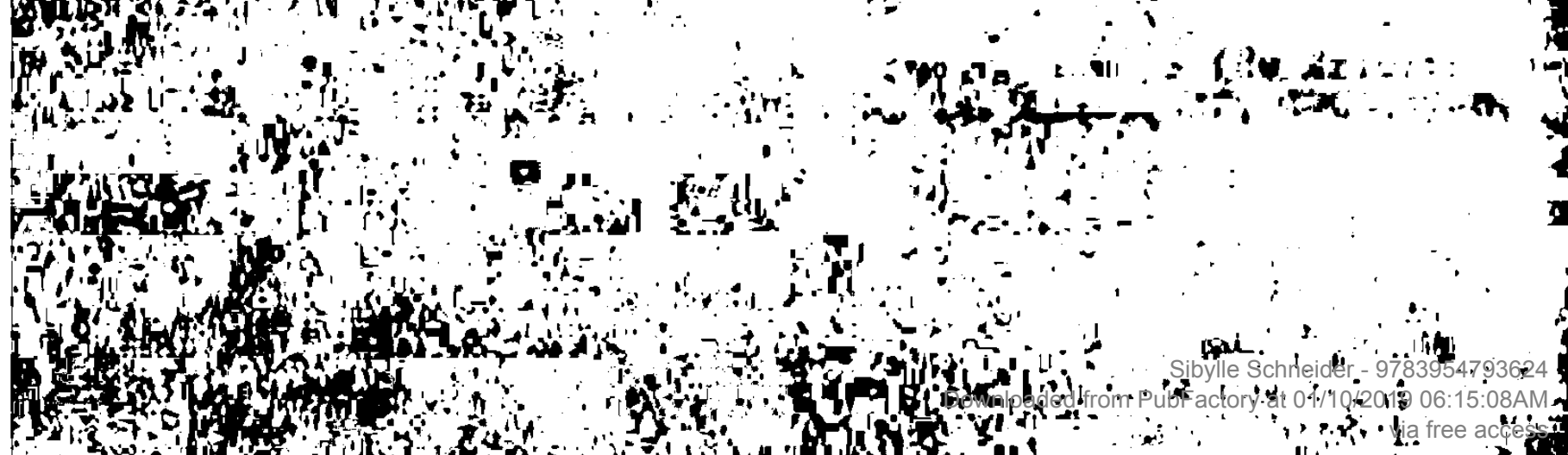

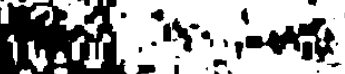

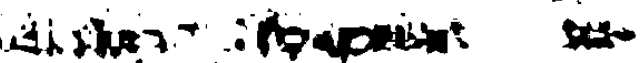

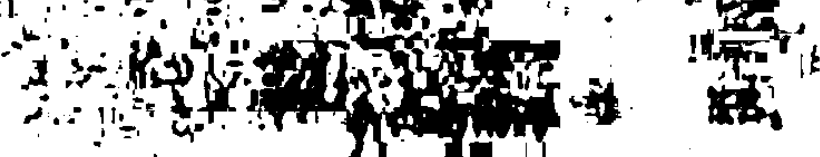

Ixy $\because$ intats 
Nachwort

Die vorliegende Arbeit murde 1968 von der Philosophischen Fakultät der Universität München als Disserta-. tion angenommen.

Nieln besonderer Dank gilt Herm Professor Dr. A. Schmaus, der diese Arbeit, die mich seit dem Wintersemester 1963/ 64 beschäftigte, angeregt und gefördert hat und der mir mit vielfältigem Rat zur Seite stand.

München, April 1969 